ORNL/TM-9179/R4

OAK RIDGE

NATIONAL

LABRATORY

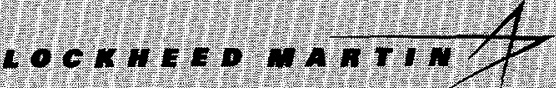

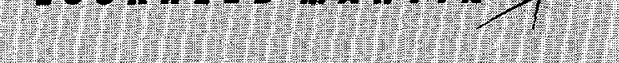

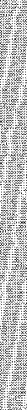

$(14$

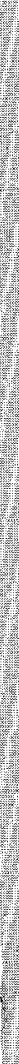

MAMAGED AND OPERATED BY

LOCXHEED UARTN ENERGY RESEARCH CORPORATION FORTHE UKTED STATES

OLPARTHENT OF ENERGY

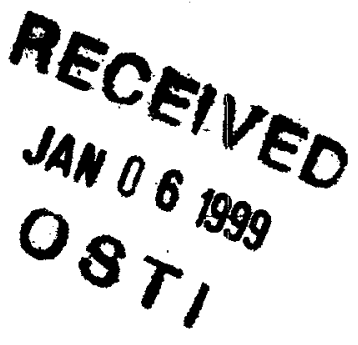

\section{Updated Users' Guide for SAMMY: Multilevel R-Matrix Fits to Neutron Data Using Bayes' Equation}

Nancy M. Larson

NOTICE: This document contains information of a preliminary nature. It is subject to revision or correction and therefore does not represent a final report. 
This report has been reproduced from the best available copy.

Reports are available to the public from the following source.

National Technical Information Service

5285 Port Royal Road

Springfield, VA 22161

Telephone 703-605-6000 (1-800-553-6847)

TDD 703-487-4639

Fax 703-605-6900

E-mail orders@ntis.fedworld.gov

Web site $h$ ttp://www.ntis.gov/ordering.htm

Reports are available to U.S. Department of Energy (DOE) employees, DOE contractors, Energy Technology Data Exchange (ETDE) representatives, and International Nuclear Information System (INIS) representatives from the following source.

Office of Scientific and Technical information

P.O. Box 62

Oak Ridge, TN 37831

Telephone 423-576-8401

Fax 423-576-5728

E-mail reports@adonis.osti.gov

Web site http://www.osti.gov/products/sources.html

Reports produced after January 1, 1996, are generally available via the DOE Information Bridge.

Web site http://www.doe.gov/bridge 
Computational Physics and Engineering Divison

\title{
UPDATED USERS' GUIDE FOR SAMMY: MULTILEVEL R-MATRIX FITS TO NEUTRON DATA USING BAYES' EQUATION
}

Nancy M. Larson

Date Published: August 1984

Date of Revision 1: April 1985

Date of Revision 2: June 1989

Date of Revision 3: September 1996

Date of Revision 4: December 1998

NOTICE: This document contains information of a preliminary nature. It is subject to revision or correction and therefore does not represent a final report.

\author{
Prepared by the \\ OAK RIDGE NATIONAL LABORATORY \\ Oak Ridge, TN 37831 \\ operated by \\ LOCKHEED MARTIN ENERGY RESEARCH CORPORATION \\ for the \\ U.S. DEPARTMENT OF ENERGY \\ under contract DE-AC05-96OR22464
}




\section{DISCLAIMER}

This report was prepared as an account of work sponsored by an agency of the United States Government. Neither the United States Government nor any agency thereof, nor any of their employees, make any warranty, express or implied, or assumes any legal liability or responsibility for the accuracy, completeness, or usefulness of any information, apparatus, product, or process disclosed, or represents that its use would not infringe privately owned rights. Reference herein to any specific commercial product, process, or service by trade name, trademark, manufacturer, or otherwise does not necessarily constitute or imply its endorsement, recommendation, or favoring by the United States Government or any agency thereof. The views and opinions of authors expressed herein do not necessarily state or reflect those of the United States Government or any agency thereof. 


\section{DISCLAIMER}

Portions of this document may be illegible in electronic image products. Images are produced from the best available original document. 
December 1998

Dear SAMMY user:

Enclosed is Revision 4 of the SAMMY users' guide. This document contains only those pages that are changed from Revision 3; extra copies of R3 (combined with pages from earlier versions) are available from the author for those who need them. The pages from R4 are either replacements or additions to pages from earlier versions.

Please note the page numbering system: Pages are numbered sequentially in the middle of the bottom of each page (except for some pages from the early versions where these numbers occasionally occur at the center top of the page). When new pages have been inserted, the appropriate letter of the alphabet is used along with the numeral; thus, for example, pages 122a, $122 \mathrm{~b}, \ldots 122 \mathrm{z}$ appear between pages 122 and 123 . When this numbering system is inadequate, decimal values are use; for example, pages $150 \mathrm{z} .1$ through $150 \mathrm{z} .4$ occur between pages $150 \mathrm{z}$ and 151.

A second numbering system is also used within each section (and subsection, etc.). The section number (e.g., "Section IV.B") appears on the lower left-hand corner of each page, and the page number within that section appears on the lower right-hand corner.

Appended to this note is a table that provides the complete set of page numbers and revision numbers for each page; this may be helpful in ensuring that your manual contains the most recent update for each page.

A partial description of SAMMY modifications and additions described in R4 is given in the Introduction to R4.

Please send your comments, both negative and positive, regarding this manual and/or the SAMMY code, to me at one of the addresses listed below. Especially, I would appreciate hearing if you find mistakes, inconsistencies, or ambiguities. My goal is to have both the manual and the code as errorfree and easy to use as possible; that goal can be achieved only with feedback from users such as yourself.

Sincerely,

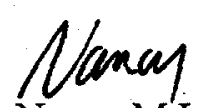

$m$

Nancy M Larson

e-mail: nml@ornl.gov

Regular mail: N. M. Larson

Oak Ridge National Laboratory

Building 6011, MS 6370

P O Box 2008

Oak Ridge, TN 37831-6370 USA
RECEIVED

JAN O 61999

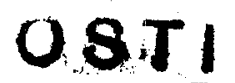

Fax: (423) 574-3527 
Revision number for pages of SAMMY Users' Guide 12/15/98

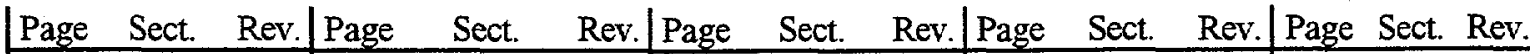

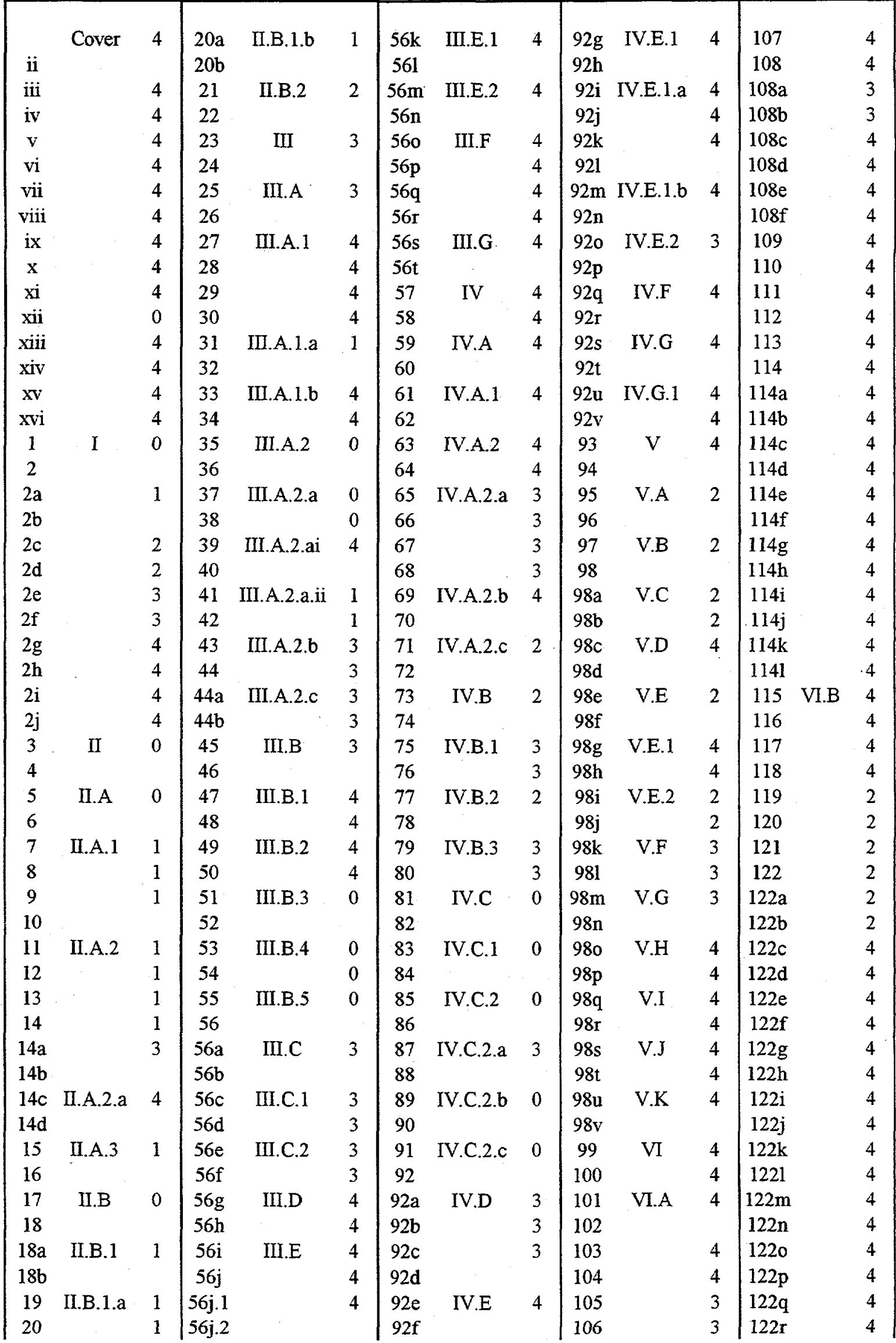

Page 1 
Revision number for pages of SAMMY Users' Guide 12/15/98

|Page Sect. Rev.| Page Sect. Rev. Page Sect. Rev.|Page Sect. Rev.|Page Sect. Rev.|

\begin{tabular}{|ll|ll|ll|lll|lll|}
\hline $122 \mathrm{~s}$ & 4 & $140 \mathrm{c}$ & 4 & 161 & 0 & 211 & XI.B & 4 & 245 dist. & 4 \\
$122 \mathrm{t}$ & 4 & $140 \mathrm{~d}$ & & 162 & 0 & 212 & & 4 & 246 & 4 \\
$122 \mathrm{u}$ & 4 & 141 & 3 & 163 & & 0 & 213 & & 4 & 247 & 4 \\
$122 \mathrm{v}$ & 4 & 142 & 3 & 164 & & & 214 & 4 & 248 & \\
$122 \mathrm{w}$ & 4 & 143 & 3 & 165 & IX B & 0 & $214 \mathrm{a}$ & & 4 & &
\end{tabular}

$122 \mathrm{w}$

$4 \quad 143$

165

$122 \mathrm{x}$

144

IX.B

$122 \mathrm{y}$

$122 \mathrm{z}$

4.145

(

123

124

125 VI.C. 1

126

127 VI.C. 2

128

$128 \mathrm{a}$

$128 b$

129

130

$130 \mathrm{a}$

$130 \mathrm{~b}$

$130 \mathrm{c}$

$130 \mathrm{~d}$

130e VI.E

$130 \mathrm{f}$

$130 \mathrm{~g}$

\begin{tabular}{lll|ll}
$130 \mathrm{~h}$ & & 2 & $150 \mathrm{n}$ & \\
$130 \mathrm{i}$ & VI.G & 3 & 1500 & VIII.I
\end{tabular}

$130 \mathrm{k}$

$130 \mathrm{j}$ VI.H

1301

$130 \mathrm{~m}$ VI.I

$130 \mathrm{n}$
131 VII

132

133 VII.A

134

135 VII.B

136

$136 \mathrm{a}$

$136 \mathrm{~b}$

137 VII.C

138
138.1

138.1

138.2

138 a VII.D

$138 \mathrm{~b}$

138c VII.E

$\begin{array}{cc}138 \mathrm{~d} & \\ 139 & \text { VIII }\end{array}$

13

4.146

$$
3
$$

166

166
167

\begin{tabular}{l|l}
3 & 168 \\
3 & 169
\end{tabular}

$0 \quad 214 b$

$0 \quad 214 c$

$0214 d$

$0 \quad 214 \mathrm{e}$

0 214f

$\begin{array}{llll}148 & & 170\end{array}$

$\begin{array}{lll}0 & 215 & \text { XI.C }\end{array}$

$0 \quad 216$

\begin{tabular}{l|l}
0 & 216 \\
0 & $216 a$
\end{tabular}

$0 \quad 216 b$

$0 \quad 216 \mathrm{c}$

$0 \quad 216 \mathrm{~d}$

$0 \quad 216 \mathrm{e}$

$0 \quad 216 \mathrm{f}$

$0 \quad 216 \mathrm{~g}$

\begin{tabular}{l|l}
0 & $216 \mathrm{~g}$ \\
0 & $216 \mathrm{~h}$
\end{tabular}

$\begin{array}{lll}0 & 216 \mathrm{~h} \\ 0 & 216 \mathrm{i}\end{array}$

$0 \quad 216 \mathrm{j}$

$\begin{array}{lll}0 & 217\end{array}$

\begin{tabular}{l|l}
0 & 217 \\
0 & 218
\end{tabular}

$0 \quad \begin{aligned} & 218 \\ & 0\end{aligned}$

185

\begin{tabular}{l|l}
4 & 186 \\
4 & 187 \\
4 & 188
\end{tabular}

$150 \mathrm{p}$

\begin{tabular}{l|l}
4 & 189 \\
4 & 190
\end{tabular}

\begin{tabular}{l|l}
4 & 190 \\
4 & 191
\end{tabular}

$\mathrm{x} \quad 0$

\begin{tabular}{l|l}
221 \\
222
\end{tabular}

X.A

223

$150 \mathrm{q}$
$150 \mathrm{r}$

$150 \mathrm{~s}$

$150 \mathrm{t}$

$150 \mathrm{u}$

\begin{tabular}{ll|l}
$150 \mathrm{v}$ & 4 & 194
\end{tabular}

150w VIII.J

$150 \mathrm{x}$

\begin{tabular}{|lll|l}
$150 \mathrm{x}$ & & & 196 \\
$150 \mathrm{y}$ & VIII.K & 4 & 197
\end{tabular}

197

198

230

$150 \mathrm{z} .1$ VIII.L

$150 z .2$

$150 \mathrm{z} .3$ VIII.M

$150 z .4$

4

151

(15

153

154

155

156

157

\begin{tabular}{|lll|l}
140 a & VIII.A & 4 & 158 \\
159
\end{tabular}

$140 \mathrm{~b}$

$4 \longdiv { 1 6 0 }$

IX

IX.A

200

201

203 X.C. 10

204

205 X.C. 20

0206

$0 \quad 206 \mathrm{a}$ X.D

$0206 \mathrm{~b}$

\begin{tabular}{l|ll}
0 & 207 & $\mathrm{XI}$ \\
0 & 208 & \\
0 & 209 & $\mathrm{XI}$
\end{tabular}

\begin{tabular}{l|l}
0 & 209 \\
0 & 210
\end{tabular}

Page 2 


\section{CONTENTS}

LIST OF TABLES $\ldots \ldots \ldots \ldots \ldots \ldots \ldots \ldots \ldots \ldots \ldots \ldots \ldots \ldots \ldots \ldots \ldots$ vii

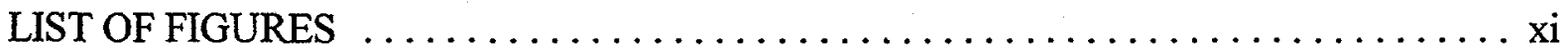

ACKNOWLEDGMENTS $\ldots \ldots \ldots \ldots \ldots \ldots \ldots \ldots \ldots \ldots \ldots \ldots \ldots \ldots \ldots \ldots \ldots \ldots \ldots \ldots$ xiii

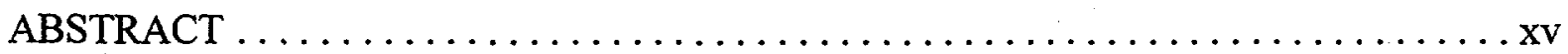

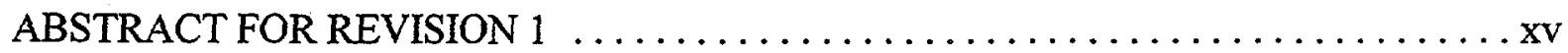

ABSTRACT FOR REVISION $2 \ldots \ldots \ldots \ldots \ldots \ldots \ldots \ldots \ldots \ldots \ldots \ldots \ldots \ldots \ldots \ldots \ldots$

ABSTRACT FOR REVISION $3 \ldots \ldots \ldots \ldots \ldots \ldots \ldots \ldots \ldots \ldots \ldots \ldots \ldots \ldots \ldots \ldots$

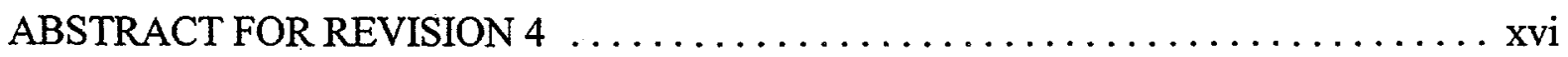

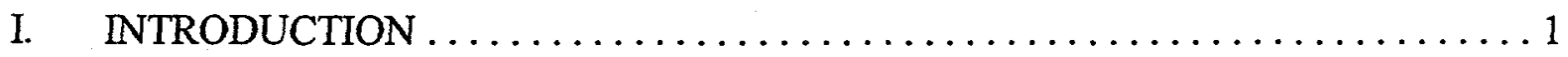

INTRODUCTION TO REVISION $1 \ldots \ldots \ldots \ldots \ldots \ldots \ldots \ldots \ldots \ldots \ldots \ldots \ldots \ldots \ldots$

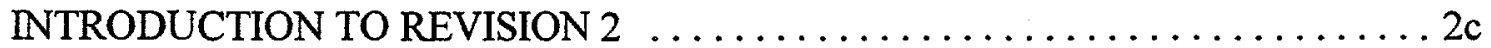

INTRODUCTION TO REVISION $3 \ldots \ldots \ldots \ldots \ldots \ldots \ldots \ldots \ldots \ldots \ldots \ldots \ldots$

INTRODUCTION TO REVISION $4 \ldots \ldots \ldots \ldots \ldots \ldots \ldots \ldots \ldots \ldots \ldots \ldots \ldots \ldots \ldots$

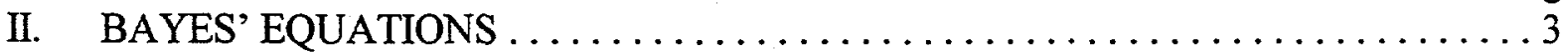

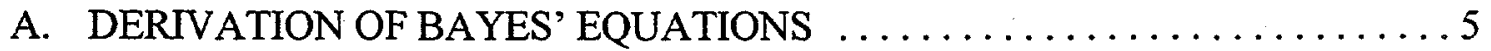

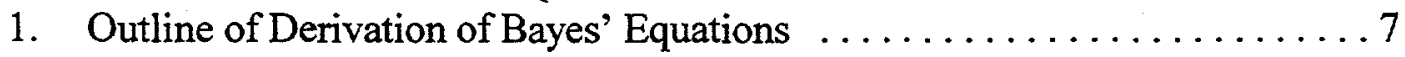

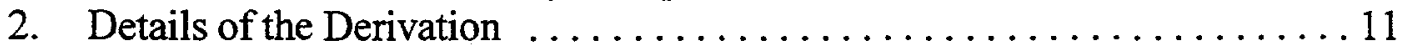

a. Implicit data covariance matrix $\ldots \ldots \ldots \ldots \ldots \ldots \ldots \ldots \ldots \ldots \ldots \ldots$

3. Iteration Scheme .................................. 15

B. IMPLEMENTATION OF BAYES' EQUATIONS $\ldots \ldots \ldots \ldots \ldots \ldots \ldots \ldots \ldots$

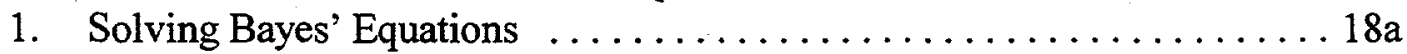

a. Solving Bayes' equations: $(\mathrm{N}+\mathrm{V})$ inversion scheme $\ldots \ldots \ldots \ldots .19$

b. Solving Bayes' equations: $(I+Q)$ inversion scheme $\ldots \ldots \ldots \ldots 20 \mathrm{a}$

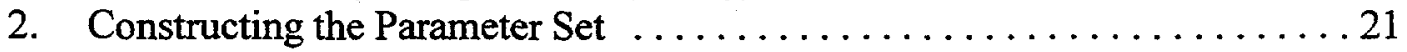

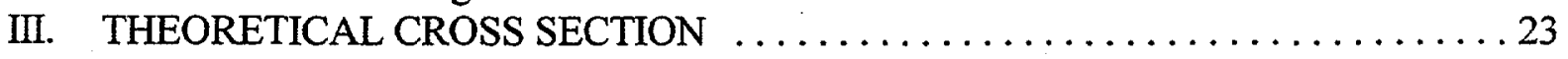

A. MULTILEVEL R-MATRIX THEORY: REICH-MOORE

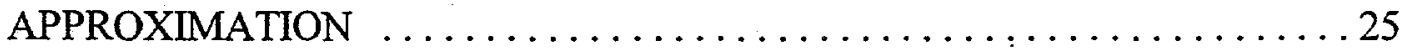

1. Cross Section in Terms of R-Matrix ...................... 27

a. Logarithmic parameterization of external R-function .......... 31

b. Reich-Moore approximation to multilevel R-matrix $\ldots \ldots \ldots \ldots, 33$

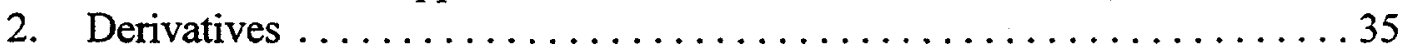

a. Derivatives with respect to R-matrix parameters $\ldots \ldots \ldots \ldots \ldots . \ldots 37$

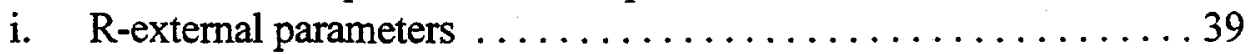

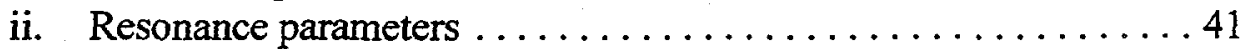

b. Derivatives with respect to matching radius .............. 43

c. Derivatives with respect to $t_{0}$ and $L \ldots \ldots \ldots \ldots \ldots \ldots \ldots \ldots \ldots \ldots$

B. DETAILS AND CONVENTIONS CHOSEN FOR CROSS SECTION

EVALUATION IN SAMMY ........................... 45

1. Spin and Angular Momentum Conventions ................ 47

2. Comparison of Reich-Moore Approximation to Multilevel Breit Wigner

Approximation ............................... 49 
3. Evaluation of Hard-Sphere Phase Shift $\ldots \ldots \ldots \ldots \ldots \ldots \ldots \ldots \ldots \ldots \ldots \ldots$

4. Momentum in the Center of Mass System ..................53

5. Derivative of One Complex Variable with Respect to Another Complex Variable ..................................... 55

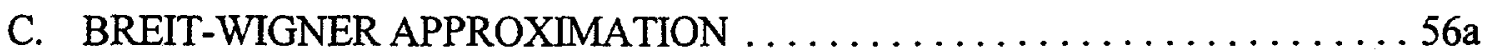

1. Single and Multilevel Breit-Wigner Cross Sections ........... 56c

2. Derivatives of MLBW and SLBW Cross Sections ............. 56e

D. ALTERNATIVE FORMULATION OF REICH-MOORE MULTILEVEL R-

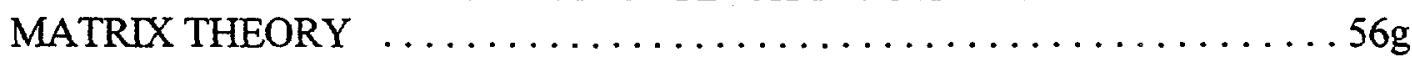

E. DIFFERENTIAL ELASTIC CROSS SECTION $\ldots \ldots \ldots \ldots \ldots \ldots \ldots \ldots \ldots \ldots \ldots \ldots$

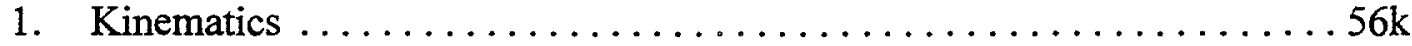

2. Attenuation ............................... $56 \mathrm{~m}$

F. SELF-SHIELDING AND MULTIPLE-SCATTERING CORRECTIONS TO

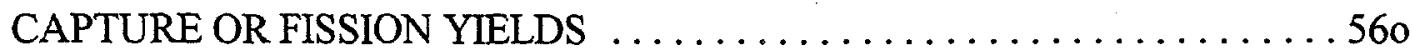

G. SELF-INDICATION MEASUREMENTS $\ldots \ldots \ldots \ldots \ldots \ldots \ldots \ldots \ldots \ldots$ s

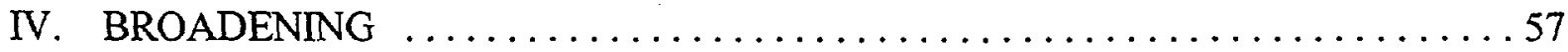

A. THEORETICAL FOUNDATION FOR MULTI-STYLE BROADENING

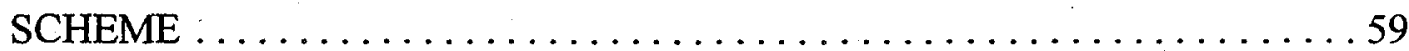

1. Doppler Broadening-MULTI Method ...................61 61

2. Resolution Broadening-MULTI Method .................6. 63

a. Resolution broadening: Gaussian ..................6 65

b. Resolution broadening: exponential . . . . . . . . . . . . 69

c. Resolution broadening: convolution of Gaussian and exponential ... 71

B. EVALUATING BROADENING INTEGRALS FOR MULTI-STYLE

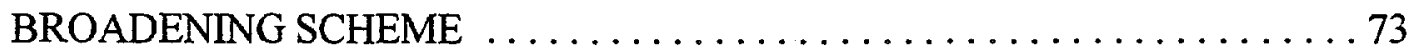

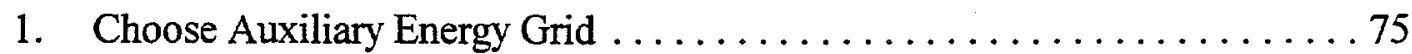

2. Evaluate Theoretical Cross Section for Each Energy in the Auxiliary Grid . . 77

3. Perform Numerical Integration ....................... 79

C. DERIVATIVES OF CROSS SECTION WITH RESPECT TO BROADENING PARAMETERS $\ldots \ldots \ldots \ldots \ldots \ldots \ldots \ldots \ldots \ldots . \ldots \ldots 1$

1. Derivatives with Respect to Effective Temperature $T \ldots \ldots \ldots \ldots \ldots 83$

2. Derivatives with Respect to Resolution-Broadening Parameters . . . . . . 85

a. Gaussian ................................. 87

b. Exponential ............................... 89

c. Convolution of Gaussian and exponential .............. 91

D. LEAL-HWANG DOPPLER BROADENING $\ldots \ldots \ldots \ldots \ldots \ldots \ldots \ldots 92 \mathrm{a}$

E. REALISTIC RESOLUTION BROADENING $\ldots \ldots \ldots \ldots \ldots \ldots \ldots . \ldots 92 \mathrm{e}$

1. Individual Components of the Resolution Function ........... 92g

a. Description of the components . ................. 92i

b. Converting length- to time-dependence $\ldots \ldots \ldots \ldots \ldots \ldots \ldots 92 \mathrm{~m}$

2. Convolution of the Components of the Resolution Function ........ 920

F. FREE-GAS MODEL OF DOPPLER BROADENING $\ldots \ldots \ldots \ldots \ldots \ldots 92 q$

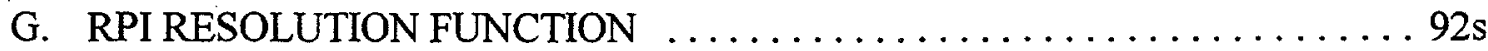

1. Description of the Components of the RPI Resolution Function ...... 92u 


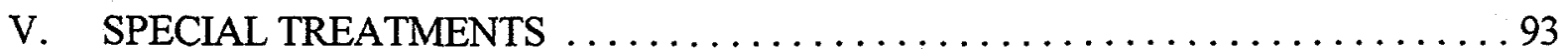

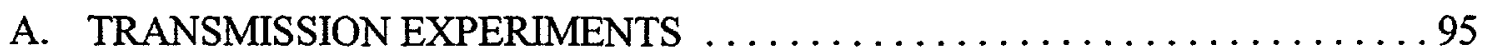

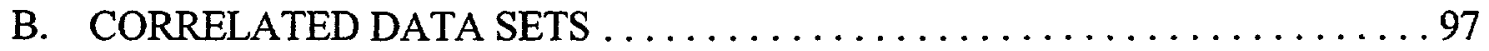

C. AVERAGING THE CROSS SECTIONS $\ldots \ldots \ldots \ldots \ldots \ldots \ldots \ldots \ldots . \ldots . \ldots . \ldots$

D. COMBINING SEVERAL NUCLIDES IN A SINGLE SAMPLE $\ldots \ldots \ldots \ldots . .98 \mathrm{c}$

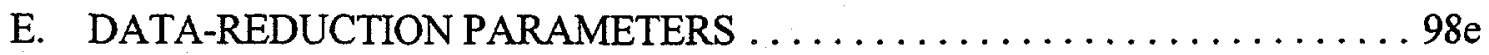

1. Explicit Normalization and/or Background Functions ........... 98g

2. User-supplied Data-Reduction Parameters . . . . . . . . . . . . . . 98i

F. STELLAR-AVERAGED CAPTURE CROSS SECTIONS $\ldots \ldots \ldots \ldots \ldots 98 \mathrm{k}$

G. RECONSTRUCTING POINT-WISE CROSS SECTIONS $\ldots \ldots \ldots \ldots \ldots 98 \mathrm{~m}$

H. PARAMAGNETIC CROSS SECTION $\ldots \ldots \ldots \ldots \ldots \ldots \ldots \ldots \ldots . \ldots 90$

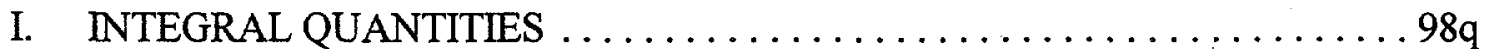

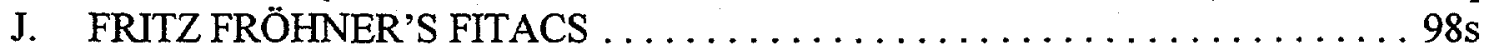

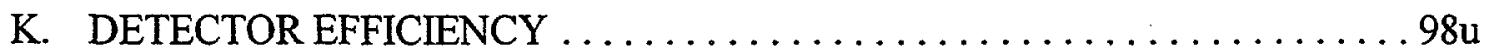

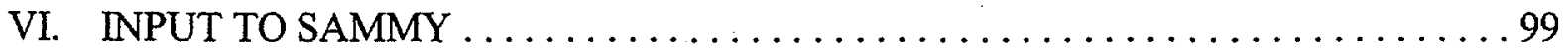

A. THE INPUt FILE .................................... 101

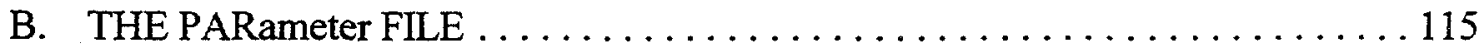

C. THE DATa AND Data CoVariance FILES $\ldots \ldots \ldots \ldots \ldots \ldots \ldots \ldots \ldots \ldots \ldots \ldots \ldots$

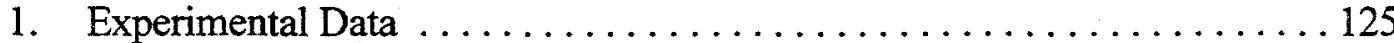

2. Explicit and Implicit Data Covariance Matrices ................ 127

D. INTERACTIVE OR BATCH INPUT TO SAMMY $\ldots \ldots \ldots \ldots \ldots \ldots \ldots \ldots \ldots$

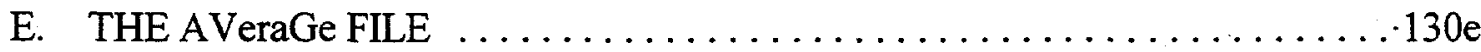

F. TO PRODUCE A FILE IN ENDF/B-VI FORMAT $\ldots \ldots \ldots \ldots \ldots \ldots 130 \mathrm{~g}$

G. USING ENDF/B FILE 2 AS INPUT TO SAMMY $\ldots \ldots \ldots \ldots \ldots \ldots \ldots 130 \mathrm{i}$

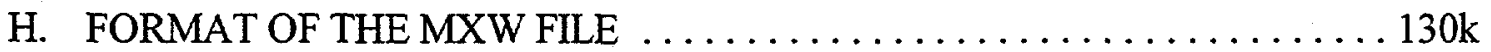

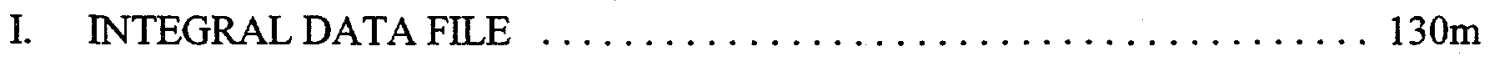

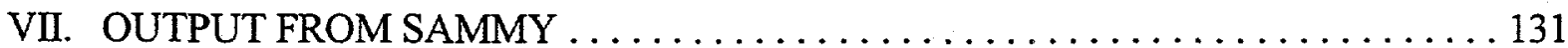

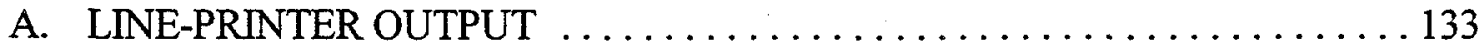

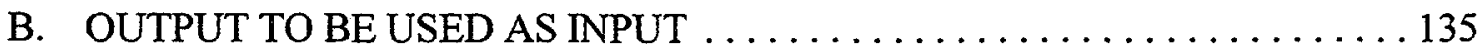

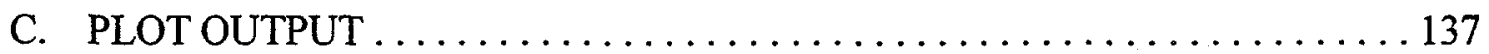

D. COMPLETE SET OF PARTIAL DERIVATIVES FOR RESONANCE

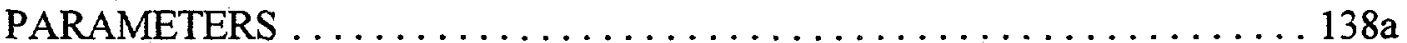

E. CONCISE FORMAT FOR COVARIANCE INFORMATION $\ldots \ldots \ldots \ldots 138 \mathrm{c}$

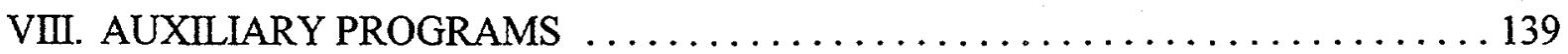

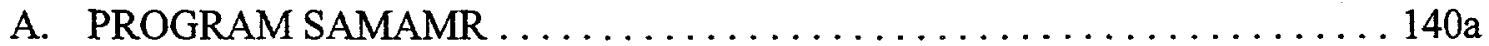

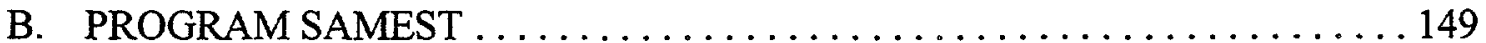

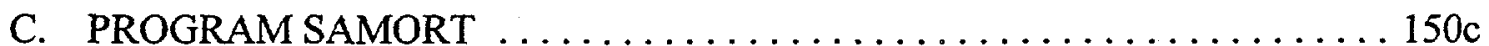

D. CONVERT TO AN ASCII COVARIANCE MATRIX $\ldots \ldots \ldots \ldots \ldots \ldots 150 \mathrm{e}$

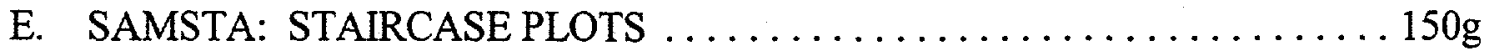

F. SAMBIN: ALTERNATIVE FORM FOR PLOT FILES $\ldots \ldots \ldots \ldots \ldots \ldots 150 \mathrm{i}$

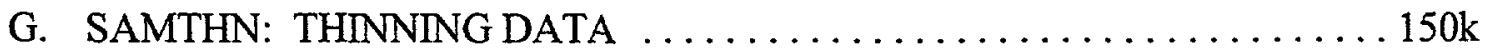

H. ANGODF: CONVERT FROM ENERGY/ANGLE TO ANGLE/ENERGY . $150 \mathrm{~m}$

I. SAMQUA: RESONANCE QUANTUM NUMBERS $\ldots \ldots \ldots \ldots \ldots \ldots \ldots$ 
J. CONVRT: CONVERT FROM REFIT INPUT TO SAMMY OR VICE VERSA ..................................... 150w

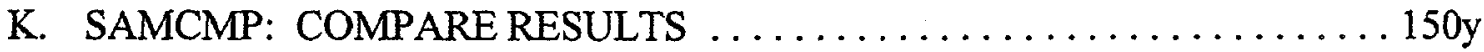

L. SAMRST - PLOT RESOLUTION FUNCTION ............... 150z.1

M. SAMRPT - PLOT RPI RESOLUTION FUNCTION $\ldots \ldots \ldots \ldots \ldots \ldots 150 \mathrm{z} .3$

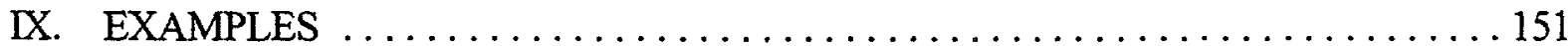

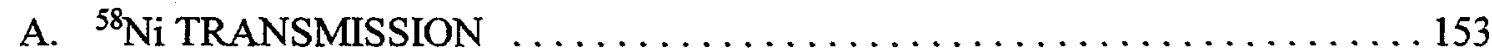

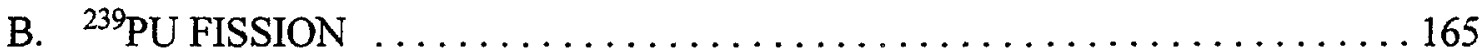

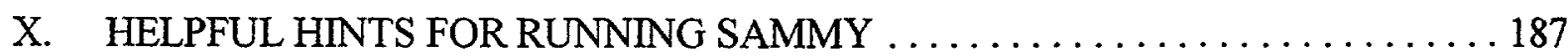

A. HOW TO RUN SAMMY $\ldots \ldots \ldots \ldots \ldots \ldots \ldots \ldots \ldots \ldots \ldots \ldots \ldots \ldots \ldots$

1. Suggested Practical Way to Run SAMMY $\ldots \ldots \ldots \ldots \ldots \ldots \ldots \ldots \ldots$

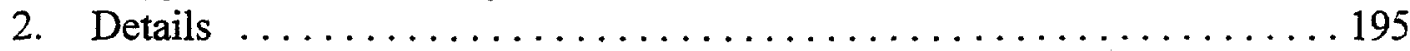

B. PROCEDURES TO FOLLOW WHEN YOU HAVE PROBLEMS $\ldots \ldots \ldots 199$

C. MISCELLANEOUS COMMENTS AND SUGGESTIONS ............201

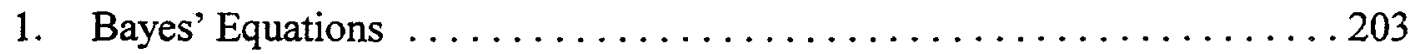

2. Comments Unrelated to Bayes' Equations .................. 205

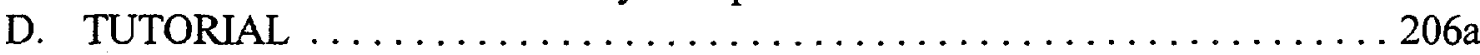

XI. DESCRIPTION OF THE COMPUTER CODE SAMMY $\ldots \ldots \ldots \ldots \ldots \ldots \ldots 207$

A. DYNAMIC ALLOCATION OF ARRAY STORAGE ..............209

B. USE OF TEMPORARY DATA FILES TO STORE INTERMEDIATE

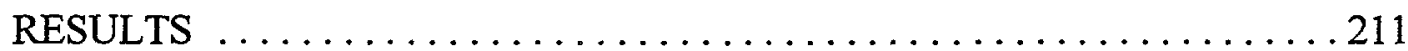

C. DIVISION OF THE PROGRAM INTO STAND-ALONE SEGMENTS $\ldots \ldots 215$

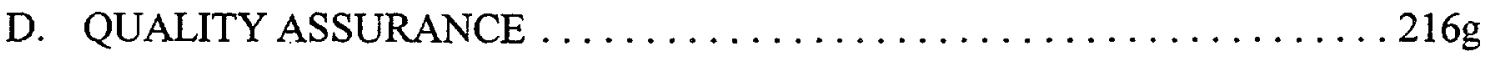

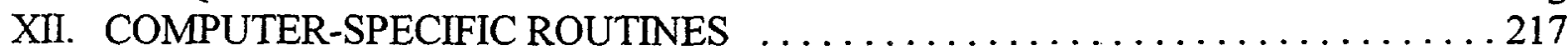

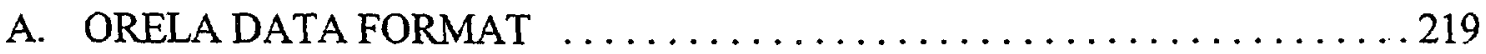

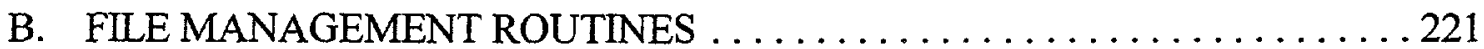

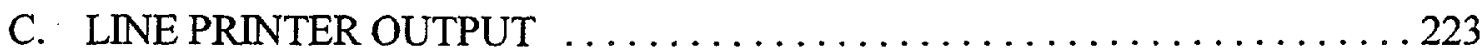

REFERENCES . . . . . . . . . . . . . . . . . . . . . . . . . . . . . . . 225

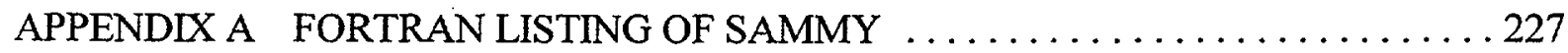

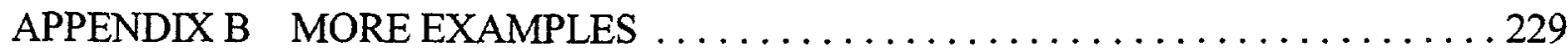

APPENDIX C POSSIBLE JCL FOR IBM-SAMMY ...................... 231

APPENDIX D BIBLIOGRAPHY OF PUBLISHED SAMMY ANALYSES $\ldots \ldots \ldots \ldots 235$

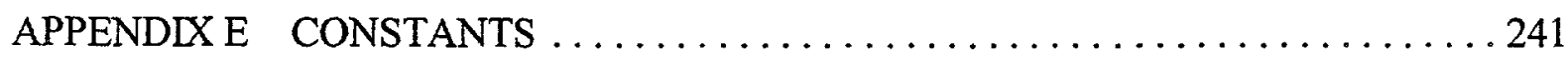




\section{LIST OF TABLES}

Table

Page

IIIA1.1 Penetrability (penetraction factor) $P$, level shift factors $S$, and potential scattering phase shifts $\phi$ for orbital angular momentum $l$, center of mass momentum $k$, and channel radius $a_{c}$, with $p=k a_{c} \ldots \ldots \ldots \ldots \ldots \ldots 29$

IIIB1.1 Spin and angular momentum conventions used in SAMMY........... 48

IVA2.1 Resolution broadening input parameters $\ldots \ldots \ldots \ldots \ldots \ldots \ldots \ldots$

IVG.1 Default values for parameters for RPI resolution function $\ldots \ldots \ldots \ldots \ldots 92 \mathrm{v}$

VH.1 Default parameter values for paramagnetic cross sections. $\ldots \ldots \ldots \ldots . \ldots 90$

VJ.1 Input for the FITACS program for treatment of the unresolved resonance region. $\ldots \ldots \ldots \ldots \ldots \ldots \ldots \ldots \ldots \ldots \ldots \ldots \ldots \ldots \ldots . \ldots \ldots t$

VI.1 SAMMY input files $\ldots \ldots \ldots \ldots \ldots \ldots \ldots \ldots \ldots \ldots \ldots \ldots$

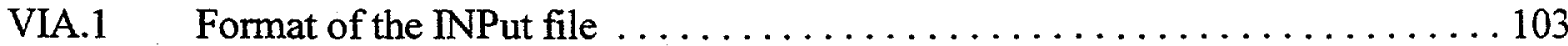

VIA.2 Alphanumeric statements acceptable for use in the INPut file, Card Set $3 \ldots 109$

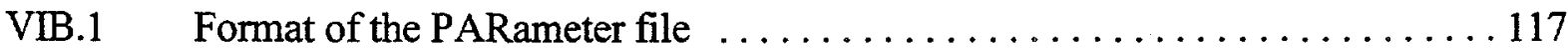

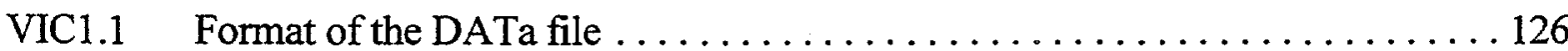

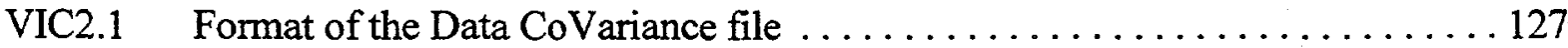

VID.1 Interactive or batch input for a typical SAMMY run, starting with a new PARameter file ................................. 130

VID.2 Interactive or batch input for a typical SAMMYrun, starting with results from

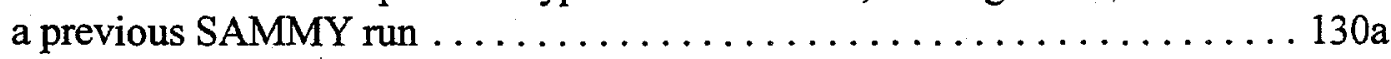

VID.3 Interactive or batch input for SAMMY when a COMBInation of data types were specified in Card Set 8 of Table VIA.1 ................ 130b

VID.4 Interactive or batch input for SAMMY, when "AVERAGE OVER ENERGY

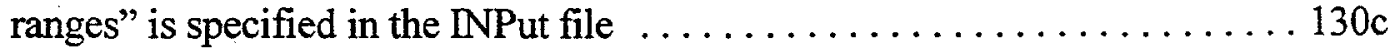


VID.5 Interactive or batch input for SAMMY, when "MAXWELLIAN AVERAGED capture cross sections" is specified in the INPut file . . . . . . . . . . 130d

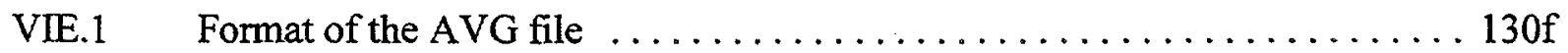

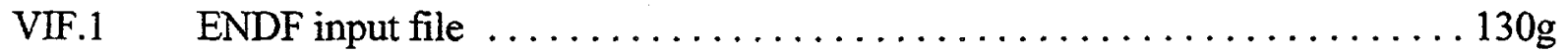

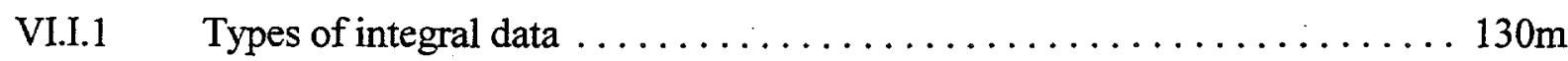

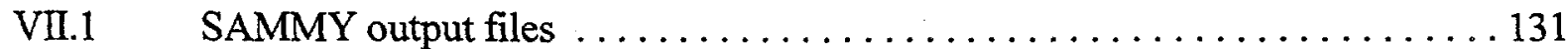

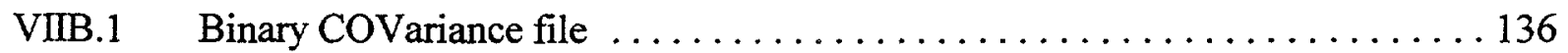

VIIC.1 Sections of the ODF file generated by SAMMY, for transmission or total cross-

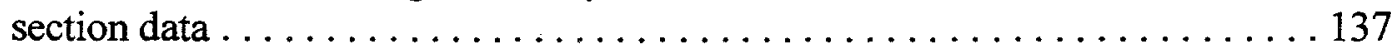

VIIC.2 Sections of the ODF file generated by SAMMY, for energy-differential data that are neither transmission nor total cross section $\ldots \ldots \ldots \ldots \ldots \ldots \ldots 138$

VIIC.3 Sections of SAMMY.ODF when data are differential elastic scattering $\ldots 138.1$

VIIC.4 Sections of the ODF file SAMMY.DAT generated by SAMMY when data are differential elastic scattering

VIID. 1 Contents of the output file SAMMY.PDS $\ldots \ldots \ldots \ldots \ldots \ldots \ldots \ldots$ 138b

VIIE.1 Map from correlation coefficient $c$ to integer $M \ldots \ldots \ldots \ldots \ldots \ldots \ldots$. $\ldots \ldots$ d

VIIIA.1 Commands to analyze data from three samples of different thicknesses at two

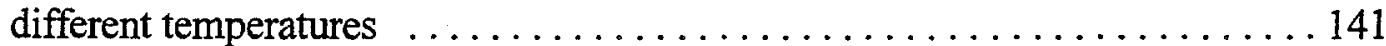

VIIIA.2 The initial PARameter file TR7AAA.PAR for the example of Section VIII.A 144

VIIIA.3 Intermediate PARameter file k1bb7.par .................... 144

VIIIA.4 Intermediate PARameter file klcc7.par ..................... 144

VIIIA.5 Intermediate PARameter file k1dd7.par .................... 145

VIIIA.6 Intermediate PARameter file klee7.par ..................... 145

VIIIA.7 Intermediate PARameter file k1ff7.par $\ldots \ldots \ldots \ldots \ldots \ldots \ldots \ldots \ldots \ldots \ldots$ 
VIIIA.8 Intermediate PARameter file klgg7.par ................... 146

VIIIA.9 PARameter file k1hh7.par, containing final results for the example of Section

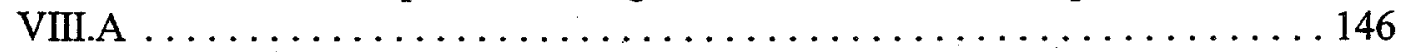

VIIIA.10 PARameter file k1ii7.par, which is a permutation of the file k1hh7.par . . . 146

VIIIA.11 PARameter file k1kk7.par, which is a permutation of the file k1hh7.par . . . 147

VIIIA.12 The PARameter file k1ll7.par, which is a permutation of the file k1hh7.par . . 147

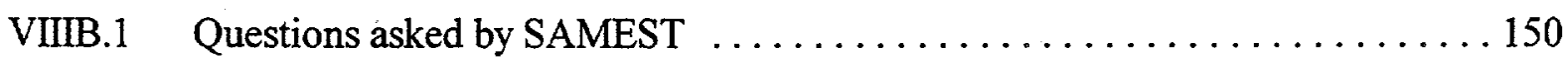

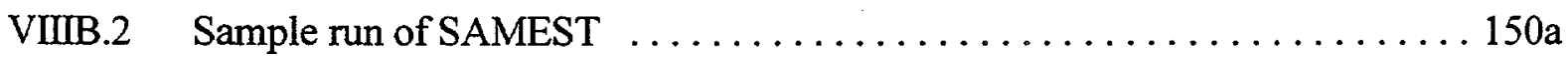

VIIID.1 Formats for the ASCII file produced by program SAMCNV $\ldots \ldots \ldots \ldots 150 \mathrm{f}$

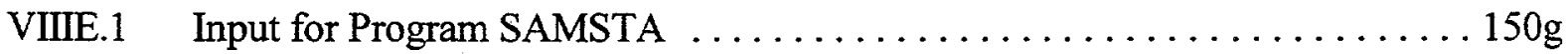

VIIIH.1 Contents of the ODF file SAMMY.DAT $\ldots \ldots \ldots \ldots \ldots \ldots \ldots \ldots \ldots \ldots \ldots \ldots$

VIIIH.2 Contents of the ODF file SAMMY.ODF for angular distribution data $\ldots \ldots 150 \mathrm{~m}$

VIIIH.3 Contents of the ODF file created by program ANGODF $\ldots \ldots \ldots \ldots \ldots$. $\ldots \ldots$ n

IXA.1 The INPut file TR8SAM.DAT for the $\mathrm{Ni}^{58}$ transmission example $\ldots \ldots \ldots 154$

IXA.2 The PARameter file TR8SAM.PAR for the $\mathrm{Ni}^{58}$ transmission example $\ldots \ldots 155$

IXA.3 DATa file TR8SAM.DAT for $\mathrm{Ni}^{58}$ transmission example $\ldots \ldots \ldots \ldots \ldots 156$

IXA.4 Batch file TR8SAM.BAT for the $\mathrm{Ni}^{58}$ transmission example $\ldots \ldots \ldots \ldots 157$

IXA.5 LOG file (terminal output) for $\mathrm{Ni}^{58}$ example $\ldots \ldots \ldots \ldots \ldots \ldots \ldots \ldots$

IXA.6 Portions of the LPT (Line PrinTer) file for the $\mathrm{Ni}^{58}$ example $\ldots \ldots \ldots \ldots \ldots 1$

IXB.1 INPut file TR9SAM.INP for $\mathrm{Pu}^{239}$ fission example $\ldots \ldots \ldots \ldots \ldots \ldots \ldots$

IXB.2 PARameter file TR9SAM.PAR for $\mathrm{Pu}^{239}$ fission example $\ldots \ldots \ldots \ldots \ldots 167$

IXB.3 DATa file TR9SAM.DAT for $\mathrm{Pu}^{239}$ fission example $\ldots \ldots \ldots \ldots \ldots \ldots$

IXB.4 Batch file TR9SAM.BAT for $\mathrm{Pu}^{239}$ fission example $\ldots \ldots \ldots \ldots \ldots \ldots$ 
IXB.5 LOG file (terminal output) for $\mathrm{Pu}^{239}$ fission example $\ldots \ldots \ldots \ldots \ldots \ldots$

IXB.6 Portions of the LPT (Line PrinTer) file for the $\mathrm{Pu}^{239}$ example $\ldots \ldots \ldots \ldots 173$

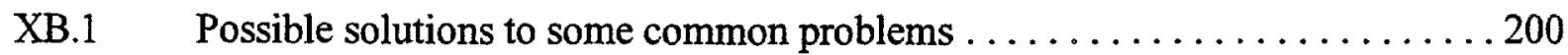

XD.1 Computer exercises for the student $\ldots \ldots \ldots \ldots \ldots \ldots \ldots \ldots \ldots \ldots \ldots \ldots \ldots$

XIA.1 Illustration of dynamic allocation of array storage $\ldots \ldots \ldots \ldots \ldots \ldots 210$

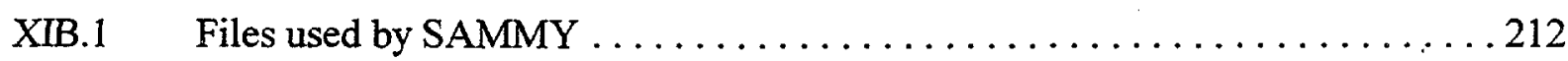

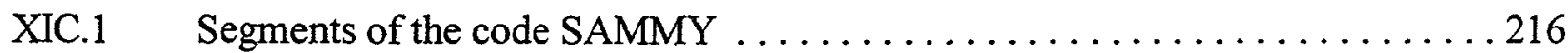

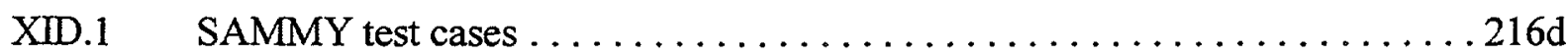

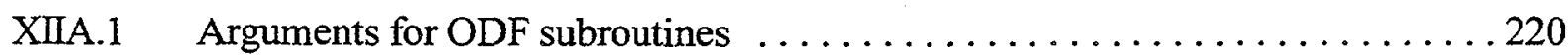

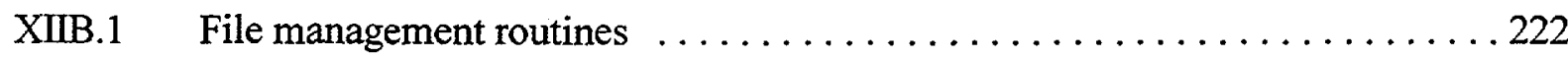




\section{LIST OF FIGURES}

Figure

Page

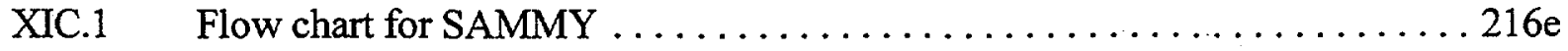


○

$\bullet$ 


\section{ACKNOWLEDGMENTS}

Impetus for the development of a comprehensive users' guide for SAMMY was provided by those brave souls who struggled through a SAMMY analysis without benefit of such a guide. Foremost on this list of data analysts are Claire Perey, Bob Carlton, and Berger Folgelberg, whose comments, suggestions, and error-detection abilities have greatly enhanced both the userfriendly aspects and the accuracy of SAMMY. Other users, too numerous to mention, have also contributed to the continuing process of maintaining and upgrading the code.

Programming help from Jack Craven and Connie Malarkey is gratefully acknowledged: Jack, for devising a method of automatically increasing array sizes as needed, and Connie, for converting SAMMY to the ORIC VAX computer, and in the process discovering a few obscure bugs.

The assistance of Francis Perey in interpreting results and understanding subtleties of Bayes' method has proven invaluable. Francis has also contributed ideas for extension of the code, some of which have already been incorporated into the present version and others of which are being studied for incorporation into the next version of SAMMY.

Thanks to Claire Perey, Francis Perey, and Gerard de Saussure for permitting the use of their preliminary analyses as examples of SAMMY runs. Special thanks to Claire Perey for a careful review of this report. Her efforts have resulted in elimination of a number of obscurities, ambiguities, and just plain errors.

Lastly, the author wishes to thank Bobbie Roth for her patient efforts in typing this manuscript and especially for producing the complicated tables presented in the later sections of this report.

\section{ACKNOWLEDGMENTS FOR REVISION 1}

Special thanks go to Sue Damewood for typing and assembling this document, and to Gerard de Saussure, without whose patient insistence many of the improvements described in this report would not have been made. 


\section{ACKNOWLEDGMENTS FOR REVISION 2}

The scientists and researchers who collectively constitute the SAMMY users group provide the author with a seemingly unending source of inspiration and (at times) frustration. Without the persistent encouragement of Claire Perey, Gerard de Saussure, Mike Moore, Herve Derrien, Ron Winters, Francis Perey, and Duane Larson (among others), this code would never have reached its current state. Special thanks go to Claire Perey and Ron Winters for carefully reviewing the pages of this revision.

Encouragement and financial support for implementation of an IBM version of SAMMY were provided by the Linac group at the Central Bureau for Nuclear Measurements (GELINA) in Geel, Belgium.

Once again the author gratefully acknowledges the able assistance of Sue Damewood in the preparation of the many tables and pages of text for this manual.

\section{ACKNOWLEDGMENTS FOR REVISION 3}

SAMMY users throughout the world continue to provide inspiration, encouragement, and support for the author's endeavors to improve and extend the code; the author is grateful for their interest. Among these are Luiz Leal of ORNL, and the research staff of ORELA. In addition the author wishes to thank Ann McCoy, who patiently typed the first drafts of most pages in this revision.

\section{ACKNOWLEDGMENTS FOR REVISION 4}

Encouragement from and collaboration with the research staff at Renssaelar Polytechnic Institute are gratefully acknowledged. The continued support from colleagues here at Oak Ridge National Laboratory (notably Luiz Leal and Herve Derrien) and around the world is also appreciated. Thanks to SAMMY users who report problems with coding or documentation (John Burke, Olivier Bouland, Klaus Guber, Bob Spencer, Albert Popov). Thanks to Luiz Leal and Royce Sayer for careful proofreading of equations, and to Cecil Lubitz and Norm Francis for thorough reading of this and other documents. Finally, the author wishes to thank M. C. Moxon for numerous interesting conversations relevant to the further development of data analysis tools such as SAMMY and Moxon's code REFIT.

This work was sponsored by the U.S. Department of Energy (DOE), under contract DEAC05-960R22464 with Lockheed Martin Energy Research Corporation. The author is particularly indebted to D. Cabrilla, Environmental Management, U.S. Department of Energy, Washington, D.C., for his support. 


\begin{abstract}
In 1980 the multilevel multichannel R-matrix code SAMMY was released for use in analysis of neutron data at the Oak Ridge Electron Linear Accelerator. Since that time, SAMMY has undergone significant modifications: (1) User-friendly options have been incorporated to streamline common operations and to protect a run from common user errors. (2) The Reich-Moore formalism has been extended to include an optional logarithmic parameterization of the external R-matrix, for which any or all parameters may be varied. (3) The ability to vary sample thickness, effective temperature, matching radius, and/or resolution-broadening parameters has been incorporated. (4) To avoid loss of information (i.e., computer round-off errors) between runs, the "covariance file" now includes precise values for all variables. (5) Unused but correlated variables may be included in the analysis.

Because of these and earlier changes, the 1980 SAMMY manual is now hopelessly obsolete. This report is intended to be complete documentation for the current version of SAMMY. Its publication in looseleaf form will permit updates to the manual to be made concurrently with updates to the code itself, thus eliminating most of the time lag between update and documentation.
\end{abstract}

\title{
ABSTRACT FOR REVISION 1
}

In August of 1984 the users' guide for version $\mathrm{P}$ of the multilevel multichannel R-matrix code SAMMY was published. Recently, major changes within SAMMY have led to the creation of version $\mathrm{O}$, which is documented in this report. Among these changes are: (1) an alternative matrix-manipulation method for use in certain special cases; (2) division of theoretical cross-section generation and broadening operations into separate segments of the code; (3) an option to use the multilevel Breit-Wigner approximation to generate theoretical cross sections; (4) new input options; (5) renaming all temporary files as SAM??.DAT; (6) more sophisticated use of temporary files to maximize the number of data points that may be analyzed in a single run; and (7) significant internal restructuring of the code in preparation for changes described here and for planned future changes. 


\section{ABSTRACT FOR REVISION 2}

In the fall of 1985, the Oak Ridge Electron Linear Accelerator (ORELA) group purchased a VAX-785 to replace their outmoded PDP10 system. SAMMY (and all other ORELA computations) thus migrated to the VAX, a move which required only slight modifications to the program. Shortly thereafter, a Floating Point System (FPS) Array Processor was obtained (jointly with the Physics Division at ORNL) for our use; the move to that machine required significant alterations in the internal structure of SAMMY, especially since we wished to produce a code which was, to as great an extent as possible, compatible for both machines. Finally, in the fall of 1987 an IBM-compatible version was produced, again necessitating some modifications in the internal structure. These changes should not be noticeable to the casual user. IBM users should be aware of some changes in input from those needed for VAX or FPS; such changes are noted in the text.

New capabilities added to SAMMY subsequent to Revision 1 of this report include: (1) increased accuracy in calculations of Doppler-broadened cross sections; (2) the option to use an entirely new method for Doppler broadening; (3) the ability to generate energy-averaged theoretical cross sections; (4) the option to omit specified spin groups from a given analysis; (5) the use of datareduction parameters (normalization, background, etc.) as varied parameters; (6) separate radii for potential scattering vs penetrability and shift factor; (7) different values for radii for different spin groups; (8) a "realistic" version of resolution broadening. These and other changes are documented in Revision 2 of this manual.

\section{ABSTRACT FOR REVISION 3}

Recent additions and improvements to the resonance analysis code SAMMY are documented in Revision 3 of the Users' Guide. Of major interest is the incorporation of self-shielding and multiple-scattering corrections in the calculation of capture yields. Other additions include the abilities to fit differential elastic angular distributions, to calculate Maxwellian (stellar) averages for capture cross sections, and to reconstruct point-wise cross sections on an automatically-generated energy grid.

\section{ABSTRACT FOR REVISION 4}

Modifications and new features of the resonance analysis code SAMMY are documented in Revision 4 of the SAMMY Users' Guide. Several features are designed specifically for use with data taken at the Renssaeler Polytechnic Institute linac (but with more general applicability): additional options for the treatment of backgrounds, a new resolution function, the ability to analyze selfindication experiments, a better multiple-scattering correction, and an option to include paramagnetic cross sections. Other features were designed to facilitate interaction between differential and integral data analysis: an option to calculate average cross sections with no corrections on the theoretical values, the ability to fit directly to some types of integral data, an option to introduce systematic data errors (and hence covariances) without having to explicitly generate the entire data covariance matrix, and output of the resonance parameter covariance matrix in a format that should be efficient for transmittal to other computer codes. 


\section{INTRODUCTION TO REVISION 4}

Modifications and improvements to SAMMY subsequent to the publication of Revision 3 of this manual are documented here. These changes fall into several categories: (1) Significant additions to the code were requested (and funded) to ensure compatibility with experimental conditions of the linac at Renssaelar Polytechnic Institute (RPI). (2) Other features were designed to facilitate interaction between differential and integral data analysis; this work was funded primarily by the Nuclear Criticality Predictability Program (NCPP). (3) Miscellaneous new features and/or new descriptions of old features. (4) Modifications that fall under the general heading of "routine maintenance." (5) Planned future modifications and improvements. Even though the features are itemized in this section under these categories, the reader is encouraged to read the entire introduction, because features developed for one purpose are often suitable for use for another.

\section{RPIOptions}

Further options have been added for background functions. See Section V.E.1, page 98g.

A resolution function has been added which was designed specifically for use with data taken at the Gaerttner LINAC at RPI, but is presumably useful for data taken on other machines as well. See Section IV.G, page 92 s. Note that this resolution function is not necessarily the "final word" for RPI data, but may be updated for the next revision of SAMMY.

The ability to analyze self-indication experiments has been implemented; composition and temperature of the transmission and capture samples need not be identical. See Section III.G.

A truly multiple multiple-scattering correction has been developed for capture and fission yields, and implemented in the code; see Section III.F. Detailed documentation is being prepared, to describe precisely what approximations are used for this important correction factor.

An option has been added to use $l$-dependent detector efficiencies for capture or fission yields or for self-indication experiments. See Section V.K.

An option has been added to include paramagnetic cross section in addition to the total cross section calculated from the resonance parameters. See Section V.H.

\section{Integral/differential features}

Average theoretical cross sections can now be calculated accurately, using SAMMY's auxiliary energy grid, without generating experimental corrections (Doppler and resolution broadening, etc.) on the theoretical values. The inability to do so was a shortcoming overlooked 
until recently and therefore not included in earlier versions of the code. Use the command "MAKE NO CORRECTIONS To theoretical values" in the INPut file (see Section VI.A., Table VIA.2), and do include some broadening parameters (which will not be used, but will force SAMMY to generate and use the dense auxiliary grid).

In addition to the energy-differential (and angle-differential) data that SAMMY was designed to analyze, some types of integral data can now be fitted directly with SAMMY. These are described in Section VI.I, page $130 \mathrm{~m}$, and in greater detail in a separate document [NL97]. (Note that two additional types of integral data have been added to SAMMY subsequent to the release of that document.)

Most experimental data have both statistical errors (for which the covariance matrix is diagonal) and systematic errors (for which the covariance matrix is decidedly off-diagonal). Often analyses include only the statistical errors, or only the diagonal portion of the systematic errors, even though this practice is known to give inaccurate results. To make it easier for SAMMY users to use the correct covariance matrix, SAMMY now contains an option to include Implicit Data Covariance (IDC) information, for which the user must provide only minimal input; see Section VI.C.2. For an application of this technique, see ref. [HD97].

In an effort to improve communication with data processing codes, and to encourage such codes to make use of covariance information for resonance parameters, SAMMY can now provide output of the resonance parameter covariance matrix in a format that may be efficient for transmittal to those codes. See Section V.K (page 98u).

\section{Miscellaneous New Features}

Values for fundamental physical and mathematical constants have been sited at one location only within the code, to ensure that the exact same values are used consistently throughout the code. Default values have been modified to conform to the current ENDF standards; see Appendix E, page 241, for the Cross Section Evaluation Working Group recommendations regarding values of constants.

Test cases (both input and output) have always been available for quality control with SAMMY and can also be useful in learning to use a new feature. A table describing the various test cases has been added to this manual (see Section XI.D, Table XID.1), and many sections now include references to the appropriate test cases.

For the Workshop on Nuclear Reaction Data and Nuclear Reactors-Physics, Design and Safety (held February 23 through March 27, 1998, at the International Centre for Theoretical Physics, Trieste, Italy), a series of exercises was developed as an aid in learning how to run SAMMY. These exercises are now included in the standard SAMMY package when the code is requested from the Radiation Safety Information Computational Center (RSICC) (formerly 
the Radiation Shielding Information Center) or other data centers. See Section X.D (page 206a) for information about these exercises. The companion lecture notes are available as [NL98a].

Generating the appropriate set of spin groups for the nuclide of interest can be a confusing task. See Section VIII.I (page 150o) for guidance.

Converting from REFIT input [MM89] to SAMMY input (or vice versa) is discussed in Section VIII.J (page 150w).

Direct comparison of theoretical cross sections calculated by SAMMY with those calculated by other codes is facilitated by the use of program SAMCMP. See Section VIII.K, page 150y.

SAMMY now automatically calculates average resonance widths and uncertainties thereon. These widths and uncertainties are reported in the LPT file, along with the updated resonance parameters, after data are fitted.

For guidance on the analysis of experimental data for which the sample contains more than one nuclide (multiple isotopes, chemical compounds, contaminants), see Section V.D on page $98 \mathrm{c}$.

Previously, when varying channel radii, SAMMY has implicitly assumed that reduced width amplitudes are held constant; hence the various partial widths (neutron widths, in particular) would be modified even if there were not explicitly varied. The user now has an option to override this assumption, by specifying "DO NOT MODIFY UNVARied widths" in the INPut file; see Table VIA.2, page $114 \mathrm{c}$.

\section{Routine Maintenance}

The entire code has been converted to double precision; previously, only those pieces deemed critical utilized double precision.

Output in the LPT file has been modified to (usually) fit 80 columns rather than 120; this change was driven by the current habit of viewing files on a screen rather than making hard (paper) copy of each file.

A few of the defaults have been changed:

USE 1999 ENDF-102 CONSTANT VALUES now replaces USE PRECISE VALUES OF CONSTANTS. This change ensures that SAMMY results are consistent both with ENDF conventions and with results obtained from other Reich-Moore codes such as NJOY [RM82], MULTIPOLE [RH87], and REFIT [MM89]. Internally, values for the constants are now sited in only one location in the coding, to ensure self-consistency and to facilitate future changes. 
See Appendix E for the CSEWG recommendations regarding values for physical constants, and Table VIA.2 (page 114) for description of how "older" values of the constants may be obtained.

The free-gas model (FGM) of Doppler broadening has been shown [NL98] to be a better choice for all energies, rather than the high-energy Gaussian approximation to the free-gas model. FGM is now the default option for Doppler broadening.

The "new" spin group format is more versatile and contains more information than the original format, and is now the default. Users whose INPut files do not use this format will receive error messages from SAMMY, along with suggestions about the necessary changes. Note: The obsolete spin group format has been found to produce erroneous results when used in conjunction with angle-differential calculations (e.g., multiple-scattering corrections for capture or fission yields). Use of the obsolete spin group option is therefore not permitted in cases where it would produce errors.]

Minor bugs have been fixed; a partial list is given here:

The ASCII option for reading differential elastic scattering data now works consistently.

Integration limits for Doppler broadening have been extended somewhat to ensure more accurate results in those situations where the end of the integration region falls in the middle of a resonance. In addition, the algorithm for choosing the auxiliary grid near small resonances has been improved.

Errors in the documentation of the differential elastic cross section (Section III.E) have been corrected. These errors were only in the documentation, not in the coding.

A correction has been made for programming error affecting only reaction (inelastic or fission) cross sections, in the case when there are more than two reaction channels.

\section{Future Plans}

Among the features planned for addition to sammy in the near future are: (1) More integral quantities, particularly those appropriate for intermediate energies. (2) Charge-dependent penetrabilities, to more accurately describe outgoing fission channels and to extend the capability of the code from neutron-induced reactions to charged-particle-induced reactions. (3) Interface with other codes for use of covariance matrix. (4) Resolution function appropriate for use with Geel data (in collaboration with Saclay and Cadarache). (5) Restructuring of the code to permit truly simultaneous analysis of any and all data sets; see Appendix $\mathrm{F}$ for details. 


\section{II.A.2.a Implicit data covariance matrix}

Bayes' Equations, as derived above, can be modified slightly to efficiently incorporate certain types of off-diagonal data covariance matrices. Often (e.g., in the case of normalization or background subtraction) it is possible to write the data covariance matrix as the sum of two terms, the first of which is diagonal and the second of which is "separable" in the sense that

$$
V^{i j}=v^{i} \delta_{i j}+\sum_{k} X_{k}^{i} w_{k} X_{k}^{j}
$$

In this case the modification to the $(\mathrm{N}+\mathrm{V})$ version of Bayes' equations is immediate: simply replace $V$ by $v+X w X^{t}$. The modification to the $(\mathrm{I}+\mathrm{Q})$ version is not so obvious, but may be far more important because it eliminates the need for inversion of a very large matrix. Note that $V$ can be inverted via

$$
V^{-1}=\left(v+X w X^{t}\right)^{-1}=v^{-1}-v^{-1} X\left(w^{-1}+X^{t} v^{-1} X\right)^{-1} X^{t} v^{-1} .
$$

Although it appears far messier to calculate this than to invert $v+X w X^{t}$ directly, in practice this is the easier calculation, because the dimension of $w$ is small $(\sim 10$ 's $)$ while the dimension of $v$ can be very large ( 1000's ). Substituting Eq. (IIA2a.2) into (IIA2.11) or (IIA1.13) gives

$$
Q=G^{t} v^{-1} G M-G^{t} v^{-1} X\left(w^{-1}+X^{t} v^{-1} X\right)^{-1} X^{t} v^{-1} G M
$$

which is then used directly to calculate $M^{\prime}$ and $P^{\prime}$ in Eqs. (IIA1.11) and (IIIA1.12). 


\section{III.A.1 Cross Section in Terms of R-Matrix}

The angle-integrated cross sections from entrance channel $c$ to exit channel $c^{\prime}$ with total angular momentum $J$ is represented by $\sigma_{c c^{\prime}}^{J}$. (The subscripts $c$ and $c^{\prime}$ represent both the physical configuration and the quantum numbers; a detailed description of the channel, as used in SAMMY, is given in Subsection III.B.1.) This cross section is given in terms of the scattering matrix $U_{c c^{\prime}}^{J}$ as

$$
\sigma_{c c^{\prime}}^{J}=\frac{\pi}{k_{c}^{2}} g_{c}\left|\delta_{c c^{\prime}}-U_{c c^{\prime}}\right|^{2}
$$

where $k_{c}$ is the wave number associated with incident channel $c$ (see Subsection III.B.4) and $g_{c}$ is the spin statistical factor (see Subsection III.B.1).

The total cross section (sum over all exit channels) may be expressed as

$$
\sigma^{\text {total }}=\frac{2 \pi}{k^{2}} \sum_{J} g_{J} \sum_{\substack{c=\text { incident } \\ \text { charnel }}}\left(1-\operatorname{Re}\left(U_{c c}^{J}\right)\right)
$$

in which the spin statistical factor $g_{c}$ is removed from the sum over $c$ and renamed $g_{J}$, since it depends only on the (conserved) total angular momentum $J$; likewise, the wave number for all incident channels (assuming there are more than one) is the same. The elastic (or scattering) cross section is

$$
\sigma^{\text {elastic }}=\frac{\pi}{k^{2}} \sum_{J} g_{J} \cdot \sum_{\substack{c=\text { incident } \\ \text { channel }}}\left(1-2 \operatorname{Re}\left(U_{c c}^{J}\right)+\sum_{\substack{\epsilon^{\prime}=\text { incident } \\ \text { channel }}}\left|U_{c c^{\prime}}^{J}\right|^{2}\right) \text {. }
$$

Note that the innermost summation includes only those exit channels $c^{\prime}$ which are also incident channels.

Similarly, the reaction (or fission) cross section is

$$
\text { o }^{\text {reaction }}=\frac{\pi}{k^{2}} \sum_{J} g_{J} \sum_{\substack{c=\text { incident } \\
\text { channel }}} \sum_{\begin{array}{c}
c^{\prime}=\text { exit } \\
\text { channel }
\end{array}}\left|U_{c c^{\prime}}^{J}\right|^{2} \text {, }
$$

and the capture cross section is

$$
\sigma^{\text {capture }}=\frac{\pi}{k^{2}} \sum_{J} g_{J} \sum_{\substack{c=\text { incident } \\ \text { channels }}}\left(1-\sum_{\substack{c^{\prime}=\text { amy } \\ \text { channel }}}\left|U_{c c^{\prime}}^{J}\right|^{2}\right) .
$$


The absorption cross section is the sum of $\sigma^{\text {reaction }}$ and $\sigma^{\text {capture }}$. Note that the total cross section is the sum of the other three:

$$
\sigma^{\text {total }}=\sigma^{\text {elastic }}+\sigma^{\text {reaction }}+\sigma^{\text {capture }} .
$$

The scattering matrix $U$ can be written in terms of the matrix $W$ as

$$
U_{c c^{\prime}}^{J}=\Omega_{l} W_{c c^{\prime}}^{J} \Omega_{l^{\prime}},
$$

where $l$ represents the orbital angular momentum (see Subsection III.B.1), and $\Omega$ is given by

$$
\Omega_{l}=e^{-i \phi_{l}} .
$$

The potential scattering phase shifts $\phi_{l}$ are shown in Table IIIA1.1.

The matrix $W$ in Eq. (IIIA1.7) is related to the R-matrix via (in matrix notation with indices suppressed)

$$
W=P^{1 / 2}(I-R L)^{-1}\left(I-R L^{*}\right) P^{-1 / 2}
$$

where the quantity $L$ in Eq. (IIIA1.9) is given by

$$
L=(S-B)+i P
$$

with $P$ the penetrability, $S$ the shift factor, and $B$ the arbitrary boundary constant at the channel radius $\mathrm{a}_{c}$ (see Table IIIA1.1). The quantity $I$ in Eq. (IIIA1.9) represents the identity matrix.

SAMMY uses a modified form of Eq. (IIIA1.9) to evaluate $W$. Since $S, B$, and $P$ are all real, $L^{*}$ may be expressed as $L-2 i P$, which gives

$$
\begin{aligned}
W & =P^{1 / 2}(I-R L)^{-1}(I-R L+2 i R P) P^{-1 / 2} \\
& =P^{1 / 2}(I-R L)^{-1}(I-R L) P^{-1 / 2}+P^{1 / 2}(I-R L)^{-1} 2 i R P P^{-1 / 2} \\
& =I+P^{1 / 2}(I-R L)^{-1} 2 i\left\{-(I-R L) L^{-1}+L^{-1}\right\} P^{1 / 2},
\end{aligned}
$$

where the quantity in curly brackets is equal to $R$. Further simplification gives

$$
\begin{aligned}
W & =I-2 i P^{1 / 2} L^{-1} P^{1 / 2}+2 i P^{1 / 2}(I-R L)^{-1} L^{-1} P^{1 / 2} \\
& =I-2 i P L^{-1}+2 i P^{1 / 2} L^{-1}\left(L^{-1}-R\right)^{-1} L^{-1} P^{1 / 2},
\end{aligned}
$$


Table IIIA1.1. Penetrability (penetration factor) $P$, level shift factor $S$, and potential scattering phase shift $\phi$ for orbital angular momentum $l$, center of mass momentum $k$, and channel radius $a_{c}$, with $\rho=k a_{c}$.

\begin{tabular}{lllll}
\hline$l$ & $P_{l}$ & $S_{l}$ & $\phi_{l}$ \\
\hline 0 & $\rho$ & 0 & $\rho$ &
\end{tabular}

$1 \quad \rho^{3} /\left(1+\rho^{2}\right)$

$2 \quad \rho^{5} /\left(9+3 \rho^{2}+\rho^{4}\right)$

그 $\quad 3 \quad \rho^{7} /\left(225+45 \rho^{2}+6 \rho^{4}+\rho^{6}\right)$

$4 \quad \rho^{9} /\left(11025+1575 \rho^{2}+135 \rho^{4}\right.$

$\left.+10 \rho^{6}+\rho^{8}\right)$
$-1 /\left(1+\rho^{2}\right)$

$-\left(18+3 \rho^{2}\right) /\left(9+3 \rho^{2}+\rho^{4}\right)$

$-\left(675+90 \rho^{2}+6 \rho^{4}\right) /\left(225+45 \rho^{2}+6 \rho^{4}+\rho^{6}\right)$

$-\left(44100+4725 \rho^{2}+270 \rho^{4}+10 \rho^{6}\right) /$

$\left(11025+1575 \rho^{2}+135 \rho^{4}+10 \rho^{6}+\rho^{8}\right)$ $\rho-\tan ^{-1} \rho$

$\rho-\tan ^{-1}\left[3 \rho /\left(3-\rho^{2}\right)\right]$

$\rho-\tan ^{-1}\left[\rho\left(15-\rho^{2}\right) /\left(15-6 \rho^{2}\right)\right]$

$\rho-\tan ^{-1}\left[\rho\left(105-10 \rho^{2}\right) /\right.$

$\left.\left(105-45 \rho^{2}+\rho^{4}\right)\right]$ $l \frac{\rho^{2} P_{l-1}}{\left(l-S_{l-1}\right)^{2}+P_{l-1}^{2}} \quad \frac{\rho^{2}\left(l-S_{l-1}\right)}{\left(l-S_{l-1}\right)^{2}+P_{l-1}^{2}}-l$

$$
\phi_{l-1}-\tan ^{-1}\left(P_{l-1} /\left(l-S_{l-1}\right)\right)
$$

or

$$
\begin{aligned}
& B_{l}=\left(B_{l-1}+X_{l}\right) /\left(1+B_{l-1} X_{l}\right) \\
& \text { where } B_{l}=\tan ^{-1}\left(\rho-\phi_{l}\right) \\
& \text { and } X_{l}=\left(P_{l-1}\right) /\left(l-S_{l-1}\right)
\end{aligned}
$$


which is the form used directly in SAMMY. If subscripts are reinserted, this expression becomes

$$
W_{c c^{\prime}}=\delta_{c c^{\prime}}\left(1-2 i P_{l} L_{i}^{-1}\right)+2 i \sqrt{P_{l}} L_{l}^{-1}\left[(I-R L)^{-1}\right]_{c c^{\prime}} L_{l}^{-1} \sqrt{P_{l}} .
$$

Using these definitions of $U$ and $W$, the elastic cross section can be written as

$$
\mathbf{\sigma}^{\text {elassic }}=\frac{\pi}{k^{2}} \sum_{J} g_{J} \sum_{\text {incc }}\left\{1-2 \cos 2 \phi_{l} R e W_{c c}^{J}-2 \sin 2 \phi_{l} I m W_{c c}^{J}+\sum_{i n c c^{\prime}}\left|W_{c c^{\prime}}^{J}\right|^{2}\right\} \text {. }
$$

Similarly, the reaction cross section becomes

$$
\sigma^{\text {reaction }}=\frac{\pi}{k^{2}} \sum_{J} g_{J} \sum_{\text {ince }} \sum_{\text {exit } t^{\prime}}\left|W_{c c^{\prime}}^{J}\right|^{2},
$$

and the capture cross section is

$$
\sigma^{\text {capture }}=\frac{\pi}{k^{2}} \sum_{J} g_{J} \sum_{\text {ince }}\left(1-\sum_{\text {allc }}\left|W_{c c^{\prime}}^{J}\right|^{2}\right) .
$$

Finally, the total cross section may be written as the sum of the others, or

$$
\sigma^{\text {ital }}=\frac{2 \pi}{k^{2}} \sum_{J} g_{J} \sum_{i n c c}\left\{1-\cos 2 \phi_{I} R e W_{c c}^{J}-\sin 2 \phi_{l} \operatorname{Im} W_{c c}^{J}\right\} .
$$

These equations can of course be expanded in terms of $R$ using the formulae on page 28 . The matrix $R$ can, in turn, be expanded in terms of resonances (levels) and "external" functions. Within SAMMY, there are two formulations for the Reich-Moore approximation to the Rmatrix; the first is discussed in Section III.A.1.b on page 33 and the second in Section III.D on page $56 \mathrm{~g}$. In addition, the user may wish to include a logarithmic approximation to the external R-matrix; that is described in Section III.A.l.a on page 31. 


\section{III.A.1.b Reich-Moore approximation to multilevel R-matrix}

The Reich-Moore approximation to the multiplevel R-matrix may be written as

$$
R_{c c^{\prime}}^{R M J}=\sum_{\lambda} \frac{\gamma_{\lambda c} \gamma_{\lambda c^{\prime}}}{E_{\lambda}-E-i \alpha_{\lambda}^{2}},
$$

where all levels (resonances) with total spin and parity $J^{\pi}$ are included in the sum. The number of levels to be included should be infinite; for practial purposes this number is of course truncated to a finite value and the effect of the omitted levels approximated either by large distant levels or by a parameterized $R^{\text {ext }}$ such as that given in Section III.A.1.a.

For neutron channels, the channel width $\Gamma_{\lambda c}$ is given in terms of the reduced width amplitude $\gamma_{\lambda c}$ by

$$
\Gamma_{\lambda c}^{\text {neutron }}=2 \gamma_{\lambda c}^{2} P_{l},
$$

where $P_{l}$ is the centrifugal-barrier penetrability (sometimes called the penetration factor), which depends on the orbital angular momentum $l$ and on the energy $E$; formulae for $P_{l}(E)$ are shown in Table IIIA.1. Note that the reduced width $\gamma_{\lambda c}{ }^{2}$ is independent of energy, but the neutron width $\Gamma_{\lambda c}$ depends on energy via the penetrability. For fission channels in the resolvedresonance region, the width is assumed to be constant and is given by

$$
\Gamma_{\lambda c}^{f_{i s s i o n}}=2 \gamma_{\lambda c}^{2},
$$

that is, by a penetrability of unity. Similarly, the gamma width $\Gamma_{\lambda}{ }^{\gamma}$ is given in terms of the reduced capture width amplitude (or gamma width amplitude) $\alpha_{\lambda}$ as

$$
\Gamma_{\lambda}^{\gamma}=2 \alpha_{\lambda}^{2} \text {. }
$$

The $u$-parameters (see Section II.B.2) associated with the resonances are given by

$$
u\left(E_{\lambda}\right)= \pm \sqrt{|E|},
$$

where the negative sign is chosen if $E_{\lambda}$ is negative,

$$
u\left(\Gamma_{\lambda c}\right)=\gamma_{\lambda c},
$$

and, finally,

$$
u\left(\Gamma_{\lambda}^{\gamma}\right)=\alpha_{\lambda} .
$$

Note that $\gamma_{\lambda}$ and $\alpha_{\lambda}$ may be either positive or negative. The $u$-parameters are the basis on which Bayes' Equations operate.

With these definitions, the various cross sections defined in Section II.A.1 can be expressed in terms of resonance parameters. We shall explicitly consider the one-level, twochannel case; users are reminded, however, that SAMMY is by no means restricted to this simple case and can be used with as many levels and as many channels as are needed to describe the particular physical situation. 
In the one-level, two-channel case, the $W$ matrix takes the form

$$
\left(\begin{array}{cr}
1-\frac{i P_{1} \gamma_{1}^{2}}{D} & -\frac{i \sqrt{P_{1}} \gamma_{1} \sqrt{P_{2}} \gamma_{2}}{D} \\
-\frac{i \sqrt{P_{1}} \gamma_{1} \sqrt{P_{2}} \gamma_{2}}{D} & 1-\frac{i P_{2} \gamma_{2}^{2}}{D}
\end{array}\right)^{-1}\left(\begin{array}{cc}
1+\frac{i P_{1} \gamma_{1}^{2}}{D} & \frac{i \sqrt{P_{1}} \gamma_{1} \sqrt{P_{2}} \gamma_{2}}{D} \\
\frac{i \sqrt{P_{1}} \gamma_{1} \sqrt{P_{2}} \gamma_{2}}{D} & 1+\frac{i P_{2} \gamma_{2}^{2}}{D}
\end{array}\right),
$$

in which the subscript on the penetrabilities denotes the channel number (not the angular momentum), and the symbol $D$ has been used for $\left\{E_{\lambda}-E-i \alpha^{2}\right\}$. This equation in turn reduces to the form

$$
W=\frac{1}{E_{\lambda}-E-i \Gamma / 2}\left(\begin{array}{cc}
E_{\lambda}-E-i\left(\alpha^{2}-P_{1} \gamma_{1}^{2}+P_{2} \gamma_{2}^{2}\right) & 2 i \sqrt{P_{1}} \gamma_{1} \sqrt{P_{2}} \gamma_{2} \\
2 i \sqrt{P_{1}} \gamma_{1} \sqrt{P_{2}} \gamma_{2} & E_{\lambda}-E-i\left(\alpha^{2}+P_{1} \gamma_{1}^{2}-P_{2} \gamma_{2}^{2}\right)
\end{array}\right) \text {, }
$$

in which $\Gamma$ is the sum of the partial widths $\Gamma_{1}+\Gamma_{2}+\Gamma_{\gamma}$. Using the appropriate terms from this matrix equation, we can find expressions for the cross sections in terms of resonance parameters. The elastic cross section becomes

$$
\sigma^{\text {elastic }}=\frac{2 \pi}{k^{2}} g\left\{1-\cos 2 \phi\left(1-\frac{\Gamma_{1} \Gamma}{2 d}\right)-\sin 2 \phi \frac{\Gamma_{1}\left(E_{\lambda}-E\right)}{d}-\frac{\Gamma_{1}\left(\Gamma_{\gamma}+\Gamma_{2}\right)}{2 d}\right\},
$$

where $d$ represents $\left(E_{\lambda}-E\right)^{2}+(\Gamma / 2)^{2}$. Similarly the reaction cross section can be written

$$
\sigma^{\text {reaction }}=\frac{\pi}{k^{2}} g \frac{\Gamma_{1} \Gamma_{2}}{d} \text {, }
$$

and the capture cross section is

$$
\sigma^{\text {capture }}=\frac{\pi}{k^{2}} g \frac{\Gamma_{1} \Gamma_{\gamma}}{d} .
$$

Finally, the total cross section becomes

$$
\sigma^{\text {total }}=\frac{2 \pi}{k^{2}} g\left\{1-\cos 2 \phi\left(1-\frac{\Gamma_{1} \Gamma}{2 d}\right)-\sin 2 \phi \frac{\Gamma_{1}\left(E_{\lambda}-E\right)}{d}\right\} .
$$




\section{III.A.2.a.i R-external parameters}

Derivatives of $\mathrm{R}^{\mathrm{ext}}$ with respect to the $u$-parameters are found from Eq. (IIIA1a.1) to be

$$
\begin{gathered}
\frac{\partial R_{c}^{\text {ext }}}{\partial E_{c}^{u p}}=-\frac{s_{\text {con }, c}+s_{l i n, c} E_{c}^{u p}}{E_{c}^{u p}-E}, \\
\frac{\partial R_{c}^{\text {ext }}}{\partial E_{c}^{\text {down }}}=-\frac{s_{c o n, c}+s_{l i n, c} E_{c}^{\text {down }}}{E-E_{c}^{\text {down }}},
\end{gathered}
$$

$$
\frac{\partial R_{c}^{e x t}}{\partial \bar{R}_{c o n, c}}=1
$$

$$
\frac{\partial R_{c}^{e x t}}{\partial \bar{R}_{l i n, c}}=E
$$

$$
\frac{\partial R_{c}^{e x t}}{\partial \bar{R}_{q, c}}=E^{2}
$$

$$
\frac{\partial R_{c}^{e x t}}{\partial \sqrt{s_{c o n c, c}}}=-2 \sqrt{s_{c o n, c}} \ln \left(\frac{E_{c}^{u p}-E}{E-E_{c}^{\text {down }}}\right),
$$

and

$$
\frac{\partial R_{c}^{\text {ext }}}{\partial s_{\text {lin, }}}=-\left(E_{c}^{u p}-E_{c}^{\text {down }}\right)-E \ln \left(\frac{E_{c}^{u p}-E}{E-E_{c}^{\text {down }}}\right) .
$$




\section{III.B.1 Spin and Angular Momentum Conventions}

The spin and angular momentum conventions used in SAMMY (and MULTI) are described in Table III.B.1. Note that the word "channel" refers to the physical configuration as well as to the quantum numbers given here. For example, an incident channel would be a neutron (intrinsic spin $i=1 / 2$ ) impinging on a target (sample) whose spin is $I$, so that the channel spin is $j$ (often called $s$ ), where $\vec{j}=\vec{i}+\vec{I}$. The relative orbital angular momentum of this channel (neutron + target) is $l$, and total spin is $J$, where $\vec{J}=\vec{j}+\vec{l}$. The exit channel might be the same as the entrance channel, or it might be, for example, two fission products whose individual spins ( $i^{\prime}$ and $I^{\prime}$ ) need not be defined but whose channel spin is $j^{\prime}$, where $\vec{j}^{\prime}=\vec{i}^{\prime}+\vec{I}^{\prime}$. The relative angular momentum of the two fission products is $l^{\prime}$, and the total $J$ must satisfy $\vec{J}=\vec{j}^{\prime}+\vec{l}^{\prime}$.

The spin statistical factor $g_{J}$ or $g_{c}^{J}$ appearing in the equations for cross section (see Section III.A) is given by

$$
g_{J}=\frac{(2 J+1)}{(2 i+1)(2 I+1)}=\frac{(2 J+1)}{2(2 I+1)},
$$

since the incident particle is always a neutron.

A few words of discussion about the use of these quantum numbers in SAMMY are warranted here, to avoid possible confusion:

(1) Incident spin $i$ is assumed to be $1 / 2$, and values for exit spins $i^{\prime}$ and $I^{\prime}$ are given in the "alternative to Card Set 10" of the INPut file; see Section VI.A. SAMMY will test for consistency, but will only give error messages (and not abort the run) if these quantities are not correct. With the "obsolete spin group format" (Card Set 10), these values are not defined.

(2) Channel spins $j$ and $j^{\prime}$ are used as channel descriptors in the output (LPT or IO file; see Section VII). SAMMY will issue a warning statement (but not abort) if these values are inconsistent (i.e., if $\vec{j} \neq \vec{i}+\vec{I}$ ).

(3) Target spin $I$ is required for evaluation of the spin statistical factor $g$, Eq. (IIIB1.1). SAMMY will issue warnings (but not abort) if $I$ is defined to be inconsistent with other spins.

(4) The same applies to total spin $J$. In the obsolete spin group format (Card Set 10 of the INPut file, Table VIA.1), $g$ may be input directly in the same location normally used to give the value for $J$; in this case consistency checks cannot be made.

(5) Orbital angular momentum must be given correctly since the value of $l$ is used for generating penetrabilities, shift factors, and potential phase shifts.

Finally, please note that it is the user, not the program, who is ultimately responsible for including the proper spin definitions. SAMMY will issue warnings for obvious errors, but it is the responsibility of the user to notice and heed those warnings. It is also the responsibility of the user to ensure that the set of spin groups is complete. Program SAMQUA, described in Section VIII.I (page 150o), can be used for guidance. 
Table III.B1.1 Spin and angular momentum conventions used in SAMMY ${ }^{a}$

\begin{tabular}{|c|c|c|c|}
\hline Symbol & FORTRAN name used in SAMMY & Meaning & $\begin{array}{c}\text { Value or } \\
\text { range of values } \\
\end{array}$ \\
\hline$i$ or $i^{\prime}$ & & $\begin{array}{l}\text { Intrinsic spin of incident } \\
\text { neutron or outgoing } \\
\text { particle. }\end{array}$ & $\begin{array}{l}1 / 2 \text { for incident } \\
\text { neutron }\end{array}$ \\
\hline $\operatorname{Ior} I^{\prime}$ & SPINI & $\begin{array}{l}\text { Spin of target [i.e., sample] } \\
\text { or residual nuclei }\end{array}$ & $\begin{array}{l}\text { integer or } \\
\text { half-integer }\end{array}$ \\
\hline $\operatorname{lor} l^{\prime}$ & $\begin{array}{l}\text { LSPIN (channel 1, group number) or } \\
\text { LSPIN (whatever channel, group number) }\end{array}$ & $\begin{array}{l}\text { Orbital angular momentum } \\
\text { of incident or outgoing } \\
\text { particle }\end{array}$ & $\begin{array}{l}\text { non-negative } \\
\text { integer }\end{array}$ \\
\hline$j$ or $j^{\prime}$ & $\begin{array}{l}\text { CHSPIN (channel 1, group number) or } \\
\text { CHSPIN (whatever channel, group number) }\end{array}$ & $\begin{array}{l}\text { Incident or outgoing channel } \\
\text { spin, equal to target } \\
\text { spin plus neutron spin. }\end{array}$ & $\begin{array}{l}\vec{j}=\vec{I}+\vec{i} \quad \text { or } \\
\vec{j}^{\prime}=\vec{I}^{\prime}+\vec{i}^{\prime}\end{array}$ \\
\hline$J$ & SPINJ (group number) & $\begin{array}{l}\text { (1) Spin of resonance } \\
\text { (2) Spin of excited level in } \\
\text { the compound nucleus } \\
\text { (3) Total angular momentum } \\
\text { quantum number }\end{array}$ & $\begin{aligned} \vec{J} & =\vec{l}+\vec{j} \\
& =\vec{l}^{\prime}+\vec{j}^{\prime}\end{aligned}$ \\
\hline
\end{tabular}

${ }^{a}$ Note: The channel $\operatorname{spin} j$ or $j$ 'is referred to by the symbol $s$ or $s$ 'in some references [AL58, FF80]. 


\section{III.B.2 Comparison of Reich-Moore Approximation to Multilevel Breit Wigner Approximation}

The Reich-Moore approximation (RM), described in Section III.A.1.b and (in a slightly different guise) in Section III.D, is not the only possible incarnation of multilevel R-Matrix theory. Another one in realtively common use is the Multilevel Breit Wigner Approximation (MLBW), used, for example, in the code SIOB [GD78]; others are discussed in some detail by Fröhner [FF80]. In this section, the RM and MLBW formulations are compared, using ideas introduced by Wigner and Eisenbug [EW47] and by Vogt [EV58].

The exact equation for the scattering matrix $U$ may be written as

$$
U_{c c^{\prime}}=\Omega_{l}\left(\delta_{c c^{\prime}}+i \sum_{\lambda, \mu} \Gamma_{\lambda c}^{1 / 2} A_{\lambda \mu} \Gamma_{\mu c^{\prime}}^{1 / 2}\right) \Omega_{l^{\prime}},
$$

where the level matrix $A$ is given by

$$
\left(A^{-1}\right)_{\lambda \mu}=\left(E_{\lambda}^{0}-E\right) \delta_{\lambda \mu}-\sum_{c} \gamma_{\lambda c} L_{c} \gamma_{\mu c},
$$

and all other quantities are as defined in Section III.A.

In the MLBW approximation, all off-diagonal elements of $A$ are neglected, that is,

$$
\left(A^{-1}\right)_{\lambda \mu} \approx\left(E_{\lambda}^{0}-E-\sum_{c} \gamma_{\lambda c}^{2} L_{c}\right) \delta_{\lambda \mu}
$$

Using the definition of $L_{c}$ from Eq. (IIIA.10), this equation may be rearranged as

$$
\left(A^{-1}\right)_{\lambda \mu} \simeq\left[E_{\lambda}^{0}-E-\sum_{c}\left(S_{c}-B_{c}\right) \gamma_{\lambda c}^{2}-i \sum_{c} P_{c} \gamma_{\lambda c}^{2}\right] \delta_{\lambda \mu},
$$

or

$$
\left(A^{-1}\right)_{\lambda \mu} \simeq\left(E_{\lambda}^{0}+\Delta_{\lambda}-E-i \sum_{c} \Gamma_{\lambda c} / 2\right) \delta_{\lambda \mu}
$$

where the level shift $\Delta_{\lambda}$ is given by

$$
\Delta_{\lambda}=-\sum_{c}\left(S_{c}-B_{c}\right) \gamma_{\lambda c}^{2}
$$

and the width $\Gamma_{\lambda c}$ by

$$
\Gamma_{\lambda c}=2 P_{c} \gamma_{\lambda c}^{2}
$$


In the $\mathrm{RM}$ approximation, only those off-diagonal elements arising from photon channels are neglected, that is,

$$
\left(A^{-1}\right)_{\lambda \mu} \simeq\left(E_{\lambda}^{0}-E-\sum_{c \in \gamma}\left(S_{c}-B_{c}\right) \gamma_{\lambda c}^{2}-i \sum_{c \in \gamma} P_{c} \gamma_{\lambda c}^{2}\right) \delta_{\lambda \mu}-\sum_{c \in \gamma} \gamma_{\lambda c} L_{c} \gamma_{\mu c},
$$

where by " $c \in \gamma$ " we mean " $c$ is a photon channel" and by " $c \notin \gamma$ " we mean " $c$ is a particle channel." Rearranging, we find

$$
\left(A^{-1}\right)_{\lambda \mu} \simeq\left(E_{\lambda}^{0}+\Delta_{\lambda \gamma}-E-i \Gamma_{\lambda \gamma} / 2\right) \delta_{\lambda \mu}-\sum_{c \notin \gamma} \gamma_{\lambda c} L_{c} \gamma_{\mu c},
$$

where the level shift $\Delta_{\lambda \gamma}$ is defined as

$$
\Delta_{\lambda \gamma}=-\sum_{c \notin \gamma}\left(S_{c}-B_{c}\right) \gamma_{\lambda c}^{2}
$$

and the capture width $\Gamma_{\lambda y}$ is given by a special case of Eq. (IIIB2.7),

$$
\Gamma_{\lambda \gamma}=2 P_{\gamma} \gamma_{\lambda \gamma}^{2}=2 \gamma_{\lambda \gamma}^{2}
$$

Data analysis using either the RM or the MLBW approximation yields three (or more) parameters for each level: the resonance energy $E_{\lambda}$ (equal to $E_{\lambda}^{0}+\Delta_{\lambda \gamma}$ for RM, or to $E_{\lambda}^{0}+\Delta_{\lambda}$ for MLBW), the radiation width $\Gamma_{\lambda \gamma}$, and the particle channel width(s) $\Gamma_{\lambda c}$. For isolated resonances of non-fissile nuclei, the values for these parameters would be equal in the two cases. The MLBW formulation, however, does not include the level-level interference nor the multichannel features of the RM. 


\section{III.D. ALTERNATIVE FORMULATION OF REICH-MOORE MULTILEVEL R- MATRIX THEORY}

While the equations given in Section III.A.1 for the Reich-Moore approximation to multilevel R-matrix theory are correct, they may not be optimal for computer calculations. In particular, the calculation of the absorption or capture cross section at very low energies involves computation of a quantity having the form $1-(1-\epsilon)$, where $\epsilon$ is small. This may result in large random fluctuations, the familiar "small difference of large numbers" problem. To circumvent this difficulty, the Reich-Moore equations have been programmed in an alternative manner: Starting from Eq. (IIIA1.12), the matrix $W$ can be expressed in the form

$$
W=I-2 i P L^{-1}\left(L^{-1}-R\right)^{-1}\left(L^{-1}-R\right)+2 i P^{1 / 2} L^{-1}\left(L^{-1}-R\right)^{-1} L^{-1} P^{1 / 2},
$$

which reduces to

$$
W=I+2 i P^{1 / 2} L^{-1}\left(L^{-1}-R\right)^{-1} R P^{1 / 2},
$$

or, explicitly displaying the subscripts,

$$
W_{c c^{\prime}}=\delta_{c c^{\prime}}+2 i P_{l}^{1 / 2} L_{l}^{-1} \sum_{c^{\prime}}\left[\left(L^{-1}-R\right)^{-1}\right]_{c c^{-}} R_{c^{-c^{\prime}}} P_{l^{\prime}}^{1 / 2}
$$

If we define a matrix $X$ such that then $\mathrm{X}$ is given by

$$
X_{c c^{\prime}}=P_{l}^{1 / 2} L_{l}^{-1} \sum_{c^{-}}\left[\left(L^{-1}-R\right)^{-1}\right]_{c c^{-}} R_{c^{*} c^{\prime}} P_{l^{1}}^{1 / 2} .
$$

The absorption cross section can then be expressed in terms of $\mathrm{X}$ as

$$
\sigma^{a b s o r p t i o n}(E)=\frac{\pi}{k^{2}} \sum_{J} g_{J} \sum_{c}\left[1-\sum_{c^{\prime}}\left|(1+2 i X)_{c c^{\prime}}\right|^{2}\right],
$$

where $c$ and $c^{\prime}$ are incident channels only. Letting $X^{r}$ be the real part and $X^{i}$ the imaginary part of $X$, this expresion becomes

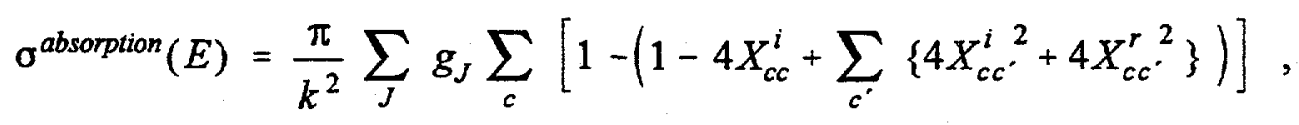

or

$$
\sigma^{a b s o r p t i o n}(E)=\frac{4 \pi}{k^{2}} \sum_{J} g_{J} \sum_{c}\left[X_{c c}^{i}-\sum_{c^{\prime}}\left\{X_{c c^{\prime}}^{i 2}+X_{c c^{\prime}}^{r^{2}}\right\}\right]
$$

Other cross sections (total, fission, elastic, etc.) can similarly be expressed in terms of matrix $X$. The fission (reaction) cross section becomes 


$$
\sigma^{\text {reaction }}(E)=\frac{4 \pi}{k^{2}} \sum_{J} g_{J} \sum_{\text {inc } c} \sum_{\text {exit } c^{\prime}}\left\{X_{c c^{\prime}}^{i^{2}}+X_{c c^{\prime}}^{r^{2}}\right\},
$$

where the sums are over incident and exit channels, respectively. The capture cross section is

$$
\sigma^{\text {capture }}(E)=\frac{4 \pi}{k^{2}} \sum_{J} g_{J} \sum_{\text {inc } c}\left[X_{c c}^{i}-\sum_{\text {all } c^{0^{\prime}}}\left\{X_{c c^{\prime}}^{i 2}+X_{c c^{\prime}}^{r^{2}}\right\}\right] .
$$

The elastic cross section is given by

$$
\begin{aligned}
\dot{\sigma}^{\text {elastic }}(E)= & \frac{4 \pi}{k^{2}} \sum_{J} g_{J} \sum_{i n c c}\left[\sin ^{2} \phi_{l}\left(1-2 X_{c c}^{i}\right)\right. \\
& \left.-X_{c c}^{r} \sin \left(2 \phi_{l}\right)+\sum_{i n c c^{\prime}}\left\{X_{c c^{\prime}}^{i 2}+X_{c c^{\prime}}^{r^{2}}\right\}\right] .
\end{aligned}
$$

Finally the total cross section is the sum of all others, and can be written

$$
\sigma^{\text {total }}(E)=\frac{4 \pi}{k^{2}} \sum_{J} g_{J} \sum_{\text {inc } c}\left[\frac{1}{2} \sin ^{2} \phi_{l}+X_{c c}^{i} \cos \left(2 \phi_{l}\right)-X_{c c}^{r} \sin \left(2 \phi_{l}\right)\right] .
$$

This formulation of the Reich-Moore equations has been implemented in segment XCT of the code SAMMY, and is now the default for all calculations.

To override this default (i.e., to use the original formulation of the Reich-Moore equations), include the following card in the INPut file (See Table VIA.2):

\section{ORIGINAL REICH-MOORE FORMULATION IS WANTED}

Use of this formulation is not permitted for certain types of data (e.g., differential elastic scattering, or capture yields with multiple-scattering corrections), and is discouraged in all cases. 


\section{III.E. DIFFERENTIAL ELASTIC CROSS SECTION ${ }^{1}$}

Following Blatt and Biedenharn [JB52] with some notational changes, the differential elastic angular distribution cross section in the center-of-mass system may be written

$$
\frac{d \sigma^{\text {elastic }}}{d \Omega_{C M}}=\sum_{L} C_{L}(E) P_{L}(\cos \alpha)
$$

where $P_{L}$ is the Legendre polynomial of degree $L$ and $\alpha$ is the angle of the outgoing neutron relative to the incoming neutron in the center-of-mass system. The coefficients $C_{L}(E)$ are given by

$$
C_{L}(E)=\frac{1}{4 k^{2}} \sum_{J_{1} c_{1} c_{1}^{\prime}} \sum_{J_{2} c_{2} c_{2}^{\prime}} X_{c_{1} c_{1}^{\prime} c_{2} c_{2}^{\prime}}^{L J_{1} J_{2}} \operatorname{Re}\left[\left(\delta_{c_{1} c_{1}^{\prime}}-U_{c_{1} c_{1}^{\prime}}^{J_{1}}\right)\left(\delta_{c_{2} c_{2}^{\prime}}-U_{c_{2} c_{2}^{\prime}}^{J_{2}{ }^{\prime}}\right)\right]
$$

where $c_{1}$ represents the (incident) channel quantum numbers $\left\{l_{1}, j_{1}, J_{1}\right\}$. The sum over $c_{1}$ ' also includes only incident channels: $c_{1}{ }^{\prime}=\left\{l_{1}{ }^{\prime}, j_{1}{ }^{\prime}, J_{1}\right\}$; note that $J_{1}=J_{1}{ }^{\prime}$. Summation indices with subscript 2 are defined similarly. (See Section III.B.1 for details of quantum numbers.) The geometric factor $X$ can be exactly evaluated as a product of terms:

$$
X_{c_{1} c_{1}^{\prime} c_{2} c_{2}^{\prime}}^{L J_{1} J_{2}}=\frac{1}{(2 i+1)(2 I+1)} A_{l_{1} j_{1} l_{1}^{\prime} j_{1}^{\prime}}^{J_{1}} A_{l_{2} j_{2} l_{2}^{\prime} j_{2}^{\prime}}^{J_{2}} D_{l_{1} j_{1} l_{1}^{\prime} j_{1}^{\prime} l_{2} j_{2} l_{2}^{\prime} j_{2}^{\prime}}^{L J_{1} J_{2}}
$$

where the factor $A_{l_{1} j_{1} l_{1}{ }^{\prime} j_{1}{ }^{\prime}}^{J_{1}}$ is of the form

$$
A_{l_{1} j_{1} l_{1}^{\prime} j_{1}^{\prime}}^{J_{1}}=\sqrt{\left(2 l_{1}+1\right)\left(2 l_{1}^{\prime}+1\right)}\left(2 J_{1}+1\right) \Delta\left(l_{1} J_{1} j_{1}\right) \Delta\left(l_{1}^{\prime} J_{1} j_{1}^{\prime}\right),
$$

and the expression for $D$ is

$$
\begin{aligned}
& D_{l_{1} j_{1} l_{1}^{\prime} j_{1}{ }^{\prime} l_{2} j_{2} l_{2}^{\prime} j_{2}^{\prime}}=(2 L+1) \Delta^{2}\left(J_{1} J_{2} L\right) \Delta^{2}\left(l_{1} l_{2} L\right) \Delta^{2}\left(l_{1}^{\prime} l_{2}^{\prime} L\right) \\
& \quad \times w\left(l_{1} J_{1} l_{2} J_{2}, j_{1} L\right) w\left(l_{1}^{\prime} J_{1} l_{2}^{\prime} J_{2}, j_{1}^{\prime} L\right) \delta_{j_{1} j_{2}} \delta_{j_{1}^{\prime} j_{2}^{\prime}(-1)^{j_{1}-j_{1}^{\prime}}} \\
& \quad \times \frac{g !(-1)^{g}}{\left(g-l_{1}\right) !\left(g-l_{2}\right) !(g-L) !} \frac{g^{\prime} !(-1)^{g^{\prime}}}{\left(g^{\prime}-l_{1}^{\prime}\right) !\left(g^{\prime}-l_{2}^{\prime}\right) !\left(g^{\prime}-L\right) !},
\end{aligned}
$$

in which $g$ is defined by

1 Equations (IIIE.2) through (IIIE.5) of Revision 3 contained errors; thanks to A. Papov for bringing them to the author's attention. Note that the errors were only in the documentation, not in the coding. In addition to correcting those errors, the equations in Revision 4 have been generalized to include more than one channel. Specialization to one channel is given on page $56 \mathrm{j} .1$. 


$$
2 g=l_{1}+l_{2}+L
$$

note that $2 g$ must be even. A similar expression defines $g^{\prime}$. The $\Delta^{2}$ term is given by

$$
\Delta^{2}(a b c)=\frac{(a+b-c) !(a-b+c) !(-a+b+c) !}{(a+b+c+1) !},
$$

for which the arguments $a, b$, and $c$ are to be replaced by the appropriate values given in Eqs. (IIIE.4) and (IIIE.5). The quantity $w$ in Eq. (IIIE.5) is defined as

$$
\begin{aligned}
w\left(l_{1} J_{1} l_{2} J_{2}, j L\right)=\sum_{k=\min }^{\max } \frac{(-1)^{k+l_{1}+J_{1}+l_{2}+J_{2}}(k+1) !}{\left(k-\left(l_{1}+J_{1}+j\right)\right) !\left(k-\left(l_{2}+J_{2}+j\right)\right) !} \\
\quad \times \frac{1}{\left(k-\left(l_{1}+l_{2}+L\right)\right) !\left(k-\left(J_{1}+J_{2}+L\right)\right) !} \\
\quad \times \frac{1}{\left(l_{1}+J_{1}+l_{2}+J_{2}-k\right) !\left(l_{1}+J_{2}+j+L-k\right) !\left(l_{2}+J_{1}+j+L-k\right) !}
\end{aligned}
$$

(and similarly for the primed expression), where min and max are chosen such that none of the arguments of the factorials are negative. Note that the expression for $\Delta^{2}(a b c)$ implicitly includes a selection rule for the arguments; that is, the vector sum

must hold.

$$
\vec{a}+\vec{b}=\vec{c}
$$

Differential elastic cross sections are sometimes reported as if measured in the center-ofmass system rather than in the laboratory system; hence SAMMY can calculate either version. To specify which is wanted, insert one of the phrases

USE CENTER OF MASS CrOSS sections

USE LABORATORY CROSS sections into your INPut file (see Tables VIA.1 and VIA.2). Center-of-mass is the default. 
For the single-channel case, the coefficients $C_{L}(E)$ are given by

$$
C_{L}(E)=\frac{1}{4 k^{2}} \sum_{c_{1} c_{2}} \tilde{X}_{c_{1} c_{2}}^{L J_{1} J_{2}} \operatorname{Re}\left[\left(1-U_{c_{1} c_{1}}^{J_{1}}\right)\left(1-U_{c_{2} c_{2}}^{J_{2}^{*}}\right)\right],
$$

where $c_{1}$ again represents the (incident) channel quantum numbers $\left\{l_{1}, j_{1}, J_{1}\right\}$ and similarly for $c_{2}$, and where the tilde indicates that $\tilde{X}$ is described with fewer indices than $X$. $\tilde{X}$ can be written

$$
\tilde{X}_{c_{1} c_{2}}^{L J_{1} J_{2}}=\frac{1}{(2 i+1)(2 I+1)} \tilde{A}_{l_{1} j_{1}}^{J_{1}} \tilde{A}_{l_{2} j_{2}}^{J_{2}} \tilde{D}_{l_{1} j_{1} l_{2} j_{2}}^{L J_{1} J_{2}}
$$

where the factor $\tilde{A}$ becomes

$$
\tilde{A}_{l_{1} j_{1}}^{J_{1}}=\left(2 l_{1}+1\right)\left(2 J_{1}+1\right) \Delta^{2}\left(l_{1} J_{1} j\right)
$$

and the expression for $\tilde{D}$ reduces to

$$
\begin{aligned}
\tilde{D}_{l_{1} j_{1} l_{2} j_{2}}^{L J_{1} J_{2}} & =(2 L+1) \Delta^{2}\left(J_{1} J_{2} L\right) \Delta^{4}\left(l_{1} l_{2} L\right) \\
\times & w^{2}\left(l_{1} J_{1} l_{2} J_{2}, j_{1} L\right) \delta_{j_{1} j_{2}} \\
\times & {\left[\frac{g !}{\left(g-l_{1}\right) !\left(g-l_{2}\right) !(g-L) !}\right]^{2}, }
\end{aligned}
$$

in which $g$ is again defined by

$$
2 g=l_{1}+l_{2}+L,
$$

and $2 g$ is even. 


\section{III.E.1 Kinematics}

If $E$ represents the laboratory energy of the incident neutron, $E^{\prime}$ the lab energy of the outgoing neutron, and $\theta$ the laboratory angle of the outgoing neutron with $\mu=\cos \theta$, then $E^{\prime}$ may be expressed in terms of $E$ and $\mu$ as

$$
E^{\prime}=E\left[\frac{m_{n}}{m_{t}+m_{n}} \mu+\sqrt{\left(\frac{m_{t}}{m_{t}+m_{n}}\right)^{2}-(1-\mu)^{2}\left(\frac{m_{n}}{m_{t}+m_{n}}\right)^{2}}\right]^{2}
$$

where $m_{n}$ represents the mass of the neutron and $m_{t}$ the mass of the sample (target) nucleus. Similarly, the center-of mass angle $\alpha$ between outgoing and incoming neutron is found from

$$
\cos \alpha= \pm \frac{m_{n}}{m_{t}}\left\{\mu \sqrt{\frac{m_{t}^{2}}{m_{n}^{2}}-\left(1-\mu^{2}\right)}-\left(1-\mu^{2}\right)\right\}
$$

and the Jacobian of transformation from center-of-mass to laboratory system as

$$
\frac{d(\cos \alpha)}{d \mu}=2 \mu \frac{m_{n}}{m_{t}}+\frac{1+\left(2 \mu^{2}-1\right) m_{n}^{2} / m_{t}^{2}}{\sqrt{1-\left(1-\mu^{2}\right) m_{n}^{2} / m_{t}^{2}}} .
$$

The elastic angular distribution cross section in the laboratory system is then found by combining Eqs. (IIE.1) with (IIEE1.3), using the relationship in Eq. (IIIE1.2), to give

$$
\frac{d \sigma}{d \Omega_{l a b}}(\mu)=\frac{d \sigma}{d \Omega_{C M}} \frac{d(\cos \alpha)}{d \mu} \text {. }
$$

Note that the lowest energy into which a neutron may scatter (i.e., the energy of a neutron after $180^{\circ}$ scattering) is

$$
E^{\prime}(\mu=-1)=E\left[\frac{m_{t}-m_{n}}{m_{t}+m_{n}}\right]^{2},
$$

and the energy of $90^{\circ}$ scattering is

$$
E^{\prime}(\mu=0)=E\left[\frac{m_{t}-m_{n}}{m_{t}+m_{n}}\right] .
$$




\section{III.E.2 Attenuation}

Corrections for finite-sample size are handled here in much the same manner as in RFUNC, a code developed by F. G. Perey [FP89a] for calculating elastic angular distributions using the $\mathrm{R}$-function approximation for spin-zero samples. Two effects are included, which are denoted "incident neutron attenuation" and "scattered neutron attenuation," respectively.

Incident neutron attenuation is accomplished by multiplying the cross section by the factor

$$
\exp \left(-\dot{n}_{i n}(\theta) \sigma_{t o t, D}(E)\right)
$$

where the "thickness" or attenuation $n_{\text {in }}(\theta)$ may be specified independently for each angle and may be treated as a search parameter. The cross section appearing in Eq. (IIIE2.1) is the Doppler-broadened total cross section.

The so-called "scattered neutron attenuation" is used to approximately describe three distinct effects: (1) Neutrons initially scattered in the direction of the detector may be rescattered (or captured, etc.). (2) Neutrons not initially scattered toward the detector may, after two or more scatterings, ultimately reach the detector. (3) Both the sample and the detectors have large angular spreads.

To describe these effects, the cross section is multiplied by the attenuation factor

$$
\exp \left(-n_{\text {out }}(\theta) \sigma_{t o t, x}\left(E^{\prime}\right)\right)
$$

Here the attenuation $n_{\text {out }}(\theta)$ again may be different for each angle and may be treated as a search parameter. The cross section in this equation is evaluated at the scattered energy for the particular angle, and has been broadened (using a triangular resolution function) to approximate the effects of the angular spread of the detector and sample.

See Table VI.B.1, Card Set 11, Card 4, for details of the input for these attenuation factors. 


\section{III.F SELF-SHIELDING AND MULTIPLE-SCATTERING CORRECTIONS TO CAPTURE OR FISSION YIELDS}

The theoretical capture or fission cross section may be calculated directly from Eq. (IIIA1.5) using the Reich-Moore (or other) approximation to the multilevel R-matrix. However, in order to compare with experiment, corrections must be made for the finite (non-infinitesimal) size of the sample. Both "self-shielding" and "multiple-scattering" effects must be included in the calculation. [Note: to avoid arduous repetition, for the rest of this section "capture" will be taken to mean "capture or fission"; the corrections described here apply to both.] Derivation of the appropriate expressions for self-shielding and multiple-scattering corrections, and details of the methods of calculation, will be presented in a separate publication [NL99a].

\section{Self-Shielding}

Self-shielding is the reduction in the observed capture cross section due to interactions of incident neutrons with other nuclei in front of the current position. The probability that capture will occur at depth $z$ (within $d z$ ) can be written as

$$
\frac{n}{D} e^{-n \sigma_{t} z / D} \sigma_{c} d z
$$

where $n$ is the sample thickness in atoms/barn and $D$ is the sample thickness in the same units as $z$. Subscripts $t$ and $c$ denote total and capture cross sections, respectively. Integrating over $z$ (from 0 to $D$ ) gives the self-shielded capture yield

$$
Y_{0}=\left\{1-e^{-n \sigma_{t}}\right\}\left(\frac{\sigma_{c}}{\sigma_{t}}\right) .
$$

(See the end of this section for a discussion of the normalization options for capture yields.)

\section{Single-Scattering}

The scattering correction is the increase in the observed capture cross section due to capture of neutrons that have been scattered out of the original beam path. Calculation of the scattering effect is more complicated than the self-shielding, because it involves the product of (1) the probability of reaching a position $(x, y, z)$ inside the sample, (2) the probability of scattering from that position into solid angle $\Omega$ within $d \Omega$, (3) the probability of those scattered nuclei reaching position $q$ within $d q$ along that direction, and (4) the probability of being captured at that location. This product is then integrated over the position $q$, over solid angle, and over the sample volume, giving the single-scattering result. If the $z$-axis is defined by the beam line, this expression can be reduced to the form

$$
Y_{1}(E)=\frac{\int d x \int d y}{S} \frac{n}{D} \int d z \exp \left(-\frac{n}{D} \sigma_{t} z\right) \int d \Omega \frac{d \sigma}{d \Omega} \sigma_{c}^{\prime} \frac{n}{D} \int d q \exp \left(-\frac{n}{D} \sigma_{t}^{\prime} q\right),
$$


in which primes indicate evaluation at the scattered energy, rather than at the incident energy of the neutron. The scattered energy is given by

$$
E^{\prime}=E\left[\frac{\cos \theta}{(1+r)}+\sqrt{\frac{1}{(1+1 / r)^{2}}-\frac{\sin ^{2} \theta}{(1+r)^{2}}}\right]^{2}=E \epsilon(\theta) \text {. }
$$

Explicit evaluation of the expression in Eq. (IIIF.3) requires detailed knowledge of the geometry of the sample and its positioning relative to the neutron beam. In the case where the sample is a round disk, with a flat surface perpendicular to the beam, the expression can be reduced to

$$
Y_{1}(E)=Y_{1 \infty f}+Y_{1 \infty b}+Y_{1 \phi f}+Y_{1 \phi b},
$$

where the subscripts " $f$ " and " $b$ " refer to forward and backward scattering, respectively. The subscript $\infty$ indicates that this term assumes the sample extends to infinity in the dimensions perpendicular to the beam; subscript of indicates that this term is the correction for finite size. (NOTE: Corrections for a rectangular shape, rather than a round disk, will be available in future releases of the code.)

The "infinite" terms in Eq. (IIIF.4) are one-dimensional integrals,

$$
\begin{aligned}
& Y_{1 \infty f}(E)=\frac{1}{2} \int_{0}^{1} d \mu \frac{d \sigma}{d \Omega} \frac{\sigma_{c a p}^{\prime}}{\sigma_{t o t}^{\prime}}\left(\frac{1-e^{-n \sigma_{t o t}}}{\sigma_{t o t}}+\frac{e^{-n \sigma_{t o t}}-e^{-n \sigma^{\prime}{ }_{t o t} / \mu}}{\sigma_{t o t}-\sigma_{t o t}^{\prime} / \mu}\right), \\
& \text { and } Y_{1 \infty b}(E)=\frac{1}{2} \int_{-1}^{0} d \mu \frac{d \sigma}{d \Omega} \frac{\sigma_{c a p}^{\prime}}{\sigma_{t o t}^{\prime}}\left(\frac{1-e^{-n \sigma_{t o t}}}{\sigma_{t o t}}-\frac{1-e^{-n\left(\sigma_{t o t}-\sigma_{t o t}^{\prime} / \mu\right)}}{\sigma_{t o t}-\sigma_{t o t}^{\prime} / \mu}\right),
\end{aligned}
$$

in which $\mu=\cos (\theta)$. The "finite" corrections involve four-dimensional integrals of the form

$$
\begin{gathered}
Y_{1 \phi f}(E)=\int_{0}^{1} d \mu \frac{d \sigma}{d \Omega} \frac{\sigma_{c a p}^{\prime}}{\sigma_{t o t}^{\prime}} Q_{f}\left(\mu, \sigma_{t o t}, \sigma_{t o t}^{\prime}\right) \\
\text { and } Y_{1 \phi b}(E)=\int_{-1}^{0} d \mu \frac{d \sigma}{d \Omega} \frac{\sigma_{c a p}^{\prime}}{\sigma_{t o t}^{\prime}} Q_{b}\left(\mu, \sigma_{t o t}, \sigma_{t o t}^{\prime}\right),
\end{gathered}
$$

in which the three-dimensional integral $Q_{f}$ is given by

$$
Q_{f}\left(\mu, \sigma, \sigma^{\prime}\right)=\int d z e^{-n \sigma^{\prime} \frac{D}{z}} \int d^{2} S\left(e^{-n \sigma(D-z) /(D \mu)}-e^{-n \sigma L / D}\right),
$$

and $Q_{b}$ by

$$
Q_{b}\left(\mu, \sigma, \sigma^{\prime}\right)=\int d z e^{-n \sigma^{\prime} \frac{D-z}{z}} \int d^{2} S\left(e^{-n \sigma(D-z) /(D \mu)}-e^{-n \sigma L / D}\right),
$$


where $L$ is the actual path length, within the sample, available for travel by the scattered neutron; note that $L$ is geometry-dependent. The integration over $d^{2} S$ in this expression for $Q$ is over the beam cross section; the integration over $z$ is over the thickness of the sample. SAMMY evaluates $Q$ on a separate grid and interpolates to produce the required values for Eqs. (IIIF.7-8).

Values for $Q$ are generated in advance (in segment SAMPAR) and stored in a file named SAMMY.SSM. This file may be renamed and reused for subsequent runs, so long as the geometry remains the same.

\section{Two or More Scatters}

Derivation of the effect of two or more scatters followed by capture is accomplished in a similar manner to the derivation of the single-scattering effect. The exact expression for $k$ scatters involves $(3 k+3)$ embedded integrations; it is therefore necessary to make severe approximations in order to derive an expression which can be calculated in a finite amount of time. The approximation currently employed by SAMMY is borrowed from Moxon [MM89], based on a derivation by Case et al. [KC53]; an independent derivation is presented in [NL99a]. The approximation assumes that after two scatterings, neutrons are uniformly distributed both in direction of motion and in position within the sample. This approximation has the effect of decoupling $2 k$ of the embedded integrals, so that they can be performed separately from the others. Quantization of this approximation is achieved by assuming that the escape probability for a neutron after $k$ scatterings (i.e., at energy $E^{(k)}$ ) depends only on the energy; specifically, the escape probability is given by the formula

$$
p_{\text {escape }}\left(E^{(k)}\right)=\frac{1}{n \sigma^{(k)}}\left[\frac{1}{2}-\int_{1}^{\infty} u^{-3} d u e^{-n \sigma^{(k)} u}\right] \times \frac{1+2 n \sigma_{t}^{(k)}}{1+\frac{2 n \sigma_{t}^{(k)}}{1+Z / R}},
$$

where $\mathrm{R}$ is the radius of the sample. With this approximation, one can recursively define a function $y$ via

$$
y_{j-1}=\int d \Omega_{j} \frac{d \sigma^{(j-1)}}{d \Omega_{j}}\left(\sigma_{c}^{(j)}+y_{j}\right)\left(1-p_{\text {escape }}\left(E^{(j)}\right)\right),
$$

in which the superscript denotes the energy at which the cross section is to be calculated. The initial estimate for a neutron scattered $k$ times is

$$
y_{k-1} \approx 2 \pi \int d \mu_{k} \frac{d \sigma^{(k-1)}}{d \Omega_{k}} \sigma_{c}^{(k)}\left(1-p_{\text {escape }}\left(E^{(k)}\right)\right) .
$$

This function $y$ can then be used to estimate the capture yield for two or more scatterings,

$$
\bar{Y}_{2}(E)=\frac{\int d x \int d y}{S} \frac{n}{D} \int d z e^{-\frac{n}{D} \sigma_{2} z} \int d \Omega \frac{d \sigma}{d \Omega} y_{1} \frac{n}{D} \int d q e^{-\frac{n}{D} \sigma_{i}^{\prime} q}
$$


In this form the multiple-scattering capture yield has the same mathematical properties as the single-scattering capture yield of Eq. (IIIF.3). Similar computational techniques can therefore be used to evaluate both quantities.

\section{Normalization and Input Options}

Capture yield data may be normalized in a variety of ways; therefore SAMMY allows the user to choose which normalization is to be taken. The normalization generally referred to as capture "yield" is the one shown in the equations in this section; this choice has the property that values are in the range from 0 to 1 . Another commonly used normalization requires dividing by thickness $n$; in this case the value approaches the capture cross section in the limit of zero

thickness. Finally, the data may be normalized as $\left(1-e^{-n \sigma_{t}}\right) \sigma_{t}$, that is, by multiplying the yield by the total cross section. To use these options, the user must include the appropriate phrase in the alphanumeric section of the INPut file:

NORMALIZE AS CROSS Section rather than yield

NORMAIIZE AS YIELD Rather than cross section

NORMALIZE AS (1-E) SIgma

The first of these is the default option.

The default in SAMMY is to not include self-shielding and multiple-scattering corrections.; therefore users will need to include the following phrases in their INPut file:

For self-shielding but no multiple-scattering:

USE SELF SHIELDING OnIy, no scattering, or SEIF SHIELD

For self-shielding, single-scattering (with edge-effects correction), and no double-scattering: USE SINGLE SCATTERINg plus self shielding, or SINGLE

For self-shielding, single-scattering (infinite slab approximation), and no double-scattering: SINGIE INEINITE SLAB

For self-shielding, single-scattering (with edge-effects correction), and multiple-scattering: USE DOUBLE SCATTERINg plus single scattering, or DOUBLE

For self-shielding, single-scattering (infinite-slab approximation), and multiple-scattering: DOUBLE INEINITE SLAB

When finite-size corrections are wanted, additional input is needed to express the geometric properties of the beam and of the sample. These include the dimensions of the sample (in any consistent set of units), the cross-sectional dimensions of the beam if different from and smaller than the sample, and integers that determine the accuracy to which the function $Q$ will be calculated. Details are given in Table VIA.1, Card Set 11. 


\section{III.G SELF-INDICATION MEASUREMENTS}

Self-indication experiments involve a combination of both capture and transmission measurements. Two samples are used: the one closer to the source is used for transmission and the other is used for capture. Both samples contain the nuclide of interest. Such an experiment preferentially removes neutrons near the peak of the resonances for this nuclide, thus focusing on the shoulders or wings of a resonance.

Analysis of a self-indication experiment requires both calculation of transmission through the first sample and calculation of capture yield with self-shielding and multiple-scattering corrections for the second sample. Transmission is calculated as described in Section V.A, using parameters appropriate for that sample (for thickness, nuclide abundances, contaminants, temperature, etc.). Essentially, transmission $T$ is given by

$$
T(E)=e^{-n_{T} \sigma_{t}},
$$

in which $n_{T}$ represents the sample thickness and $\sigma_{t}$ the total cross section (appropriately Doppler broadened). Subscript $T$ indicates that the thickness is that of the transmission sample; subscript $t$ refers to the total cross section. The capture yield $Y(E)$ is calculated as described in Section III.F, using parameters appropriate for the capture sample; note that any of the three normalizations (as cross section, as yield, or as yield times total cross section) described in that section may be applied to the capture "yield" calculation here. The selfindication result is the product of the transmission and the capture yield,

$$
S I(E)=T(E) Y(E),
$$

followed by resolution broadening.

Parameters such as "isotopic" (nuclide) abundances, effective temperature, and thickness, which are input in the usual fashion into SAMMY, are assumed to be those of the capture sample. Input of parameters appropriate for the transmission sample is via Card Set 11, Card 7 of the PARameter file (see Table VIB.1, page 122n). The phrase "self-indication" must occur in the INPut file (Card Set 8, page 107).

Test case tr 57 has examples, using artificial data, for self-indication experiments.

[Note that the option to calculate the self-indication ratio is not yet implemented into SAMMY. This quantity is defined as the resolution-broadened $S I(E)$ divided by the resolution-broadened capture yield $Y(E)$; implementation of this feature is one of many "on the drawing board" for future work.] 


\section{BROADENING}

In general it is not possible to directly compare the cross sections extracted from experiments to those generated via R-matrix theory (or via any other theory). This is because "perfect" experimental conditions do not exist: (1) individual nuclei within the sample are not at rest; (2) finite time intervals are required both for the neutron beam and for the detecting apparatus; and (3) the flight-path length traversed by a neutron depends both upon its position of origin within the neutron-producing target and upon its position of interaction within the sample. The first of these conditions leads to the effect known as Doppler broadening, and the others, to resolution broadening. To compare theory to experiment, either the theory must be broadened or the effects of broadening must be removed from the experiment. The former is far easier.

Three options are available within SAMMY to accomplish Doppler broadening; each is based ultimately upon the free-gas model. The first (i.e., the original) method is based on an adaptation of the method used by George Auchampaugh in his code MULTI [GA74] and is described in Section IV.A. The second, due to work by Leal and Hwang [LL85], is described in Section IV.D. The third option, which was added to SAMMY in order to overcome shortcomings of the first two, is discussed in Section IV.F. It is this third option which the author recommends, and which is now the default in SAMMY; this option is hereafter denoted the "free-gas model." Details are in [NL98].

Three distinct types of resolution broadening are available in SAMMY. The original resolution broadening is based upon the MULTI method [GA74], and is described in Section IV.A. The second option is a more realistic function (the "Oak Ridge Resolution function" [NL99b]), which uses mathematical descriptions of the components in the experimental broadening as determined from careful studies of ORELA experiments. Section IV.E gives specifics about this resolution function. The third option is a realistic function designed to describe the experimental situation for the linac at Rensselaer Polytechnic Institute [NL99c]. A fourth option is under consideration, to be used in conjunction with data taken at the Geel facility.

Readers interested in a detailed study of resolution broadening (with emphasis on the 200-m flight path at ORELA) are referred to the paper by Larson, Larson, and Harvey [DL84].

Section IV.B describes the integration scheme used in SAMMY to accomplish the numerical integrations needed for the various types of broadening. This scheme is a refinement of the fourpoint progressive interpolation method used in MULTI and is used in one form or another throughout SAMMY. (The one notable exception is the Leal-Hwang Doppler broadening method, which requires the use of an equally spaced grid in velocity space.)

Section IV.C discusses how derivatives with respect to broadening parameters are evaluated, for the original (MULTI-style) broadening schemes. 
Note that both cross sections (and/or transmissions, or whatever quantity was measured in the experiment to be analyzed) and derivatives are broadened in SAMMY; in MULTI, only cross sections were broadened. 
SAMMY's original prescription for Doppler broadening, as adapted from MULTI [GA74], is described in Section IV.A.1. The three original prescriptions for resolution broadening are discussed in Section IV.A.2.

Note that the use of this version of Doppler broadening is now discouraged [NL98], since this is a high-energy approximation to the free-gas model. The free-gas model, described in Section IV.F, is a more accurate description of Doppler broadening and requires only slightly more computation time to calculate. 


\section{IV.A.1 Doppler Broadening - MULTI Method}

The high-energy Gaussian approximation to the free-gas model for Doppler broadening has been used successfully for many years [WV12, AF71, FF80], and is the original option available within SAMMY. Its use, however, is now discouraged [NL98]; nevertheless, it is still included in the code for comparison purposes.

The Doppler-broadened cross section may be approximated by convoluting the unbroadened cross section with a Gaussian function of energy as

$$
\sigma_{D}(E)=\frac{1}{\Delta_{D} \sqrt{\pi}} \int_{-\infty}^{\infty} \exp \left\{-\frac{\left(E-E^{\prime}\right)^{2}}{\Delta_{D}^{2}}\right\} \sigma\left(E^{\prime}\right) d E^{\prime},
$$

where the Doppler width $\Delta_{D}$ is given by

$$
\Delta_{D}=\sqrt{\frac{4 m E k T}{M}} .
$$

In this equation, $m$ represents the mass of the neutron, $M$ is the target mass, $k$ is Boltzmann's constant, and $T$ is the effective temperature of the sample material. SAMMY evaluates the Doppler width directly from this formula (i.e., without using heavy-mass approximations): The infinite integration limits in Eq. (IVA1.1) are approximated by $E \pm 5 \Delta_{D}$.

For Doppler broadening via the high-energy Gaussian approximation, the only input quantity which the user must provide to SAMMY is the effective temperature $T$. See Table VIA.1, Card Set 5, variable TEMP, or Table VIB.1, Card Set 4, variable TEMP.

Caveat: For very low energies, the integration limits may fall below zero. In this case, SAMMY will issue a warning and switch to the free-gas model. To circumvent this problem, either use the free-gas model directly (see Section IV.F), use the Leal-Hwang Doppler broadening (Section IV.D), or invoke the option "NO LOW-ENERGY BROADEning is to be used" in the INPut file (see Table VIA.2).

Again, the recommended method of Doppler broadening is the free-gas model, described in Section IV.D. Use of the high-energy Gaussian approximation described in this section is not encouraged. 


\section{A. 2 Resolution broadening - MULTI method}

To understand how a resolution broadening may be described mathematically, we first consider the formula that describes how the neutron's energy is extracted from measured quantities:

$$
E=\frac{1}{2} m v^{2}=\frac{1}{2} m\left(\frac{L}{t}\right)^{2},
$$

where $m$ is the neutron mass and $v$ its velocity. The velocity is equal to the flight path length $L$ divided by travel time $t$. From this definition, it is clear that two types of resolution broadening are possible, one due to distributions in time and the other due to distributions in length.

Several factors may contribute to each of the two types of resolution broadening. Treated explicitly in SAMMY are a square distribution in flight path length (due, e.g., to the neutron moderator and/or detector), a square distribution in time (channel width), and a Gaussian distribution in time (burst width); these three are convoluted and converted to an approximate Gaussian distribution in energy (see Section IV.A.2.a). An exponential distribution may also be included (see Section IV.A.2.b).

Table IVA2.1 shows relationships between SAMMY input parameters and the resolution width associated with various types of resolution distribution functions. This table is included here as an aid in determining appropriate values to use as input to SAMMY. Note that "equivalent," as used in the following pages, indicates only equivalent first and second moments of the distributions, not that the distributions have the same shapes.

Two options for "realistic" resolution-broadening functions are also available in SAMMY; see Section IV.E and IV.G for details.

For a detailed discussion of resolution broadening with emphasis on flight path 1 at ORELA, see [DL84]. 
Table IVA2.1 Resolution-broadening input parameters

\begin{tabular}{|c|c|c|}
\hline $\begin{array}{c}\text { SAMMY } \\
\text { input variable }\end{array}$ & $\begin{array}{c}\text { "Equivalent" } \\
\text { quantity }\end{array}$ & Description \\
\hline \multirow[t]{5}{*}{$\begin{array}{l}\triangle L \text { or DELTAL } \\
\text { (SectionIV.A.2.a) }\end{array}$} & & $\begin{array}{l}\Delta L \text { is the full width of a square distribution in } \\
\text { flight-path length }\end{array}$ \\
\hline & $\sqrt{12} \sigma_{L}$ & $\begin{array}{l}\sigma_{L} \text { is the standard deviation of a Gaussian } \\
\text { distribution in flight-path length }\end{array}$ \\
\hline & $\frac{F_{L}}{\sqrt{(\ln 2) 2 / 3}}$ & $\begin{array}{l}F_{L} \text { is the full width at half maximum of a } \\
\text { Gaussian distribution in flight-path length }\end{array}$ \\
\hline & $S_{L} \sqrt{3} L / E$ & $\begin{array}{l}S_{L} \text { is the standard deviation of a Gaussian } \\
\text { distribution in energy } E \text {, where } L \text { is the flight- } \\
\text { path length }\end{array}$ \\
\hline & $\Delta_{L} \sqrt{3 / 2} L / E$ & $\begin{array}{l}\Delta_{\mathrm{L}} \text { is the full width at half maximum of a } \\
\text { Gaussian distribution in energy } E \text {, where } L \text { is the } \\
\text { flight-path length }\end{array}$ \\
\hline \multirow[t]{4}{*}{$\begin{array}{l}\Delta t_{c} \text { or DELTAB } \\
\times \text { Cf }_{\mathrm{i}} \text { (see Section } \\
\text { IV.A.2.a) }\end{array}$} & & $\begin{array}{l}\Delta t_{c} \text { is the full width of a square distribution in } \\
\text { time (channel width); this is the equivalent of the } \\
\text { quantity } b \text { in [DL84], page } 30 \text {. }\end{array}$ \\
\hline & $\sqrt{12} \sigma_{c}$ & $\sigma_{c}$ is standard deviation of Gaussian in time \\
\hline & $\sqrt{3 / 2 \ln 2} F_{c}$ & $F_{c}$ is full width at half max of Gaussian in time \\
\hline & $\frac{\sqrt{3} t}{E} S_{c}=\sqrt{\frac{3 m}{2}} \frac{L}{E^{3 / 2}} S_{c}$ & $\begin{array}{l}S_{c} \text { is the standard deviation of a Gaussian } \\
\text { distribution in energy }\end{array}$ \\
\hline \multirow[t]{3}{*}{$\begin{array}{l}\Delta t_{G} \text { or DELTAG } \\
\text { (Section IV.A.2.a) }\end{array}$} & & $\begin{array}{l}\Delta t_{G} \text { is the full width at half max of a Gaussian } \\
\text { distribution in neutron transit time }\end{array}$ \\
\hline & $\sqrt{8 \ln 2} \sigma_{G}$ & $\begin{array}{l}\sigma_{G} \text { is the standard deviation of a Gaussian } \\
\text { distribution in time }\end{array}$ \\
\hline & $\sqrt{2 \ln 2 / 3} f$ & $f$ is the full width of square distribution in time \\
\hline \multirow[t]{2}{*}{$\begin{array}{l}\Delta t_{E} \text { or DELTAE } \\
\text { (see Section } \\
\text { IV.A.2.b) }\end{array}$} & & $\begin{array}{l}\Delta t_{E} \text { is the exponential folding width in } \\
\text { microseconds of an exponential distribution in } \\
\text { time; note that this is an asymmetric function. }\end{array}$ \\
\hline & $\frac{L(m / 2)^{1 / 2} \Delta_{E}}{2 E^{3 / 2}}$ & $\begin{array}{l}\Delta_{E} \text { is the exponential folding width of the } \\
\text { exponential distribution in energy }\end{array}$ \\
\hline
\end{tabular}




\section{A. 2 .b. Resolution broadening: Exponential}

An exponential form for the resolution-broadening is also provided in SAMMY (and MULTI). Physically this may correspond to an asymmetry in the burst width or moderator or detector resolution function. When only the exponential function is to be used, the broadened cross section (or transmission) is given by the integral

$$
f_{\text {exp }}(E)=\frac{1}{\Delta t_{E}} \int_{t}^{\infty} \exp \left\{-\frac{\left(t^{\prime}-t\right)}{\Delta t_{E}}\right\} f\left(E^{\prime}\right) d t^{\prime},
$$

where $f\left(E^{\prime}\right)$ represents the unbroadened cross section. This expression may be rewritten in terms of $E^{\prime}$ rather than $t^{\prime}$ using the relationship (IVA2.1), and assuming $\sqrt{E^{\prime}} \simeq \sqrt{E}$ as needed. Eq. (IVA2b.1) becomes

$$
f_{\exp }(E)=\frac{1}{\Delta_{E}} \int_{E}^{\infty} \exp \left\{-\frac{\left(E^{\prime}-E\right)}{\Delta_{E}}\right\} f\left(E^{\prime}\right) d E^{\prime},
$$

in which the width is given by

$$
\Delta_{E}=\frac{2 E^{3 / 2}}{L(m / 2)^{1 / 2}} \Delta t_{E}
$$

Setting $m / 2 \approx(72.3)^{2}$ as in the previous section gives the result used in SAMMY,

$$
\Delta_{E}=c E^{3 / 2} \text {, }
$$

in which $c$ is defined as

$$
c=2(m / 2)^{1 / 2} \Delta t_{E} / L \approx 0.02766 \Delta t_{E} / L ;
$$

exact values used for the constants are discussed in Appendix E.

The width $\Delta t_{E}$ is the "exponential folding width in microseconds," and is the required input quantity DELTAE (see Table VIA.1, Card Set 5, page 104, or Table VIB.1, Card Set 4, page 122). Two options are available for energy-dependent width: The first assumes the form

$$
\Delta t_{E}=\frac{\Delta t_{x}}{\sqrt{E / E_{x}}} .
$$

In this case the input quantity is $\Delta t_{x}$ and $E_{x}$ is fixed at $100 \mathrm{eV}$. The line "EXPONENTIAL FOLDING width is energy-dependent" must be included in the INPut file; see Table VIA.2. The second option assumes energy-dependence of the form

$$
\Delta t_{E}=D_{1} E+D_{0}+D_{2} \ln (E) ;
$$

parameters $D_{i}$ are specified in Card Set 11, Card 10, of the PARameter file (page 122o). 


\section{IV.E REALISTIC RESOLUTION BROADENING}

For ORELA data, the resolution-broadening functions described in Section IV.A.2 are not especially accurate approximations. We have therefore developed a more realistic mathematical description of the experimental situation at ORELA, based on concepts described by D. C. Larson et al. [DL84].

The resolution function has four components: the electron burst, the ORELA moderator, the neutron detector, and the time-of-flight channel width. Experimentally, the resolution-broadened cross section $\bar{\sigma}(E)$ is formed when each contributing feature provides its own broadening; the combined effect of the several components is all that is actually noticed. Mathematically, this may be viewed as follows: Each component is modeled separately as a function of flight time (rather than energy), and then each is convoluted in turn with the unbroadened (or partially broadened) cross section; the convolution process is performed analytically where possible and numerically where necessary. That is, the resolution-broadened cross section $\bar{\sigma}(t)$ may be expressed as

$$
\bar{\sigma}(t)=\int I_{1}\left(t-t_{1}\right) d t_{1} \int I_{2}\left(t_{1}-t_{2}\right) d t_{2} \int I_{3}\left(t_{2}-t_{3}\right) d t_{3} \int I_{4}\left(t_{3}-t_{4}\right) d t_{4} \sigma\left(t_{4}\right),
$$

where $I_{i}$ is our mathematical model for the $i$ th component. This expression may then be rearranged into the form

$$
\bar{\sigma}(t)=\int I\left(t-t^{\prime}\right) \sigma\left(t^{\prime}\right) d t^{\prime},
$$

where the resolution function $I\left(t-t^{\prime}\right)$ is defined as

$$
I\left(t-t^{\prime}\right)=\int I_{1}\left(t-t_{1}\right) d t_{1} \int I_{2}\left(t_{1}-t_{2}\right) d t_{2} \int I_{3}\left(t_{2}-t_{3}\right) d t_{3} I_{4}\left(t_{3}-t^{\prime}\right) .
$$

Because SAMMY deals with cross sections as functions of energy, rather than time, the relationship

$$
E=\frac{1}{2} m v^{2}=\frac{1}{2} m \frac{L^{2}}{t^{2}}
$$

is used to convert from energy to time (or time to energy) in Eq. (IVE.2), yielding

$$
\bar{\sigma}(E)=\int I^{\prime}\left(t(E)-t^{\prime}\right) \sigma\left(E^{\prime}\left(t^{\prime}\right)\right) d t^{\prime} .
$$

In the following sections we describe our choices for the $I_{i}$ and the convolution procedure. Complete details will be presented in a separate report [NL99b]. See also Section VIII.C (page $150 \mathrm{c}$ ), which describes program SAMORT, used for plotting the individual pieces and the complete ORR function at a specified energy. 


\section{IV.E.1 Individual Components of the Resolution Function}

In Subsection IV.E.1.a, the four components of the resolution function are described mathematically in terms of either time-of-flight variable $t$ or flight-path-length $\ell$. In Subsection IV.E.1.b, conversion from flight-path-length $\ell$ to time-of-flight variable $t$ (for fixed energy $E$ ) is discussed; this conversion is necessary in order to convolute the four components to produce the "total" resolution function.

Input for using this resolution function is described in Card Set 9, Table VIB.1, pages 122 and following. 


\section{IV.E.1.a Description of the components}

\section{Electron Burst}

The electron burst from ORELA is closely approximated by a square function in time:

$$
I_{1}(t)=\left\{\begin{array}{cl}
1 / p & \text { for } 0<t<p \\
0 & \text { otherwise }
\end{array},\right.
$$

where $p$ is the burst width in nanoseconds. The value $1 / p$ for this function gives a normalization of unity.

\section{Neutron Sources}

Experiments at ORELA can utilize neutrons from a Ta target, or collimate on the water moderator surrounding the Ta target. The two are modeled separately; experiments are assumed to use predominantly one or the other, rather than a mixture of both. [The implications to this representation if neutrons are emitted from both the Ta target and the water moderator will be studied as time and funding permit.]

\section{2a. ORELA Water Moderator}

The distribution of flight path lengths of neutrons in the ORELA water moderator that has the most physical basis [SC92] is the chi-square distribution with $2(m+1)$ degrees of freedom, where $m=4$ or 5 :

$$
I_{2 a}^{\prime}(\ell)=\frac{\ell^{m}}{m ! \Lambda^{m+1}} \exp \left(-\frac{\ell}{\Lambda}\right),
$$

where $\ell$ is the flight-path-length variable and where the moderation distance $\Lambda$ is a mean free path. The value of $\Lambda$ varies with energy as $\Lambda=\Lambda_{0}+\Lambda_{1} \ln (E)+\Lambda_{2}(\ln (E))^{2}[$ CC83].

\section{2b. Tantalum target}

The distribution of flight path lengths for the tantalum target is somewhat more complicated: Monte Carlo calculations of F. G. Perey [FP92] have shown that this distribution function has the form

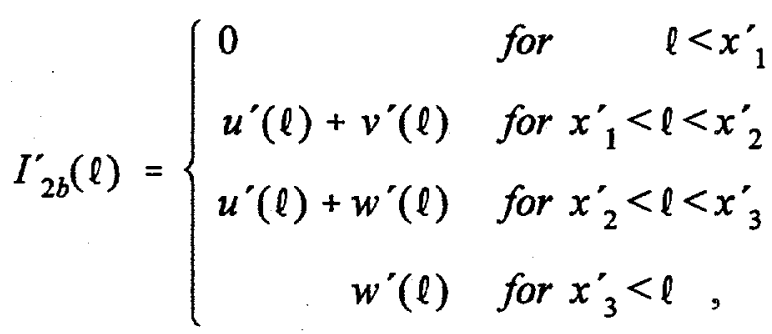


where the functions $u^{\prime}(\ell), v^{\prime}(\ell)$, and $w^{\prime}(\ell)$ are defined as

$$
\begin{aligned}
& u^{\prime}(\ell)=N^{\prime} \exp \left\{-\epsilon^{\prime 2}\left(\ell-x_{0}^{\prime}\right)^{2}\right\} \quad \text { for } x_{1}^{\prime}<\ell<x_{3}^{\prime}, \\
& v^{\prime}(\ell)=\frac{N^{\prime} \alpha^{\prime} \ell}{x_{2}^{\prime}} \exp \left\{-\beta^{\prime}\left(\ell-x_{2}^{\prime}\right)\right\} \quad \text { for } x_{1}^{\prime}<\ell<x_{2}^{\prime} \text {, }
\end{aligned}
$$

and

$$
w^{\prime}(\ell)=N^{\prime} \alpha^{\prime} \exp \left\{-\beta^{\prime}\left(\ell-x_{2}^{\prime}\right)\right\} \text { for } x_{2}^{\prime}<\ell \text {. }
$$

The factor $N^{\prime}$ is a normalization, and $\alpha^{\prime}$ determines the relative strengths of the pieces of the function $I_{2 b}^{\prime}$. The relative values of the $x^{\prime}$ s are given by

$$
x_{1}^{\prime} \leq x_{0}^{\prime} \leq x_{2}^{\prime} \leq x_{3}^{\prime} \text {. }
$$

\section{Time-of-Flight Channel Width}

Like the electron burst, the time-of-flight channel width may be modeled as a rectangular distribution of width $c$. This functional form ignores "electronic" time jitter, which is a reasonable approximation. The time distribution due to the finite channel width is therefore assumed to be:

$$
I_{3}(t)=\left\{\begin{array}{cc}
1 / c & \text { for } 0<t<c \\
0 & \text { otherwise }
\end{array}\right.
$$

where the channel width $c$ may be different for different energy regions.

\section{Detectors}

Two types of neutron detectors are commonly used for transmission measurements at ORELA: the NE110 (a recoil proton detector) and the lithium glass (for which moderation of neutrons in the detector plays an important role).

\section{4a. NE110 Detector}

If $\delta$ is the thickness of the NE110 detector, then the resolution function appropriate for that detector is 


$$
I_{4 a}^{\prime}(\ell)= \begin{cases}\Delta \exp (-\lambda \sigma \ell) & \text { for } 0<\ell<\delta \\ 0 & \text { otherwise },\end{cases}
$$

where $\lambda$ is the number of molecules per mm.b of the detector $(0.0047$ for NE110) and $\sigma(E)$ is the total cross section of the detector material $\left(\mathrm{CH}_{1.104}\right.$ for NE110). $\Delta$ is a normalization factor found by setting the integral over all space of $I_{4 a}^{\prime}$ equal to 1.

\section{4b. Lithium Glass Detector}

For the lithium glass detector, the resolution function is assumed to have the form

$$
I_{4 b}(t)= \begin{cases}D g & \text { for } 0<t<d \\ D \exp (-f(t-d)) & \text { for } d<t\end{cases}
$$

where $g$ is a constant, and $D$ is chosen to give an integral of unity. 


\section{IV.E.1.b Converting length- to time-dependence}

The relationship between energy $E$, flight time $t$, and flight path length $\ell$ may be used to convert from a function of $\ell$ to a function of $t$ (assuming $E$ is fixed):

$$
E=\frac{m}{2} \frac{\ell^{2}}{t^{2}},
$$

which may be rearranged to give

$$
\ell=\sqrt{\frac{2 E}{m}} t=b t,
$$

in which we have defined $b$ as the square root of $2 E / \mathrm{m}$. A distribution function in $\ell$ may then be converted to a distribution function in $t$ by (a) replacing $\ell$ by $b t$ everywhere, and (b) replacing $d l$ by $b d t$. Formulae for all four components in terms of $t$ are given in [NL99b]; here we merely note that the distances $x_{i}^{\prime}$ (tantalum target) translate to the time-dimension via

$$
x_{i}=x_{i}^{\prime} / b,
$$

(IVE1b.3)

and, similarly, $\delta$ (NE110 detector) translates via

$$
d=\delta / b \text {. }
$$

(IVE1b.4)

For the NE1 10 detector we also define $f$ via

$$
f=\lambda \sigma b \text {. }
$$




\section{IV.F FREE-GAS MODEL OF DOPPLER BROADENING}

A detailed discussion of the "exact" free-gas model of Doppler broadening is given in [NL98]; results are summarized in this section. The formula for the free-gas model of Doppler broadening takes the form

$$
\sigma_{D}(E)=\frac{1}{\Delta_{D} \sqrt{\pi}} \int_{0}^{\infty}\left[e^{\left.-4\left(E-\sqrt{E E^{\prime}}\right)^{2} / \Delta_{D}^{2}\right)}-e^{\left.-4\left(E+\sqrt{E E^{\prime}}\right)^{2} / \Delta_{D}^{2}\right)}\right] \sigma\left(E^{\prime}\right) \sqrt{E^{\prime} / E} d E^{\prime},
$$

in which the Doppler width $\Delta_{\mathrm{D}}$ is given by

$$
\Delta_{D}=\sqrt{\frac{4 m E k T}{M}},
$$

where, as elsewhere in this section, $m$ represents the neutron mass, $M$ the target (sample) mass, $k$ is Boltzman's constant, and $T$ is the effective temperature. Alternatively, this equation may be written in terms of "velocity" $v$, where $v$ is the square root of energy $E$, as

$$
v \sigma_{D}\left(v^{2}\right)=\frac{1}{\sqrt{\pi} u} \int_{0}^{\infty}\left[e^{-\left(v-v^{\prime}\right)^{2} / u^{2}}-e^{-\left(v+v^{\prime}\right)^{2} / u^{2}}\right] v^{\prime} \sigma\left(v^{\prime 2}\right) v^{\prime} / v d v^{\prime},
$$

in which we have substituted $v^{\prime}$ for the square root of $E^{\prime}$ and defined $u$ as

$$
u=\sqrt{m k T / M} \text {. }
$$

To evaluate this integral, replace $v^{\prime}$ by $-w$ in the second term; this gives

$$
\begin{aligned}
v \sigma_{D}\left(v^{2}\right)=\frac{1}{\sqrt{\pi} u} & {\left[\int_{0}^{\infty} e^{-\left(v-v^{\prime}\right)^{2} / u^{2}} v^{\prime} \sigma\left(v^{\prime 2}\right) v^{\prime} / v d v^{\prime}\right.} \\
& \left.-\int_{0}^{\infty} e^{-(v-w)^{2} / u^{2}}(-w) \sigma\left((-w)^{2}\right) w / v d w\right] .
\end{aligned}
$$

Replacing $v^{\prime}$ by $w$ in the first term, rearranging the second term, and defining

$$
s(w)=\left\{\begin{array}{rl}
\sigma\left(w^{2}\right) & \text { for } w \geq 0 \\
-\sigma\left(w^{2}\right) & \text { for } w \leq 0
\end{array},\right.
$$

puts this equation into the form

$$
v \sigma_{D}\left(v^{2}\right)=\frac{1}{\sqrt{\pi} u} \int_{-\infty}^{\infty} e^{-(v-w)^{2} / u^{2}} w s(w) w / v d w .
$$

In the form of Eq. (IVF.7) with definition (IVF.6), the Doppler-broadening integration can be accomplished readily within SAMMY using numerical techniques similar to those described for the original Doppler-broadening method and for the resolution broadening. The auxiliary energy grid is chosen as described in Section IV.B.1, with the exception that the additional low-energy points are chosen equally spaced in velocity rather than in energy. Negative velocities are included as needed, in order to properly evaluate the integral at low values of $E$ (i.e., of $v$ ). 


\section{IV.G RPI RESOLUTION BROADENING}

Researchers at Rensselaer Polytechnic Institute (RPI) have carefully measured the resolution function associated with the "bounce target" and the transmission detector ( $\mathrm{Li}$ glass) for the LINAC at RPI [BM96]. This resolution function may be described by the sum of a chi-squared function (with six degrees of freedom) plus two exponential terms. The total resolution function appropriate for data measured on that machine is then the convolution of the target-detector resolution function with a Gaussian function representing the electron burst and a square function representing the channel width.

Within SAMMY, this resolution function is formed in much the same manner as described for the realistic resolution function of Section IV.E, i.e., the resolution-broadened cross section $\overline{\boldsymbol{\sigma}}(t)$ may be expressed as

$$
\bar{\sigma}(t)=\int I_{1}\left(t-t_{1}\right) d t_{1} \int I_{2}\left(t_{1}-t_{2}\right) d t_{2} \int I_{3}\left(t_{2}-t_{3}\right) d t_{3} \sigma\left(t_{3}\right),
$$

where $I_{i}$ is our mathematical model for the $i$ th component. This expression may then be rearranged into the form

$$
\bar{\sigma}(t)=\int I\left(t-t^{\prime}\right) \sigma\left(t^{\prime}\right) d t^{\prime},
$$

where the resolution function $I\left(t-t^{\prime}\right)$ is defined as

$$
I\left(t-t^{\prime}\right)=\int I_{1}\left(t-t_{1}\right) d t_{1} \int I_{2}\left(t_{1}-t_{2}\right) d t_{2} I_{3}\left(t_{2}-t^{\prime}\right) .
$$

Because SAMMY deals with cross sections as functions of energy, rather than time, the relationship

$$
E=\frac{1}{2} m v^{2}=\frac{1}{2} m \frac{L^{2}}{t^{2}}
$$

is used to convert from energy to time and v.v. in Eq. (IVG.2), yielding

$$
\bar{\sigma}(E)=\int I^{\prime}\left(t(E)-t^{\prime}\right) \sigma\left(E^{\prime}\left(t^{\prime}\right)\right) d t^{\prime} .
$$

In the following section the component functions $I_{i}$ are described, along with the parameters for those components. Complete details will be presented in a separate report [NL99c].

Test case TR54 gives several examples using the RPI resolution function. To make plots of this resolution function and the individual components, see Section VIII.M, page 150z.3. 


\section{IV.G.1 Description of the Components of the RPI Resolution Function}

1. Electron Burst

The electron burst from the RPI linac may be described by a Gaussian function in time, of the form:

$$
I_{1}(t)=\frac{w}{\sqrt{\pi}} e^{-w^{2} t^{2}}
$$

where $2 \sqrt{\ln 2} / w=p$ is the full width at half $\max$ of the burst. Normalization is unity for this function.

\section{Target plus Detector}

The RPI transmission resolution function, which represents the combined components for the "bounce target" and transmission detector, has been found by RPI researchers [BM96] to be best described by the sum of a chi-squared function with six degrees of freedom plus two exponential terms. A similar function (with different values for the parameters) describes the bounce target plus capture detector. Specifically, this function has the form

$$
I_{2}(t)=A_{0}\left\{\frac{(t+\tau)^{2}}{2 ! \Lambda^{3}} e^{-(t+\tau) / \Lambda}+A_{1}\left[A_{2} e^{-A_{3}\left(t+t_{0}\right)}+A_{4} e^{-A_{5}\left(t+t_{0}\right)}\right] X(t)\right\}
$$

in which the function $X(t)$ is zero if the quantity within the square brackets (the sum of the exponential terms) is negative, and unity otherwise. The value of $A_{0}$ is chosen to give an overall normalization of unity for this function. Parameters $\Lambda, \tau$, and $A_{1}$ are functions of energy, the specific forms being

$$
\Lambda(E)=\Lambda_{0}+\Lambda_{1} \ln (E)+\Lambda_{2}[\ln (E)]^{2}
$$

for $\Lambda$,

$$
\tau(E)=\tau_{1} e^{-\tau_{2} E}+\tau_{3} e^{-\tau_{4} E}+\tau_{5}
$$

for $\tau$, and

$$
A_{1}(E)=a_{1} e^{-a_{2} E}+a_{3} e^{-a_{4} E}+a_{5}
$$

for $A_{1}$. All other quantities in Eq. (IVG1.2) are independent of energy. Input formats for all parameters are given in Table VIB.1 Card Set 14 starting on page 122s; default values for all constants from Eq. (IVG1.2) through (IVG1.5) are shown in Table IVG.1. See Test Case TR53 and TR54 for sample input for the RPI resolution function. 


\section{Time-of-Flight Channel Width}

The time-of-flight channel width may be modeled as a rectangular distribution of width $c$. The time distribution due to the finite channel width is therefore assumed to be:

$$
I_{3}(t)=\left\{\begin{array}{cl}
1 / c & \text { for }-c / 2<t<c / 2 \\
0 & \text { otherwise }
\end{array}\right.
$$

where the channel width $c$ may be different for different energy-regions.

Table IVG.1. Default values for parameters for RPI resolution function.

\begin{tabular}{rcccc}
\hline & $\begin{array}{c}\text { Parameter } \\
\text { name }\end{array}$ & $\begin{array}{c}\text { Value for } \\
\text { transmission }\end{array}$ & $\begin{array}{c}\text { Value for } \\
\text { capture }\end{array}$ & Units \\
\hline 1 & $p=2 \sqrt{\ln 2} / w$ & & & $\mathrm{~ns}$ \\
2 & $\tau_{1}$ & 326. & 381. & $\mathrm{~ns}$ \\
3 & $\tau_{2}$ & 0.0241 & 0.0058 & per eV \\
4 & $\tau_{3}$ & 323. & 323. & $\mathrm{~ns}$ \\
5 & $\tau_{4}$ & 0.029 & 0.094 & per eV \\
6 & $\tau_{5}$ & 240. & 105. & ns \\
7 & $\Lambda_{0}$ & 686.5 & 686.5 & ns \\
8 & $\Lambda_{1}$ & -224.9 & -224.9 & ns \\
9 & $\Lambda_{2}$ & 21.04 & 21.04 & ns \\
10 & $a_{1}$ & -0.000985 & -0.001106 & per ns \\
11 & $a_{2}$ & 0.0241 & 0.0058 & per eV \\
12 & $a_{3}$ & -0.000626 & 0.04752 & per ns \\
13 & $a_{4}$ & 3.531 & 65.083 & per eV \\
14 & $a_{5}$ & 0.001029 & 0.001264 & per ns \\
15 & $t_{0}$ & 940. & 940. & ns \\
16 & $A_{2}$ & -65.638 & -65.638 & [dimensionless] \\
17 & $A_{3}$ & 0.005 & 0.005 & per ns \\
18 & $A_{4}$ & 0.39383 & 0.39383 & [dimensionless] \\
19 & $A_{5}$ & 0.0008 & 0.0008 & per ns \\
20 & $c$ & & & ns \\
\hline & & & &
\end{tabular}

${ }^{a}$ Values listed in this column are not those which are appropriate for the RPI capture resolution function, which has not yet been fully defined; these values are for illustrative purposes only. 


\section{SPECIAL TREATMENTS}

This section is our "junk drawer," containing information on a variety of topics which did not seem to fit well into any particular category. Included here are discussions of SAMMY's treatment of transmission data (Section V.A), and of the handling of correlated data sets (Section V.B). Section V.C describes how SAMMY may be used to average cross sections (both theoretical and experimental) over an energy range after the analysis is complete, in order to compare with other experimental data. The means by which one may analyze samples containing multiple nuclides (mutiple isotopes, chemical compounds, contaminants) are discussed in Section V.D. Section V.E is devoted to two methods of including data-reduction parameters within the SAMMY analysis. Maxwellian, or stellar, averages of capture cross sections are discussed in Section V.F. Methods for reconstructing point-wise cross sections without having to specify an energy grid are given in Section V.G. Paramagnetic cross sections are discussed in Section V.H. Section V.I includes a disccussion of integral quantities. Fröhner's treatment of the unresolved region, now introduced as a part of the SAMMY code, is described in Section V.J. Finally, a treatment of $l$-dependent detector efficiencies is outlined in Section V.K. 


\section{D COMBINING SEVERAL NUCLIDES IN A SINGLE SAMPLE}

Because the samples used in neutron experiments are often made from natural materials rather than isotopically pure materials, and may contain chemical combinations of elements and/or impurities, the SAMMY INPut and PARameter files may need to describe resonances corresponding to several different nuclides. A number of features of SAMMY have evolved to deal with this consideration; these features are described below. In addition, users are referred to test case tr60, which treats multiple isotopes of $\mathrm{Ba}$ as well as $\mathrm{O}$ and $\mathrm{C}$. Note that the user must provide abundances for each nuclide; however, if the exact composition of a diluent is unknown, abundances may be flagged (varied) so that SAMMY can determine the optimal values.

The SAMMY features relevant to multiple nuclides in a single sample are:

1. Spin groups may be specified in one of two ways, either of which may contain information about abundances of isotopes or elements. See Section VI.A, Table VIA.1, Card Set 10 and Alternative to Card Set 10 for details. The nuclear spin (as well as mass and isotopic abundance) can be specified for each isotope or element separately, when "Alternative to Card Set 10" is used in the INPut file.

2. When using a multinuclide PARameter file, flags on the appropriate spin groups in the INPut file will eliminate the use of those spin groups in performing the calculation of cross sections; thus, the same PARameter file may be used both for the analysis of data from an isotopically pure sample and for the analysis of data from a "natural" sample, or for data from a specific nuclide and for a chemical combination. Input details are again given in Table VIA.1.

3. Channel radii (see Section III.A.1) for the different nuclei (and for different spin groups) may be specified separately. In addition, the radius (PAREFF) used in evaluation of the potential-scattering phase shift $\phi_{\ell}$ may differ from the radius (PARTRU) used in evaluation of penetration factor $P_{\ell}$ and level shift factor $S_{\ell}$, and any or all of these various radii may be varied; this is included for compatibility with ENDF [ENDF-102]. Input details are given in Card Set 7 of Table VIB.1.

4. To specify a single abundance and the correct mass for all spin groups corresponding to a given nucleus, use Card Set 10 of the PARameter file (see Section VI.B.). Abundances, but not masses, may be varied.

SAMMY will confirm that the sets of spin groups corresponding to a given nuclide are defined consistently between the INPut and the PARameter files.

Note that SAMMY is no longer restricted to a small number of spin groups; if it is necessary to include more spin groups than can be inserted on a line in the PARameter file (e.g., for channel radii), the remainder may be inserted on a subsequent line. Details are given in Table VIB.1. 


\section{E. 1 Explicit Normalization and/or Background Functions}

A constant overall normalization and a variety of different analytical models for backgrounds may be applied to the theoretical values (cross sections, transmissions, etc.) generated within SAMMY. Note that these corrections are applied to the theory, not to the data. Normalization is applied first, followed by background corrections, so that the backgrounds are not multiplied by the normalization.

Let $T_{u}$ represent the uncorrected theoretical value (for cross section, transmission, etc.); then the corrected value is given by

$$
T(E)=a T_{u}(E)+b(E),
$$

in which energy dependences have been explicitly displayed.

Input for the normalization $a$ and four specific backgrounds is specified in Card Set 6 of the PARameter file (page 122c). The four backgrounds are

$$
\begin{aligned}
b_{1}(E) & =B_{a}, \\
b_{2}(E) & =B_{b} / \sqrt{E}, \\
b_{3}(E) & =B_{c} \times \sqrt{E}, \\
\text { and } \quad b_{4}(E) & =B_{d} \times e^{-B_{f} / \sqrt{E}} .
\end{aligned}
$$

Input for other background functions is given in Card Set 13 (page 122q). Again, there are four different types of background functions; however, unlike those given above, any number of each type may be included, so that the "actual" background is the sum of all such functions. Further, an energy range may be specified for each function. The functional forms for these backgrounds are, respectively, constant, exponential, power, and exponential of a logarithmic function. Explicitly,

$$
\begin{aligned}
b_{1}(E) & =A, \\
b_{2}(E) & =A e^{-B t}, \\
b_{3}(E) & =A t^{B}, \\
\text { and } \quad b_{4}(E) & =e^{A+B t+C / \ln (t)},
\end{aligned}
$$

in which the time $t$ is derived from the energy in the usual manner,

$$
t=\sqrt{\frac{m L^{2}}{2 E}},
$$

where $L$ is the flight-path length. If the value for $L$ is already given (e.g., for transmission data), that value can be used here. Otherwise, $L$ can be specified along with the other parameters for these functions. 
Because any of these parameters (excluding Emin, Emax, and $L$ ) can be varied, partial derivatives of the theoretical values $T$ are required. These derivatives are found directly from Eqs. (VE1.1 through VE1.4) and are not listed explicitly here. Derivatives generated prior to these corrections (i.e., derivatives with respect to resonance parameters, broadening parameters, etc.) are also corrected by the normalization factor, as needed.

For examples of the use of normalization and/or background functions, the reader is referred to the test cases that are distributed with the SAMMY code. Test cases TR32 and TR45 (among others) include normalization and constant background on Card Set 6 of the PARameter file. Test case TR56 specifically addresses the use of more general background functions provided in Card Set 13 of the PARameter file. 


\section{H. PARAMAGNETIC CROSS SECTION}

The total cross section of nuclides like $\mathrm{Er}, \mathrm{Ho}$, and $\mathrm{Tm}$ at low neutron energies may include both nuclear and paramagnetic (PM) cross sections. The PM cross section may be written in the following form [YD98]:

$$
\sigma_{P M}=C\left(\frac{A \tan ^{-1}\left(B E^{P}\right)}{B E^{P}\left(1+\left(B E^{P}\right)^{2}\right)^{4}}\right)^{2} .
$$

Here $E$ is the energy in $\mathrm{eV}$, and $A, B, P$, and $C$ are parameters (variables) whose default values are given in Table VH.1; these may be treated either as constants or as varied parameters whose values are to be determined by the Bayes (generalized least squares) fitting procedure.

As presently implemented within SAMMY, the paramagnetic cross section may be invoked only in calculations for data types "total cross section" or "transmission." In particular, paramagnetic cross sections cannot be included in angular distributions nor in generating selfshielding or multiple-scattering corrections for capture or fission yields.

Table VH.1. Default parameter values for paramagnetic cross sections

\begin{tabular}{ccccc}
\hline & A & B & P & C \\
\hline Tm & 6.1691 & 1.1308 & 0.3367 & 1.0 \\
Er & 7.9012 & 1.1278 & 0.3263 & 1.0 \\
Ho & 8.7597 & 1.1435 & 0.3225 & 1.0 \\
\hline
\end{tabular}

Input for using PM cross section (for total cross sections only) is given in Table VIB.1, Card Set 12, page 122p. See test case TR55 for examples of this input.

Although SAMMY can search on any or all of these parameters, the user should be aware that variables $A$ and $C$ are mathematically redundant; it is only the product $C A^{2}$ that is unique. When values for both parameters are permitted to vary, the correlation coefficient will always be -1 .

Derivatives of $\sigma_{\mathrm{PM}}$ are as follows: Let $x$ represent the quantity $B E^{P}$. The derivatives with respect to each of the four parameters are then 


$$
\begin{gathered}
\frac{d \sigma}{d A}=\frac{2 \sigma}{A}, \\
\frac{d \sigma}{d B}=C A^{2} 2 f \frac{d f}{d x} \frac{x}{B}, \\
\frac{d \sigma}{d P}=C A^{2} 2 f \frac{d f}{d x} x \ln E
\end{gathered}
$$

and

$$
\frac{d \sigma}{d C}=\frac{\sigma}{C}
$$

In these equations we have made the substitution

$$
f=\frac{\tan ^{-1} x}{x\left(1+x^{2}\right)^{4}}
$$

so that

$$
\frac{d f}{d x}=\frac{1}{x\left(1+x^{2}\right)^{5}}\left[1-\frac{1-9 x^{2}}{x} \tan ^{-1} x\right]
$$




\section{V.I INTEGRAL QUANTITIES}

Although SAMMY was designed for calculating and fitting "differential" quantities such as cross section as a function of energy, nevertheless it often is useful to have the code calculate integral quantities for comparison with integral data. These integral quantities can also be included in the fitting procedure, if desired. Details of the methods used to calculate these quantities are given in ref. [NL97]. Additional features have been added to the code subsequent to publication of that report, in order to facilitate direct comparisons between calculations made by SAMMY and those made by NJOY [RM82]; see items 9 and 10 below.

A single SAMMY run is used to calculate a variety of integral quantities. The first four quantities listed below are calculated for $x=$ capture, fission, and absorption (as appropriate for the nuclide under consideration); the others are calculated only for fissile nuclides.

1. Thermal cross section,

$$
\sigma_{0 x}=\sigma_{x}\left(E_{0}\right) \quad \text { for } E_{0}=0.0253 \mathrm{eV} .
$$

2. Maxwellian average at thermal energy. This quantity is defined with somewhat different normalization from that used in Sect. V.F, that is, as

$$
\bar{\sigma}_{x}=\int_{E_{1}}^{E_{2}} \sigma_{x}(E) \frac{E}{E_{0}} e^{-E / E_{0}} d E / \int_{E_{1}}^{E_{2}} \frac{E}{E_{0}} e^{-E / E_{0}} d E
$$

where $E_{1}=10^{-5} \mathrm{eV}$ and $E_{2}=3 \mathrm{eV}$.

3. Westcott's g-factor,

$$
g_{x}=\frac{2}{\sqrt{\pi}} \frac{\bar{\sigma}_{x}}{\sigma_{0 x}}
$$

4. Resonance integral,

$$
I_{x}=\int_{E_{3}}^{E_{4}} \sigma_{x}(E) \frac{d E}{E}+X_{4 x}
$$

in which $E_{3}=0.5 \mathrm{eV}$, and $E_{4}$ and $X_{4 \mathrm{x}}$ are specified by the user.

5. Average integral,

$$
\hat{\sigma}_{x}=\int_{E_{5}}^{E_{6}} \sigma_{x}(E) d E /\left(E_{6}-E_{5}\right)
$$


6. Watt spectrum average,

$$
\bar{\sigma}_{W f}=\int_{E_{1}}^{E_{7}} \sigma_{f}(E) \Phi(E) d E / \int_{E_{1}}^{E_{7}} \Phi(E) d E
$$

in which the upper limit $E_{7}=20 \mathrm{MeV}$. The Watt fission spectrum, $\Phi(E)$, is given by the function

$$
\begin{aligned}
\Phi(E) & =e^{-E / a} \sinh (\sqrt{b E}) \\
& =e^{-E / a}\left(e^{\sqrt{b E}}-e^{-\sqrt{b E}}\right) / 2 .
\end{aligned}
$$

Here $a$ and $b$ are constants to be supplied by the user. For ${ }^{235} \mathrm{U}$, values of $a$ and $b$ are 0.988 $\mathrm{MeV}$ and $2.249 \mathrm{MeV}^{-1}$, respectively.

7. $\mathrm{K} 1$,

$$
K 1=v \sigma_{0 f} g_{f}-\sigma_{0 a} g_{a}=\left(v \bar{\sigma}_{f}-\bar{\sigma}_{a}\right) \frac{2}{\sqrt{\pi}},
$$

where $v$ is a constant provided by the user.

8. Alpha, or $\alpha$,

$$
\alpha=I_{c} / I_{f}
$$

9. Thermal alpha integral (NJOY's $\alpha)$ [RM98],

$$
\alpha_{N J O Y}=\int_{E_{1}}^{E_{2}} \frac{\sigma_{c}(E)}{\sigma_{f}(E)} \frac{E}{E_{0}} e^{-E / E_{0}} d E / \int_{E_{1}}^{E_{2}} \frac{E}{E_{0}} e^{-E / E_{0}} d E .
$$

10. Thermal eta integral (NJOY's $\eta$ ) [RM98],

$$
\eta_{N J O Y}=\int_{E_{1}}^{E_{2}} \frac{v \sigma_{f}(E)}{\sigma_{a}(E)} \frac{E}{E_{0}} e^{-E / E_{0}} d E / \int_{E_{1}}^{E_{2}} \frac{E}{E_{0}} e^{-E / E_{0}} d E
$$

Input to SAMMY for fitting integral quantities is essentially the same as for fitting differential quantities, with a few minor changes and one additional file. Please see SectionVI.I on page $130 \mathrm{~m}$ for details. 


\section{J FRITZ FRÖHNER'S FITACS}

As a first step towards expansion into the unresolved resonance region, Fritz Fröhner's code FITACS [FF89] has been obtained and inserted into SAMMY. FITACS uses Hauser-Feshbach theory with width fluctuations. The adjustable parameters are strength functions, distant-level parameters, average radiation widths (at $E=0$ ), and average fission widths (at $E=0$ ). The energy dependence of the radiation widths is specified via the giant dipole model, of the fission widths via Hill-Wheeler fission barrier transmission coefficients, and of the mean level spacing for $s$-waves via the Gilbert-Cameron composite formula. Mean spacings for $l>0$ are given via Bethe formula. Moldauer's prescription is used for partial cross sections.

To date, FITACS has been incorporated into SAMMY (as segment SAMFFF) in a limited fashion only: Internal changes were made, to be consistent with SAMMY notation and to use dynamic dimensioning of arrays. The $M+W$ version of Bayes' method has replaced the fitting procedure used in FITACS. Calculation of penetrabilities has been extended to all $l$ values. The new output includes files from which plots can be made. Results are reported in SAMMY.PAR in the same format as is used in the input file (as well as in more legible fashion in SAMMY.LPT). No other significant changes have been made in the FITACS input, method of calculation, or output.

Changes are planned, however. The primary change will be to use the results of the analysis of the resolved-resonance region as input for the analysis of the unresolved region, in order to provide more consistent evaluated cross sections. Other changes, such as generalization of the theory, redesign of input and/or output, etc., will be made as experience indicates their need.

Two input files are required for the use of this option. The first is the SAMMY INPut file, which contains three lines only: Card Set 1 of Table VIA.1 (the title line), Card Set 2 (nuclide name, atomic weight, and energy range), and one line for Card Set 3 (alphanumeric information). The alphanumeric line contains the phrase UNRESOLVED RESONANCE REGION.

The second file is exactly the same as Fröhner's original FITACS file (as described in Table VJ.1); note this includes both parameters and data. To inform the code that a parameter is to be varied, FITACS assumes that, if the uncertainty is given as zero for a given parameter, then that parameter is not varied. (Hence there is no default value for uncertainty). This procedure is in contrast with the usual SAMMY procedure of assigning a value (generally, 1) to a flag for each varied parameter. [In the future, the formats for input to the FITACS portion of SAMMY will be modified to conform to SAMMY standards.] Currently all numbers, both integer and real, are specified with $F 10$ formats.

To run this option, the user should specify the two file names, the INPut file on one line and the FITACS file on the next. No other input is required.

Test case tr73 gives sample input and output for use of this option. 
Table VJ.1. Input for the FITACS program for treatment of the unresolved resonance region

\begin{tabular}{|c|c|}
\hline Line No. & Description \\
\hline $1-4$ & First four lines are alphanumeric title \\
\hline 5 & $\begin{array}{l}\text { Number of iterations, fitting tolerance (essentially, delta chi-squared). Note } \\
\text { that even integers are given as real numbers. All formats are F10 }\end{array}$ \\
\hline 6 & $\begin{array}{l}\text { Mass in amu, radius in Fermi (or use default), neutron binding energy in } \mathrm{MeV} \text {, } \\
\text { pairing energy in } \mathrm{MeV} \text {. Again, formats are F10 }\end{array}$ \\
\hline $7,8, \ldots$ & $\begin{array}{l}\text { Center-of-mass energy, spin, and parity for the } n \text {th target level (beginning with } \\
\text { ground state) }\end{array}$ \\
\hline 9 & (Blank) \\
\hline 10 & $\begin{array}{l}\text { Strength function, uncertainty, distant-level parameter, uncertainty, radiation } \\
\text { width in } \mathrm{eV} \text {, uncertainty, mean level spacing in } \mathrm{eV} \text { for } l=0\end{array}$ \\
\hline 11 & $\begin{array}{l}\text { Strength function, uncertainty, distant-level parameter, uncertainty, radiation } \\
\text { width in } \mathrm{eV} \text {, uncertainty, for } l=1\end{array}$ \\
\hline 12 & $\begin{array}{l}\text { Strength function, uncertainty, distant-level parameter, uncertainty, radiation } \\
\text { width in } \mathrm{eV} \text {, uncertainty, for } l=2\end{array}$ \\
\hline $13,14, \ldots$ & As above, for higher $l$ values as needed \\
\hline 15 & (Blank) \\
\hline $16, \ldots$ & $\begin{array}{l}\text { Fission width (eV), degree of freedom for fission width distribution, Hill- } \\
\text { Wheeler threshold energy, HW threshold width, uncertainty on fission width }\end{array}$ \\
\hline 17 & (Blank) \\
\hline 18 & Type of cross-section data (TOTAl, CAPTure, FISSion, or INELastic) \\
\hline 19 & Uncertainties are RELAtive or ABSOlute \\
\hline $20, \ldots$ & $\begin{array}{l}\text { Energy, cross section, uncertainty (Note: if RELAtive then need specify only } \\
\text { for first data point, rest are assumed to be the same) }\end{array}$ \\
\hline 21 & (Blank) \\
\hline $22, \ldots$ & Repeat 19 to 21 as many as four times, in any order \\
\hline
\end{tabular}




\section{V.K. DETECTOR EFFICIENCY}

For measurements of capture or fission yields, the detectors may have different efficiencies for different $l$-values. SAMMY is equipped with a spin-group-dependent detector efficiency (multiplicative factor), which can be used to model this effect. The user may specify as many different efficiencies as needed, and delineate the spin groups to which those efficiencies apply. (See Table VIB.1, Card Set 15, page $122 \mathrm{u}$ for input details.) SAMMY will multiply the calculated capture or fission partial cross sections by the efficiencies, prior to applying selfshielding and multiple-scattering corrections; these efficiencies can also be used with selfindication data. Note that the total and elastic cross sections (used in the calculation of self-shielding and multiple-scattering effects) are not multiplied by the efficiencies.

Test case tr78 contains examples of the use of spin-group-dependent detector efficiencies. 


\section{INPUT TO SAMMY}

Input to SAMMY consists of three or more files, which may be user-generated or (sometimes) produced by earlier SAMMY runs. These files are summarized in Table VI.1 and described in detail in subsequent sections.

Table VI.1. SAMMY input files

\begin{tabular}{|c|c|c|c|}
\hline Description & $\begin{array}{l}\text { Unit } \\
\text { No. }\end{array}$ & Contents & $\begin{array}{l}\text { Where details } \\
\text { may be found }\end{array}$ \\
\hline Batch file & 5 & $\begin{array}{l}\text { Interactive or batch input to SAMMY; } \\
\text { file names, energy ranges }\end{array}$ & Section VI.D \\
\hline INPut file & 11 & $\begin{array}{l}\text { Details about the interaction being } \\
\text { studied; SAMMY control information }\end{array}$ & $\begin{array}{l}\text { Section VI.A } \\
\text { Tables VIA. } 1 \& 2\end{array}$ \\
\hline PARameter file & 12 & $\begin{array}{l}\text { Initial values for resonance and other } \\
\text { parameters, flags defining which are to be } \\
\text { varied, uncertainty information }\end{array}$ & $\begin{array}{l}\text { Section VI.B } \\
\text { Table VIB.1 }\end{array}$ \\
\hline DATa file & 13 & $\begin{array}{l}\text { Experimental data, including energy, } \\
\text { cross section (or transmission, e.g.), and } \\
\text { uncertainty }\end{array}$ & $\begin{array}{l}\text { Section VI.C } \\
\text { Table VIC.1 }\end{array}$ \\
\hline COVariance file & 62 & $\begin{array}{l}\text { Covariance matrix for the parameters as } \\
\text { output by an earlier SAMMY run }\end{array}$ & $\begin{array}{l}\text { Section VII.B } \\
\text { Table VIC.1 }\end{array}$ \\
\hline $\begin{array}{l}\text { DCV (Data } \\
\text { CoVariance) }\end{array}$ & 63 & Covariance information for the data & Section VI.C \\
\hline AVG file & 28 & $\begin{array}{l}\text { Information needed by SAMMY in order } \\
\text { to produce energy-averaged cross sections }\end{array}$ & Section VI.E \\
\hline NTG file & 10 & Integral data file & Section VI.I \\
\hline NDF input file & 10 & $\begin{array}{l}\text { Information needed by SAMMY in order } \\
\text { to generate an ENDF/B-VI output file }\end{array}$ & Section VI.F \\
\hline $\begin{array}{l}\text { ENDF resonance } \\
\text { parameter file }\end{array}$ & 10 & $\begin{array}{l}\text { File } 2 \text { from ENDF, to be used instead of } \\
\text { the usual SAMMY PARameter file (and } \\
\text { for part of the SAMMY NNPut file) }\end{array}$ & Section VI.G \\
\hline
\end{tabular}


Table VI.1 (continued)

\begin{tabular}{|c|c|c|c|}
\hline Description & $\begin{array}{l}\text { Unit } \\
\text { No. }\end{array}$ & Contents & $\begin{array}{l}\text { Where details } \\
\text { may be found }\end{array}$ \\
\hline ENDF File 3 & 10 & $\begin{array}{l}\text { Smooth cross sections to be added to the } \\
\text { cross section calculated from resonance } \\
\text { parameters }\end{array}$ & \\
\hline MXW file & 10 & $\begin{array}{l}\text { Temperatures at which the Maxwellain } \\
\text { averages are to be evaluated }\end{array}$ & Section VI.H \\
\hline SSM file & 25 & $\begin{array}{l}\text { Edge-effects corrections to single-scattering } \\
\text { correction for capture cross sections (file is } \\
\text { generated by a previous SAMMY run) }\end{array}$ & Section III.F \\
\hline
\end{tabular}




\section{VI.A THE INPut FILE}

Table VIA.1 gives details about the information provided to SAMMY via the INPut file.

Card Set 1 of that table contains a title, which is reproduced in the output LPT file (See Sect. VII.A).

Card Set 2 contains miscellaneous information, including the mass of the sample, the energy range, a flag to indicate how many iterations of Bayes' equations are to be run. Some of the information given here may be input elsewhere, in which case numbers given here are ignored.

The user specifies control options via Card Set 3, which contains statements (in English) regarding the manner in which SAMMY is to proceed for this analysis. Valid control statements are given in Table VIA.2; any of these statements may be used in any order in Card Set 3. (In the case of a conflict between two statements, the later command is used.) Note that SAMMY does not understand misspellings! Instead, SAMMY will print an error message in the LPT file and proceed to ignore the statement. Control statements may be either capital letters or lowercase, but must be entirely one or the other on any given statement; that is, do not mix lowercase and capitals on the same line.

Card Set 4 is blank, terminating Card Set 3.

Card Sets 5 and 6 describe the input for Doppler- and resolution-broadening (See Sect. IV). Card Set 7 gives matching radius for the R-matrix formalism, sample thickness, and various other parameters. Values for many of these parameters may, however, be superseded by values specified in the PARameter file (See Sect. VI.B).

Card Set 8 specifies the type of data to be analyzed (e.g., capture cross section, transmission). When the data are angular distributions, angles are specified here.

Quantum numbers for the sample nucleus are specified in Card Set 9, though values given here may be overwritten by values given in "Alternative to Card Set 10."

Card Set 10 describes quantum numbers for the various spin groups. NOTE: The "Alternative to Card Set 10" is now the preferred method for inputting these quantum numbers, because in this format all spins, masses, etc. (e.g., of minor isotopes) may be given explicitly.

Card Set 11 is needed only when analyzing capture cross sections using self-shielding and multiple-scattering corrections. Dimensions of the sample, and interpolation and integration parameters, are specified in this Card Set. 
Table VIA.1 Format of the INPut File

Note: All integer formats (e.g., 12,15) require that the numbers be in the right-most columns

\begin{tabular}{llllllll}
\hline $\begin{array}{l}\text { Number } \\
\text { of cards } \\
\text { in this } \\
\text { set }\end{array}$ & $\begin{array}{l}\text { Which } \\
\text { card is } \\
\text { shown } \\
\text { here }\end{array}$ & $\begin{array}{l}\text { Col- } \\
\text { umn }\end{array}$ & Variable & $\begin{array}{l}\text { For- } \\
\text { mat }\end{array}$ & Meaning (units) & $\begin{array}{l}\text { Range of } \\
\text { values }\end{array}$ & Notes \\
\hline 1 & 1 & 1 & $1-80$ & TITLE & 16A5 & & \\
\hline 2 & 1 & 1 & $1-10$ & ELMNT & A10 & Sample element's name & \\
& & & $11-20$ & AW & F10.1 & Atomic weight (amu)
\end{tabular}

21-30 EMIN F10.1 Minimum energy for this data set $(\mathrm{eV})$

31-40 EMAX F10.1 Maximum energy (eV)

41-45 NEPNTS I5 Maximum number of points to be analyzed at one time (default $=500$, but see Note)

or: number of points to be used in generating artificial energy grid (default $=$ 10001)

49-50 ITMAX I2 $\quad \begin{aligned} & \text { Number of iterations } \\ & \text { (default }=2 \text { ) }\end{aligned}$

51-52 ICORR I2 Correlations smaller than this value (divided by 100 ) are not to be printed
$0 \leq \mathrm{ICORR} \leq 100$

Default $=50$

This value is ignored unless the phrase "DO NOT PRINT SMALL

Correlation coefficients" occurs in Card Set 3

EMIN \& EMAX will be ignored here if they are given in the BATch file (See Section VI:D)

NEPNTS is the number of data points to be included in each region when "DIVIDE DATA INTO REGions" is specified in Card Set 3. (See Section V.G; use of this option is discouraged.)

$0 \leq$ NXTRA $\leq 999$ Default $=0$

The minimum number of points in the auxiliary grid is (NXTRA+1) $\times$ NDAT, where NDAT is the number of points in the data grid
Number of extra points to be added between each pair of data points for the auxiliary energy grid 
Table VIA.1 (continued)

\begin{tabular}{llllllll}
\hline $\begin{array}{l}\text { Card } \\
\text { set }\end{array}$ & $\begin{array}{l}\text { Number } \\
\text { of cards }\end{array}$ & $\begin{array}{l}\text { Which } \\
\text { card }\end{array}$ & Column & Variable & $\begin{array}{l}\text { For- } \\
\text { mat }\end{array}$ & Meaning (units) & $\begin{array}{c}\text { Range of } \\
\text { values }\end{array}$ \\
\hline $\begin{array}{l}2, \\
\text { cont. }\end{array}$ & 1 & 1, & $56-57$ & IPTDOP & I2 & $\begin{array}{l}\text { Number of points to be } \\
\text { added to auxiliary energy } \\
\text { grid in the neighborhood } \\
\text { of small resonances }\end{array}$ & Default $=9$
\end{tabular}

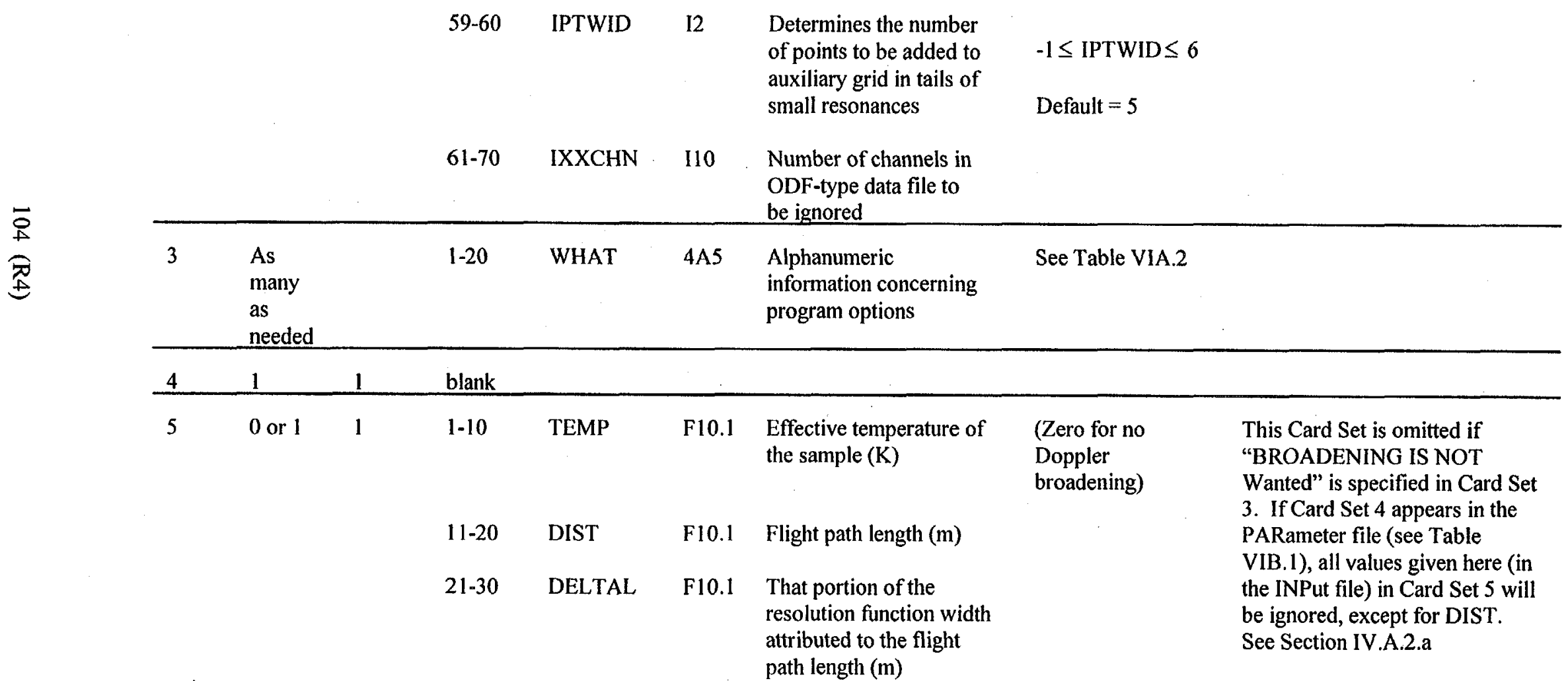


Table VIA.1 (continued)

\begin{tabular}{|c|c|c|c|c|c|c|c|c|}
\hline $\begin{array}{l}\text { Card } \\
\text { set }\end{array}$ & $\begin{array}{l}\text { Number } \\
\text { of cards }\end{array}$ & $\begin{array}{l}\text { Which } \\
\text { card }\end{array}$ & Column & Variable & Format & Meaning (units) & Range of values & Notes \\
\hline \multirow[t]{7}{*}{8} & $\begin{array}{l}\text { At } \\
\text { least } \\
1\end{array}$ & 1 & $1-80$ & CROSS & 16A5 & Type of data & $\begin{array}{l}\text { TRANSmission } \\
\text { TOTAL cross section } \\
\left\{\begin{array}{l}\text { ELASTic } \\
\text { SCATTering }\end{array}\right. \\
\text { INELAstic scattering } \\
\text { DIFFErential elastic } \\
\text { \{FISSion } \\
\text { REACTion } \\
\text { CAPTUre } \\
\text { SELF-indication } \\
\text { ABSORption } \\
\text { ETA }\end{array}$ & $\begin{array}{l}\text { Only those characters in capitals } \\
\text { are required } \\
\text { (Values connected with curley } \\
\text { brackets are equivalent.) } \\
\\
\text { Note ABSOR = CAPTU + FISSI } \\
\text { Note ETA is defined as } \\
\text { NU× (fission/absorption) where } \\
\text { NU is specified in Card Set } 11 \\
\text { (Card 3) of the PARameter file } \\
\text { (Table VIB.1) }\end{array}$ \\
\hline & & 2 & $1-5$ & NANGLE & 15 & $\begin{array}{l}\text { Number of } \\
\text { angles }\end{array}$ & $>0$ & $\begin{array}{l}\text { This card is present only for } \\
\text { DIFFErential elastic cross sections }\end{array}$ \\
\hline & & & $11-20$ & ANGLE(1) & F10.1 & $\begin{array}{l}\text { First angle, in } \\
\text { laboratory } \\
\text { (degrees) }\end{array}$ & Between 0 and $180^{\circ}$ & \\
\hline & & & $21-30$ & ANGLE(2) & F 10.1 & $\begin{array}{l}\text { Second angle } \\
\text { (degrees) }\end{array}$ & & \\
\hline & & & $\vdots$ & $\vdots$ & $:$ & $:$ & & \\
\hline & & & $71-80$ & ANGLE(7) & F10.1 & Seventh angle & & \\
\hline & & $\begin{array}{l}3,4 \\
\text { etc. }\end{array}$ & $\begin{array}{c}1-10 \\
11-20, \\
\text { etc. }\end{array}$ & $\begin{array}{l}\text { ANGLE(8) } \\
\text { etc. }\end{array}$ & F10.1 & $\begin{array}{l}\text { Other angles } \\
\text { (degrees) }\end{array}$ & & $\begin{array}{l}\text { These cards are absent if } \\
\text { NANGLE } \leq 7\end{array}$ \\
\hline
\end{tabular}


Table VIA.1 (continued)

\begin{tabular}{|c|c|c|c|c|c|c|c|c|}
\hline $\begin{array}{l}\text { Card } \\
\text { set }\end{array}$ & $\begin{array}{l}\text { Number } \\
\text { of cards }\end{array}$ & $\begin{array}{l}\text { Which } \\
\text { card }\end{array}$ & Columns & Variable & Format & Meaning (units) & Range of values & Notes \\
\hline \multirow[t]{5}{*}{$\begin{array}{l}8, \\
\text { cont. }\end{array}$} & \multirow[t]{5}{*}{$\begin{array}{l}\text { at least } \\
1\end{array}$} & \multirow[t]{4}{*}{5} & $11-20$ & DANGLE(1) & F10.1 & \multirow[t]{4}{*}{$\begin{array}{l}\text { Angular spread of } \\
\text { detector at } \\
\text { ANGLE(1) } \\
\text { (degrees) }\end{array}$} & $\cdot$ & \multirow[t]{4}{*}{$\begin{array}{l}\text { Card is included only for } \\
\text { differential elastic cross } \\
\text { sections }\end{array}$} \\
\hline & & & $21-30$ & DANGLE(2) & F10.1 & & & \\
\hline & & & $:$ & $:$ & $\vdots$ & & & \\
\hline & & & $71-80$ & DANGLE(7) & F10.1 & & & \\
\hline & & $6,7, \cdots$ & $1-80$ & $\begin{array}{l}\text { DANGLE(7) } \\
\text { to DANGLE } \\
\text { (NANGLE) }\end{array}$ & F10.1 & Angular spread & & Absent if NANGLE $\leq 7$ \\
\hline $\begin{array}{l}\text { Alter- } \\
\text { native } \\
\text { to } 8\end{array}$ & $\begin{array}{l}\text { At least } \\
5\end{array}$ & 1 & $1-80$ & CROSS & $16 \mathrm{~A} 5$ & & $\begin{array}{l}\text { COMBInation of } \\
\text { TWO types } \\
\text { COMBInation of } \\
\text { THREE types } \\
\vdots \\
\text { COMBInation of } \\
\text { SEVEN types }\end{array}$ & $\begin{array}{l}\text { Columns } 16 \text { through } 20 \\
\text { indicate how many types of } \\
\text { data are to be included, to a } \\
\text { maximum of SEVEN }\end{array}$ \\
\hline \multirow{2}{*}{\multicolumn{2}{|c|}{$\begin{array}{l}\text { WARNING: } \\
\text { This alternative } \\
\text { has never been } \\
\text { used except for } \\
\text { test cases. } \\
\text { Contact N. M. } \\
\text { Larson when you } \\
\text { start to use this } \\
\text { option. }\end{array}$}} & 2 & $1-80$ & $\mathrm{CROSS}_{1}$ & $16 \mathrm{~A} 5$ & $\begin{array}{l}\text { Type of cross } \\
\text { section for data set } 1\end{array}$ & & $\begin{array}{l}\text { See the other version of } \\
\text { Card Set } 8\end{array}$ \\
\hline & & 3 & $11-20$ & EMIN $_{1}$ & F10.1 & $\begin{array}{l}\text { Minimum energy for } \\
\text { data set } 1(\mathrm{eV}) \\
\text { Maximum energy } \\
\text { for data set } 1(\mathrm{eV})\end{array}$ & & $\begin{array}{l}\text { These energies override } \\
\text { those given in Card Set } 2\end{array}$ \\
\hline
\end{tabular}


Table VIA.1 (continued)

\begin{tabular}{|c|c|c|c|c|c|c|c|c|}
\hline $\begin{array}{l}\text { Card } \\
\text { set }\end{array}$ & $\begin{array}{l}\text { Number } \\
\text { of cards }\end{array}$ & $\begin{array}{l}\text { Which } \\
\text { card }\end{array}$ & Columns & Variable & $\begin{array}{l}\text { For- } \\
\text { mat }\end{array}$ & Meaning (Units) & $\begin{array}{l}\text { Range of } \\
\text { values }\end{array}$ & Notes \\
\hline \multirow[t]{8}{*}{$\begin{array}{l}10 \\
\text { cont. }\end{array}$} & \multirow[t]{8}{*}{$\begin{array}{l}\text { One for } \\
\text { each } \\
\text { spin } \\
\text { group }\end{array}$} & \multirow[t]{7}{*}{$\begin{array}{l}1, \\
\text { cont. }\end{array}$} & $41-45$ & $\operatorname{LSPIN}(2,1)$ & I5 & $\begin{array}{l}\text { Orbital angular momen- } \\
\text { tum for channel } 2 \text { for } \\
\text { resonances in group } 1\end{array}$ & Integer & $\begin{array}{l}\text { Card is blank in columns } 41-79 \\
\text { if there is only } 1 \text { channel (i.e., if } \\
N E N T=1 \text { and NEXT }=0 \text { ) }\end{array}$ \\
\hline & & & $46-50$ & CHSPIN $(2,1)$ & F5.1 & $\begin{array}{l}\text { Channel spin for channel } 2 \text {, } \\
\text { group } 1\end{array}$ & & \\
\hline & & & $51-60$ & $\operatorname{ENBND}(2,1)$ & F10.1 & $\begin{array}{l}\text { Boundary condition for } \\
\text { channel } 2 \text {, group } 1(\mathrm{eV})\end{array}$ & & \\
\hline & & & $61-65$ & $\operatorname{LSPIN}(3,1)$ & I5 & $\begin{array}{l}\text { Orbital angular momentum } \\
\text { for channel } 3 \text {, group } 1\end{array}$ & & \multirow[t]{4}{*}{$\begin{array}{l}\text { Card is blank in columns } 61-79 \\
\text { if there are only } 2 \text { channels (i.e., } \\
\text { if NENT+NEXT } \leq 2 \text { ) }\end{array}$} \\
\hline & & & $66-70$ & CHSPIN $(3,1)$ & F5.1 & & & \\
\hline & & & $71-79$ & $\operatorname{ENBND}(3,1)$ & F9.1 & & & \\
\hline & & & 80 & IXCLD & II & $\begin{array}{l}\text { Flag to exclude this spin } \\
\text { group from calculation, but } \\
\text { not from PAR or COV } \\
\text { files }\end{array}$ & $\begin{array}{l}0 \text { for include } \\
1 \text { for exclude }\end{array}$ & \\
\hline & & 2 , etc. & . & & & & & $\begin{array}{l}\text { Same as card } 1 \text { in this card set, } \\
\text { with the quantum numbers } \\
\text { appropriate for group number } 2\end{array}$ \\
\hline \multirow{2}{*}{$\begin{array}{l}\text { Al- } \\
\text { terna- } \\
\text { tive } \\
\text { to } \\
\text { Card } \\
\text { Set } \\
10\end{array}$} & \multirow[t]{2}{*}{$\begin{array}{l}\text { At least } \\
\text { two for } \\
\text { each } \\
\text { spin } \\
\text { group }\end{array}$} & \multirow[t]{2}{*}{1} & $\begin{array}{l}1-3 \\
4\end{array}$ & $\begin{array}{l}\text { JJ } \\
\text { (blank) }\end{array}$ & 13 & Spin group number & $1,2,3, \ldots$ & \multirow[t]{2}{*}{$\begin{array}{l}\text { "USE NEW SPIN GROUP } \\
\text { format" must appear in Card Set } \\
3 \text { if this alternative is used. } \\
\text { Contact the author if you want } \\
\text { more than } 999 \text { spin groups }\end{array}$} \\
\hline & & & 5 & EXCL & Al & $\begin{array}{l}\text { Flag if exclude from } \\
\text { calculation }\end{array}$ & $\begin{array}{l}\text { blank = include } \\
\text { "X" = exclude }\end{array}$ & \\
\hline
\end{tabular}


Table VIA.1 (continued)

\begin{tabular}{|c|c|c|c|c|c|c|c|c|}
\hline $\begin{array}{l}\text { Card } \\
\text { set }\end{array}$ & $\begin{array}{l}\text { Number } \\
\text { of cards }\end{array}$ & $\begin{array}{l}\text { Which } \\
\text { card }\end{array}$ & $\begin{array}{l}\text { Col- } \\
\text { umns }\end{array}$ & Variable & $\begin{array}{l}\text { For- } \\
\text { mat }\end{array}$ & Meaning (Units) & Range of values & Notes \\
\hline \multirow{10}{*}{$\begin{array}{l}\text { Alt } \\
10 \\
\text { cont. }\end{array}$} & \multirow{10}{*}{$\begin{array}{l}\text { At least } \\
\text { two for } \\
\text { each spin } \\
\text { group }\end{array}$} & \multirow[t]{5}{*}{$\begin{array}{l}1 \\
\text { cont. }\end{array}$} & $6-10$ & NENT(JJ) & I5 & $\begin{array}{l}\text { Number of entrance } \\
\text { channels }\end{array}$ & $>0$ & $\begin{array}{l}\text { NENT + NEXT is the total } \\
\text { number of particle channels } \\
\text { for this spin group }\end{array}$ \\
\hline & & & $11-15$ & $\operatorname{NEXT}(J J)$ & 15 & $\begin{array}{l}\text { Number of exit chan- } \\
\text { nels, excluding those } \\
\text { which are also } \\
\text { entrance channels }\end{array}$ & $\geq 0$ & 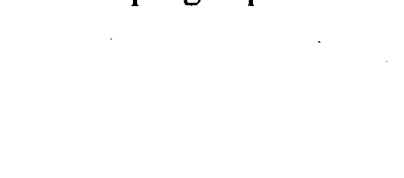 \\
\hline & & & $16-20$ & $\operatorname{SPINJ}(J J)$ & F5.1 & $\begin{array}{l}\text { Spin for resonances } \\
\text { in group } \mathrm{J}\end{array}$ & $\begin{array}{l}\text { Integer or half- } \\
\text { integer }\end{array}$ & $\begin{array}{l}\text { positive for even parity and } \\
\text { negative for odd }\end{array}$ \\
\hline & & & $21-30$ & ABNDNC(JJ) & F10.1 & $\begin{array}{l}\text { Isotopic abundance } \\
\text { for this spin group }\end{array}$ & & \\
\hline & & & $31-35$ & SPINI & F5.1 & $\begin{array}{l}\text { Ground-state spin for } \\
\text { this isotope }\end{array}$ & $\begin{array}{l}\text { integer or half- } \\
\text { integer }\end{array}$ & $\begin{array}{l}\text { positive for even parity and } \\
\text { negative for odd }\end{array}$ \\
\hline & & \multirow[t]{5}{*}{2} & $1-5$ & $\mathrm{~N}$ & 15 & Channel number & $>0$ & $\begin{array}{l}\text { Note: one card is needed for } \\
\text { each channel }\end{array}$ \\
\hline & & & $6-10$ & LPENT(N,JJ) & I5 & $\begin{array}{l}\text { Calculate penetra- } \\
\text { bility for channel } \mathrm{N} \text {, } \\
\text { spin group } \mathrm{J}\end{array}$ & $\begin{array}{l}0=\text { no } \\
1=\text { yes }\end{array}$ & \\
\hline & & & 15 & ISHIFT(N,JJ) & Il & Calculate shift? & \multirow[t]{2}{*}{$\begin{array}{l}0=\text { no } \\
1=\text { yes }\end{array}$} & \\
\hline & & & $19-20$ & LSPIN(N,JJ) & I2 & $\begin{array}{l}\text { Orbital angular } \\
\text { momentum }\end{array}$ & & \\
\hline & & & $21-30$ & $\operatorname{CHSPIN}(\mathrm{N}, \mathrm{JJ})$ & F10.1 & Channel spin & $\begin{array}{l}\text { integer or half- } \\
\text { integer }\end{array}$ & \\
\hline
\end{tabular}


Table VIA.1 (continued)

\begin{tabular}{|c|c|c|c|c|c|c|c|c|}
\hline $\begin{array}{l}\text { Card } \\
\text { set }\end{array}$ & $\begin{array}{l}\text { Number } \\
\text { of cards }\end{array}$ & $\begin{array}{l}\text { Which } \\
\text { card }\end{array}$ & Column & Variable & Format & Meaning (units) & $\begin{array}{l}\text { Range of } \\
\text { values }\end{array}$ & Notes \\
\hline \multirow[t]{9}{*}{$\begin{array}{l}\text { Alt. } \\
10 \\
\text { cont. }\end{array}$} & $\begin{array}{l}\text { At least } \\
\text { two for } \\
\text { each } \\
\text { spin } \\
\text { group }\end{array}$ & $\begin{array}{l}2 \\
\text { cont. }\end{array}$ & $31-40$ & ENBND(N,JJ) & Fl0.1 & Boundary condition (eV) & & $\begin{array}{l}\text { If ENBND>0, then } \mathrm{B}=\mathrm{S}_{/}(\alpha) \text {, where } \alpha \\
=k a \text { and } k \text { is the center-of-mass } \\
\text { momentum for energy ENBND (see } \\
\text { Section IIIA.1). If ENBND }<0 \text {, } \\
\text { then B=ENBND }\end{array}$ \\
\hline & & & $41-50$ & ECHAN(N,JJ) & F10.1 & $\begin{array}{l}\text { Excitation energy of residual } \\
\text { nucleus in an inelastic } \\
\text { channel }(\mathrm{eV})\end{array}$ & $\geq 0$ & \\
\hline & & & $51-55$ & $\operatorname{RDEFF}(\mathrm{N}, \mathrm{JJ})$ & F5.1 & Effective radius $(\mathrm{F})$ & $\geq 0$ & $\begin{array}{l}\text { As defined by ENDF; used in } \\
\text { calculating phase shift only. If zero, } \\
\text { SAMMY uses CRFN from Card Set } \\
7 \text { or PAREFF from Card Set } 7 \text { of the } \\
\text { PARameter file (Table VIB.1) }\end{array}$ \\
\hline & & & $56-60$ & RDTRU(N,JJ) & F5.1 & True radius $(\mathrm{F})$ & $\geq 0$ & $\begin{array}{l}\text { As defined by ENDF; used in } \\
\text { calculating penetrabilities and phase } \\
\text { shifts }\end{array}$ \\
\hline & & & $61-70$ & $\operatorname{EMM} 1(\mathrm{~N}, \mathrm{JJ})$ & $\mathrm{F} 10.1$ & $\begin{array}{l}\text { Mass of fragment \# } 1 \text { (i.e. } \\
\text { of target, for channel } \\
\text { number 1) (amu) }\end{array}$ & $\geq 0$ & If zero, uses AW from Card Set 2 \\
\hline & & & $71-80$ & EMM2(N,JJ) & F10.1 & $\begin{array}{l}\text { Mass of fragment \#2 (i.e. } \\
\text { of neutron, for channel } \\
\text { number 1) (amu) }\end{array}$ & $\geq 0$ & $\begin{array}{l}\text { If zero, uses atomic weight of } \\
\text { neutron }\end{array}$ \\
\hline & & 3 , etc. & Repeat $\mathrm{ca}$ & rd number 2 for & otal of $(1$ & ENT+NEXT) cards & & \\
\hline & & 4 , etc. & Repeat (C & ard 1 and Card & once for & very spin group & & \\
\hline & & Last & (blank) & & & & & \\
\hline
\end{tabular}


Table VIA.1 (continued)

\begin{tabular}{|c|c|c|c|c|c|c|c|c|}
\hline $\begin{array}{l}\text { Card } \\
\text { set }\end{array}$ & $\begin{array}{l}\text { Number } \\
\text { of cards }\end{array}$ & $\begin{array}{l}\text { Which } \\
\text { card }\end{array}$ & Column & Variable & Format & Meaning (units) & $\begin{array}{l}\text { Range of } \\
\text { values }\end{array}$ & Notes \\
\hline \multirow[t]{9}{*}{11} & 1 & 1 & $1-10$ & THSAMP & F10.1 & Sample thickness $(\mathrm{cm})$ & $>0$ & \multirow{9}{*}{$\begin{array}{l}\text { This card set is present } \\
\text { only if self-shielding and } \\
\text { multiple-scattering } \\
\text { corrections are mentioned } \\
\text { in Card Set } 3\end{array}$} \\
\hline & & & $11-20$ & XSAMP & F10.1 & $\begin{array}{l}\text { Sample height }(\mathrm{cm}) \text { or } \\
\text { sample radius }(\mathrm{cm})\end{array}$ & $>0$ & \\
\hline & & & $21-30$ & YSAMP & F10.1 & $\begin{array}{l}\text { Sample width }(\mathrm{cm}) \text { or zero if } \\
\text { circular }\end{array}$ & $\geq 0$ & \\
\hline & & & $31-40$ & XBEAM & F10.1 & $\begin{array}{l}\text { Beam height }(\mathrm{cm}) \text { or beam } \\
\text { radius }(\mathrm{cm}) \text {, or zero if beam is } \\
\text { larger than sample }\end{array}$ & $\geq 0$ & \\
\hline & & & $41-50$ & YBEAM & F10.1 & $\begin{array}{l}\text { Beam width }(\mathrm{cm}) \text { or zero if } \\
\text { circular or if beam is larger } \\
\text { than sample }\end{array}$ & $\geq 0$ & \\
\hline & & & $51-55$ & NTHETA & 15 & $\begin{array}{l}\text { Number of points for part of } \\
\theta \text {-integration }\end{array}$ & $\begin{array}{l}\geq 0 \\
\text { default }=28\end{array}$ & \\
\hline & & & $56-60$ & NGAUSZ & I5 & $\begin{array}{l}\text { Number of points for pieces } \\
\text { of } z \text {-integration }\end{array}$ & $\begin{array}{l}4,8, \text { or } 16 \\
\text { default }=16\end{array}$ & \\
\hline & & & $61-65$ & NGAUS & 15 & $\begin{array}{l}\text { Number of points for pieces of } \\
\text { integration over cross- section } \\
\text { of beam }\end{array}$ & $\begin{array}{l}4,8, \text { or } 16 \\
\text { default }=16\end{array}$ & \\
\hline & & & $66-70$ & MTHETA & 15 & $\begin{array}{l}\text { Number of points for rest of } \\
\theta \text {-integration }\end{array}$ & $\begin{array}{l}\geq 0 \\
\text { default }=11\end{array}$ & \\
\hline
\end{tabular}




\section{Table VIA.2 Alphanumeric statements acceptable for use in the INPUT file, Card Set 3}

Note: Any of the valid statements listed here may be included in the INPut file, in any order. Usually only the first 20 characters of the statement are required; occasionally other information must be given in specific columns, as indicated below. Characters shown here in lower-case letters are optional in the INPut file, but are included here for clarity. Characters shown here in upper case can be either upper case or lower case in the INPut file, but the cases must not be mixed for any one command. In the event that contradictory statements are included, the last to appear is the instruction that SAMMY will honor. Default instructions need not be included explicitly. Options that are described "for debug purposes" should generally be avoided, because considerable output is generated thereby, especially when many data points are included within the energy range.

\begin{tabular}{|c|c|c|c|}
\hline Category & Default & Statements & Notes \\
\hline \multirow{6}{*}{$\begin{array}{l}\text { Input } \\
\text { control } \\
\text { for } \\
\text { experi- } \\
\text { mental } \\
\text { data }\end{array}$} & \multirow[t]{6}{*}{$\mathrm{x}$} & DATA ARE IN ORIGINAL multi-style format & $\begin{array}{l}\text { Three points per line, relative uncertainties, in } 3(2 \mathrm{~F} 15.5, \mathrm{~F} 7.3) \\
\text { format. See Section VI.C.1 }\end{array}$ \\
\hline & & $\begin{array}{l}\text { DATA FORMAT IS ONE Point per line, or } \\
\text { USE CSISRS FORMAT FOr data, or } \\
\text { CSISRS }\end{array}$ & $\begin{array}{l}\text { The ASCII data file contains one point per line, in ( } 3 \mathrm{G} 11.8) \text { format, } \\
\text { with uncertainties being absolute rather than relative }\end{array}$ \\
\hline & & $\begin{array}{l}\text { USE TWENTY SIGNIFICAnt digits, or } \\
\text { TWENTY }\end{array}$ & $\begin{array}{l}\text { The ASCII data file contains one point per line in (3F20.10) format. } \\
\text { Uncertainties are absolute }\end{array}$ \\
\hline & & DATA ARE IN STANDARd odf format & $\begin{array}{l}\text { The data file is the "standard" ODF file with energy in section 1, data } \\
\text { in section } 2 \text {, absolute uncertainty in section } 3 \text {, and partial derivatives } \\
\text { with respect to data-reduction parameters in section } 4 \mathrm{ff} \text {. See Section } \\
\text { V.E. } 2 \text { of this manual for details }\end{array}$ \\
\hline & & DATA ARE IN ODF FILE & $\begin{array}{l}\text { The data file, whose name you specify either on-line or in your batch } \\
\text { file, is in ORELA Data Format. Section } 1 \text { contains energies, } 2 \text { the } \\
\text { data, and } 3 \text { the (absolute) uncertainties. See Section VI.C of this report } \\
\text { for details }\end{array}$ \\
\hline & & DIFFERENTIAL DATA ARE in ascii file & See Section VI.C.1 for details \\
\hline & & IMPLICIT DATA COVARIance is wanted & See Section VI.C.2 \\
\hline
\end{tabular}


Table VIA.2 (continued)

\begin{tabular}{|c|c|c|c|}
\hline Category & Default & Statements & Notes \\
\hline \multirow{7}{*}{$\begin{array}{l}\text { Input } \\
\text { control } \\
\text { for } \\
\text { experi- } \\
\text { mental } \\
\text { data, } \\
\text { cont. }\end{array}$} & \multirow{3}{*}{$\mathrm{X}$} & ADD CONSTANT TERM TO data covariance & \multirow{3}{*}{$\begin{array}{l}\text { These three statements refer to the option of adding a constant to } \\
\text { the data covariance matrix, both on- and off-diagonal, over the } \\
\text { energy region in which the effect of the (non-s-wave) resonance is } \\
\text { felt. Magnitude of this constant is specified in columns } 68-80 \text { in the } \\
\text { parameter file, for each resonance. For the third option, the default } \\
\text { value of this constant is set at 1.E-6 for every non-s-wave resonance }\end{array}$} \\
\hline & & $\begin{array}{l}\text { DO NOT ADD CONSTANT term to data } \\
\text { covariance }\end{array}$ & \\
\hline & & $\begin{array}{l}\text { USE DEFAULT FOR CONStant term to add to } \\
\text { data covariance }\end{array}$ & \\
\hline & & ADD TEN PERCENT DATA uncertainty & To be used only in nonphysical situations \\
\hline & \multirow[t]{3}{*}{$\mathrm{x}$} & DATA COVARIANCE IS Diagonal & \\
\hline & & $\begin{array}{l}\text { DATA HAS OFF-DIAGONAI contribution to } \\
\text { covariance matrix of the form }\left(a+b E_{t}\right)\left(a+b E_{j}\right)\end{array}$ & $\begin{array}{l}a \text { and } b \text { are specified as DCOVA and DCOVB in the INP file, } \\
\text { card set number } 7 \text { in Table VIA.1 }\end{array}$ \\
\hline & & $\begin{array}{l}\text { DATA COVARIANCE FILE is named } \\
\text { YYYYYY.YYY }\end{array}$ & $\begin{array}{l}\text { Substitute your own file name for YYYYYY.YYY in columns } \\
31-40 \text {. See Table VIC. } 2 \text { for the format for this file }\end{array}$ \\
\hline
\end{tabular}


VIA.2 (continued)

\begin{tabular}{|c|c|c|c|}
\hline Category & Default & Statements & Notes \\
\hline \multirow{6}{*}{$\begin{array}{l}\text { Input } \\
\text { control } \\
\text { for para- } \\
\text { meters }\end{array}$} & & USE NEW SPIN GROUP Format & See Card Sets 9 and (Alternative to) 10 in Table VIA.1 \\
\hline & & USE OBSOLETE SPIN GRoup format & $\begin{array}{l}\text { This option will be removed from future releases of SAMMY; } \\
\text { please begin now to use the "new" spin-group format }\end{array}$ \\
\hline & & INPUT IS ENDF/B FILE 2 & $\begin{array}{l}\text { Resonance parameters and spin-group quantum number information } \\
\text { is taken from an ENDF/B file; see Section VI.G }\end{array}$ \\
\hline & & USE ENERGY RANGE FROm endf/b file 2 & Otherwise, read energy range from INPut file or batch input \\
\hline & & $\begin{array}{l}\text { ENERGY UNCERTAINTIES are at end of } \\
\text { line in parameter file }\end{array}$ & See Table VIB.1, Card Set 1 , columns $68-80$, second alternative \\
\hline & & $\begin{array}{l}\text { IGNORE INPUT BINARY covariance file, or } \\
\text { IGNORE }\end{array}$ & $\begin{array}{l}\text { Your PARameter file specifies that the parameter covariance } \\
\text { matrix is kept in a binary file. For this particular run, however, } \\
\text { you wish to pretend that there were no previous runs generating } \\
\text { such a file; instead you wish to use the large (ideally } \infty \text { ) } \\
\text { uncertainties that indicate no prior knowledge of parameter } \\
\text { values }\end{array}$ \\
\hline
\end{tabular}


Table VIA.2 (continued)

\begin{tabular}{|c|c|c|c|}
\hline Category & Default & Statements & Notes \\
\hline \multirow{12}{*}{$\begin{array}{l}\text { Line- } \\
\text { printer } \\
\text { control } \\
\text { options }\end{array}$} & \multirow[t]{3}{*}{$\mathrm{X}$} & DO NOT PRINT ANY INPut parameters & \\
\hline & & PRINT ALL INPUT PARAmeters & \\
\hline & & PRINT VARIED INPUT Parameters & $\begin{array}{l}\text { Resonances for which no parameters are flagged will not be } \\
\text { printed. Use this option for direct comparison with output } \\
\text { parameters, which are always printed in this mode }\end{array}$ \\
\hline & \multirow[t]{2}{*}{$\mathrm{x}$} & DO NOT PRINT INPUT Data & \multirow{2}{*}{$\begin{array}{l}\text { Note that this refers to experimental values of the measured } \\
\text { cross section (or transmission, etc.), as read in from the } \\
\text { DATa file (see Section VI.C) }\end{array}$} \\
\hline & & PRINT INPUT DATA & \\
\hline & \multirow[t]{2}{*}{$\mathrm{X}$} & DO NOT PRINT THEORETical values & \multirow{2}{*}{$\begin{array}{l}\text { Often these are available in the ODF file (see Table VIIC.1) } \\
\text { so they need not be printed in the LPT file }\end{array}$} \\
\hline & & PRINT THEORETICAL VAlues & \\
\hline & \multirow[t]{2}{*}{$\mathrm{x}$} & DO NOT PRINT PARTIAL derivatives & \\
\hline & & PRINTT PARTIAL DERIVAtives & Use this option only for debug purposes \\
\hline & \multirow[t]{3}{*}{$\mathrm{x}$} & DO NOT SUPPRESS INTErmediate printout & $\begin{array}{l}\text { Updated parameter values and covariance matrix elements } \\
\text { are printed after completion of each energy region }\end{array}$ \\
\hline & & SUPPRESS INTERMEDIATe printout & $\begin{array}{l}\text { Updated parameter values and covariance matrix elements } \\
\text { are printed only upon completion of entire run }\end{array}$ \\
\hline & & DO NOT SUPPRESS ANY intermediate printout & $\begin{array}{l}\text { Updated parameter values are printed after each iteration of } \\
\text { Bayes' equations (i.e., typically twice for each energy } \\
\text { region). Updated covariance matrix elements are evaluated } \\
\text { and printed only upon completion of an energy region }\end{array}$ \\
\hline
\end{tabular}


Table VIA.2 (continued)

\begin{tabular}{|c|c|c|c|}
\hline Category & Default & Statements & Notes \\
\hline \multirow{3}{*}{$\begin{array}{l}\text { Line- } \\
\text { printer } \\
\text { control } \\
\text { options, } \\
\text { cont. }\end{array}$} & \multirow[t]{2}{*}{$\mathrm{X}$} & DO NOT USE SHORT FORmat for output & \\
\hline & & USE SHORT FORMAT FOR output & $\begin{array}{l}\text { Resonance parameters are printed in the LPT file (Section } \\
\text { VII.A), in F12.4 format rather than E format. Even though } \\
\text { this may produce more legible output, often fewer } \\
\text { significant digits will be printed }\end{array}$ \\
\hline & \multirow[t]{3}{*}{$\mathrm{X}$} & DO NOT PRINT REDUCED widths & \\
\hline \multirow[t]{5}{*}{, } & & PRINT REDUCED WIDTHS & $\begin{array}{l}\text { Reduced width amplitudes will be printed in the LPT file } \\
\text { (Section VII.A), along with the square root of the resonance } \\
\text { energies. That is, what are printed are the "u-parameters" } \\
\text { as described in Section III of this report }\end{array}$ \\
\hline & & DO NOT PRINT SMALL Correlation coefficients & $\begin{array}{l}\text { Any line of the correlation matrix whose off-diagonal } \\
\text { elements are small will not be printed. "Small" is defined } \\
\text { less than ICORR/100 in abslute value, where ICORR is } \\
\text { specified in Card Set } 2 \text { (Table VIA.1) }\end{array}$ \\
\hline & \multirow[t]{3}{*}{$\mathrm{X}$} & DO NOT PRINT DEBUG Information & \\
\hline & & $\begin{array}{l}\text { PRINT DEBUG INFORMATion, or } \\
\text { DEBUG }\end{array}$ & Use for debug purposes only on short runs \\
\hline & & PRINT CAPTURE AREA in Ipt file & $\begin{array}{l}\text { The capture area, defined as } A=g \Gamma_{n} \Gamma_{\gamma} / \Gamma \text {, is printed in } \\
\text { the SAMMY.LPT file }\end{array}$ \\
\hline
\end{tabular}




\begin{tabular}{lcll}
\hline Category & Default & Statements & Notes \\
\hline Constants & $\mathrm{X}$ & $\begin{array}{l}\text { USE ENDF VALUES For constants, or } \\
\text { USE 1999 ENDF-102 COnstant values }\end{array}$ & $\begin{array}{l}\text { SAMMY is now using those values for the physical } \\
\text { constants which have been "blessed" by ENDF (See } \\
\text { Appendix E) }\end{array}$ \\
& $\begin{array}{l}\text { USE 1995 ENDF-102 COnstant values, or } \\
\text { USE OLDER VALUES OF constants }\end{array}$ & USE SAMMY-K1 DEFAULts for constants & This will give the values which "USE PRECISE VALUES \\
& & Of constants" used to give
\end{tabular}

$\underset{D}{\stackrel{D}{D}}$ 
Table VIA.2 (continued)

\begin{tabular}{|c|c|c|c|}
\hline Category & Default & Statements & Notes \\
\hline \multirow{10}{*}{$\begin{array}{l}\text { Operation } \\
\text { control } \\
\text { for } \\
\text { standard } \\
\text { runs }\end{array}$} & \multirow[t]{2}{*}{$\mathrm{X}$} & SOLVE BAYES EQUATIONS & Update parameter values and covariances via Bayes' equations \\
\hline & & DO NOT SOLVE BAYES Equation & $\begin{array}{l}\text { Parameter values are not updated, but remain fixed. Theoretical } \\
\text { values of transmission or cross section are evaluated for each } \\
\text { energy region specified, using these fixed parameter values }\end{array}$ \\
\hline & \multirow[t]{4}{*}{$\mathrm{X}$} & $\begin{array}{l}\text { REICH-MOORE FORMALISm is wanted, or } \\
\text { MORE ACCURATE REICH-moore, or } \\
\text { XCT }\end{array}$ & $\begin{array}{l}\text { See Section III.D. Note that "more accurate" refers to the } \\
\text { computational method, not to the formalism }\end{array}$ \\
\hline & & $\begin{array}{l}\text { ORIGINAL REICH-MOORE formalism, or } \\
\text { CRO }\end{array}$ & $\begin{array}{l}\text { See Section III.A. This method of calculating the RM formalism } \\
\text { is sometimes inaccurate, particularly at low energies for capture }\end{array}$ \\
\hline & & $\begin{array}{l}\text { MULTILEVEL BREIT-WIGner is wanted, or } \\
\text { MLBW FORMALISM IS WAnted, or } \\
\text { MLBW }\end{array}$ & See Section III.C \\
\hline & & $\begin{array}{l}\text { SINGLE LEVEL BREIT-WIgner is wanted, or } \\
\text { SLBW FORMALISM IS WAnted, or } \\
\text { SLBW }\end{array}$ & See Section III.C \\
\hline & \multirow[t]{4}{*}{$\mathrm{X}$} & $\begin{array}{l}\text { LET SAMMY CHOOSE WHIch inversion } \\
\text { scheme to use }\end{array}$ & \\
\hline & & USE $(\mathrm{N}+\mathrm{V})$ INVERSION scheme & Original method; Section II.B.1.a \\
\hline & & USE $(I+Q)$ INVERSION scheme & See Section II.B.1.b \\
\hline & & $\begin{array}{l}\text { USE POLAR COORDINATEs for fission } \\
\text { widths }\end{array}$ & $\begin{array}{l}\text { When there are two channels for fission, the pair may be treated as } \\
\text { a vector, in which case the two independent variables are the } \\
\text { magnitude of the vector and the polar angle, rather than the two } \\
\text { widths. Compare, for example, with the Vogt formalism [EV58] }\end{array}$ \\
\hline
\end{tabular}


Table VIA.2 (continued)

\begin{tabular}{lclc}
\hline Category & Default & \multicolumn{1}{c}{ Statements } & Notes \\
\hline $\begin{array}{l}\text { Operation } \\
\text { control } \\
\text { for }\end{array}$ & $\mathrm{X}$ & $\begin{array}{l}\text { DO NOT DIVIDE DATA Into } \\
\text { regions - do entire energy range } \\
\text { at once }\end{array}$
\end{tabular}

standard

runs,

DIVIDE DATA INTO REGions

cont.

with a fixed number of data

SAMMY will automatically choose energy regions of NEPNTS (see Card Set points per region

2, Table VIA.1) data points each, for sequential analysis. Warning: SAMMY merely counts; it does not consider carefully whether dividing point is located in a region where the theoretical values ( $\sigma$ or $T$ ) are nonlinear with respect to the parameters. Dividing in such a location (at or near a resonance) will invalidate the linearity assumption used in deriving Bayes' equation, and thus lead to spurious results. Users are urged to use this option only on the "zeroth pass," as an aid in deciding where to divide the data, and not for final runs

USE S-WAVE CUTOFF Non-s-wave resonances far away from the data being analyzed are omitted in parts of the calculation of the R-matrix. The definition of "far away" used in setting the partial derivatives to zero is

$$
\left|E-E_{\lambda}\right|>20\left(\sum_{c} \Gamma_{\lambda c}+\Gamma_{\lambda}^{\gamma}\right)+3(d+r),
$$

where $d$ and $r$ are Doppler and resolution widths, respectively. The definition of "far away" for the contribution to the imaginary part of $R$ is 100 times that for the derivatives; contributions to the real part of $R$ are always included

For $s$-wave resonances, the user may choose whether to use a similar cutoff. If a cutoff is desired, its value is twice that for non $s$-wave resonance

Caution: Though SAMMY will run faster with the cutoff option invoked, results may not be as accurate 
Table VIA.2 (continued)

\begin{tabular}{llll}
\hline Category & Def. & \multicolumn{1}{c}{ Statements } & \multicolumn{1}{c}{ Notes } \\
\hline $\begin{array}{l}\text { Operation } \\
\text { control }\end{array}$ & $\mathrm{X}$ & $\begin{array}{l}\text { MODIFY UNVARIED WIDths when } \\
\text { varying radii }\end{array}$ & $\begin{array}{l}\text { The reduced width amplitudes are held constant; hence the partial widths may } \\
\text { vary when the channel radius is varied }\end{array}$ \\
$\begin{array}{l}\text { standard } \\
\text { runs, }\end{array}$ & $\begin{array}{l}\text { DO NOT MODIFY UNVARied widths } \\
\text { when varying radii }\end{array}$ & $\begin{array}{l}\text { The partial widths are assumed to be constant when varying the channel radius; } \\
\text { hence the reduced width amplitudes may vary. Note that derivatives with respect } \\
\text { to the channel radiusare not properly calculated for this convention; this minor } \\
\text { inconsistency should not give rise to significantly different results }\end{array}$
\end{tabular}

CHI SQUARED IS NOT Wanted, or DO NOT PRINT LS CHI squared

$\vec{D}$
0
$\stackrel{0}{\oplus}$

\section{$\mathrm{X}$ CHI SQUARED IS WANTEd, or PRINT LS CHI SQUARED}

$X$ DO NOT PRINT BAYES Chi squared unless it can be easily generated without additional calculations
Remember that in Bayes' (as opposed to least-squares) $\chi^{2}$ is an irrelevant quantity and is therefore not even calculated. Nevertheless it is often useful for comparing results of different fits. For each energy region, $\chi^{2}$ may be calculated from

$$
\chi_{L S}^{2}=\sum_{i}\left(D_{i}-T_{i}\right)\left(V^{-1}\right)_{i}\left(D_{i}-T_{i}\right)
$$

is calculated, and $\chi^{2}$ and $\chi^{2} /$ NDAT (where NDAT is the number of data points in that region) are reported. Note that SAMMY does not report $\chi^{2} /$ dof (where dof $=$ degrees of freedom $=$ NDAT-NPAR, with NPAR being the number of parameters), since with Bayes' method dof can be zero or negative.

In addition to $\chi^{2}$, the quantity we choose to call the Bayesian $\chi^{2}$ may also be reported, where

$$
\chi_{B}^{2}=\sum_{i, j}\left(D_{i}-T_{i}\right)(N+V)_{i j}^{-1}\left(D_{j}-T_{j}\right)
$$

Caveat: Theoretical values $T_{i}$ are generated using the values of the parameters prior to analysis of this energy region 


\section{Table VIA.2 (continued)}

\begin{tabular}{lclll}
\hline Category & Def. & \multicolumn{1}{c}{ Statements } & \multicolumn{1}{c}{ Notes } \\
\hline $\begin{array}{l}\text { Operation } \\
\text { control }\end{array}$ & $\mathrm{X}$ & $\begin{array}{l}\text { DO NOT PRINT WEIGHTEd residuals; or } \\
\text { DO NOT PRINT LS WEIGhted residuals }\end{array}$ & $\begin{array}{l}\text { Two types of weighted residuals may be printed. } \\
\text { weighted residual is defined as }\end{array}$ & The least-squares \\
for & & DO
\end{tabular}

standard

runs,

$$
R_{i i}^{L S}=\sqrt{\left(V^{-1}\right)_{i i}}\left(D_{i}-T_{i}\right),
$$

cont.

PRINT WEIGHTED RESIDuals; or

PRINT LS WEIGHTED Residuals where $D$ is the experimental data, $V$ its covariance matrix, and $T$ the theoretical value evaluated at the initial values of the parameters. The Bayesian weighted residual is defined as

$$
X \text { PRINT BAYES WEIGHTED residuals }
$$

$$
R_{i}^{B}=\sum_{j}\left(N+V_{i j}^{-1}\left(D_{j}-T_{j}\right)\right.
$$

where

DO NOT PRINT BAYES Weighted

residuals

$$
N_{k n}=\sum_{i j} \frac{\partial T_{k}}{\partial u_{i}} M_{i j} \frac{\partial T_{n}}{\partial u_{j}}
$$

and $M_{i j}$ is the initial covariance matrix element for parameters $u_{i}$ and $u_{i}$
In the LPT file

$X \quad$ DO NOT PRINT PHASE shifts

PRINT PHASE SHIFTS For input

parameters

5
0
0
0
0
0 
Table VIA.2 (continued)

\begin{tabular}{|c|c|c|c|}
\hline Category & Default & Statements & Notes \\
\hline \multirow{6}{*}{$\begin{array}{l}\text { Broad- } \\
\text { ening } \\
\text { options }\end{array}$} & \multirow[t]{2}{*}{$\mathrm{X}$} & BROADENING IS WANTED & Some form of broadening is to be used; see Section IV \\
\hline & & BROADENING IS NOT WAnted & $\begin{array}{l}\text { If you do not wish to have SAMMY Doppler- or resolution- } \\
\text { broaden the theoretical values, be sure to remove Card Sets } \\
5 \text { and } 6 \text { (see Table VIA.1) from the INP file, as well as } \\
\text { include this card }\end{array}$ \\
\hline & \multirow[t]{4}{*}{$\mathrm{X}$} & $\begin{array}{l}\text { USE FREE GAS MODEL Of doppler broadening, or } \\
\text { FGM }\end{array}$ & $\begin{array}{l}\text { The free-gas model of Doppler broadening, as described in } \\
\text { Section IV.F, is to be used }\end{array}$ \\
\hline & & USE LEAL,HWANG DOPPLer broadening & $\begin{array}{l}\text { The Doppler-broadening method of Leal and Hwang, as } \\
\text { described in Section IV.D, is to be used }\end{array}$ \\
\hline & & $\begin{array}{l}\text { USE MULTI-STYLE DOPPPler broadening, or } \\
\text { HEGA }\end{array}$ & $\begin{array}{l}\text { High-energy Gaussian approximation to the free-gas model } \\
\text { is to be used for Doppler broadening, as described in Section } \\
\text { IV.A.1 }\end{array}$ \\
\hline & & NO LOW-ENERGY BROADEning is to be used & $\begin{array}{l}\text { Theoretical values are not to be broadened below the energy } \\
\text { value ELOWBR given in Card Set } 5 \text { of Table VIA.1 (the } \\
\text { INPut file). This option works only with the original } \\
\text { (MULTI-style) broadening, and not with the Leal-Hwang } \\
\text { method nor with the free-gas model }\end{array}$ \\
\hline
\end{tabular}


Table VIA.2 (continued)

\begin{tabular}{|c|c|c|c|}
\hline Category & Default & Statements & Notes \\
\hline \multirow{3}{*}{$\begin{array}{l}\text { Broad- } \\
\text { ening } \\
\text { options, } \\
\text { cont. }\end{array}$} & & $\begin{array}{l}\text { EXPONENTIAL FOLDING width is energy- } \\
\text { dependent }\end{array}$ & See Section IV.A.2.b, Eq. (IVA2b.6) \\
\hline & & $\begin{array}{l}\text { DO NOT SHIFT ENERGY for exponential tail } \\
\text { on resolution broadening }\end{array}$ & See Section IV.A.2.c; the energy shift $\Delta E_{s}$ is assumed zero here \\
\hline & $X$ & $\begin{array}{l}\text { SHIFT ENERGY FOR EXPonential tail on } \\
\text { resolution broadening }\end{array}$ & $\begin{array}{l}\text { See Section IV.A.2.c; the energy shift } \Delta E_{s} \text { is chosen to give a } \\
\text { maximum of the integrand at the resonance energy }\end{array}$ \\
\hline
\end{tabular}


Table VIA.2 (continued)

\begin{tabular}{|c|c|c|c|}
\hline Category & Default & Statements & Notes \\
\hline \multirow{11}{*}{$\begin{array}{l}\text { Multiple- } \\
\text { scattering } \\
\text { corrections }\end{array}$} & $\mathrm{X}$ & $\begin{array}{l}\text { USE SELF SHIELDING Only, no scattering, or } \\
\text { SELF SHIELD }\end{array}$ & $\begin{array}{l}\text { Only self-shielding is to be included; no single- or } \\
\text { double-scattering (see Section III.F) }\end{array}$ \\
\hline & & $\begin{array}{l}\text { USE SINGLE SCATTERINg plus self shielding, or } \\
\text { SINGLE }\end{array}$ & Include self-shielding plus single-scattering corrections \\
\hline & & $\begin{array}{l}\text { INCLUDE DOUBLE SCATTering corrections, or } \\
\text { DOUBLE, or } \\
\text { USE MULTIPLE SCATTERing plus single scattering }\end{array}$ & $\begin{array}{l}\text { Include self-shielding, single-scattering, and double- } \\
\text { scattering corrections (See Section III.F) }\end{array}$ \\
\hline & & INFINITE SLAB & Single-scattering correction does not include edge-effects \\
\hline & $\mathrm{X}$ & FINITE SLAB & Edge effects corrections are included \\
\hline & $\mathrm{x}$ & MAKE NEW FILE WITH Edge effects & $\begin{array}{l}\text { See Section III.F. This statement is ignored if } \\
\text { "INFINITE SLAB" is specified. }\end{array}$ \\
\hline & & FILE WITH EDGE EFFECts already exists & \\
\hline & & MAKE PLOT FILE OF MUltiple scattering pieces & $\begin{array}{l}\text { Store } \mathrm{Y} 0, \mathrm{Y} 1 \text {, and } \mathrm{Y} 2 \text { in file SAM53.DAT, to be read } \\
\text { by program SAMCMP }\end{array}$ \\
\hline & & $\begin{array}{l}\text { NORMALIZE AS CROSS Section rather than yield, or } \\
\text { CROSS SECTION }\end{array}$ & See Section III.F \\
\hline & $\mathrm{x}$ & $\begin{array}{l}\text { NORMALIZE AS YIELD Rather than cross section, or } \\
\text { YIELD }\end{array}$ & \\
\hline & & NORMALIZE AS (1-E)SIgma & \\
\hline
\end{tabular}


Table VIA.2 (continued)

\begin{tabular}{|c|c|c|c|}
\hline Category & Default & Statements & Notes \\
\hline \multirow{6}{*}{$\begin{array}{l}\text { Angular } \\
\text { distri- } \\
\text { bution } \\
\text { data }\end{array}$} & & USE LABORATORY CROSs sections & For differential elastic scattering; see Section III.E \\
\hline & $\mathrm{X}$ & USE CENTER-OF-MASS cross sections & \\
\hline & & OMIT FINITE SIZE CORrections & \\
\hline & & INCIDENT NEUTRON ATTenuation is included & \\
\hline & & APPROXIMATE SCATTEREd neutron attenuation is wanted & \\
\hline & & SCATTERED NEUTRON ATtenuation is included & \\
\hline
\end{tabular}

$\varpi$
$\square$
$\Xi$
$\Xi$ 
Table VIA.2 (continued)

\begin{tabular}{|c|c|c|c|}
\hline Category & Default & Statements & Notes \\
\hline \multirow[t]{9}{*}{$\begin{array}{l}\text { Special } \\
\text { options }\end{array}$} & & $\begin{array}{l}\text { ENDF/B-VI FILE } 2 \text { IS wanted, or } \\
\text { ENDF }\end{array}$ & $\begin{array}{l}\text { Resonance parameters are to be provided in the format } \\
\text { required for ENDF/B-VI File } 2 \text { (Reich-Moore representation) } \\
\text { is wanted. See Section VI.F for details }\end{array}$ \\
\hline & & $\begin{array}{l}\text { RECONSTRUCT CROSS SEction from resonance } \\
\text { parameters }\end{array}$ & $\begin{array}{l}\text { SAMMY will automatically choose an appropriate grid and } \\
\text { evaluate total, elastic, capture, and fission cross sections on } \\
\text { that grid, using NJOY method. See Section V.G }\end{array}$ \\
\hline & & ARTIFICIAL ENERGY grid is needed & $\begin{array}{l}\text { SAMMY will automatically choose an appropriate grid and } \\
\text { evaluate, using SAMMY method. See Section V.G }\end{array}$ \\
\hline & $\mathrm{X}$ & DO NOT AVERAGE OVER ENERGY RANGES & \\
\hline & & AVERAGE OVER ENERGY RANGES & $\begin{array}{l}\text { Produce energy-averaged experimental data and theoretical } \\
\text { values, using output parameters from an earlier SAMMY } \\
\text { analysis. See Section V.C for details }\end{array}$ \\
\hline & & MAKE NO CORRECTIONS to theoretical values & $\begin{array}{l}\text { Do not perform Doppler or resolution broadening corrections, } \\
\text { nor include normalizations or backgrounds, before averaging }\end{array}$ \\
\hline & & $\begin{array}{l}\text { MAXWELLIAN AVERAGED capture cross sections } \\
\text { are wanted, or } \\
\text { STELLAR AVERAGED Capture cross sections are } \\
\text { wanted }\end{array}$ & $\begin{array}{l}\text { Generate stellar averaged capture cross section; see Section } \\
\text { V.F }\end{array}$ \\
\hline & & $\begin{array}{l}\text { CALCULATE MAXWELLIAN averages after } \\
\text { reconstructing cross sections }\end{array}$ & \\
\hline & & ADD CROSS SECTIONs from endf/b file 3 & For use in generating Maxwellian averages; see Table VID.5 \\
\hline
\end{tabular}


Table VIA.2 (continued)

\begin{tabular}{|c|c|c|c|}
\hline Category & Default & Statements & Notes \\
\hline \multirow{6}{*}{$\begin{array}{l}\text { Special } \\
\text { options, } \\
\text { cont. }\end{array}$} & \multirow[t]{2}{*}{$\mathrm{X}$} & \multicolumn{2}{|l|}{ DO NOT PERFORM SUMMAry analysis } \\
\hline & & PERFORM SUMMARY ANALysis & $\begin{array}{l}\text { Evaluate and print the summed strength function and } \\
\text { the corresponding covariance matrix. Note: SAMMY } \\
\text { stops upon completion of this task }\end{array}$ \\
\hline & & GENERATE PARTIAL DERivatives only & $\begin{array}{l}\text { SAMMY will assume all resonance parameters, and } \\
\text { only resonance parameters, are to be varied; that } \\
\text { Bayes' equations are not to be solved; and that the } \\
\text { partial derivatives of the theory with respect to those } \\
\text { parameters is to be output in file SAMMY.PDS }\end{array}$ \\
\hline & & \multicolumn{2}{|l|}{ GENERATE SPIN GROUP cross sections } \\
\hline & & \multicolumn{2}{|l|}{ REFORMULATE DATA FOR implicit data covariances } \\
\hline & & $\begin{array}{l}\text { FITACS, or } \\
\text { UNRESOLVED RESONANCE region, or } \\
\text { FRITZ FROEHNERS FITAcs }\end{array}$ & $\begin{array}{l}\text { Use the SAMMY version of Fritz Froehner's code } \\
\text { FITACS for analysis of the unresolved resonance } \\
\text { region }\end{array}$ \\
\hline
\end{tabular}

COMPARE EXPERIMENT To theory and put results into

binary file SAM53.DAT 
Table VIA.2 (continued)

\begin{tabular}{lcl}
\hline Category & Def. & \multicolumn{1}{c}{ Statements } \\
\hline $\begin{array}{l}\text { Plot file } \\
\text { control }\end{array}$ & $\mathrm{X}$ & $\begin{array}{l}\text { DO NOT GENERATE PLOT file } \\
\text { automatically }\end{array}$ \\
& & GENERATE ODF FILE AUtomatically; or \\
& & GENERATE PLOT FILE Automatically
\end{tabular}

The output ODF file is described fully elsewhere (Table VIIC.1). To complete all sections of this file requires (1) initialization; (2) running SAMMY without solving Bayes' equations to obtain theoretical values determined by the input parameters; (3) solving Bayes' equations to obtain updated parameter values; and (4) obtaining theoretical values determined by the updated parameters. That is, the ODF file requires an initialization plus three complete passes through SAMMY. The option to GENERATE ODF (or PLOT) FILE AUtomatically does all this busy-work for you. If you do not need plots, do not use this option

Note to users who do not have ODF plotting package: SAMMY is now able to produce a binary file containing the information that would normally be included in the ODF file. It is strongly recommended that users without the ODF option extract the information from this binary file rather than from the LPT file. A FORTRAN file mbin.f is available as a guide for reading the binary file (whose name is also SAMMY.ODF); comment cards in the FORTRAN file explain how to link SAMMY to produce the binary rather than the ODF file

ODF FILE IS WANTED--XXXXXX.XXX, ZEROth order guess

These statements are all ignored if you choose to GENERATE ODF FILE automatically. To use these options, replace XXXXXX.XXX (columns 21-30) with the name of your ODF file. Be sure that the file already contains energies

ODF FILE IS WANTED--XXXXXX.XXX, and data (Sections 1,2,3, and possibly 6 and 7; see Table VIIC.1) FINAl guess

PLOT UNBROADENED Cross sections

Generate file SAMMY.UNB which contains the auxiliary energy grid in Section 1 and the unbroadened theoretical values in Sections 2 etc. SAMMY also generates an ASCII file samunb.dat with the same information in CSISRS format 
Table VIA.2 (continued)

\begin{tabular}{lllc}
\hline Category & Def. & \multicolumn{1}{c}{ Statements } & Notes \\
\hline $\begin{array}{l}\text { Plot file } \\
\text { control, }\end{array}$ & $\mathrm{X}$ & $\begin{array}{l}\text { DO NOT INCLUDE THEORetical } \\
\text { uncertainties in plot file }\end{array}$ & The covariance matrix element connecting theory point $T_{i}$ with point $T_{j}$ is \\
cont. & & $\begin{array}{l}\sum_{k, n} \frac{\partial T_{l}}{\partial u_{k}} M_{k n} \frac{\partial T_{j}}{\partial u_{n}}, \\
\text { INCLUDE THEORETICAL }\end{array}$ &
\end{tabular}

uncertainties in plot file

where $M_{k n}$ is the covariance matrix element connecting parameter $u_{k}$ with parameter $u_{n}$. The theoretical uncertainty on theory $T_{i}$ is the square root of the diagonal element; that is,

$$
\Delta T_{t}^{2}=\sum_{k, n} \frac{\partial T_{i}}{\partial u_{k}} M_{k n} \frac{\partial T_{i}}{\partial u_{n}}
$$

The values $\Delta T_{i}$ are reported in Sections 10 and 11 (or $6 \& 7$ ) of the ODF file 


\section{VI.B THE PARameter FILE}

The PARameter file contains initial values for all those parameters that are to be varied, as well as others which are held fixed. In addition, this file may contain a priori uncertainties on the varied parameters and correlations among those uncertainties. Details about the PAR file are given in Table VIB.1.

Card Set 1 contains resonance parameters, ending in a blank card. Card Set 2 contains a single number, called FUDGE, which is the "fudge factor" by which a parameter is multiplied to give the initial uncertainty for that parameter, unless that uncertainty is specified elsewhere.

Only Card Set 1 is required to be in the file; if any of Card Sets 3 through "Last" are present, Card Set 2 must also be present.

Card Set 3 gives values for parameters of the external R-function (see Section III.A.1.a).

Card Set 4 gives values for some broadening (and other) parameters.

Card Set 5 gives values of "unused" parameters, that is, of those data-reduction parameters that are not directly affected by the data set to be analyzed but that are coupled via the covariance matrix to other parameters that are directly affected. An example of such a parameter would be the thickness of a thin sample, for which the data have already been analyzed via SAMMY, while the current data set is from a measurement with a thick sample. The auxiliary code SAMAMR must be used between the two SAMMY runs to ensure that the correct thickness is used with the appropriate data set (see Section IX).

Card Set 6 gives values for normalization and background parameters, as described in Eqs. (VE1.1) and (VE1.2) of Section V.E.1.

Card Set 7 contains values for the two radii (as used for potential scattering and for penetrability and shift factor). See Section V.D.

Card Set 8 gives names and values for data reduction parameters, as described in Section V.E.2.

Card Set 9 gives values of parameters for the realistic resolution function (ORR) parameters, as described in Section IV.F.

Card Set 10 contains isotopic mass and abundance values, as described in Section V.D.

Card Set 11 contains values for miscellaneous parameters, described in various locations throughout this manual.

Card Set 12 provides parameter values for paramagnetic cross sections; see Section V.H. 
Card Set 13 contains values for parameters of the background functions described in the latter half of Section V.E.1.

Card Set 14 gives parameters of the RPI resolution function, Section IV.G.

Card Set 15 provides values for $l$ - and isotope-dependent detector efficiencies, Section V.K.

The last Card Set defines the prior covariance matrix for the parameters. Three alternative methods are given (the presence of the third eliminates the possibility of any others being there, but the first and second may be interchanged at will so long as each occurs at most once in a PARameter file). A fourth alternative is available for resonance energies only (see columns $68-80$, second alternative, in Card Set 1). A fifth is to omit this card set entirely, in which case default uncertainties are used for every parameter.

Note that each card set in the PAR file (except for Card Sets 1 and 2) begins with an alphanumeric description of what follows. Note also that each card set (except Card Set 2) terminates with a blank card. A blank card at the very end of the file may be omitted, but all others must be present. 
Table VIB.1. Format of the PARameter file

Note: All integer formats (e.g., I2, 15) require that the numbers be in the right-most columns. Real numbers (e.g.,F10 or F10.1 formats) require that a decimal point be placed somewhere within the column range. When the format is specified as $F$ or $E$, either may be used; when using the $E$ format

(e.g., 1.544E+05), note that the exponent need to be in right-most columns.

\begin{tabular}{|c|c|c|c|c|c|c|c|}
\hline $\begin{array}{l}\text { Card Set, how } \\
\text { many cards in } \\
\text { the set }\end{array}$ & $\begin{array}{l}\text { Which } \\
\text { card is } \\
\text { this? }\end{array}$ & $\begin{array}{l}\text { Col- } \\
\text { umn }\end{array}$ & $\begin{array}{l}\text { Variable } \\
\text { Name }\end{array}$ & Format & Meaning (units) & Values & Notes \\
\hline \multirow{4}{*}{$\begin{array}{l}1 \text {, as many as } \\
\text { are needed } \\
\text { (number of } \\
\text { resonances, } \\
\text { plus one) }\end{array}$} & \multirow[t]{11}{*}{$\begin{array}{l}\text { Any } \\
\text { except } \\
\text { the last }\end{array}$} & $1-11$ & $\begin{array}{l}\text { ERES or } \\
E_{\lambda}\end{array}$ & F11 & Resonance energy $E_{\lambda}(e V)$ & & \multirow{10}{*}{$\begin{array}{l}\text { If any particle width } \Gamma \text { is } \\
\text { negative, SAMMY uses }|\Gamma| \text { for } \\
\text { the width and set the associated } \\
\text { amplitude } \gamma \text { to be negative. } \\
\text { That is, SAMMY uses } \\
\gamma=-\alpha \sqrt{|\Gamma|} \text {, where } \alpha \text { is the } \\
\text { appropriate factor (see Section } \\
\text { III.A.1.b) }\end{array}$} \\
\hline & & $12-22$ & $\mathrm{r}_{\gamma}$ & F11 & Capture width (milli-eV) & & \\
\hline & & $23-33$ & $\Gamma_{\mathrm{cl}}$ & F11 & $\begin{array}{l}\text { Particle width for channel } 1 \\
\text { (milli-eV) }\end{array}$ & & \\
\hline & & $34-44$ & $\Gamma_{c 2}$ & F11 & $\begin{array}{l}\text { Particle width for channel } 2 \\
\text { (milli-eV) }\end{array}$ & & \\
\hline \multirow{7}{*}{ - } & & $45-55$ & $\Gamma_{c 3}$ & F11 & $\begin{array}{l}\text { Particle width for channel } 3 \\
\text { (milli-eV) }\end{array}$ & & \\
\hline & & $56-57$ & $I_{S_{E}}$ & 12 & Vary $\mathrm{E}_{\mathrm{R}}$ ? & $0=$ no, $1=$ yes & \\
\hline & & $58-59$ & $\mathrm{IS}_{\gamma}$ & 12 & Vary $\Gamma \gamma$ ? & $0=$ no, $1=$ yes & \\
\hline & & $60-61$ & $\mathrm{IS}_{\mathrm{cl}}$ & 12 & Vary $\Gamma_{\mathrm{cl}}$ ? & $0=$ no, $1=$ yes & \\
\hline & & $62-63$ & $\mathbf{I} \mathbf{S}_{\mathrm{c} 2}$ & 12 & Vary $\Gamma_{\mathrm{c} 2}$ ? & $0=$ no, $1=$ yes & \\
\hline & & $64-65$ & $\mathrm{IS}_{\mathrm{c} 3}$ & 12 & Vary $\Gamma_{c 3}$ ? & $0=$ no, $1=$ yes & \\
\hline & & $66-67$ & IGROUP & 12 & $\begin{array}{l}\text { Quantum numbers for this } \\
\text { resonance are those of group } \\
\text { number IGROUP (see Card } \\
\text { Set } 10 \text { in Table VIA.1) }\end{array}$ & & $\begin{array}{l}\text { If IGROUP is negative or } \\
\text { greater than } 50 \text {, this resonance } \\
\text { will be omitted from the } \\
\text { calculation }\end{array}$ \\
\hline
\end{tabular}

68-80 $\quad \mathrm{X} \quad \mathrm{F} 13$

For many cases, this variable is not used (columns may be left blank). However, there are three possible uses for this variable: 
Table VIB.1 (continued)

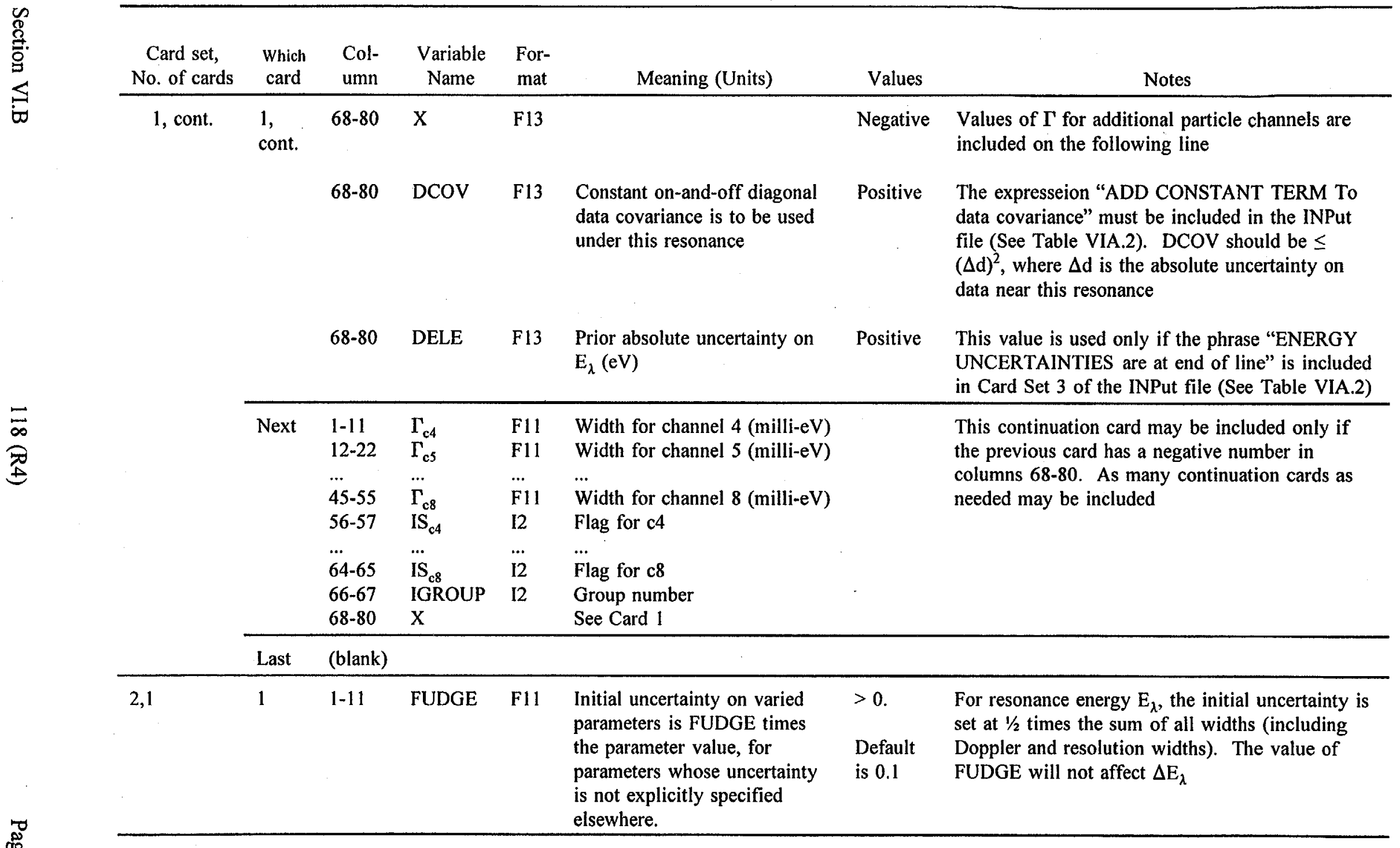




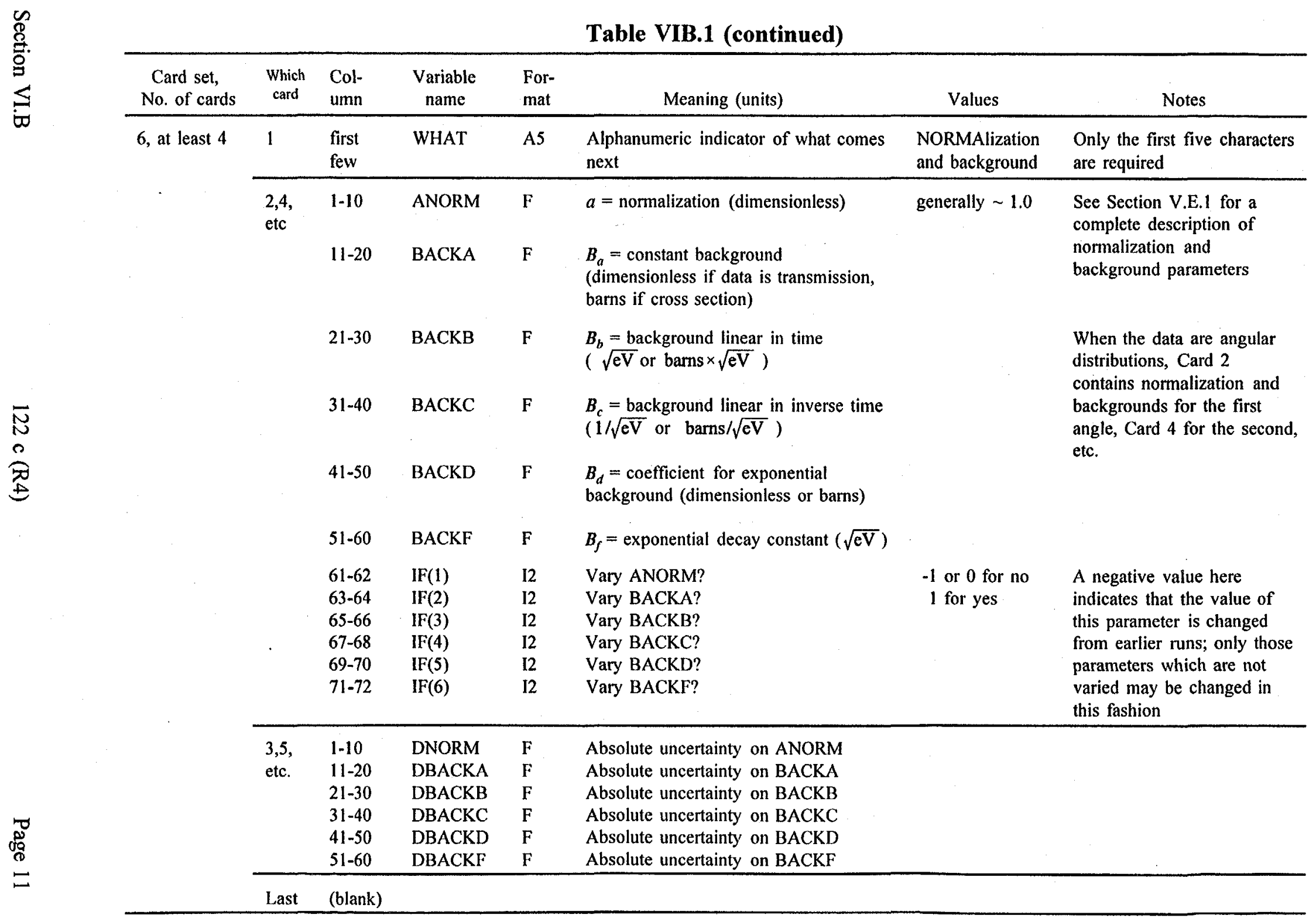


Table VIB.1 (continued)

\begin{tabular}{|c|c|c|c|c|c|c|c|}
\hline $\begin{array}{l}\text { Card set, } \\
\text { No. of cards }\end{array}$ & $\begin{array}{l}\text { Which } \\
\text { card }\end{array}$ & Column & $\begin{array}{l}\text { Variable } \\
\text { name }\end{array}$ & $\begin{array}{l}\text { For- } \\
\text { mat }\end{array}$ & Meaning (units) & Values & Notes \\
\hline \multirow[t]{6}{*}{7 , at least 3} & 1 & $\begin{array}{l}\text { First } \\
\text { few }\end{array}$ & WHAT & A5 & $\begin{array}{l}\text { Alphanumeric indicator } \\
\text { of what comes next }\end{array}$ & $\begin{array}{l}\text { RADIUs parameters come } \\
\text { next }\end{array}$ & $\begin{array}{l}\text { Only the first five characters are } \\
\text { required }\end{array}$ \\
\hline & 2 & $1-10$ & PAREFF & F10.1 & $\begin{array}{l}\text { Radius }(F) \text { to be used } \\
\text { for potential scattering }\end{array}$ & $>0.0$ & \\
\hline & & $11-20$ & PARTRU & $\mathrm{F} 10.1$ & $\begin{array}{l}\text { Radius }(F) \text { to be used } \\
\text { for penetrabilities and } \\
\text { shifts, } \\
\text { or (if negative), } \\
\text { Negative of the ratio of } \\
\text { the mass of the sample } \\
\text { nucleus to that of a } \\
\text { neutron }\end{array}$ & $\begin{array}{l}\text { (a) Greater than zero } \\
\text { (b) Negative }\end{array}$ & $\begin{array}{l}\text { Use value given } \\
\text { The (absolute value) of the } \\
\text { number given is the ratio of mass } \\
\text { of the sample nucleus to that of a } \\
\text { neutron. SAMMY then } \\
\text { calculates PARTRU using } 1.23 \\
\text { (AWRI) }+0.8 \text { which is the } \\
\text { ENDF formula, converted to } \\
\text { FERMI }\end{array}$ \\
\hline & & & & & & (c) 0.0 & $\begin{array}{l}\text { SAMMY uses the value of CRFN } \\
\text { from INPut file or from Card Set } \\
4 \text { of PARameter file for } \\
\text { PARTRU }\end{array}$ \\
\hline & & 21 & ICHAN & I1 & Channel flag & $\begin{array}{l}0 \text { if applies to every channel } \\
1 \text { if applies to certain } \\
\text { specified channels only }\end{array}$ & \\
\hline & & 22 & IFLEFF & I1 & $\begin{array}{l}\text { Flag to indicate whether } \\
\text { PAREFF is to be varied }\end{array}$ & $\begin{array}{l}0 \text { if not varied } \\
>0 \text { if varied }\end{array}$ & \\
\hline
\end{tabular}


Table VIB.1 (continued)

\begin{tabular}{|c|c|c|c|c|c|c|c|}
\hline $\begin{array}{l}\text { Card set, } \\
\text { No. cards }\end{array}$ & $\begin{array}{l}\text { Which } \\
\text { card }\end{array}$ & $\begin{array}{l}\text { Col- } \\
\text { umn }\end{array}$ & $\begin{array}{l}\text { Variable } \\
\text { name }\end{array}$ & $\begin{array}{l}\text { For- } \\
\text { mat }\end{array}$ & Meaning (units) & Values & Notes \\
\hline \multirow[t]{12}{*}{$\begin{array}{l}7 \text { cont., } \\
\text { at least } 3\end{array}$} & $\begin{array}{l}2 \\
\text { cont. }\end{array}$ & $23-24$ & IFLTRU & 12 & $\begin{array}{l}\text { flag to indicate } \\
\text { how PARTRU } \\
\text { is to be treated }\end{array}$ & $\begin{array}{l}=0 \\
>0 \\
\text { or }<0\end{array}$ & $\begin{array}{l}0 \text { if not varied; }>0 \text { if varied independently of PAREFF; } \\
<0 \text { if the two radii are treated as identical and } 100 \% \text { correlated }\end{array}$ \\
\hline & & $\begin{array}{l}25-26 \\
27-28\end{array}$ & $\begin{array}{l}\text { IG1 } \\
\text { IG2 }\end{array}$ & $\begin{array}{l}12 \\
12\end{array}$ & $\begin{array}{l}\text { the number of a } \\
\text { spin group }\end{array}$ & & $\begin{array}{l}\text { As many spin groups as needed are given in columns } 25-80 \text { ( } 2 \\
\text { columns per group) }\end{array}$ \\
\hline & & $29-30$ & IG3 & 12 & using these & & When there are more than 99 spin groups, all I formats in this \\
\hline & & $\cdots$ & $\cdots$ & $\cdots$ & radii & & $\begin{array}{l}\text { card are changed from } 12 \text { to I5. A maximum of } 10 \text { spin group } \\
\text { numbers can be specified on this card }\end{array}$ \\
\hline & & & IX & 12 & $\begin{array}{l}0 \text { denoting end } \\
\text { of spin group. } \\
\text { list }\end{array}$ & & $\begin{array}{l}\text { When ICHAN }=1 \text {, specify channel numbers by inserting a zero } \\
(I X=0) \text { after the string of IG's, and follow with the string of } \\
\text { channel numbers }\end{array}$ \\
\hline & & & & 12 & & 12 & To specify more than 28 (or 10) spin groups (or spin groups + \\
\hline & & & $1 \mathrm{C} 2$ & 12 & channel using & & this card. Continue specifying spin groups on subsequent cards, \\
\hline & & & $\cdots$ & $\cdots$ & these radii & . & $\begin{array}{l}\text { in } 1615 \text { (not } 12 \text { ) format, ending with a negative number whenever } \\
\text { another card follows }\end{array}$ \\
\hline & & & & & & & $\begin{array}{l}\text { Note that unspecified channels and/or spin groups will be } \\
\text { assigned to the first radius-pair in this Card Set }\end{array}$ \\
\hline & 3 & & IG's & $16 \mathrm{I} 5$ & & & $\begin{array}{l}\text { When more than } 28 \text { (or 10) spin group plus channel numbers are } \\
\text { needed in the previous card, insert a negative number in columns } \\
79-80 \text {. Include this card, with group (channel) numbers in } 15 \text { (not } \\
\text { 12) format }\end{array}$ \\
\hline & $4,5, \ldots$ & & & & & & (Just like card \#3) \\
\hline & Last & & (blank) & & & & \\
\hline
\end{tabular}


Table VIB.1 (continued)

\begin{tabular}{|c|c|c|c|c|c|c|c|}
\hline $\begin{array}{c}\text { Card set, } \\
\text { No. of cards }\end{array}$ & $\begin{array}{l}\text { Which } \\
\text { card }\end{array}$ & $\begin{array}{l}\text { Col- } \\
\text { umn }\end{array}$ & $\begin{array}{c}\text { Variable } \\
\text { Name }\end{array}$ & $\begin{array}{l}\text { For- } \\
\text { mat }\end{array}$ & Meaning (units) & Values & Notes \\
\hline \multirow[t]{7}{*}{$\begin{array}{l}8, \\
\text { at least } 3\end{array}$} & 1 & $\begin{array}{l}\text { First } \\
\text { few }\end{array}$ & WHAT & A5 & $\begin{array}{l}\text { Alphanumeric indicator } \\
\text { of what comes next }\end{array}$ & $\begin{array}{l}\text { DATA reduction } \\
\text { parameters are next }\end{array}$ & $\begin{array}{l}\text { Only the first five characters } \\
\text { are required }\end{array}$ \\
\hline & $2,3, \ldots$ & 1.5 & NAMDTP & A5 & $\begin{array}{l}\text { Alphanumeric name for } \\
\text { this data reduction } \\
\text { parameter }\end{array}$ & & $\begin{array}{l}\text { See Section V.E. } 2 \text { for a } \\
\text { discussion of data-reduction } \\
\text { parameters }\end{array}$ \\
\hline & & 7 & IFLDTP & 11 & $\begin{array}{l}\text { Vary the value of this } \\
\text { parameter? }\end{array}$ & $\begin{array}{l}0 \text { if not varied } \\
1 \text { if varied }\end{array}$ & \\
\hline & & $11-20$ & PARDTP & $\mathrm{F}$ & $\begin{array}{l}\text { Current value of } \\
\text { parameter }\end{array}$ & & \\
\hline & & $21-30$ & UNCDTP & F & $\begin{array}{l}\text { absolute uncertainty } \\
\text { (standard deviation) for } \\
\text { this parameter }\end{array}$ & & \\
\hline & & $31-40$ & PTILDE & F & $\begin{array}{l}\text { value of parameter used } \\
\text { to generate partial } \\
\text { derivatives }\end{array}$ & . & $\begin{array}{l}\text { If zero, SAMMY assumes } \\
\text { PTILDE = PARDTP }\end{array}$ \\
\hline & Last & (blank) & & & & & \\
\hline
\end{tabular}


Table VIB.1 (continued)

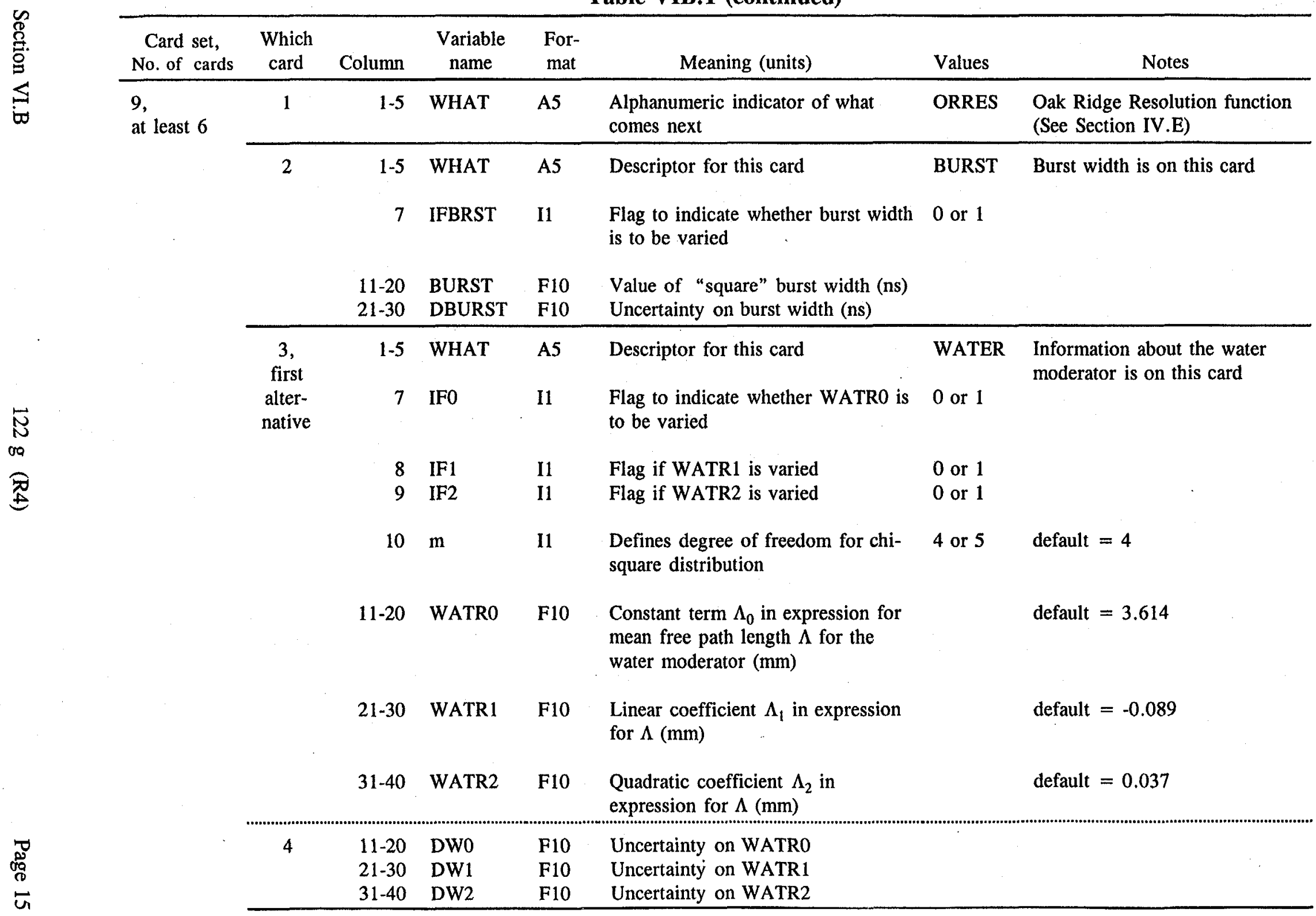


Table VIB.1 (continued)

\begin{tabular}{|c|c|c|c|c|c|c|c|}
\hline $\begin{array}{l}\text { Card Set, } \\
\text { No. of cards }\end{array}$ & $\begin{array}{l}\text { Which } \\
\text { card }\end{array}$ & Column & $\begin{array}{l}\text { Variable } \\
\text { name }\end{array}$ & Format & Meaning (units) & Values & Notes \\
\hline \multirow[t]{8}{*}{$\begin{array}{l}9 \text { cont., } \\
\text { at least } \\
\text { six }\end{array}$} & $\begin{array}{l}3, \\
\text { second } \\
\text { alterna- } \\
\text { tive }\end{array}$ & 7 & $\begin{array}{l}\text { WHAT } \\
\text { IFTANT }\end{array}$ & A5 & $\begin{array}{l}\text { Descriptor for these cards } \\
\text { Flag }\end{array}$ & TANTA & $\begin{array}{l}\text { Tantalum target is used instead } \\
\text { of water moderator; see Section } \\
\text { IV.E for precise meaning of } \\
\text { variables }\end{array}$ \\
\hline & & $11-20$ & TANTA & F10 & $\in^{\prime}(1 / \mathrm{mm})$ & & \\
\hline & & $21-30$ & DTANTA & F10 & Uncertainty on this parameter & & \\
\hline & 4 & $\begin{array}{r}7 \\
8 \\
9 \\
10\end{array}$ & $\begin{array}{l}\text { IFX1 } \\
\text { IFX2 } \\
\text { IFX3 } \\
\text { IFX0 }\end{array}$ & $\begin{array}{l}\text { I1 } \\
\text { I1 } \\
\text { I1 } \\
\text { I1 }\end{array}$ & $\begin{array}{l}\text { Flag } \\
\text { Flag } \\
\text { Flag } \\
\text { Flag }\end{array}$ & & $\begin{array}{l}\text { Omit this card if water } \\
\text { moderator is used }\end{array}$ \\
\hline & & $\begin{array}{l}11-20 \\
21-30 \\
31-40 \\
41-50\end{array}$ & $\begin{array}{l}X 1 \\
X 2 \\
X 3 \\
X 0\end{array}$ & $\begin{array}{l}\text { F10 } \\
\text { F10 } \\
\text { F10 } \\
\text { F10 }\end{array}$ & $\begin{array}{l}x_{1}^{\prime}(\mathrm{mm}) \\
x_{2}^{\prime}(\mathrm{mm}) \\
x_{3}^{\prime}(\mathrm{mm}) \\
x_{3}^{\prime}(\mathrm{mm})\end{array}$ & & \\
\hline & 5 & $\begin{array}{l}11-20 \\
21-30 \\
31-40 \\
41-50\end{array}$ & $\begin{array}{l}\text { DX1 } \\
\text { DX2 } \\
\text { DX3 } \\
\text { DX0 }\end{array}$ & $\begin{array}{l}\text { F10 } \\
\text { F10 } \\
\text { F10 } \\
\text { F10 }\end{array}$ & $\begin{array}{l}\text { Uncertainty on } x_{1}^{\prime}(\mathrm{mm}) \\
\text { Uncertainty on } x_{2}^{\prime}(\mathrm{mm}) \\
\text { Uncertainty on } x_{3}^{\prime}(\mathrm{mm}) \\
\text { Uncertainty on } x_{0}^{\prime}(\mathrm{mm})\end{array}$ & & $\begin{array}{l}\text { Omit this card if water } \\
\text { moderator is used }\end{array}$ \\
\hline & 6 & $\begin{array}{r}7 \\
8 \\
11-20 \\
21-30\end{array}$ & $\begin{array}{l}\text { IFWWW } \\
\text { IFALPHA } \\
\text { WWW } \\
\text { ALPHA }\end{array}$ & $\begin{array}{l}\text { I1 } \\
\text { I1 } \\
\text { F10 } \\
\text { F10 }\end{array}$ & $\begin{array}{l}\text { Flag for } \beta^{\prime} \\
\text { Flag for } \alpha^{\prime} \\
\beta^{\prime}(1 / \mathrm{mm}) \\
\alpha^{\prime} \text { (dimensionless) }\end{array}$ & & $\begin{array}{l}\text { Omit this card if water } \\
\text { moderator is used }\end{array}$ \\
\hline & 7 & $\begin{array}{l}11-20 \\
21-30\end{array}$ & $\begin{array}{l}\text { DWWW } \\
\text { DALPHA }\end{array}$ & $\begin{array}{l}\text { F10 } \\
\text { F10 }\end{array}$ & $\begin{array}{l}\text { Uncertainty on } \beta^{\prime}(1 / \mathrm{mm}) \\
\text { Uncertainty on } \alpha^{\prime} \\
\text { (dimensionless) }\end{array}$ & & $\begin{array}{l}\text { Omit this card if water } \\
\text { moderator is used }\end{array}$ \\
\hline
\end{tabular}


Table VIB.1 (continued)

它

\begin{tabular}{|c|c|c|c|c|c|c|c|}
\hline $\begin{array}{l}\text { Card Set, } \\
\text { No. of cards }\end{array}$ & $\begin{array}{l}\text { Which } \\
\text { card }\end{array}$ & $\begin{array}{l}\text { Col- } \\
\text { umn }\end{array}$ & $\begin{array}{l}\text { Variable } \\
\text { name }\end{array}$ & $\begin{array}{l}\text { For- } \\
\text { mat }\end{array}$ & Meaning (units) & Values & Notes \\
\hline \multirow[t]{18}{*}{$\begin{array}{l}9 \text { cont., at } \\
\text { least } 6\end{array}$} & $\begin{array}{l}\text { 8, } \\
\text { first }\end{array}$ & $1-5$ & WHAT & A5 & Descriptor for these cards & LITHI & $\begin{array}{l}\text { Lithium-glass detector is } \\
\text { used }\end{array}$ \\
\hline & altern- & 7 & IFD & I1 & Flag for $d$ & & \\
\hline & ative & 8 & IFF & I1 & Flag for $f$ & & \\
\hline & & 9 & IFG & I1 & Flag for $g$ & & \\
\hline & & $11-20$ & D & F10 & $d(\mathrm{nsec})$ & & \\
\hline & & $21-30$ & F & F10 & $f(1 / \mathrm{nsec})$ & & \\
\hline & & $31-40$ & G & F10 & $g$ (dimensionless) & & \\
\hline & 9 & $11-20$ & $\mathrm{DD}$ & F10 & Uncertainty on $d$ (nsec) & & This card is used only \\
\hline & & $21-30$ & DF & F10 & Uncertainty on $f(1 / \mathrm{nsec})$ & & for Lithium-glass \\
\hline & & $31-40$ & DG & F10 & Uuncertainty on $g$ (dimensionless) & & detector \\
\hline & $\begin{array}{l}\text { 8, } \\
\text { second }\end{array}$ & $\begin{array}{r}1-5 \\
7\end{array}$ & $\begin{array}{l}\text { WHAT } \\
\text { IFDEL }\end{array}$ & $\begin{array}{l}\text { A5 } \\
\text { Il }\end{array}$ & $\begin{array}{l}\text { Descriptor for these cards } \\
\text { Flag for } \delta\end{array}$ & $\begin{array}{l}\text { NE110 } \\
0 \text { or } 1\end{array}$ & NE1 10 detector is used \\
\hline & native & $8-10$ & NMDETS & 13 & $\begin{array}{l}\text { Number of cross-section values and energies to } \\
\text { be included (i.e., number of card \#9's to be } \\
\text { read) }\end{array}$ & & $\begin{array}{l}\text { If zero, default values } \\
\text { are used; default material } \\
\text { is } \mathrm{CH}_{1.104}\end{array}$ \\
\hline & & $11-20$ & DELTA & F10 & $\delta(\mathrm{mm})$ & & \\
\hline & & $21-30$ & DDELTA & F10 & Uncertainty on $\delta(\mathrm{mm})$ & & default is 0.0047 \\
\hline & & $31-40$ & DENSTY & F10 & $\lambda$ (number of molecules per mm.b of detector) & & \\
\hline & $9, \ldots$ & $11-20$ & ENDETS(i) & F10 & Maximum energy for this value of SIGDTS (eV) & & These cards occur only \\
\hline & & $21-30$ & SIGDTS(i) & F10 & Total cross section for detector material (barns) & & $\begin{array}{l}\text { with NE1 } 10 \text { detector, if } \\
\text { NMDETS }>0\end{array}$ \\
\hline & & & & & & & $\begin{array}{l}\text { Repeat this card a total } \\
\text { of NMDETS times }\end{array}$ \\
\hline
\end{tabular}




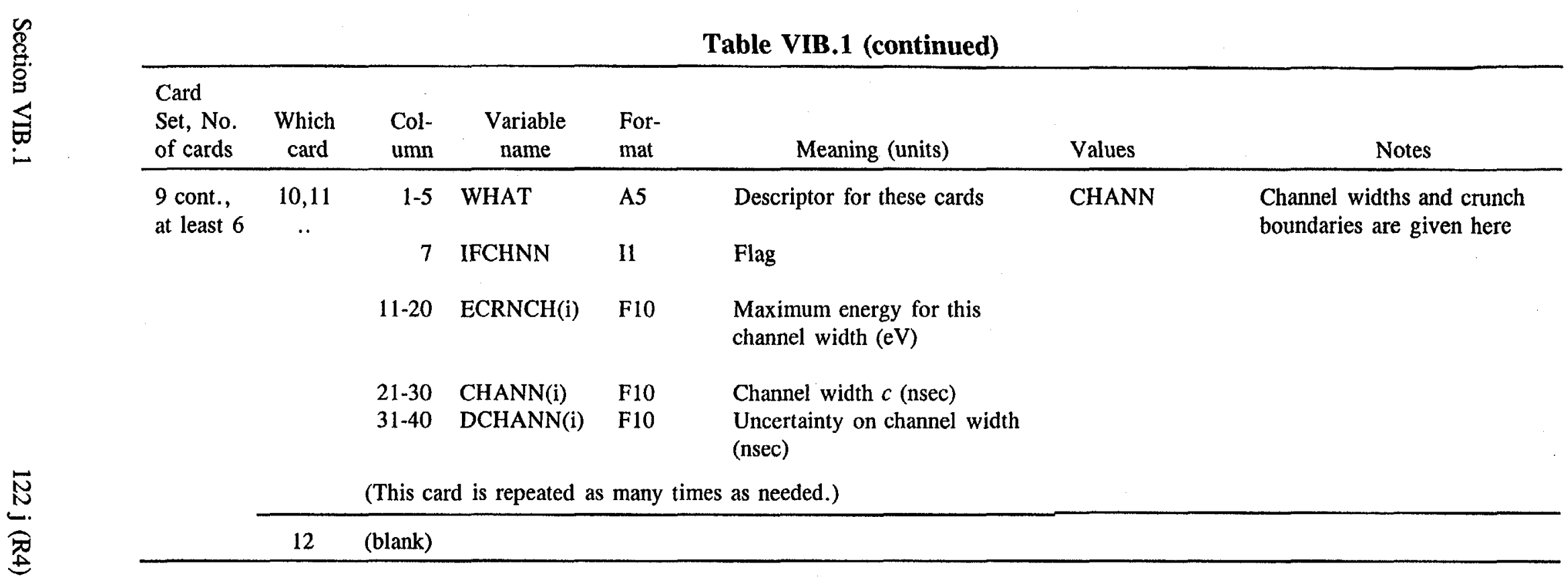


Table VIB.1 (continued)

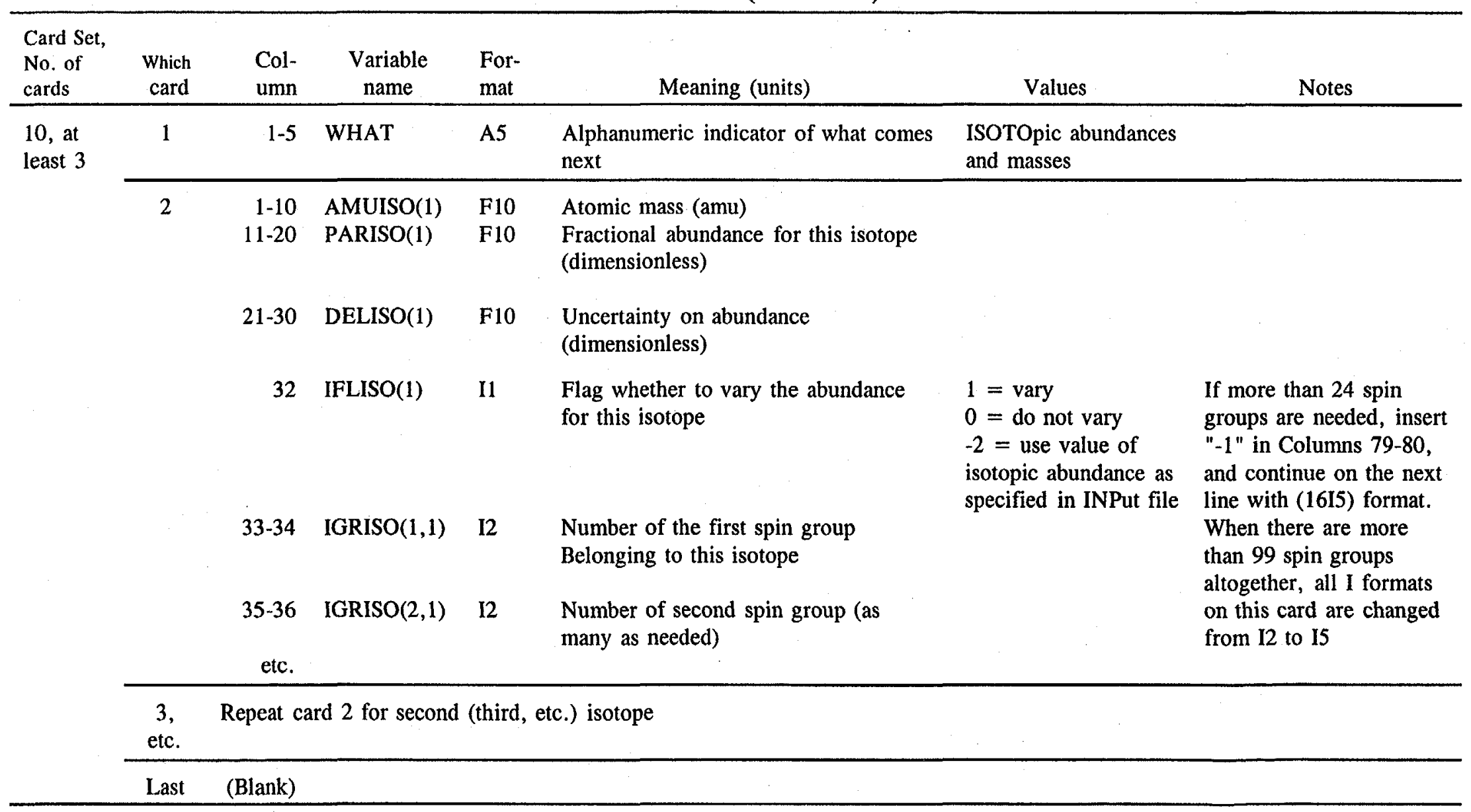


Table VIB.1 (continued)

\begin{tabular}{|c|c|c|c|c|c|c|c|}
\hline $\begin{array}{l}\text { Card Set, } \\
\text { Number }\end{array}$ & $\begin{array}{l}\text { Which } \\
\text { card }\end{array}$ & $\begin{array}{l}\text { Col- } \\
\text { umn }\end{array}$ & $\begin{array}{l}\text { Variable } \\
\text { Name }\end{array}$ & $\begin{array}{l}\text { For- } \\
\text { mat }\end{array}$ & Meaning (Units) & Values & Notes \\
\hline \multirow[t]{12}{*}{$\begin{array}{l}11 \text {, at } \\
\text { least } \\
\text { three }\end{array}$} & 1 & $1-5$ & WHAT & A5 & $\begin{array}{l}\text { Alphanumeric indicator of what } \\
\text { comes next }\end{array}$ & $\begin{array}{l}\text { MISCEllaneous } \\
\text { parameters } \\
\text { follow }\end{array}$ & \\
\hline & 2 & $1-5$ & WHAT & A5 & Descriptor for this card & DELTA & $\begin{array}{l}\Delta L=E \Delta L_{1}+\Delta L_{0} \text { is used } \\
\text { instead of DELTAL from }\end{array}$ \\
\hline & & 7 & IFLAG1 & I1 & $\begin{array}{l}\text { Flag to indicate whether parameter } \\
\Delta L_{1} \text { is to be varied }\end{array}$ & 0 or 1 & $\begin{array}{l}\text { Card Set } 4 \text { of this file, or } \\
\text { instead of DELTAL from } \\
\text { Card Set } 5 \text { of the INPut file }\end{array}$ \\
\hline & & 9 & IFLAG0 & II & $\begin{array}{l}\text { Flag to indicate whether parameter } \\
\Delta L_{0} \text { is to be varied }\end{array}$ & 0 or 1 & \\
\hline & & $11-20$ & DELL11 & F & $\begin{array}{l}\text { Coefficient of } E \text { in formula } \\
\Delta L=E \Delta L_{1}+\Delta L_{0}(\mathrm{~m} / \mathrm{eV})\end{array}$ & & \\
\hline & & $21-30$ & D1 & $\mathrm{F}$ & Uncertainty on $\Delta L_{1}(\mathrm{~m} / \mathrm{eV})$ & & \\
\hline & & $31-40$ & DELLOO & F & Constant term $\Delta L_{0}(\mathrm{~m})$ & & \\
\hline & & $41-50$ & D0 & $\mathrm{F}$ & Uncertainty on $\Delta L_{0}(\mathrm{~m})$ & & $\begin{array}{l}\text { This card may be omitted if } \\
\text { not needed }\end{array}$ \\
\hline & 3 & $1-5$ & WHAT & A5 & Descriptor for this card & ETA & $\begin{array}{l}\text { When the type of cross section } \\
\text { is ETA (see Card Set } 8 \text { of the }\end{array}$ \\
\hline & & 7 & IFLAGN & I1 & $\begin{array}{l}\text { Flag to indicate whether parameter } \\
\text { NU is to be varied }\end{array}$ & 0 or 1 & INput file), $\nu$ is given by NU \\
\hline & & $11-20$ & NU & F & $\begin{array}{l}\text { Normalization coefficient } \\
\text { NU (dimensionless) as in } \\
\text { ETA }=\mathrm{NU} \times(\text { fission/absorption })\end{array}$ & & \\
\hline & & $21-30$ & $\mathrm{dNU}$ & $\mathrm{F}$ & Uncertainty on NU (dimensionless) & & $\begin{array}{l}\text { This card may be omitted if } \\
\text { not needed }\end{array}$ \\
\hline
\end{tabular}


Table VIB.1 (continued)

\begin{tabular}{|c|c|c|c|c|c|c|c|}
\hline $\begin{array}{l}\text { Card Set, } \\
\text { No. of } \\
\text { cards }\end{array}$ & $\begin{array}{l}\text { Which } \\
\text { card }\end{array}$ & $\begin{array}{l}\text { Col- } \\
\text { umn }\end{array}$ & $\begin{array}{l}\text { Variable } \\
\text { name }\end{array}$ & $\begin{array}{l}\text { For- } \\
\text { mat }\end{array}$ & Meaning (units) & Values & Notes \\
\hline \multirow{19}{*}{$\begin{array}{l}11 \\
\text { cont., } \\
\text { at least } \\
3\end{array}$} & \multirow[t]{7}{*}{4} & $1-5$ & WHAT & A5 & Descriptor for this card & FINIT & \multirow{3}{*}{$\begin{array}{l}\text { Finite-size corrections for } \\
\text { differential elastic cross sections }\end{array}$} \\
\hline & & 7 & IFLAGI & I1 & $\begin{array}{l}\text { Flag to indicate whether parameter } \\
\text { ATTENI is to be varied }\end{array}$ & 0 or 1 & \\
\hline & & 9 & IFLAGO & I1 & $\begin{array}{l}\text { Flag to indicate whether parameter } \\
\text { ATTENO is to be varied }\end{array}$ & \multirow[t]{5}{*}{0 or 1} & \\
\hline & & $11-20$ & ATTENI & F10 & $\begin{array}{l}\text { Incident-neutron attenuation } \\
\text { (atoms/barn) }\end{array}$ & & See Section III.E \\
\hline & & $21-30$ & DTTENI & F10 & $\begin{array}{l}\text { Uncertainty on ATTENI } \\
\text { (atoms/barn) }\end{array}$ & & $\begin{array}{l}\text { This card may be omitted if not } \\
\text { needed. This card may be }\end{array}$ \\
\hline & & $31-40$ & ATTENO & F10 & $\begin{array}{l}\text { Scattered-neutron attenuation } \\
\text { (atoms/barn) }\end{array}$ & & $\begin{array}{l}\text { repeated, once for each angle. } \\
\text { If the card occurs only once, the }\end{array}$ \\
\hline & & $41-50$ & DTTENO & $\mathrm{F} 10$ & $\begin{array}{l}\text { uncertainty on ATTENO } \\
\text { (atoms/barn) }\end{array}$ & & $\begin{array}{l}\text { same attenuations are used for } \\
\text { each angle }\end{array}$ \\
\hline & \multirow[t]{4}{*}{5} & $1-5$ & WHAT & A5 & & \multirow[t]{4}{*}{ GAMMA } & \multirow{4}{*}{$\begin{array}{l}\text { Use the same radiation width for } \\
\text { all resonances in this spin } \\
\text { group. } \Gamma_{\gamma} \text { is assumed to be } \\
\text { varied } \\
\text { This card may be omitted }\end{array}$} \\
\hline & & $6-7$ & & $\mathrm{I} 2$ & Spin group number & & \\
\hline & & $11-20$ & GAMGAM & F10 & $\begin{array}{l}\text { Reduced radiation width for all } \\
\text { resonances in spin group IG }\end{array}$ & & \\
\hline & & $21-30$ & DGAM & F10 & Uncertainty on GAMGAM & & \\
\hline & \multirow[t]{8}{*}{6} & $1-5$ & WHAT & A5 & & TZERO & \multirow{7}{*}{$\begin{array}{l}\text { See Section III.A.2.c for } \\
\text { description }\end{array}$} \\
\hline & & 7 & IFTZER & I1 & Flag whether to vary $t_{0}$ & 0 or 1 & \\
\hline & & 9 & IFLZER & I1 & Flag whether to vary $L_{0}$ & 0 or 1 & \\
\hline & & $11-20$ & TZERO & F10 & $t_{0}(\mu \mathrm{s})$ & 0.0 & \\
\hline & & $21-30$ & DTZERO & F10 & Uncertainty on $t_{0}(\mu \mathrm{s})$ & \multirow{4}{*}{1.0} & \\
\hline & & $31-40$ & ELZERO & $\mathrm{F} 10$ & $L_{0}$ (dimensionless) & & \\
\hline & & $41-50$ & DLZERO & F10 & Uncertainty on $L_{0}$ & & \\
\hline & & $51-60$ & DIST & F10 & Flight path length $(\mathrm{m})$ & & $\begin{array}{l}\text { This value for fpl is used only if } \\
\text { DIST is zero (see INPut File, } \\
\text { Card Set } 5 \text {, page 104) }\end{array}$ \\
\hline
\end{tabular}


Table VIB.1 (continued)

\begin{tabular}{|c|c|c|c|c|c|c|c|}
\hline $\begin{array}{l}\text { Card Set, } \\
\text { No. of } \\
\text { cards }\end{array}$ & $\begin{array}{c}\text { Which } \\
\text { card }\end{array}$ & $\begin{array}{l}\text { Col- } \\
\text { umn }\end{array}$ & $\begin{array}{l}\text { Variable } \\
\text { name }\end{array}$ & $\begin{array}{l}\text { For- } \\
\text { mat }\end{array}$ & Meaning (units) & Values & Notes \\
\hline & \multirow[t]{10}{*}{7} & $1-5$ & WHAT & A5 & & \multirow[t]{10}{*}{ SIABN } & \multirow{4}{*}{$\begin{array}{l}\text { Abundances for self- } \\
\text { indication transmission } \\
\text { sample }\end{array}$} \\
\hline & & $6-7$ & IF1 & 12 & Flag to vary SIABND(1) & & \\
\hline & & $8-9$ & IF2 & 12 & Flag to vary SIABND(2) & & \\
\hline & & 10 & IF3 & I1 & Flag to vary SIABND(3) & & \\
\hline & & $11-20$ & SIABND(1) & F10 & Abundance for nuclide \# 1 & & \multirow{5}{*}{$\begin{array}{l}\text { Note that nuclides are defined } \\
\text { in Card Set } 10 \text {, which must } \\
\text { occur before Card Set } 11 \text { in } \\
\text { the PARameter file }\end{array}$} \\
\hline & & $21-30$ & $\operatorname{dSIABN}(1)$ & F10 & Uncertainty for nuclide \# 1 & & \\
\hline & & $31-40$ & SIABND(2) & $\mathrm{F} 10$ & Abundance for nuclide \# 2 & & \\
\hline & & $41-50$ & dSIABN(2) & F10 & Uncertainty for nuclide \# 2 & & \\
\hline & & $51-60$ & SIABND(3) & F10 & Abundance for muclide \# 3 & & \\
\hline & & $61-70$ & $\operatorname{dSIABN}(3)$ & F10 & Uncertainty for nuclide \# 3 & & $\begin{array}{l}\text { Repeat this card until all } \\
\text { nuclides have been included }\end{array}$ \\
\hline & \multirow[t]{7}{*}{8} & $1-5$ & WHAT & A5 & & \multirow{7}{*}{$\begin{array}{l}\text { SELFI } \\
0 \text { or } 1 \\
0 \text { or } 1\end{array}$} & \multirow{4}{*}{$\begin{array}{l}\text { Temperature and thickness } \\
\text { for transmission sample for } \\
\text { self indication experiment }\end{array}$} \\
\hline & & $6-7$ & IFTEMP & 12 & Flag to vary temperature & & \\
\hline & & $8-9$ & IFTHCK & $\mathrm{I} 2$ & Flag to vary thickness & & \\
\hline & & $11-20$ & SITEMP & F10 & $\begin{array}{l}\text { Effective temperature for self- } \\
\text { indication transmission } \\
\text { sample }\end{array}$ & & \\
\hline & & $21-30$ & dSITEM & F10 & Uncertainty on temp & & \multirow{3}{*}{ This card may be omitted } \\
\hline & & $31-40$ & SITHCK & F10 & Thickness (atoms/barn) & & \\
\hline & & $41-50$ & dSITHC & F10 & Uncertainty on thickness & & \\
\hline
\end{tabular}


Table VIB.1 (continued)

\begin{tabular}{|c|c|c|c|c|c|c|c|}
\hline $\begin{array}{l}\text { Card Set, } \\
\text { No. of } \\
\text { cards }\end{array}$ & $\begin{array}{r}\text { Which } \\
\text { card }\end{array}$ & Column & $\begin{array}{l}\text { Variable } \\
\text { name }\end{array}$ & $\begin{array}{l}\text { For- } \\
\text { mat }\end{array}$ & Meaning (units) & Values & Notes \\
\hline \multirow{18}{*}{$\begin{array}{l}11 \text { cont., } \\
\text { at least } 3\end{array}$} & 9 & $1-5$ & WHAT & A5 & & EFFIC & $\begin{array}{l}\text { Efficiency for capture and for fission for } \\
\text { eta calculation }\end{array}$ \\
\hline & & 6-7 & IFCAPE & 12 & Flag to vary capture efficiency & 0 or 1 & \\
\hline & & $8-9$ & IFFISE & 12 & Flag to vary fission efficiency & 0 or 1 & \\
\hline & & $11-20$ & EFFCAP & F10 & $\begin{array}{l}\text { Efficiency for detecting capture } \\
\text { events }\end{array}$ & & \\
\hline & & $21-30$ & EFFFIS & F10 & $\begin{array}{l}\text { Efficiency for detecting fission } \\
\text { events }\end{array}$ & & \\
\hline & & $31-40$ & dEFFCAP & F10 & Uncertainty on capture efficiency & & \\
\hline & & $41-50$ & dEFFFIS & F10 & Uncertainty on fission efficiency & & This card may be omitted \\
\hline & 10 & $1-5$ & WHAT & A5 & & DELTE & Delta- $E$ is energy-dependent as described \\
\hline & & 7 & IFLAGI & 12 & Flag to vary DELE11 & 0 or 1 & on page 70 , Section IV.A.2.b, Eq. \\
\hline & & 9 & IFLAG0 & 12 & Flag to vary DELE00 & 0 or 1 & $($ IVA2b.7) \\
\hline & & 10 & IFLAGL & I1 & Flag to vary DELE22 & 0 or 1 & \\
\hline & & $11-20$ & DELE11 & F10 & $\begin{array}{l}\text { Coefficient of } E \text { in Eq. (IVA2b.7) } \\
\quad(\mathrm{m} / \mathrm{eV})\end{array}$ & & \\
\hline & & $21-30$ & D1 & F10 & Uncertainty on DELE11 & & \\
\hline & & $31-40$ & DELE00 & F10 & $\begin{array}{l}\text { Constant term in Eq. (IVA2b.7) } \\
\text { (m) }\end{array}$ & & \\
\hline & & $41-50$ & Do & $\mathrm{F} 10$ & Uncertainty on DELEO0 & & \\
\hline & & $51-60$ & DELE22 & F10 & $\begin{array}{l}\text { Coefficient of } \log \text { term in Eq. } \\
\quad(\text { IVA2b.7) }(\mathrm{m} / \ln (\mathrm{eV}))\end{array}$ & & \\
\hline & & $61-70$ & D2 & F10 & Uncertainty on DELE22 & & This card may be omitted if unneeded \\
\hline & Last & (blank) & & & & & \\
\hline
\end{tabular}




\begin{tabular}{|c|c|c|c|c|c|c|c|}
\hline \multicolumn{8}{|c|}{ Table VIB.1 (continued) } \\
\hline $\begin{array}{c}\text { Card Set, } \\
\text { No. }\end{array}$ & $\begin{array}{l}\text { Which } \\
\text { card }\end{array}$ & $\begin{array}{l}\text { Col- } \\
\text { umn }\end{array}$ & $\begin{array}{l}\text { Variable } \\
\text { name }\end{array}$ & $\begin{array}{l}\text { For- } \\
\text { mat }\end{array}$ & Meaning (units) & Values & Notes \\
\hline $\begin{array}{l}12, \text { at } \\
\text { least } 4\end{array}$ & 1 & $1-5$ & WHAT & A5 & $\begin{array}{l}\text { Alphanumeric indicator of } \\
\text { what comes next }\end{array}$ & PARAMagnetic & $\begin{array}{l}\text { Paramagnetic cross section } \\
\text { parameters are given here } \\
\text { (see Section V.H) }\end{array}$ \\
\hline \multirow{15}{*}{ 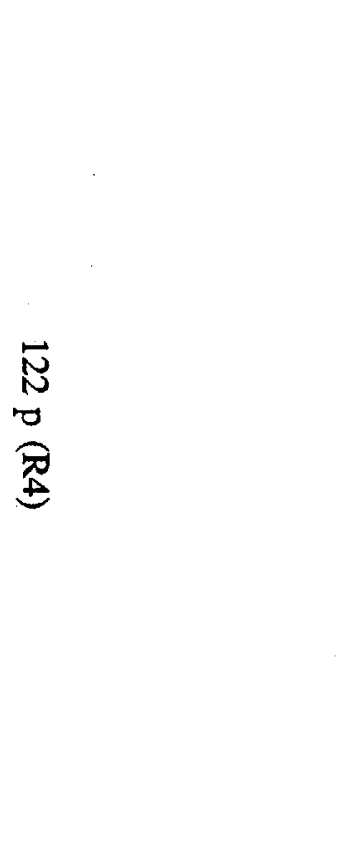 } & 2 & $1-5$ & WHAT & A5 & Which particular nuclide & $\begin{array}{l}\text { TM , ER , } \\
\text { HO }\end{array}$ & $\begin{array}{l}\text { (Two letters followed by } \\
\text { three blanks) }\end{array}$ \\
\hline & & $6-7$ & IFA & $\mathrm{I} 2$ & Flag whether to vary. $A$ & & \\
\hline & & $8-9$ & IFB & $\mathrm{I} 2$ & Flag whether to vary $B$ & & \\
\hline & & 10 & IFP & I1 & Flag whether to vary $P$ & & \\
\hline & & $11-20$ & $A$ & $\mathbf{F}$ & $A$ of Eq. (VH.1) & & See Section V.H for default \\
\hline & & $21-30$ & $d A$ & $\mathrm{~F}$ & Uncertainty on $A$ & & values \\
\hline & & $31-40$ & $B$ & $\mathrm{~F}$ & $B$ of Eq. (VH.1) & & \\
\hline & & $41-50$ & $d B$ & $\mathrm{~F}$ & Uncertainty on $B$ & & \\
\hline & & $51-60$ & $P$ & $\mathrm{~F}$ & $P$ of Eq. (VH.1) & & \\
\hline & & $61-70$ & $d P$ & $\mathbf{F}$ & Uncertainty on $P$ & & \\
\hline & 3 & $6-7$ & ISO & 12 & $\begin{array}{l}\text { Isotope (nuclide) number } \\
\text { for this paramagnetic cross } \\
\text { section }\end{array}$ & 1 & \\
\hline & & 8-9 & IFC & 12 & Flag whether to vary $C$ & & \\
\hline & & $11-20$ & $C$ & $\mathrm{~F}$ & $C$ of Eq. (VH.1) & & \\
\hline & & $21-30$ & $d C$ & $\mathrm{~F}$ & Uncertainty on $C$ & & \\
\hline & Last & (blank) & & & & & \\
\hline
\end{tabular}


Table VIB.1 (continued)

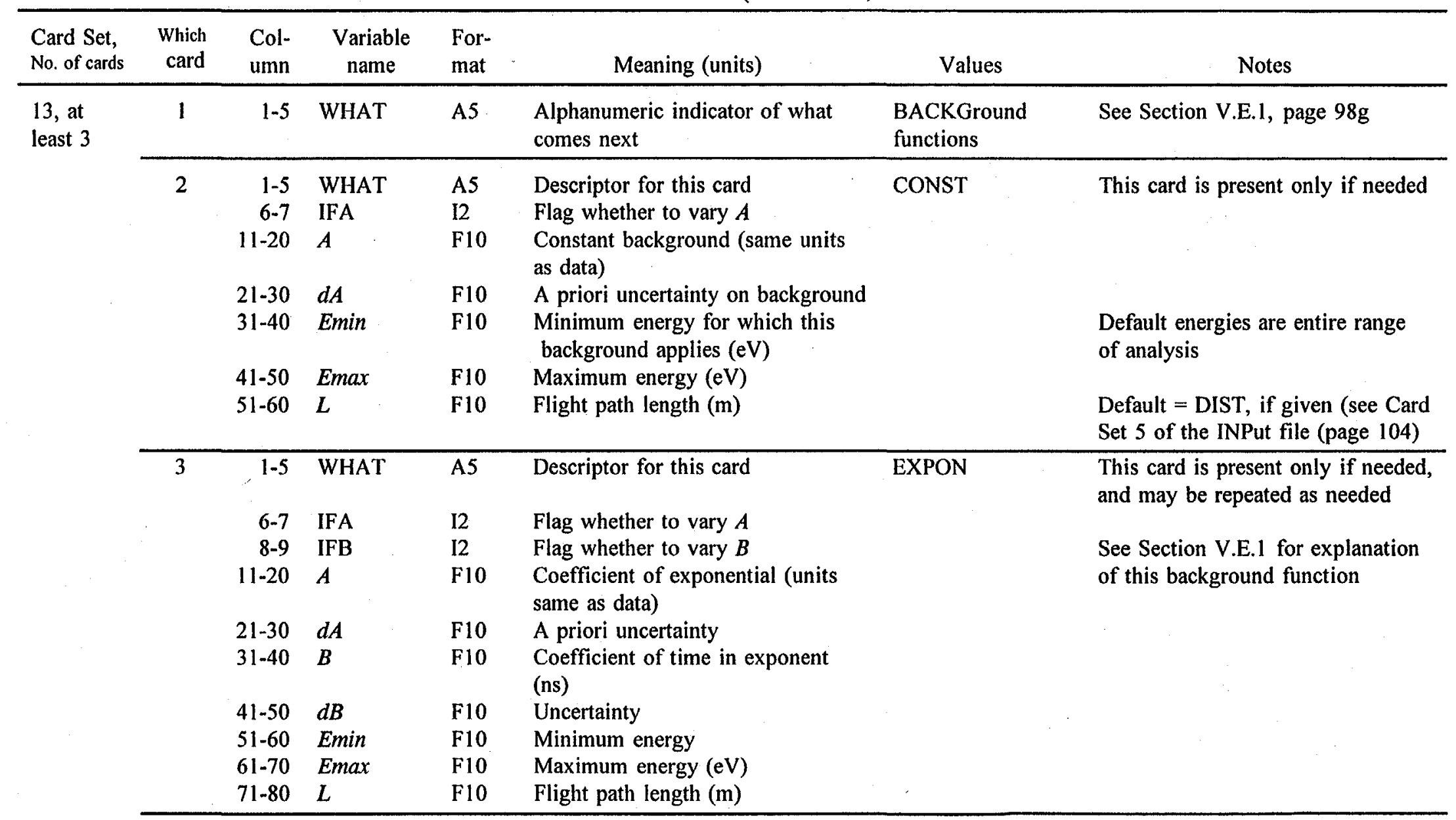




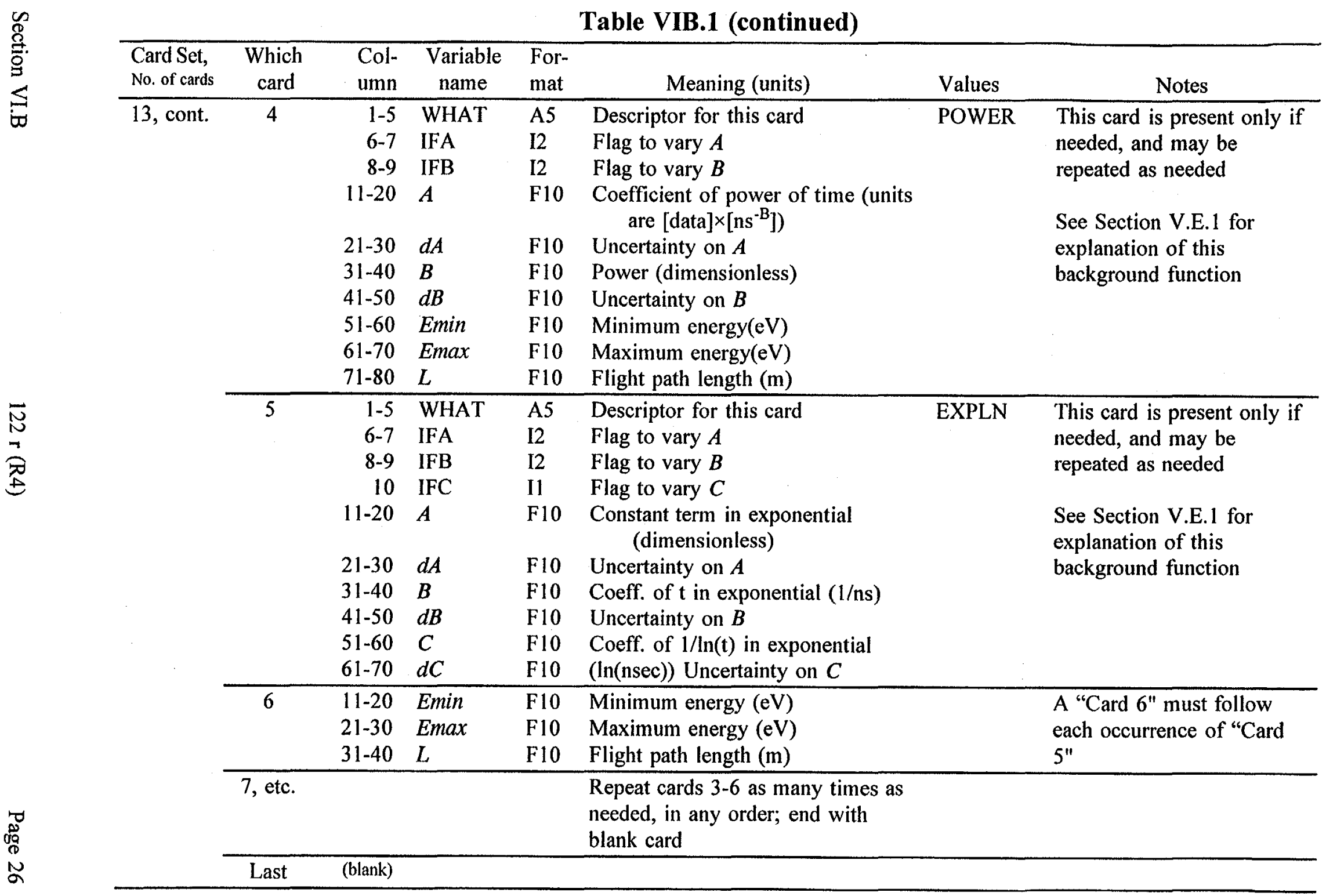


Table VIB.1 (continued)

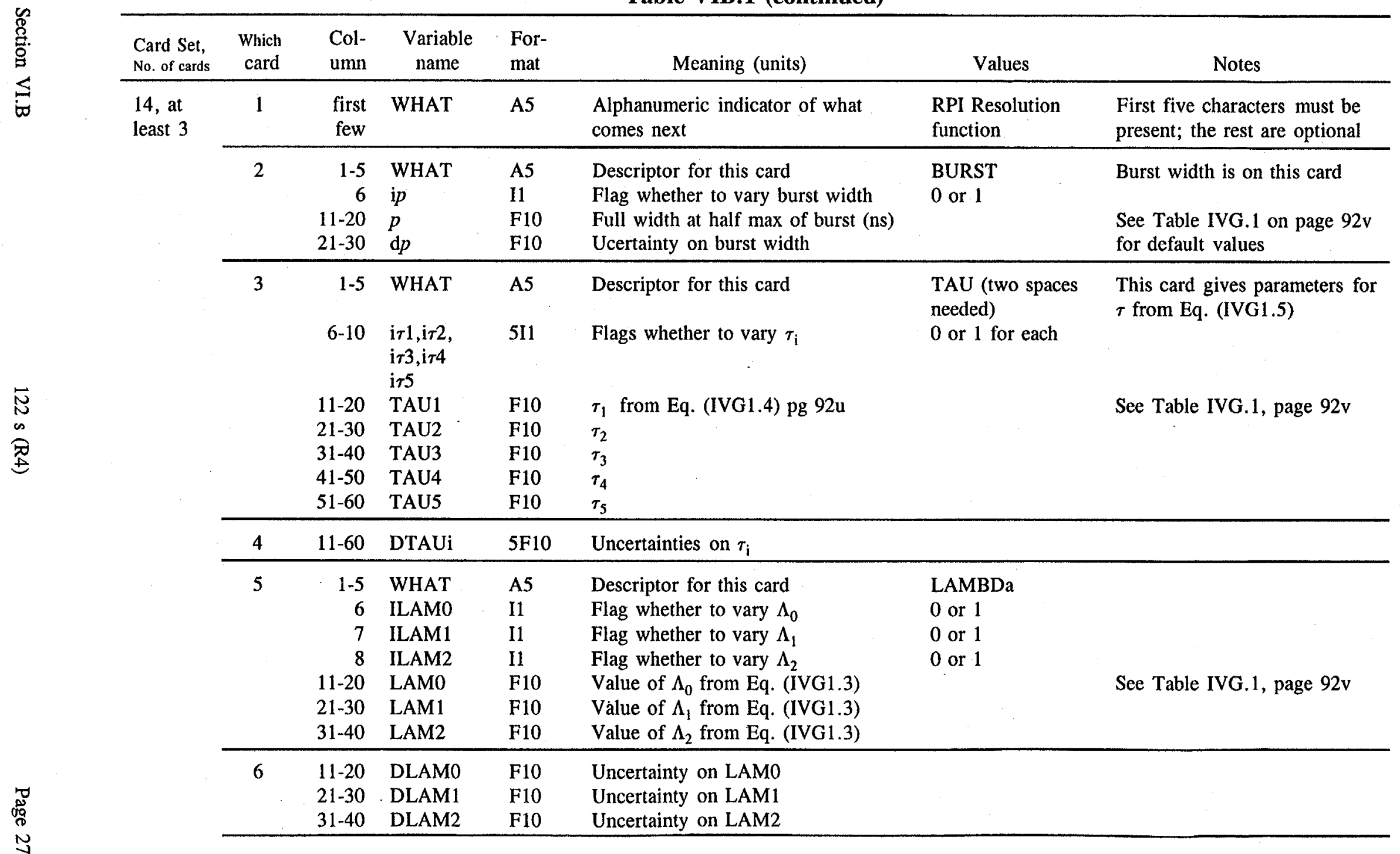


Table VIB.1 (continued)

\begin{tabular}{|c|c|c|c|c|c|c|c|}
\hline $\begin{array}{l}\text { Card Set, } \\
\text { No. of cards }\end{array}$ & $\begin{array}{l}\text { Which } \\
\text { card }\end{array}$ & $\begin{array}{l}\text { Col- } \\
\text { umn }\end{array}$ & $\begin{array}{l}\text { Variable } \\
\text { name }\end{array}$ & Format & Meaning (units) & Values & Notes \\
\hline \multirow[t]{8}{*}{14 , cont. } & 7 & $\begin{array}{r}1-5 \\
6 \\
7 \\
8 \\
9 \\
10 \\
11-20 \\
21-30 \\
31-40 \\
41-50 \\
51-60 \\
\end{array}$ & $\begin{array}{l}\text { WHAT } \\
\text { IAA1 } \\
\text { IAA2 } \\
\text { IAA3 } \\
\text { IAA4 } \\
\text { IAA5 } \\
\text { AA1 } \\
\text { AA2 } \\
\text { AA3 } \\
\text { AA4 } \\
\text { AA5 }\end{array}$ & $\begin{array}{l}\text { A5 } \\
\text { I1 } \\
\text { I1 } \\
\text { I1 } \\
\text { I1 } \\
\text { I1 } \\
\text { F10 } \\
\text { F10 } \\
\text { F10 } \\
\text { F10 } \\
\text { F10 }\end{array}$ & $\begin{array}{l}\text { Descriptor for this card } \\
\text { Flag whether to vary } a_{1} \\
\text { Flag whether to vary } a_{2} \\
\text { Flag whether to vary } a_{3} \\
\text { Flag whether to vary } a_{4} \\
\text { Flag whether to vary } a_{5} \\
a_{1} \\
a_{2} \\
a_{3} \\
a_{4} \\
a_{5}\end{array}$ & $\begin{array}{l}\text { A } 1 \text { (That's "A one, } 3 \text { blanks") } \\
0 \text { or } 1 \\
0 \text { or } 1 \\
0 \text { or } 1 \\
0 \text { or } 1 \\
0 \text { or } 1 \\
\text { See Eq. (IVG1.5) and Table IVG.1 }\end{array}$ & \\
\hline & 8 & $11-60$ & DAAi & $5 \mathrm{~F} 10$ & Uncertainties on $a_{1}$ & & \\
\hline & 9 & $\begin{array}{r}1-5 \\
6 \\
7-10 \\
11-20 \\
21-60 \\
\end{array}$ & $\begin{array}{l}\text { WHAT } \\
\text { IT0 } \\
\text { IA2 - IA5 } \\
\text { T0 } \\
\text { A2 - A5 }\end{array}$ & $\begin{array}{l}\text { A5 } \\
\text { I1 } \\
411 \\
\text { F10 } \\
4 \mathrm{~F} 10 \\
\end{array}$ & $\begin{array}{l}\text { Descriptor for this card } \\
\text { Flag whether to vary } t_{0} \\
\text { Flag whether to vary } A_{2}-A_{5} \\
t_{0} \\
A_{2}-A_{5}\end{array}$ & $\begin{array}{l}\text { EXPON } \\
0 \text { or } 1 \\
0 \text { 's or 1's } \\
\text { See Eq. (IVG1.2) and Table IVG.1 }\end{array}$ & \\
\hline & 10 & $11-60$ & DT0, DAi & $5 \mathrm{~F} 10$ & Uncertainties on $t_{0}$ and $A_{\mathrm{i}}$ & & \\
\hline & 11 & $\begin{array}{r}1-5 \\
7 \\
11-20\end{array}$ & $\begin{array}{l}\text { WHAT } \\
\text { ICH } \\
\text { ECRNCH }\end{array}$ & $\begin{array}{l}\text { A5 } \\
\text { I1 } \\
\text { F10 }\end{array}$ & $\begin{array}{l}\text { Descriptor for this card } \\
\text { Flag whether to vary channel width } \\
\text { Highest energy for this channel } \\
\quad \text { width } c(\mathrm{eV})\end{array}$ & $\begin{array}{l}\text { CHANNel crunch boundaries } \\
0 \text { or } 1\end{array}$ & \\
\hline & & $\begin{array}{r}21-30 \\
31-40 \\
\end{array}$ & $\begin{array}{l}\mathrm{CH} \\
\mathrm{DCH} \\
\end{array}$ & $\begin{array}{l}\text { F10 } \\
\text { F10 } \\
\end{array}$ & $\begin{array}{l}\text { Value for channel width } c \text { (nsec) } \\
\text { Uncertainty on channel width (nsec) }\end{array}$ & See Section IV.G.1 & \\
\hline & $\begin{array}{l}12, \\
\text { etc. }\end{array}$ & $\begin{array}{l}\text { Just } \\
\text { like } 11\end{array}$ & & & $\begin{array}{l}\text { Repeat card } 11 \text { as many times as } \\
\text { needed, end with blank card }\end{array}$ & & \\
\hline & Last & (blank) & & & & & \\
\hline
\end{tabular}


Table VIB.1 (continued)

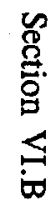

\begin{tabular}{|c|c|c|c|c|c|c|c|}
\hline $\begin{array}{l}\text { Card Set, } \\
\text { No. of cards }\end{array}$ & $\begin{array}{r}\text { Which } \\
\text { card }\end{array}$ & $\begin{array}{l}\text { Col- } \\
\text { umn }\end{array}$ & $\begin{array}{l}\text { Variable } \\
\text { name }\end{array}$ & $\begin{array}{l}\text { For- } \\
\text { mat }\end{array}$ & Meaning (units) & Values & Notes \\
\hline \multirow[t]{6}{*}{$\begin{array}{l}15 \text {, at } \\
\text { least } 3\end{array}$} & 1 & $\begin{array}{l}\text { first } \\
\text { few }\end{array}$ & WHAT & A5 & $\begin{array}{l}\text { Alphanumeric indicator of what } \\
\text { comes next }\end{array}$ & $\begin{array}{l}\text { DETECtor } \\
\text { efficiencies }\end{array}$ & $\begin{array}{l}\text { First five characters must be } \\
\text { present; the rest are optional }\end{array}$ \\
\hline & 2 & $1-10$ & PARDET(1) & F10 & $\begin{array}{l}\text { Detector efficiency appropriate for } \\
\text { these spin groups }\end{array}$ & $\geq 0$ & See Section $x x x x x x x x x x x$ \\
\hline & & $11-20$ & DELDET(1) & F10 & $\begin{array}{l}\text { Uncertainty on this detector } \\
\text { efficiency }\end{array}$ & & \\
\hline & & $21-22$ & IFLDET(1) & I2 & $\begin{array}{l}\text { Flag whether to vary this detector } \\
\text { efficiency }\end{array}$ & $\begin{array}{l}0=\text { do not vary } \\
1=\text { vary }\end{array}$ & \\
\hline & & $23-24$ & $\operatorname{IGRDET}(1,1)$ & 12 & $\begin{array}{l}\text { Number of the first spin group } \\
\text { belonging to this isotope }\end{array}$ & & $\begin{array}{l}\text { If more than } 29 \text { spin groups are } \\
\text { needed, insert "-1" in Columns } \\
79-80 \text {, and continue on the next }\end{array}$ \\
\hline & & $\begin{array}{r}25-26 \\
\text { etc. }\end{array}$ & $\operatorname{IGRDET}(2,1)$ & $\mathrm{I} 2$ & & & $\begin{array}{l}\text { line with (1615) format. When } \\
\text { there are more than } 99 \text { spin } \\
\text { groups altogether, all I formats } \\
\text { on Card } 2 \text { are changed from } 12 \\
\text { to } 15\end{array}$ \\
\hline
\end{tabular}

3, repeat card 2 for second (third, etc.) detector efficiency

etc.

Last (blank) 
Table VIB.1 (continued)

\begin{tabular}{ccccccc}
\hline $\begin{array}{c}\text { Card Set, } \\
\text { No. of cards }\end{array}$ & $\begin{array}{c}\text { Which } \\
\text { card }\end{array}$ & $\begin{array}{c}\text { Col- } \\
\text { umn }\end{array}$ & $\begin{array}{c}\text { Variable } \\
\text { name }\end{array}$ & Format & Meaning (units) & Values \\
\hline
\end{tabular}

(This page is deliberately left blank)

$\stackrel{N}{\mathbb{N}}$

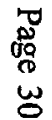


Table VIB.1 (continued)

\begin{tabular}{|c|c|c|c|c|c|c|c|}
\hline $\begin{array}{l}\text { Card set, } \\
\text { No. of cards }\end{array}$ & $\begin{array}{l}\text { Which } \\
\text { card }\end{array}$ & $\begin{array}{l}\text { Col- } \\
\text { umn }\end{array}$ & $\begin{array}{c}\text { Variable } \\
\text { name }\end{array}$ & $\begin{array}{l}\text { For- } \\
\text { mat }\end{array}$ & Meaning (units) & Values & Notes \\
\hline \multirow[t]{4}{*}{$\begin{array}{l}\text { Last (first } \\
\text { alterna- } \\
\text { tive), at } \\
\text { least } 3\end{array}$} & 1 & $\begin{array}{l}\text { first } \\
\text { few }\end{array}$ & WHAT & A5 & $\begin{array}{l}\text { alphanumeric indicator of what comes } \\
\text { next }\end{array}$ & $\begin{array}{l}\text { EXPLIcit } \\
\text { uncertainties } \\
\text { and } \\
\text { correlations } \\
\text { follow }\end{array}$ & $\begin{array}{l}\text { First five characters must be } \\
\text { present; the rest are optional }\end{array}$ \\
\hline & 2 & $\begin{array}{r}1-5 \\
6-10 \\
11-15 \\
16-20 \\
21-30\end{array}$ & $\begin{array}{l}\text { NN } \\
\text { MM } \\
\text { KK } \\
\text { LL } \\
\text { VV }\end{array}$ & $\begin{array}{l}\text { I5 } \\
15 \\
15 \\
15 \\
F\end{array}$ & See footnotes at the end of this table & & \\
\hline & $\begin{array}{l}3,4 \\
\text { etc. }\end{array}$ & & & & Repeat card 2 as many times as needed & & \\
\hline & Last & (blank) & & & & & This card may be omitted \\
\hline
\end{tabular}


Table VIB.1 (continued)

\begin{tabular}{|c|c|c|c|c|c|c|}
\hline $\begin{array}{l}\text { Card set, } \\
\text { No. of cards }\end{array}$ & $\begin{array}{l}\text { Which } \\
\text { card }\end{array}$ & $\begin{array}{l}\text { Col- } \\
\text { umn }\end{array}$ & $\begin{array}{l}\text { Variable } \\
\text { name }\end{array}$ & Format & Meaning (units) & Values \\
\hline \multirow{14}{*}{$\begin{array}{l}\text { last, (second } \\
\text { alternative), } \\
\text { at least } 3\end{array}$} & 1 & $\begin{array}{l}\text { first } \\
\text { few }\end{array}$ & WHAT & A5 & $\begin{array}{l}\text { Alphanumeric indicator of what } \\
\text { comes next }\end{array}$ & RELATive uncertainties follow \\
\hline & 2 & $1-11$ & $\operatorname{RUNCS}(1,1)$ & F11 & $\begin{array}{l}\text { Resonance energy, exactly as it } \\
\text { appears in card set } 1 \text { above }\end{array}$ & \\
\hline & & $12-22$ & $\operatorname{RUNCS}(2,1)$ & F11 & $\begin{array}{l}\text { Relative uncertainty on resonance } \\
\text { energy }\end{array}$ & $\geq 0$ \\
\hline & & $23-33$ & RUNCS $(3,1)$ & F11 & Relative uncertainty on $\Gamma_{\gamma}$ & $\geq 0$ \\
\hline & & $34-44$ & $\operatorname{RUNCS}(4,1)$ & F11 & Relative uncertainty on $\Gamma_{c t}$ & $\geq 0$ \\
\hline & & $45-55$ & RUNCS(5,1) & F11 & Relative uncertainty on $\Gamma_{\mathrm{c} 2}$ & $\geq 0$ \\
\hline & & $56-66$ & $\operatorname{RUNCS}(6,1)$ & F11 & Relative uncertainty on $\Gamma_{\mathrm{c} 3}$ & $\geq 0$ \\
\hline & & $67-68$ & $\operatorname{JUNCS}(1,1)$ & 12 & $\begin{array}{l}\text { Flag specifying whether to use this } \\
\text { uncertainty for ERES }\end{array}$ & $\begin{array}{l}=1 \text { [use relative uncertainty given } \\
\text { by RUNCS }(2,1)] \\
=0 \text { [use either the uncertainty } \\
\text { given at the end of the line, } \\
\text { or use the default] }\end{array}$ \\
\hline & & $69-70$ & $\operatorname{JUNCS}(2,1)$ & $\mathrm{I} 2$ & Flag to use this uncertainty for $\Gamma_{\gamma}$ & 1 or 0 [use $\operatorname{RUNCS}(3,1)$ or default] \\
\hline & & $71-72$ & $\operatorname{JUNCS}(3,1)$ & 12 & Flag to use this uncertainty for $\Gamma_{\mathrm{c} 1}$ & 1 or 0 [use RUNCS $(4,1)$ or default] \\
\hline & & $73-74$ & $\operatorname{JUNCS}(4,1)$ & 12 & Flag to use this uncertainty for $\Gamma_{c 2}$ & 1 or 0 [use RUNCS $(5,1)$ or default] \\
\hline & & $75-76$ & $\operatorname{JUNCS}(5,1)$ & 12 & Flag to use this uncertainty for $\Gamma_{c 3}$ & 1 or 0 [use $\operatorname{RUNCS}(6,1)$ or default] \\
\hline & 3,4 ,etc & & & & & Repeat card 2 as needed \\
\hline & Last & (blank) & & & & \\
\hline
\end{tabular}


Table VIB.1 (continued)

\begin{tabular}{lllllll}
\hline $\begin{array}{c}\text { Card set, } \\
\text { No. of cards }\end{array}$ & $\begin{array}{c}\text { Which } \\
\text { card }\end{array}$ & Column & $\begin{array}{l}\text { Variable } \\
\text { Name }\end{array}$ & Format & Meaning (units) & Values \\
\hline $\begin{array}{l}\text { Last (third } \\
\begin{array}{l}\text { alterna- } \\
\text { tive) } 1\end{array}\end{array}$ & 1 & $\begin{array}{l}\text { First } \\
\text { few }\end{array}$ & WHAT & A5 & $\begin{array}{l}\text { Alphanumeric } \\
\text { message }\end{array}$ & $\begin{array}{l}\text { COVARiance matrix is in } \\
\text { binary form in another } \\
\text { file (See Table VIIB.1) }\end{array}$ \\
\hline
\end{tabular}

Footnote for "first alternative to last card set"

For EXPLIcit input of parameter uncertainties, values for variables NN, MM, KK, LL, and VV are described here. Note that you will not include explicit uncertainties for every parameter, but only those for which you dislike the default value. Also note that uncertainties associated with parameters of Card Sets $\mathbf{8}$ and higher are provided along with values for those parameters, and therefore need not be included here.

(a) To explicitly input the initial (prior) uncertainty on resonance parameters, find the number of the resonance (i.e., count lines in Card Set 1 in this file). That number is "NN" and goes in columns 1-5, right-adjusted. The value of MM for columns 6-10 is 1 if the parameter of interest is $E_{\lambda}, 2$ if $\Gamma \gamma, 3$ if $\Gamma_{c l}, 4$ if $\Gamma_{c 2}$, , etc. KK and LL are zero. VV then represents the absolute value of the uncertainty for this parameter, in the same units as the parameter itself.

(b) To explicitly input the prior uncertainty on R-external parameters, set $N N=(100$ plus IGROUP), where IGROUP is the group number. Let $\mathrm{MM}=1$ for $E_{\alpha}^{d o w n}, 2$ for $E_{\alpha}^{u p}, 3$ for $R_{c o n, \alpha}, 4$ for $R_{l i n, \alpha}, 5$ for $s_{c o n, \alpha}, 6$ for $s_{l i n, \alpha}$, and 7 for $R_{q, \alpha}$, all for channel 1 . If using "Card Set 3" to input R-external for channel 2, use $M M=6,7,8,9,10$, and for channel 3 use $M M=11,12,13,14,15$. If using "Alternative to Card Set 3," use $M M=8,9,10,11,12,13,14$; for channel 3 , use 15 through 21 . The absolute value of the uncertainty on that parameter is then given by VV.

(c) To explicitly input the prior uncertainty on broadening (etc.) parameters, set $\mathrm{NN}=2000+n$, where $n=1$ for radius, 2 for effective temperature, 3 for sample thickness, etc. (See Card Set 4. MM is irrelevant here.) The absolute certainty on that parameter is VV.

(d) To explicitly input the prior uncertainty on normalization or background parameters (see Card Set 6), set $\mathrm{NN}=3000+n$, where $n=1$ for ANORM, $n=2$ for BACKA, etc. VV is the absolute uncertainty on that parameter. 
(e) To explicitly input the prior uncertainty on the radii (see Card Set 7), set $\mathrm{NN}=4000+n$, where $n$ is the radius pair number (i.e., the "card number," minus one, in Card Set 7). Also set $M M=1$ for potential scattering radius, $M M=2$ for the channel radius, or $M M$ $=1$ if the two radii are treated as identical. VV is the absolute uncertainty on the radius. [Note the VV does not refer to AWRI.]

(f) To explicitly input correlations between the uncertainties on two parameters, let NN and MM indicate the first parameter, as in (a) through (e) above. The second parameter is indicated by KK and LL (analogous to NN and MM, respectively). The correlation coefficient is then given by VV. Note that $-1 \leq \mathrm{VV} \leq+1$. 


\section{VI.C.1 Experimental Data}

The original format for the DATa file is shown in Table VIC1.1; this version is borrowed directly from MULTI[GA74]. Three data points, including energy, experimental value for cross section (or transmission, eta, etc.), and relative uncertainty appear on each line. (For the IBM version of SAMMY, the energy, cross section, and relative uncertainty for only one data point appear on each line.) Energies may be ordered from high to low or low to high, but the ordering must be monotonic. The data file may contain points that are not within the range [EMIN,EMAX] specified for this run; such points will be ignored (or, possibly, used for determining the auxiliary grid. See Section IV.B.1).

A second ASCII format permits one data point per line, in (3F11) or (3E11) format, with uncertainties being absolute (rather than relative as in the "original" format). To use this option, the phrase "USE CSISRS FORMAT FOr data" or an equivalent must appear in Card Set 3 of the INPut file (See Table VIA.2).

A third ASCII format is useful when many significant digits are needed (e.g., when comparing cross sections calculated by SAMMY with those calculated by other codes). This format has one data point per line, in (3F20) or (3E20) format, and uncertainties are absolute. The phrase "USE TWENTY SIGNIFICAnt digits for experimental data" (or simply "TWENTY") must appear in Card Set 3 of the INPut file (Table VIA.2).

For ORELA and others who use the plotting package FORODF [JC78] with their version of SAMMY, there are several possible methods of supplying data in ORELA Data Format (ODF): For the first, you must specify "DATA IS IN ODF FILE" in Card Set 3 of the INPut file (See Tables VIA.1 and 2). In this ODF data file, section 1 contains the energy, 2, the data, and 3, the absolute uncertainty. Use of this alternative is discouraged, because SAMMY handles it awkwardly, copying to a temporary file in the usual DATa file format of Table VIC1.1.

The second ODF format is the "standard ODF format," for which you must specify "DATA IS IN STANDARD odf format" in your input file. In this ODF file, the energies (ordered high to low) are stored in section 1 , data in section 2 , and absolute uncertainties in section 3 . Sections 4 , 5 , etc. of the same ODF file may be used to store the partial derivatives of the data with respect to the data reduction parameters. (See Section V.E.2 of this report for a discussion of data reduction parameters.) Note that section 4 of the ODF file must correspond to datareduction parameter number 1 , section 5 to parameter number 2 , etc. As with all varied parameters, initial values are given in the PARameter file (Card Set 8 of Table VIB.1). Other methods of input for the data-reduction parameters will be developed as the need arises; interested persons should contact the author for assistance.

Two options are available for specifying differential elastic scattering data. The first is via an ODF file. Section 1 of this file contains the energy; section 2 , the measured cross sections for the first angle; section 3, the absolute uncertainties on the cross sections in section 2; sections 4 and 5 , the cross sections and uncertainties for the second angle; ... In general, section $2 \mathrm{n}$ 
contains data for the $n^{\text {th }}$ angle; and section $2 n+1$ contains the uncertainties. Angles are specified in the INPut file, Card Set 8 (see Table VIA.1).

The second option for differential elastic data is via an ASCII file, all in (8F10.1) format, with at least two cards per energy. The first card contains the energy in the first ten columns, cross section at first angle in columns 11-20, cross section at second angle in columns 21-30, etc.; this card may extend onto additional cards as needed. The second card (or set of cards) is blank in columns 1-10, contains the (absolute) uncertainty in the cross section at the first angle in columns 11-20, uncertainty for the second angle in columns 11-20, etc. These two (sets of) cards are repeated once for each energy. To use this option, it is necessary to include the phrase "DIFFERENTIAL DATA ARE $\mathbb{N}$ ascii file" in the INPut file.

Table VIC1.1. MULTI-Style Format for the DATa file

\begin{tabular}{rrlll}
\hline Card & Column & Variable & Format & \multicolumn{1}{c}{ Meaning (units) } \\
\hline 1,2 ,etc. & $1-15$ & ENERGY $_{1}$ & F15 & Energy (eV) \\
& $16-30$ & DATA $_{1}$ & F15 & $\begin{array}{l}\text { Experimental cross section } \\
\text { (barns), transmission, yield, or } \\
\text { other type of data }\end{array}$ \\
& $31-37$ & FRACT $_{1}$ & F7 & Fractional uncertainty in DATA 1 \\
& $38-52$ & ENERGY $_{2}$ & F15 & \\
$53-67$ & DATA $_{2}$ & F15 & \\
$68-74$ & FRACT $_{2}$ & F7 & \\
$75-89$ & ENERGY $_{3}$ & F15 & \\
$90-104$ & DATA $_{3}$ & F15 & \\
$105-111$ & FRACT $_{3}$ & F7 & \\
\hline
\end{tabular}

Note that, although $\mathrm{F}$ formats are specified above, input can be in either $\mathrm{E}$ or $\mathrm{F}$ format. Numbers must, however, be within the columns specified, and a decimal point is required. If using $\mathrm{E}$ format, the exponent is in the right-most columns. 


\section{VI.C.2. Explicit and Implicit Data Covariance Matrices}

Two options for off-diagonal data covariance matrices are available within SAMMY. The first, which is labeled "explicit," is treated as a regular off-diagonal covariance matrix; see the description of Bayes' Equations, Section II. Use of the explicit data covariance matrix thus requires inversion of an $N \times N$ array, where $N$ is the number of data points. The second, "implicit" data covariance matrix (described in Section II.A.2.a) is input as a specific mathematical form, and is treated by a more sophisticated mathematical process that does not require inversion of such a large matrix. When either formulation could be used, the implicit is recommended since the implementation is more efficient.

\section{Explicit Data Covariance Matrix}

Table VIC2.1 shows the format for a data covariance (DCV) file, to be included when each covariance matrix element is given explicitly. The name of this file must be specified in Card Set 3 of the INPut file (Tables VIA.1 and VIA.2) in columns 31-40 of the Card reading "DATA COVARIANCE FILE is named ..."

Occasionally it may be convenient to introduce a constant on- and off-diagonal data covariance in the neighborhood of a non-s-wave resonance, permitting effective decoupling of any underlying $l=0$ state from the non- $s$ waves. This is effective because an additive constant covariance is mathematically equivalent to a constant, coherent correction term for either the

Table VIC2.1 Format of the Data CoVariance file

\begin{tabular}{lllll}
\hline Card & Column & Variable & Format & Meaning \\
\hline 1 & $1-10$ & VARDAT(1,1) & F10.1 & Variance for data point 1 \\
2 & $1-10$ & VARDAT $(2,1)$ & F10.1 & Covariance between data points 1 and 2 \\
& $11-20$ & VARDAT $(2,2)$ & F10.1 & Variance for data point 2 \\
3 & $1-10$ & VARDAT(3,1) & F10.1 & Covariance between data points 1 and 3 \\
& $11-20$ & VARDAT(3,2) & F10.1 & Covariance between data points 2 and 3 \\
& $21-30$ & VARDAT(3,3) & F10.1 & Variance for data point 3 \\
4 & $1-10 \ldots$ & $\begin{array}{l}\text { VARDAT(4,1) } \\
\text { etc. }\end{array}$ & F10.1 & \\
\hline
\end{tabular}

Note that the ordering of data points is low to high (independent of the ordering in the DATa file), and only those data points actually used in the calculation can be referenced in the DCV file. A maximum of eight matrix elements are to be included on one line; thus "card number 11", for example, will actually be two lines, with eight numbers on the first and three on the second. 
data or the theory. (Algebraic details are presented in Appendix A of the original SAMMY report [NL80].) This type of off-diagonal data covariance matrix can be generated automatically by SAMMY; details for input are given in Table VIA.2 under the category "Input Control" and in Card Set 1, columns 68 to 80 , of Table VIB.1.

Another type of explicit off-diagonal data covariance matrix which can be automatically generated by SAMMY is of the form

$$
V^{i j}=\bar{V}^{i j}+\left(a+b E^{i}\right)\left(a+b E^{j}\right),
$$

where $\bar{V}^{i j}$ is provided by the user, $E^{i}$ is the energy for data point $i$, and $a$ and $b$ are constants chosen by the user. This type of covariance is useful if there are energy-dependent coherent uncertainties in the data, for example, if a subtracted background is imperfectly known. Input for this option is given in Card Set 7 of Table VIA.1, and the "Input Control" statement "DATA HAS OFF-DIAGONAL contribution ..." of Table VIA.2.

\section{Implicit Data Covariance Matrix}

As described in Section II (Bayes' Equations) it is possible for SAMMY to treat certain types of data covariances without actually generating the complete off-diagonal data covariance matrix. These types are labeled Implicit Data Covariances (IDC) and may be understood as follows:

The data-reduction process, which is generally performed by the experimentalist who measured the data, includes background subtraction and normalization, as well as other corrections (for deadtime, self-shielding, etc.). This process produces off-diagonal data covariance matrix (i.e., systematic errors), which should then be included (along with statistical errors) in the analysis process. To reconstruct the covariance matrix due to the background and normalization corrections, SAMMY assumes that the "corrected" data $D$ and the "original" data $R$ are related via

$$
D(E)=\frac{R(E)-b(E)}{a},
$$

in which $a$ and $b$ are defined as in Section V.E.1 (Explicit Normalization and/or Background Functions). Corrections applied to the experimental data are opposite to those applied to the theory; that is, for experimental data the background is subtracted before dividing by normalization, and theoretical values are first multiplied by the normalization before adding the background.

Values and uncertainties (as well as possible correlations) for the normalization and parameters should be determined by the experimentalist. However, the analyst may wish to apply further corrections to the data. In this case, the analyst can run SAMMY, including normalization and/or background functions in the parameter file with the parameters flagged 
(varied) in order to determine the correct values for the parameters. The next step would be to produce a modified data file; this step can be accomplished with SAMMY by including a command line "REFORMULATE DATA FOR implicit data covariance" in the INPut file. SAMMY will then produce a file SAMMY.DA2 in the same format as the analyst's DATa file, with the data values corrected according to Eq. (VIC2.2). Note that uncertainties in this data file will not be changed (except to divide by the normalization $a$, if the uncertainties in the file are absolute rather than relative): This file, like the original, contains only statistical, but not systematic, errors. SAMMY will also produce a file SAMMY.IDC which contains the normalization \& broadening information, and a new parameter file SAMMY.PA2 identical to the analyst's PAR file except for the absence of the normalization and broadening information. The uncertainties in SAMMY.IDC can then be modified (or added) to be the proper experimental uncertainties on the normalization and broadening parameters, to be used in further SAMMY runs.

In subsequent SAMMY runs for that data set, the INPut file contains the command line "IMPLICIT DATA COVARIance matrix is to be used." SAMMY then looks for the IDC file, which uses the same formats as portions of the PARameter file. In particular, Card Set 6 (NORMAlization and background) and Card Set 13 (BACKGround functions) can be included in this file; see Section V.E.1 on page $98 \mathrm{~g}$ for a description of these functions. Any correlations between values should also be given here, using again the formats of the PARameter file for EXPLIcit uncertainties (Card Set Last, first alternative).

Within SAMMY, the Implicit Data Covariance information is treated as described in Section II.A.2, page 14c. Note that the SAMMY user need never generate off-diagonal data covariances directly.

For examples on the use of IDC, see test case TR70. 


\section{VI.I INTEGRAL DATA FILE}

When the data type is specified as "INTEGral quantities" (see Card Set 8 of the INPut file, page 107), two kinds of data files are needed. The first is an experimental differential data file, which is used only to generate the energy grid on which the integrals are to be calculated; the type of data and values of the cross sections in this file are ignored. The second kind of data file contains the experimental integral data and is designated as the "NTG" file.

In the NTG file, each type of integral data is specified by a unique five-character name, which is given in Columns 1 to 5 of the appropriate card. Names can be either upper or lower case, and the ordering is arbitrary. Only those data types for which experimental measurements exist need to be specified; others can simply be omitted from this file.

Table VI.I.1 shows the various types of integral data available in SAMMY. Note that underscore _ in a name denotes a blank space.

When the INPut and PARameter files specify more than one nuclide (isotope), SAMMY will calculate the integral quantities for each nuclide separately, ignoring the abundances specified in INPut and/or PARameter files. Integral data are assumed to be for a specific nuclide; it is important to note that the ordering of the nuclides must be the same in the NTG file as in the PAR file.

Correlations between experimental data are also given in the NTG file.

Table VI.I.1. Types of integral data

\begin{tabular}{ll}
\hline Name as used in NTG file & \multicolumn{1}{c}{ Description } \\
\hline THABS, THFIS, THCAP & $\begin{array}{c}\text { Absorption, fission, or capture cross section, respectively, at } \\
\text { thermal energy }(\mathrm{E}=0.0253 \mathrm{eV})\end{array}$ \\
MXABS, MXFIS, MXCAP & Maxwellian average absorption, fission, or capture cross section \\
WGABS, WGFIS, WGCAP & Westcott's $g$ factor for absorption, fission, or capture cross section \\
RIABS, RIFIS, RICAP & Resonance integral for absorption, fission, or capture cross section \\
AVABS, AVFIS, AVCAP & Average integral for absorption, fission, or capture cross section \\
WATTS & Watt spectrum average \\
K1_-- & [ $v$ (MXFIS) - (MXABS) ] $2 / \sqrt{\pi}$ \\
ALPHA & $\alpha=(\mathrm{RICAP}) /(\mathrm{RIFIS})$ \\
NJALF & NJOY's $\alpha$ \\
NJETA & NJOY's $\eta$ \\
\hline
\end{tabular}


The name of the integral data file is given directly after the name of the differential data file, in the "interactive or batch input to SAMMY." Details for the format of the NTG file are given in Table VI.I.2.

Table VI.I.2. Format of the NTG file

\begin{tabular}{|c|c|c|c|}
\hline Card No. & Column & $\begin{array}{c}\text { Variable } \\
\text { Name }\end{array}$ & Meaning \\
\hline 1 & $1-70$ & TITLE & Title for the file; is printed in LPT file but never used \\
\hline 2 & $1-5$ & NUCLID & $\begin{array}{l}\text { Nuclide number (default }=1 \text { ); nuclides must be in the } \\
\text { same order as in PAR file }\end{array}$ \\
\hline \multirow[t]{4}{*}{3,4, etc. } & $1-5$ & WHAT & Type of integral data, from list in Table VI.I.1 \\
\hline & $11-20$ & DATA & Experimental value for this data type \\
\hline & $21-30$ & UNC & Experimental uncertainty for this data type \\
\hline & $\begin{array}{l}31-40 \\
41-50\end{array}$ & $\begin{array}{l}\text { CONST } \\
\text { CONST2 }\end{array}$ & $\begin{array}{l}\text { For resonance integral data, CONST is the maximum } \\
\text { energy for integrand, and CONST } 2 \text { is the remainder to } \\
\text { be added to the integrated value } \\
\text { For average integral data, CONST is the lower limit on } \\
\text { the integral and CONST } 2 \text { the upper } \\
\text { For K1, CONST is the value of } v \\
\text { For Watt spectrum average, CONST }=a \text { and } \\
\text { CONST } 2=b\end{array}$ \\
\hline 5 & & (blank) & \\
\hline 6, etc. & & & Repeat cards 2 through 5 as many times as needed \\
\hline 7 & & (blank) & \\
\hline 8 & $1-5$ & WHAT & CORRElations follow \\
\hline \multirow[t]{5}{*}{9} & $1-5$ & WHAT1 & Type of integral data \\
\hline & $6-10$ & NUCl & Nuclide number \\
\hline & $11-15$ & WHAT2 & Type of integral data \\
\hline & $16-20$ & NUC2 & Nuclide number \\
\hline & $21-30$ & CORR & $\begin{array}{l}\text { Correlation between data of type WHAT } 1 \text { for nuclide } \\
\text { number NUC1, and WHAT2 for Nuc2 }\end{array}$ \\
\hline 10,11 , etc. & & & Repeat card 9 as many times as needed \\
\hline 12 & & (blank) & \\
\hline
\end{tabular}




\section{OUTPUT FROM SAMMY}

The output from SAMMY is presented in two or more files, depending on the control parameters set in the INPut file (Card Set 3 of Table VIA.1). Table VII.1 summarizes those output files. In the table, unit numbers correspond to those used within the FORTRAN of SAMMY; these are included for the benefit of SAMMY "managers" who may occasionally need such information. (Most users will have no such need.)

Table VII.1. SAMMY output files

\begin{tabular}{|c|c|c|}
\hline $\begin{array}{l}\text { File name and } \\
\text { unit No. }\end{array}$ & Contents & $\begin{array}{l}\text { Where } \\
\text { details may } \\
\text { be found }\end{array}$ \\
\hline $\begin{array}{l}\text { BATCH.LOG } \\
6\end{array}$ & $\begin{array}{l}\text { What appears on the screen in the interactive mode; } \\
\text { system information }\end{array}$ & \\
\hline $\begin{array}{l}\text { SAMMY.LPT } \\
21\end{array}$ & $\begin{array}{l}\text { Descriptive output, to be sent to the line printer for } \\
\text { careful examination by the analyst }\end{array}$ & $\begin{array}{l}\text { Section } \\
\text { VII.A }\end{array}$ \\
\hline $\begin{array}{l}\text { SAMMY.IO } \\
70\end{array}$ & Initial and final values of varied parameters & \\
\hline $\begin{array}{l}\text { SAMMY.PAR } \\
32\end{array}$ & $\begin{array}{l}\text { PARameter output file, in same format as the initial } \\
\text { PARameter file, containing updated values of the } \\
\text { varied parameters }\end{array}$ & $\begin{array}{l}\text { Table VIB.1 } \\
\text { Section VI.B }\end{array}$ \\
\hline $\begin{array}{l}\text { SAMMY.COV } \\
64\end{array}$ & $\begin{array}{l}\text { Updated COVariance matrix for the updated } \\
\text { parameters, in binary form. Updated parameter } \\
\text { values and other information are also included here }\end{array}$ & $\begin{array}{l}\text { Table VIIIB.1 } \\
\text { Section } \\
\text { VII.B }\end{array}$ \\
\hline $\begin{array}{l}\text { SAMMY.ODF } \\
72\end{array}$ & $\begin{array}{l}\text { This is the plot file in ORELA Data Format (ODF), } \\
\text { from which plots can be produced using the utility } \\
\text { program FORODF. On some systems, this is a } \\
\text { binary file containing the same information. } \\
\text { [For angular distribution data, see Section VIII.H] }\end{array}$ & $\begin{array}{l}\text { Table VIIC.1 } \\
\text { Section } \\
\text { VII.C }\end{array}$ \\
\hline $\begin{array}{l}\text { SAMMY.DAT } \\
72\end{array}$ & $\begin{array}{l}\text { Experimental data and uncertainties for angular } \\
\text { distribution data }\end{array}$ & $\begin{array}{l}\text { See Section } \\
\text { VIII.H }\end{array}$ \\
\hline $\begin{array}{l}\text { SAMMY.NDF } \\
75\end{array}$ & $\begin{array}{l}\text { An ASCII file containing the resonance parameters } \\
\text { in the format required for File } 2 \text { of the Evaluated } \\
\text { Nuclear Data Files (ENDF/B-6) }\end{array}$ & Section VI.F \\
\hline $\begin{array}{l}\text { SAMMY.PDS } \\
71\end{array}$ & $\begin{array}{l}\text { Partial derivatives of the theoretical values with } \\
\text { respect to every resonance parameter }\end{array}$ & Section VII.D \\
\hline
\end{tabular}




\begin{tabular}{|c|c|c|}
\hline $\begin{array}{l}\text { File name and } \\
\text { unit No. }\end{array}$ & Contents & $\begin{array}{l}\text { Where } \\
\text { details may } \\
\text { be found }\end{array}$ \\
\hline $\begin{array}{l}\text { SAMNDF.INP } \\
13\end{array}$ & $\begin{array}{l}\text { SAMMY-type INPut file produced when an ENDF/B } \\
\text { File } 2 \text { is used for resonance parameter input }\end{array}$ & Section VI.G \\
\hline $\begin{array}{l}\text { SAMNDF.PAR } \\
12\end{array}$ & $\begin{array}{l}\text { SAMMY-type PARameter file produced when an } \\
\text { ENDF/B File } 2 \text { is used for resonance parameter input }\end{array}$ & Section VI.G \\
\hline $\begin{array}{l}\text { SAMMY.CCV } \\
77\end{array}$ & $\begin{array}{l}\text { Concise parameter CoVariance matrix (uncertainties, } \\
\text { plus correlations integer format) }\end{array}$ & $\begin{array}{l}\text { Section } \\
\text { VII.E }\end{array}$ \\
\hline $\begin{array}{l}\text { SAMXAC.ODF } \\
73\end{array}$ & $\begin{array}{l}\text { A binary file in ODF format, containing the auxiliary } \\
\text { grid in Section } 1 \text { and the unbroadened cross section } \\
\text { in Section } 2\end{array}$ & Section V.G \\
\hline $\begin{array}{l}\text { SAMMY.UNB } \\
99\end{array}$ & $\begin{array}{l}\text { Binary file in ODF format, containing energy in } \\
\text { Section } 1 \text { and unbroadened cross sections in other } \\
\text { sections }\end{array}$ & \\
\hline $\begin{array}{l}\text { SAMUNB.DAT } \\
99\end{array}$ & $\begin{array}{l}\text { ASCII file containing energy and unbroadened cross } \\
\text { sections }\end{array}$ & \\
\hline $\begin{array}{l}\text { SAMMY.SSM } \\
25\end{array}$ & $\begin{array}{l}\text { A binary file containing edge-effects corrections (the } \\
\text { function } Q \text { ) to single-scattering correction for } \\
\text { capture cross sections }\end{array}$ & Section III.F \\
\hline
\end{tabular}




\section{VII.C PLOT OUTPUT}

On some computer systems, the output file SAMMY.ODF is in the ORELA DATA FORMAT [JG78] and is intended for use with the plotting program FORODF to produce plots of the results of SAMMY calculations. (On other systems, a different plotting package may be in use; see Section VIII.F.) Table VIIC.1 shows what is stored in each section of the SAMMY.ODF file, for the case when the experimental data are either total cross section or transmission. Table VIIC. 2 describes the ODF file for other types of energy-differential data, and Table VIIC. 3 shows the SAMMY.ODF file for differential elastic scattering data. In the case of differential elastic scattering data, when the input data are provided in an ASCII file, SAMMY will produce a second output ODF file (SAMMY.DAT) that contains the experimental values; if the input data are given in an ODF file, the SAMMY.DAT file is not generated.

Table VIIC.1. Sections of the ODF file generated by SAMMY, for transmission or total cross-section data

\begin{tabular}{cl}
\hline Sect. No. & \multicolumn{1}{c}{ Contents and units } \\
\hline 1 & Energy (eV if appropriate, otherwise keV) \\
2 & Experimental cross section (barns) \\
3 & Absolute uncertainty in experimental cross section (barns) \\
4 & Zeroth-order theoretical cross section as evaluated by SAMMY (barns) \\
5 & Final theoretical cross section as evaluated by SAMMY (barns) \\
6 & Experimental transmission (dimensionless) \\
7 & Absolute uncertainty in experimental transmission \\
8 & Zeroth-order theoretical transmission as evaluated by SAMMY \\
9 & Final theoretical transmission as evaluated by SAMMY \\
$10^{\text {a }}$ & Theoretical uncertainty on S4 if data were total cross section, or on S8 if data \\
$11^{\text {a }}$ & were transmission \\
$12^{\text {b }}$ & Theoretical uncertainty on S5 or S9 \\
$13^{\text {b }}$ & Adjusted energy initially, when $t_{0}$ and $L_{0}$ are to be varied \\
\hline a These sections are filled only if the phrase "INCLUE THEORETICAL errors" occurs in the INPut file (Table VIA.2). \\
bhese sections are filled only if $t_{0}$ and $L_{0}$ are to be varied.
\end{tabular}


Table VIIC.2. Sections of the ODF file generated by SAMMY, for energy-differential data that are neither transmission nor total cross section

\begin{tabular}{cl}
\hline Sect. No. & \multicolumn{1}{c}{ Contents and units } \\
\hline 1 & Energy (eV if appropriate, otherwise keV) \\
2 & Experimental cross section (barns) \\
3 & Absolute uncertainty in experimental cross section (barns) \\
4 & Zeroth-order theoretical cross section as evaluated by SAMMY (barns) \\
5 & Final theoretical cross section as evaluated by SAMMY (barns) \\
$6^{\text {a }}$ & Theoretical uncertainty on S4 (barns) \\
$7^{\text {a }}$ & Theoretical uncertainty on S5 (barns) \\
$8^{\text {b }}$ & Adjusted energy initially, when $t_{0}$ and $L_{0}$ are to be varied. See Section \\
$9^{\text {b }}$ & III.A.2.c of this report \\
& Adjusted energy finally, when $t_{0}$ and $L_{0}$ are to be varied. See Section \\
I.A.2.c of this report
\end{tabular}


Table VIIC.3. Sections of SAMMY.ODF when data are differential elastic scattering

\begin{tabular}{cl}
\hline Sect. No. & \multicolumn{1}{c}{ Contents and units } \\
\hline 1 & Energy (eV) \\
2 & Zeroth-order theoretical cross section for the first angle (barns) \\
3 & Final theoretical cross section for the first angle (barns) \\
4 & Zeroth-order theoretical cross section for the second angle (barns) \\
5 & Final theoretical cross section for the second angle (barns) \\
$\ldots$ & \\
$2 n$ & Zeroth-order theoretical cross section for the $n$th angle (barns) \\
$2 n+1$ & Final theoretical cross section for the $n$th angle (barns) \\
\hline
\end{tabular}

Table VIIC.4. Sections of the ODF file SAMMY.DAT generated by SAMMY when data are differential elastic scattering

\begin{tabular}{cl}
\hline Sect. No. & \multicolumn{1}{c}{ Contents and units } \\
\hline 1 & Energy (eV) \\
2 & Experimental cross section for the first angle (barns) \\
3 & Uncertainty on experimental cross section for the first angle (barns) \\
4 & Experimental cross section for the second angle (barns) \\
5 & Uncertainty on experimental cross section for the second angle (barns) \\
$\ldots$ & \\
$2 n$ & Experimental cross section for the $n$th angle (barns) \\
$2 n+1$ & Uncertainty on experimental cross section for the $n$th angle (barns) \\
\hline
\end{tabular}


-

$\bullet$

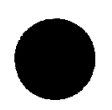




\section{VII.E CONCISE FORMAT FOR PARAMETER COVARIANCE INFORMATION}

Existing formats for communication of covariance information are often inadequate. The sheer quantity of numbers in a typical covariance matrix prohibits storage of this information in ASCII format, and binary files are generally not transportable from one computer to another. This issue is discussed at greater length [HD97], and a concise format is proposed for use in the transmission of covariance information from one code to another via ENDF.

A format similar to that proposed [HD97] is available as an option for the output of parameter covariance information for the SAMMY resonance parameters. When the alphnumeric command "put covariances into concise format" is included in the INPut file and a binary covariance file from an earlier SAMMY run is specified as input for this run, then an output file SAMMY.CCV will be generated. (The characters CCV imply Concise CoVariance.)

Within the CCV file, the covariance matrix is expressed as uncertainties plus correlation matrix. At the beginning of the CCV file, absolute uncertainties are listed for each varied parameter, in (6(1PG11.5)) format. The rest of the file specifies the non-negligible correlation matrix elements, converted to integer format.

Correlation coefficient $c$ is mapped to integer $M$ as follows:

(a) If $-0.04 \leq c \leq 0.04$, set $M=0$.

(b) If $c>0.04$, set $M=50 \times(1+c)-1$; round to the nearest integer. (Thus $c=1$ implies $M=99 ; \mathrm{C}=0.5$ implies $M=74$.)

(c) If $c<-0.04$, set $M=50 \times(1+c)+1$; round to integer. (Thus $c=-1$ implies $M=1 ; c=-0.5$ implies $M=24$.)

Table VIIE.1 shows this mapping for a few values of the correlation coefficient.

Only the lower triangular half of the $n \times n$ correlation matrix $C_{i j}$ is written into the SAMMY.CCV file. The first entry of a row is the row number $i$; the second, the initial column number $j$; and the following entries are the ( $M$-style) correlation of parameter $i$ with parameters $j$ through $k$ (where $k$ is the lesser of $i-1$ and $j+m-1$, and $m$ is the maximum number of such correlations that can fit on the line). If all entries on a line are zero, the line is omitted.

Test case tr71 contains two SAMMY runs that produce the output SAMMY.CCV file. 
Table VIIE.1. Map from correlation coefficient $c$ to integer $M$

\begin{tabular}{cc|ll}
\hline$c$ & $M$ & $c$ & $M$ \\
\hline-1.0 & 1 & 1.0 & 99 \\
-0.9 & 6 & 0.9 & 94 \\
-0.8 & 11 & 0.8 & 89 \\
-0.7 & 16 & 0.7 & 84 \\
-0.6 & 21 & 0.6 & 79 \\
-0.5 & 26 & 0.5 & 74 \\
-0.4 & 31 & 0.4 & 69 \\
-0.3 & 36 & 0.3 & 64 \\
-0.2 & 41 & 0.2 & 59 \\
-0.1 & 46 & 0.1 & 54 \\
-0.06 & 48 & 0.06 & 52 \\
-0.04 & 49 & 0.04 & 51 \\
\hline
\end{tabular}




\section{AUXILIARY PROGRAMS}

A number of "auxiliary" programs, not an integral part of SAMMY itself, are designed to be used in conjunction with SAMMY. These programs manipulate SAMMY PARameter and/or COVariance files, provide estimates of storage requirements for SAMMY runs, and aid in interpreting or illustrating SAMMY input or output.

In Section VIII.A the program SAMAMR is described; this program is used to rearrange PARameter and COVariance files to facilitate analyses of disparate data sets with the same resonance parameter set. (Note that SAMAMR replaces the two codes SAMADD and SAMMIX described in earlier versions of this report.)

The program SAMEST is described in Section VIII.B; SAMEST will estimate the storage requirements for SAMMY, based on information provided interactively by the user; this information includes such items as the number of resonances, how many parameters are varied, and how many data points are to be included. (Note: with the advent of modern computing facilities, use of this program is not as crucial as in the past. Hence little time has been spent maintaining this program.)

Program SAMORT, described in Section VIII.C, is used for plotting the components of the Oak Ridge resolution function. Similar plots can be made for the RPI resolution function using program SAMRPT (Section VIII.M) and of the original MULTI-style resolution function (Section VIII.L).

The program SAMCNV, described in Section VIII.D, was designed to read a SAMMY binary COVariance file and produce an ASCII file containing the complete covariance matrix for all resonance parameters.

The program SAMSTA, described in Section VIII.E, is used to create a file from which "staircase plots" of the resonance from a SAMMY PARameter file can be generated.

Program SAMBIN, which provides an alternative methodology for generating plots, is discussed in Section VIII.F.

Section VIII.G describes program SAMTHN, a simple program for averaging data files used as input to SAMMY runs.

When angular distribution data are analyzed, results are reported in an ODF file [JC78] from which plots can be made of energy vs cross section at a fixed angle. To plot angle vs cross section at fixed energy, it is necessary to reorganize the ODF file; this reorganization is accomplished with program ANGODF, discussed in Section VIII.H.

Quantum numbers can be generated using program SAMQUA, described in Section VIII.I. 
The task of converting from REFIT to SAMMY input can be eased by use of program CONVRT, discussed in Section VIII.J.

For assistance in comparing results of calculations performed by different computer codes, use program SAMCMP; see Section VIII.K for details.

Program LEVDEN is described in a separate manual [NL89, not yet completed]. LEVDEN is used to fit the level-density formula of Gilbert and Cameron to the number of levels (as given in a SAMMY PARameter file) in a specified energy region.

Program SAMDIST is used for calculating statistical distributions for R-Matrix resonance parameters; see ref. [LL95]. Level spacing distributions are calculated according to the Wigner distribution law, distributions for widths are calculated via $\chi^{2}$ distributions, and long-range correlations of the energies are tested via the $\Delta_{3}$ statistic of Mehta-Dyson. 


\section{VIII.A PROGRAM SAMAMR}

Because the fitting procedure in SAMMY is Bayes' method (Section II) rather than ordinary least-squares, SAMMY may be used for general evaluation purposes: that is, for determining a set of parameters which simultaneously describe a large number of different types of experimental data taken at different times and/or at different laboratories. Numerous examples of such evaluations are given in the references of Appendix D, "Analyses Using SAMMY."

Performing such evaluations with SAMMY presently requires sequential analyses of the various data sets, ${ }^{1}$ with the output parameter and covariance matrix from the first analyses used as input to the second, output from the second used as input to the third, etc. If none of the broadening parameters are varied during the analyses, and if no data-reduction parameters are included, this will pose no undue difficulty; the analyst simply changes the values of the thickness and/or of the broadening parameters in the INPut file to correspond to the data currently being analyzed. However, when any of the broadening parameters are varied, and/or when normalization or background are included in the analysis, the PARameter and COVariance files must also correspond to the current data set. The code SAMAMR performs the appropriate modifications to the PARameter and COVariance files.

For example, data may come from two or more samples of different thicknesses and at different temperatures. The initial PARameter file is set up to include thickness and temperature appropriate for the first sample; thickness and temperature for the other samples are simply omitted. After the analysis of the first data set, code SAMAMR is used to incorporate the second thickness (as yet uncorrelated to any other parameters) and to "mothball" the correlated but now-to-be-unused first thickness; a second run of SAMAMR introduces the new temperature parameter and mothballs the old. The resulting PARameter file can then be used as input for the SAMMY analysis of the second data set. If, for a subsequent SAMMY run, one of the "UNUSED" parameters must be resurrected, SAMAMR will interchange the current BROADening parameter with the appropriate UNUSED parameter.

To illustrate, suppose three data sets are available, taken from three samples at two different temperatures:

Data Set 1: Sample 1 (thickness $n_{1}$, Temperature $T_{1}$ )

Data Set 2: Sample 2 (thickness $n_{2}$, Temperature $T_{2}$ )

Data Set 3: Sample 3 (thickness $n_{3}$, Temperature $T_{1}$ )

The sequence of commands required to properly analyze these data is shown in Table VIIIA.1. The input PARameter file (TR7AAA.PAR) is listed in Table VIIIA.2. Output PARameter files are listed in Tables VIIIA.3 through VIIIA.12. (Data and analysis are courtesy

1 A planned reformulation of the implementation of Bayes' method within SAMMY will provide an alternative to this procedure. See Appendix F for details. 
of F. G. Perey [FP84].) Note that values (and covariances) of the unused parameters are updated in each SAMMY run, even though the data have no direct effect on those parameters. Rather, the effect is indirect, via the covariance matrix. Note also that values are never changed in a SAMAMR run. Complete listings of all INPut, PARameter, DATA, and LPT files for this example are given in test case TR7, which is available along with the SAMMY FORTRAN from the Radiation Safety Information Computational Center [RSICC].

SAMAMR was designed to be run interactively (though it can be run in batch once the user is sufficiently familiar with the input). The code will prompt the user with questions about the type of operation to be performed, the parameters involved, and values for any new parameters.

Type of operation. The first question asked by SAMAMR is "Do you want to Add, Mix, Remove, reCover, or Introduce variables?"; the user will type the capitalized letter for the appropriate operation.

The operations Add and Mix correspond respectively to the operations performed by the old codes SAMADD and SAMMIX. Add refers to (1) the removal of one parameter to the unused list and (2) the introduction of another parameter (of the same kind) into the active list. The user is asked to specify the particular parameter (from a list provided), to give the variable number for that parameter if it was varied in the run which produced this covariance file, and to give the value and uncertainty to be used for the new parameter. Mix refers to the interchange of one unused parameter with the corresponding parameter in the active variable set. The user must provide the location (variable number) within the unused parameter set.

The operations Remove, reCover, and Introduce are used to reorganize the attenuation or normalization-and-background parameters when the analysis involves both angle-differential data (such as the elastic angular distribution scattering data) and other data which are integrated over angle (such as transmission). The operation Remove moves normalization-and-background parameters for all angles, or attenuation parameters for all angles, from the active variable set to the unused variable set. The operation reCover performs the inverse, moving parameters from the unused to the active set. Introduce allows the introduction of new parameter values and uncertainties when switching from analysis of angle-integrated data to analysis of angular distribution data.

Type of parameter. The types of parameters to be treated by SAMAMR are different, depending on the operation to be performed.

For both Add and Mix, only one parameter is treated at a time; the example shown in Table VIIIA.1 therefore requires two runs of SAMAMR between each run of SAMMY. The parameters that can be treated are taken from the following list, in which is also given the Card Set and Card number from the PARameter file (see Table VIB.1): 
TEMP , THICK, DEL-L, DEL-G, DEL-E

NORML, BACKA, BACKB, BACKC, BACKD, BACKF

BURST

WATR0, WATR1, WATR2

TANTA

$\mathrm{X} 1, \mathrm{X} 2, \mathrm{X} 3, \mathrm{X} 0$

WWW, ALPHA

$\mathrm{D}, \mathrm{F}, \mathrm{G}$

DELTA

CHANN

DELL1, DELL0

NU

ATTENI, ATTENO

GAMMA, GAMM1, GAMM2,... GAM15
(Card Set 4, Card 3)

(Card Set 6, Card 2)

(Card Set 9, Card 2)

(Card Set 9, Card 3)

(Card Set 9, Card 3)

(Card Set 9, Card 4)

(Card Set 9, Card 6)

(Card Set 9, Card 8)

(Card Set 9, Card 8)

(Card Set 9, Card 10)

(Card Set 11, Card 2)

(Card Set 11, Card 3)

(Card Set 11, Card 4)

(Card Set 11, Card 5)

For the operations Remove, reCover, and Introduce, only the parameters ATTEN and ALLNB may be specified. When ATTEN is specified, all attenuation parameters (both incident and outgoing, from Card Set 11, Card 4 of the PARameter file) are involved. When ALLNB is specified, all normalization and background parameters are involved (see Card Set 6, Card 2). Again, only one type can be be treated during one run of SAMAMR.

When the operation Introduce is used, attenuation or normalization/background parameters are assumed to be given in a separate file in the same format as used in the PARameter file (though without the "MISCEllaneous parameters" or "NORMAlization and background" header lines of Card Sets 11 and 6). SAMMY will ask for the file name instead of the parameter values. Test case tr 36 shows examples of the use of this feature.

An additional restriction for operations Remove, reCover, and Introduce stems from the connection between the attenuation parameters and the number of angles: SAMAMR assumes that removal of attenuation parameters implies changing from angular-distribution data to angleintegrated data, and that recovery or introduction of attenuation parameters implies the reverse change. Removal of attenuation parameters, therefore, must be accomplished after removal of normalization and background parameters, and recovery or introduction of attenuation parameters must be accomplished prior to recovery or introduction of normalization and background parameters. 
Plotting with SAMMY is accomplished by means of a set of utility programs FORODF [JC78]. SAMMY produces "ODF" or "plot" files containing the information (such as energies and cross sections) from which plots made be made using FORODF. (See, e.g., Section VII.C.) Users on other systems may prefer to use other plotting packages. To facilitate this, the "SAMMY manager" can now choose between two alternatives when linking the program. To use the ODF option, the manager includes file modfio.o (compiled form of modfio.f) when linking those segments which require the plotting routines. To use the other option, the manager replaces file modfio.o with modf3.o (compiled form of modf3.f); this is most readily accomplished by simply renaming modf3.o to modfio.o prior to the link step. With this option, SAMMY will produce a "generic" binary file (also named SAMMY.ODF) which contains the same information normally stored in the ODF file, but in a form which can easily be read by a simple FORTRAN code.

A sample code SAMBIN (file mbin.f) is provided with the SAMMY FORTRAN. SAMBN reads the binary file and produces an ASCII file (ASCII.PLT) which contains the same information as the ODF file on the ORNL vresion. The local SAMMY manager may wish to modify the file mbin.f to accommodate his system's needs; mbin.f contains extensive comment cards to aid in making the needed modifications. 


\section{VII.G SAMTHN: THINNING DATA}

Often a data file will contain more points than are needed to define the measurement (e.g., data appear to be very dense in energy regions where there is little structure in the data). SAMMY runs will therefore require far more computer time than is actually needed. For these reasons it is often deemed reasonable to "thin" the data, at least for preliminary runs. A program SAMTHN has been written for this purpose; it has not, however, been studied extensively so use with caution! Please note, also, that any results obtained with thinned data should ultimately be tested against the complete dense data set, to ensure that no important features were missed.

In running SAMTHN, the user provides two files, plus the name for the new thinned data file. The first user-provided file gives instructions on how the thinning should be done; the second is the dense data file. The first line of the thinning file contains three numbers ( $N$, Emin,Emax) in I5, 2F10.1 format. The integer $N$ tells how many data points are to be averaged together in the energy range from Emin to Emax. Second and subsequent lines contain two numbers (N,Emax); Emin is assumed to be equal to the previous Emax. Note that energies must be given from low to high, no matter what the ordering of data points in the original dense data file.

The format for the output thinned data file is always (3F20.10); in using this data file for SAMMY runs, the INPut file must contain the line USE TWENTY SIGNIFICANT DIGITS FOR EXPERImental data.

The algorithms used by SAMTHN to average the data are as follows:

$$
\begin{gathered}
\bar{E}=\left(\frac{1}{N} \sum_{i=1}^{N} \frac{1}{\sqrt{E_{i}}}\right)^{-2}, \\
\bar{D}=\frac{1}{\bar{V}} \sum_{i=1}^{N} \frac{D_{i}}{V_{i}},
\end{gathered}
$$

with

$$
\bar{V}=\left(\sum_{i=1}^{N} V_{i}^{-1}\right)^{-1},
$$

in which $E$ represents the energy, $D$ the data, and $V$ the variance (i.e., the square of the uncertainty). Quantities with subscripts are from the original dense data set, and quantities with bars represent the averaged values. 


\section{VIII.H ANGODF: CONVERT FROM ENERGY/ANGLE TO ANGLE/ENERGY}

When analyzing angular distribution data (differential elastic scattering), the results are reported in two ODF files. The first file, SAMMY.DAT, contains the experimental data and uncertainties for each angle, as a function of energy; contents of each section of this file are shown in Table VIIIH.1. The second file, SAMMY.ODF, contains the results of the calculations; contents of this file are described in Table VIIIH.2.

Table VIIH.1. Contents of the ODF file SAMMY.DAT

\begin{tabular}{|c|c|}
\hline Sect. No. & Meaning \\
\hline 1 & Energy in $\mathrm{eV}$ \\
\hline 2 & Experimental cross section (barns) for the first angle \\
\hline 3 & Absolute uncertainty on experimental cross section for the first angle \\
\hline 4 & Experimental cross section (barns) for the second angle \\
\hline 5 & Absolute uncertainty on cross section (barns) for the second angle \\
\hline 6,7 , etc. & Repeat, two sections (data plus uncertainty) for each angle \\
\hline
\end{tabular}

Table VIIIH.2. Contents of the ODF file SAMMY.ODF for angular distribution data

\begin{tabular}{|c|c|}
\hline Sect. No. & Meaning \\
\hline 1 & Energy in $\mathrm{eV}$ \\
\hline 2 & Initial calculation of cross section (barns) for the first angle \\
\hline 3 & Final calculation of cross section (barns) for the first angle \\
\hline 4 & Initial calculation of cross section (barns) for the second angle \\
\hline 5 & Final calculation of cross section (barns) for the second angle \\
\hline 6,7 , etc. & Repeat, two sections (initial plus final calculation) for each angle \\
\hline
\end{tabular}


Using these two files, one can produce plots of the various cross sections (experimental vs calculated) at a given angle, with energy as the horizontal axis. Often, however, it is also useful to consider plots of cross sections at a given energy, with angle as the horizontal axis, which cannot be accomplished directly with forodf. Instead, the positions of energy and angle must be reversed in a new ODF file; this can be accomplished using the conversion program ANGODF.

To run program ANGODF, respond appropriately to the following questions:

- What is name of ODF file with experimental data? [SAMMY.DAT]

- What is name of ODF file with theoretical values? [SAMMY.ODF]

- What is name of new ODF file? [whatever name you choose]

- What is name of INPut file? [same as the INPut file which was used to generate SAMMY.DAT and SAMMY.ODF]

- Are all energies to be used? (default=NO)

- What energies? One per line, end with blank... [question is omitted if response to previous question was "yes"]

The program will generate an ODF file (with the name you chose), containing sections as described in Table VIIIH.3.

\begin{tabular}{|c|c|}
\hline Sect. No. & Meaning \\
\hline 1 & Angle in degrees \\
\hline 2 & Experimental cross section (barns) for the first energy \\
\hline 3 & Absolute uncertainty on the experimental cross section (barns) \\
\hline 4 & Initial calculation of cross section (barns) for the first energy \\
\hline 5 & Final calculation of cross section (barns) for the first energy \\
\hline 6,7 , etc. & $\begin{array}{l}\text { Repeat, four sections (data plus uncertainty, initial plus final } \\
\text { calculation) for each energy requested }\end{array}$ \\
\hline
\end{tabular}




\section{VIII.I RESONANCE QUANTUM NUMBERS}

The code SAMQUA can serve as an aide to generating the correct (and complete) set of resonance spin quantum numbers for individual nuclides. This program was designed to be run interactively, with the user answering questions as they occur; output is in a file named "quantum.dat." Printed below (and completed on subsequent pages) is the output file from a run that answers the question "Do you want complete output(C) or just one sample $(O)$ " with "c," and "What is the maximum $l$-value desired?" with " 3 " (with no punctuation). Note that portions of this file are in the format needed for "Alternative to Card Set 10" in the SAMMY NPut file.

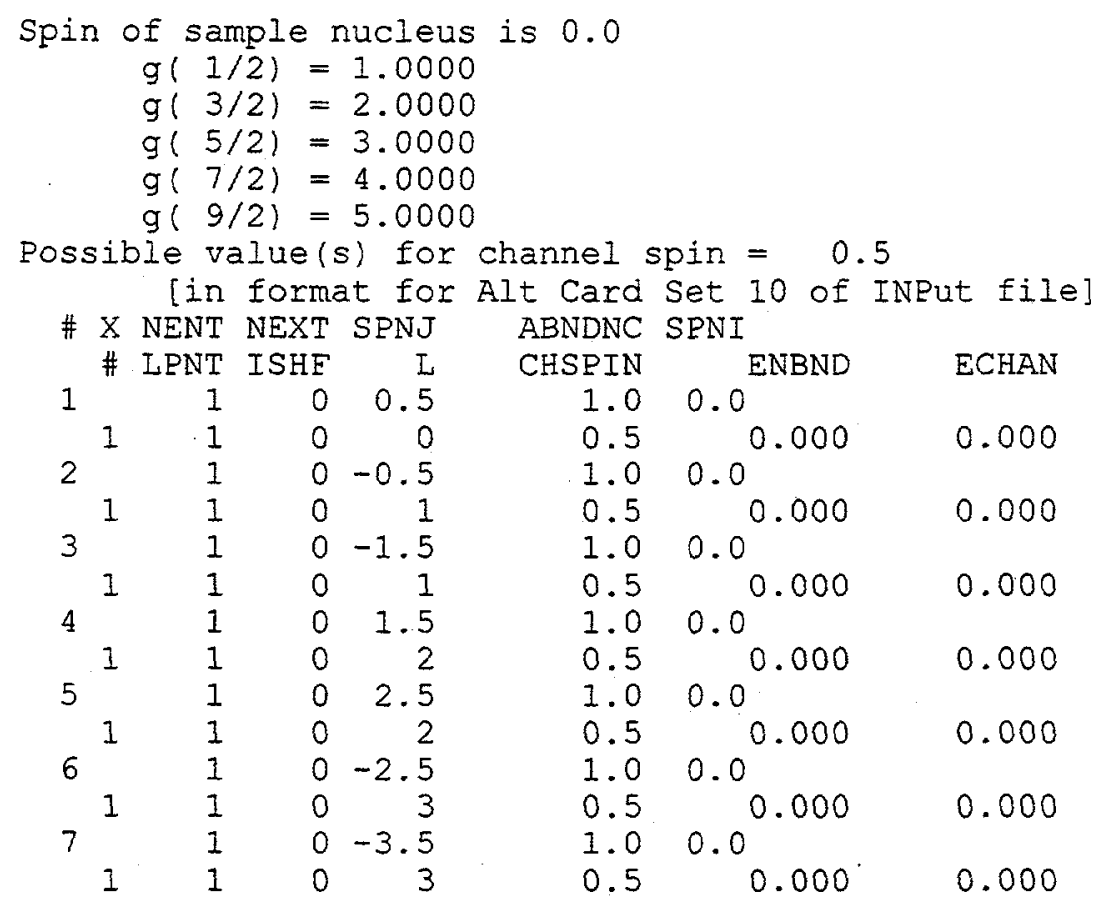




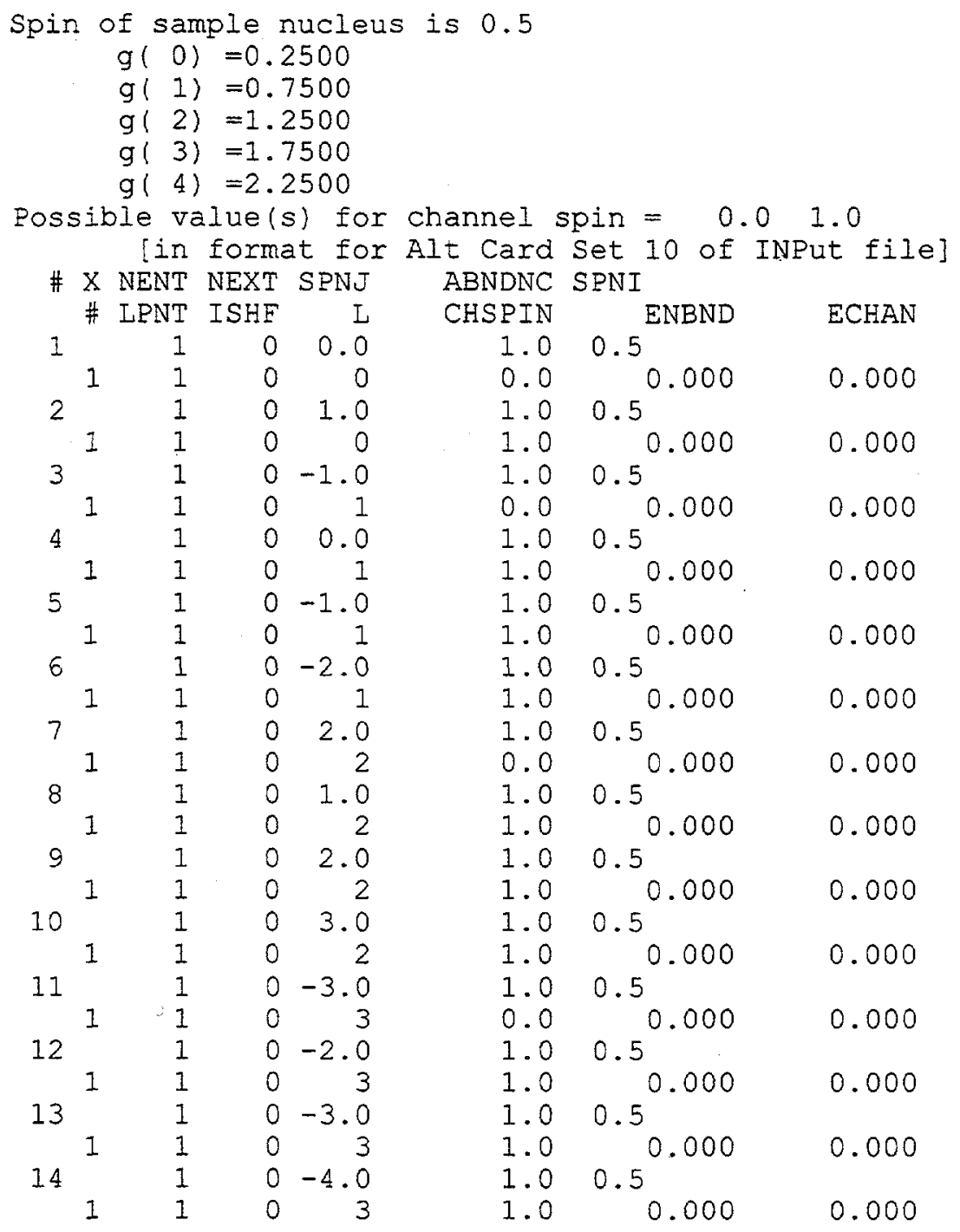




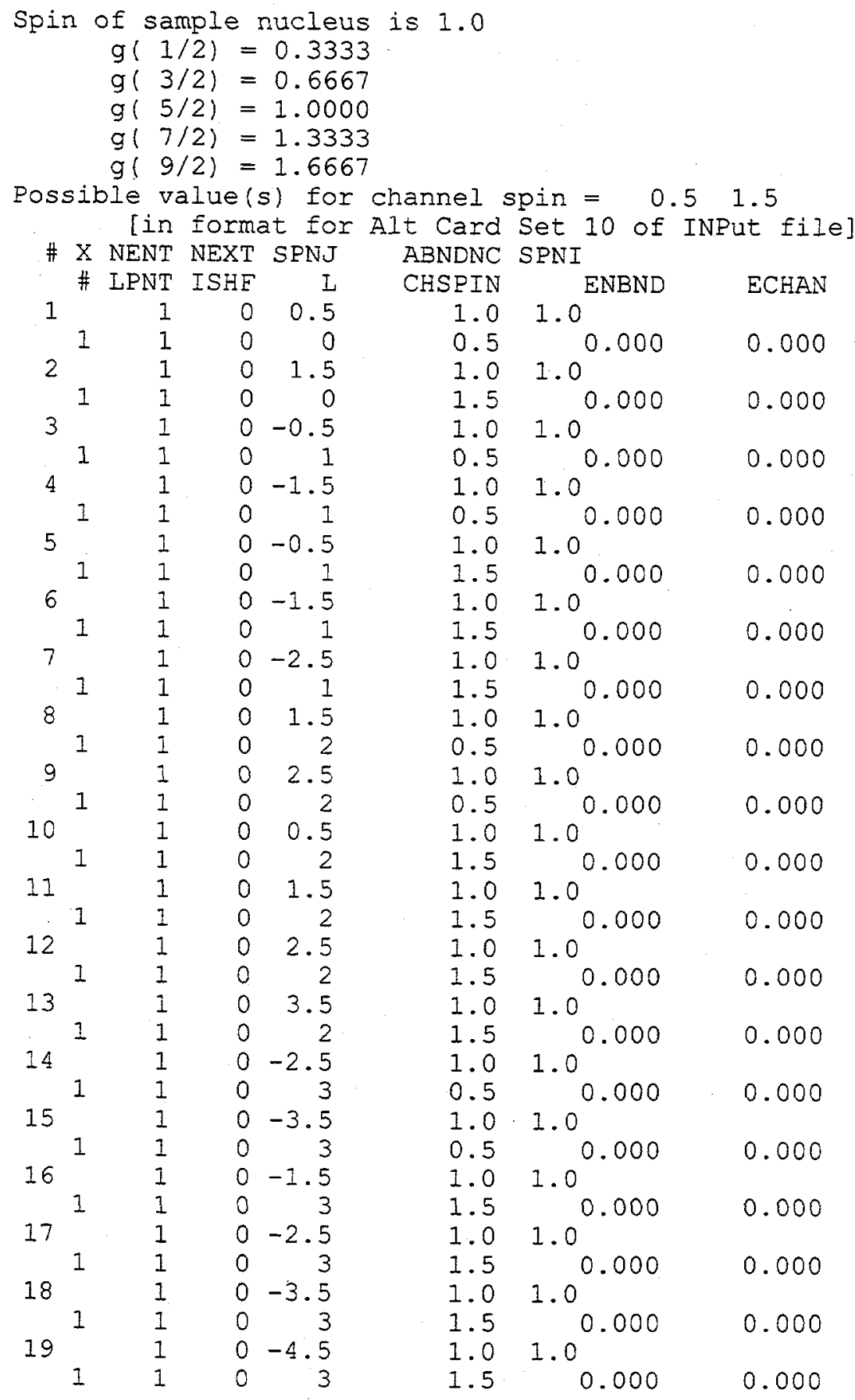




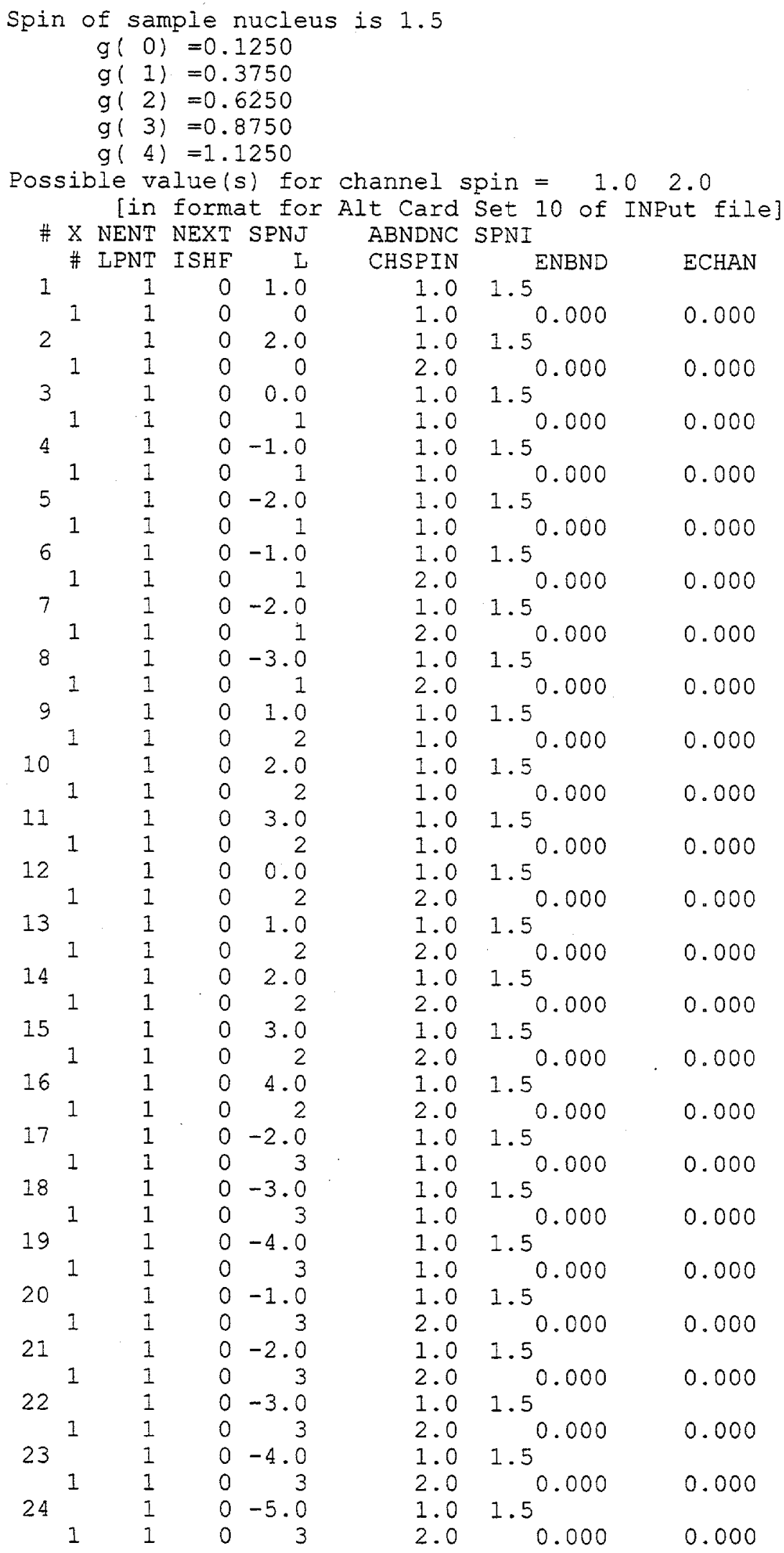




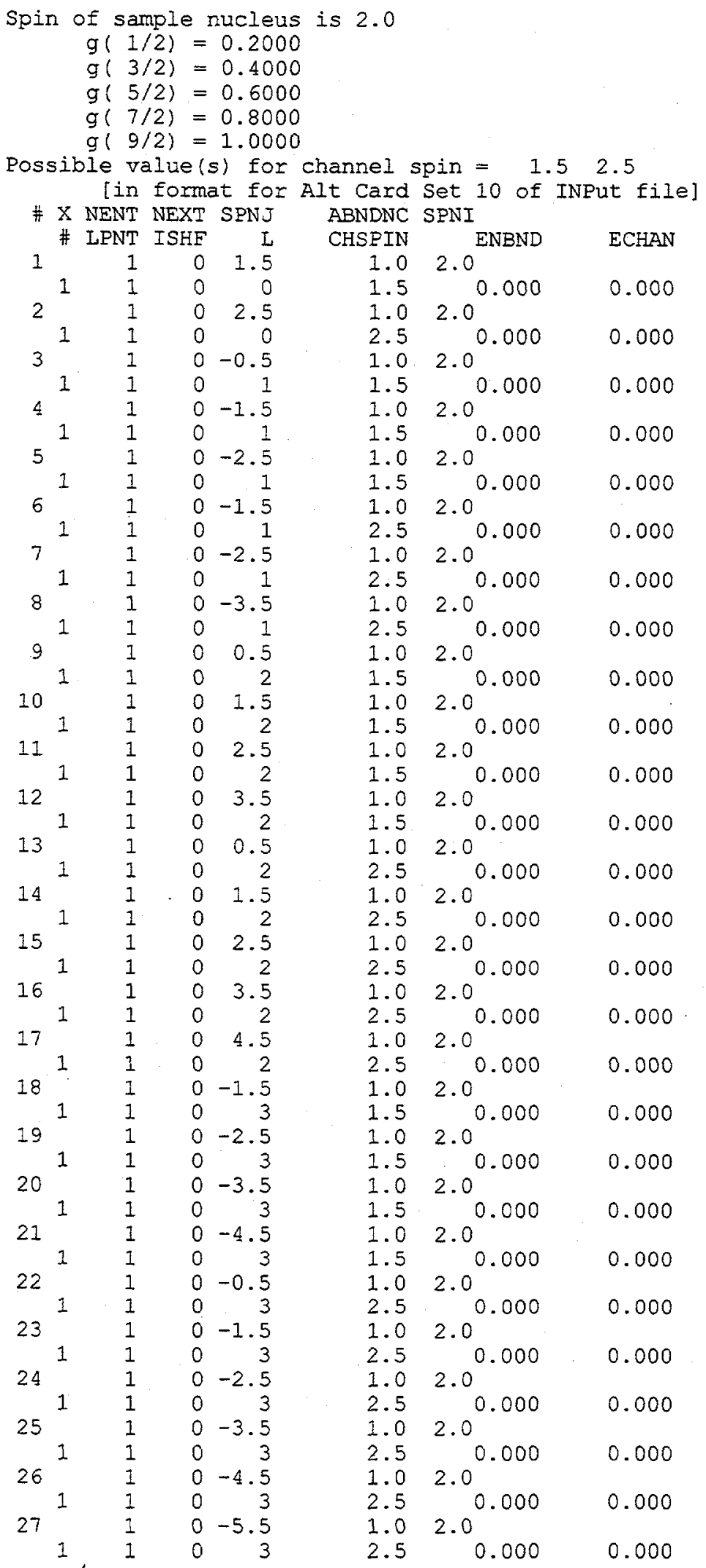




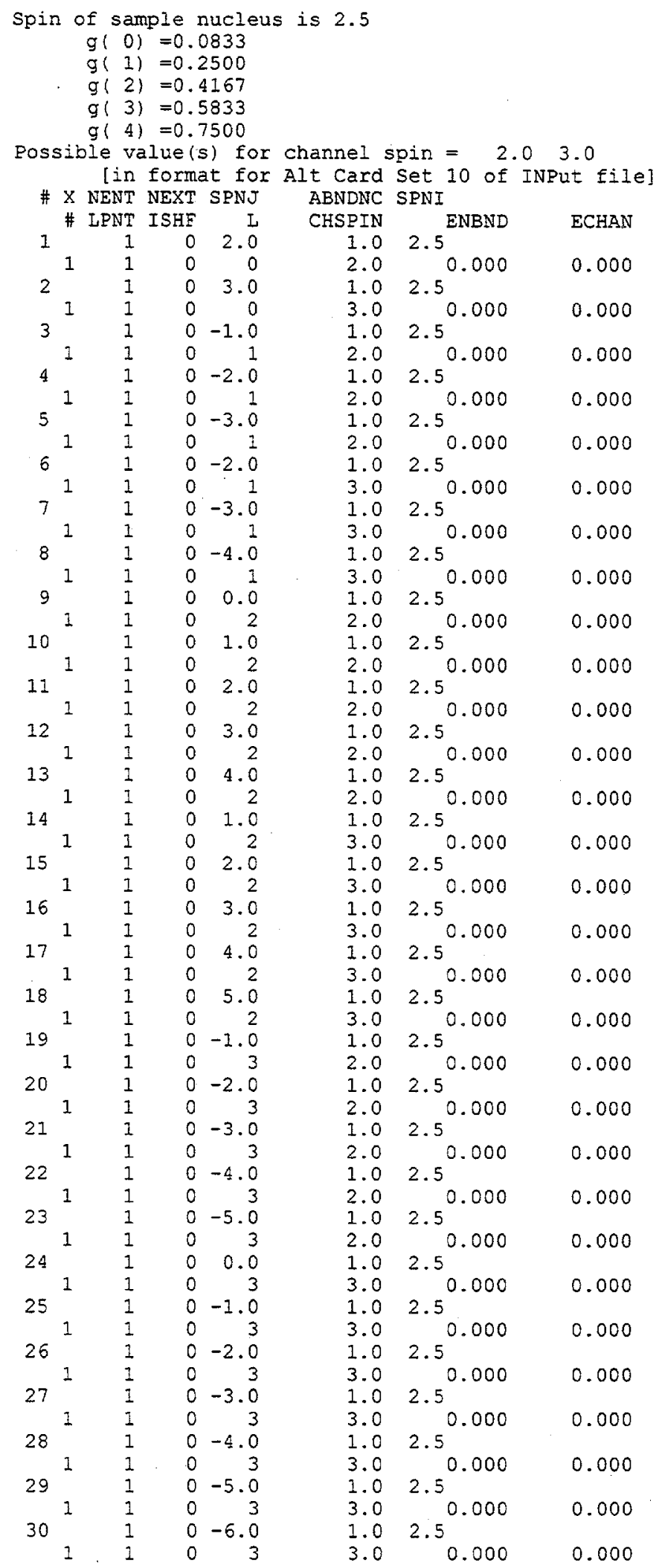




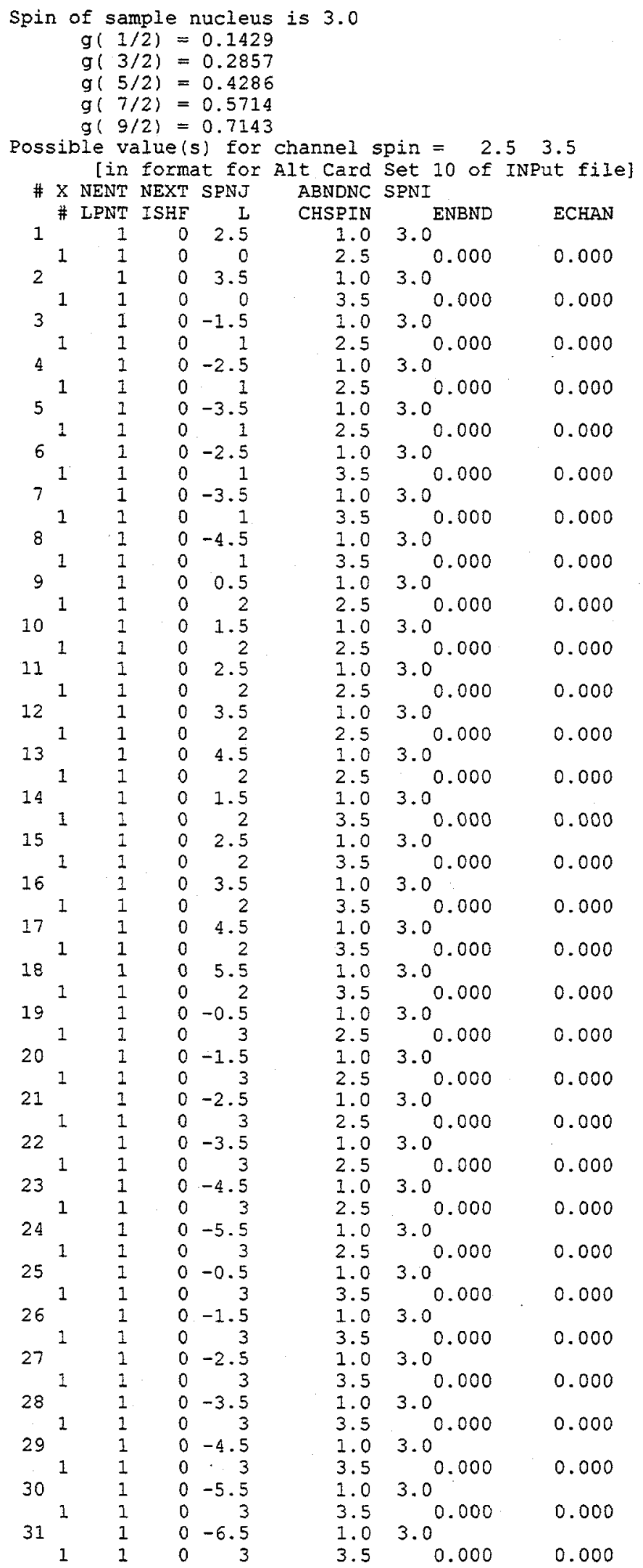




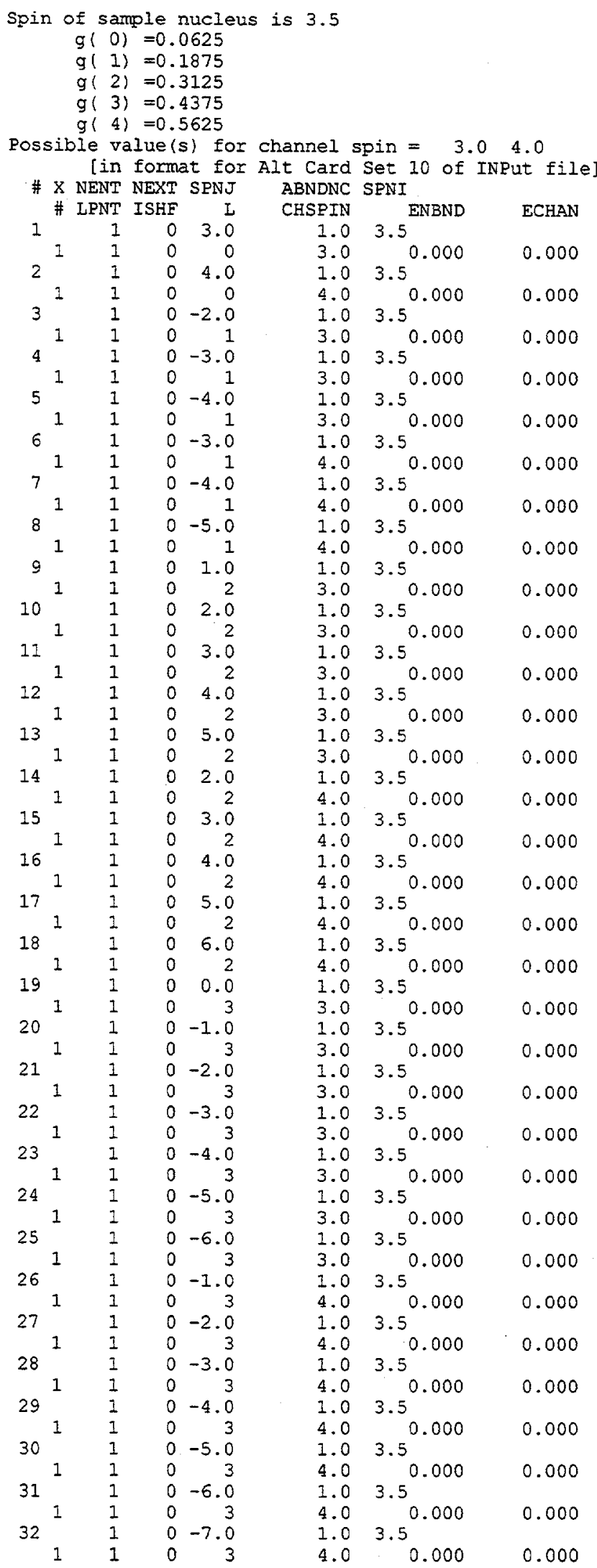


During his 1996 visit to Oak Ridge, Mick Moxon and the author made preliminary attempts to provide an interface between Moxon's code REFIT [MM89] and SAMMY. The result is a program CONVRT, which is intended to read the input files for one code and write the corresponding input files for the other code. Beginning from REFIT input files, program CONVRT is able to generate appropriate SAMMY-style INPut and PARameter files; similarly, beginning from SAMMY-style files, CONVRT can generate portions of the REFIT input files. In either case, the user will likely need to edit the new files to provide complete input. Note that CONVRT is not yet able to translate resolution parameters nor experimental data from one code to the other, because definitions are not completely compatible between SAMMY and REFIT.

Input to program CONVRT consists of one command line (either "sammy" if converting from SAMMY to REFIT, or "refit" if converting from REFIT to SAMMY), followed by names of input files.

When converting from SAMMY to REFIT, file names are given in the usual order (INPut, PARameter, and DATa file names). Output consists of a SAMMY.LPT file, plus files containing portions of the REFIT input files; these are named REFIT $x$.DAT where " $x$ " is a digit from 0 to 9 . One file is given for each nuclide type; it is the user's responsibility to combine these properly into the REFIT input file.

When converting from REFIT to SAMMY, output consists of three files: SAMMY.LPT, SAMMY.INP, and SAMMY.PAR. The user should rename these files and check to be sure they are complete before using the INPut or PARameter file as input to SAMMY runs. 


\section{VIII.K SAMCMP: COMPARE RESULTS}

Program SAMCMP is as an aide in comparing cross sections calculated by one computer code (e.g., NJOY [Rm82] or REFIT [MM89]) with those calculated by SAMMY. First, a noBayes SAMMY run is made, using the other code's calculations as the DATa file, and including the alphanumeric command "compare experiment to theory" in the INPut file. SAMMY generates a binary file SAM53.DAT, which can then be read by program SAMCMP to produce the ODF file SAMCMP.ODF.

The contents of the various sections output file SAMCMP.ODF are as follows:

$$
\begin{aligned}
& \text { S1 }=\text { energy } \\
& \text { S2 }=X=\text { "data," which may be a calculation from another code } \\
& \text { S3 }=S=\text { "theory," which is the SAMMY calculation } \\
& \text { S4 }=X-S \\
& \text { S5 }=(X-S) / S \\
& \text { S6 }=(X-S) / S \times 10^{3} \\
& \text { S7 }=(X-S) / S \times 10^{4} \\
& \text { S8 }=(X-S) / S \times 10^{5} \\
& \text { S9 }=(X-S) / S \times 10^{6} \\
& \text { S10 }=\mathrm{S} 5 \text { adjusted for small cross sections } \\
& \text { S11 }=\mathrm{S} 10 \times 10^{3} \\
& \text { S12 }=\text { S10 } \times 10^{4} \\
& \text { S13 }=\text { S10 } \times 10^{5} \\
& \text { S14 }=S 10 \times 10^{6}
\end{aligned}
$$

For Section 10 , the quantity $(X-S) / S$ is replaced by $10^{-25}$ if both $X$ and $S$ are smaller than 0.0001 . Thus the value S10 through S14 will be sizeable only when the cross sections themselves are reasonably large. 


\section{VIII.L SAMRST - PLOT RESOLUTION FUNCTION}

Even though program SAMRST is actually a module of SAMMY, it is covered in this section because comparable programs (SAMORT and SAMRPT) are also presented here.

To generate a plot file containing the MULTI-style resolution function at specific energies, insert the command line

PLOT RESOLUTION FUNCtion

in the INPut file. Also in the INPut file, directly after the blank line (Card Set 4) following the alphanumeric commands (Card Set 3), insert one line specifying the energies (in 8F10.1 format) at which the resolution function is to be reported; a maximum of eight such energies are allowed. (Note: This line is not described in Table VIA.1.)

Program SAMRST will generate one plot file (ODF file) per energy; these files are named SAMRSx.ODF, where " $\mathrm{x}$ " is a digit from 1 to 8; these files contain energy in $\mathrm{S} 1$ and resolution function in S2. In the event that there are too few points to resolution-broaden at the specified energy, an error message is printed and the plot file is not generated.

An example using SAMRST is given in test case TR18. 


\section{VII.M SAMRPT - PLOT RPI RESOLUTION FUNCTION}

To plot the components and the total RPI resolution function (see Section IV.G, page 92s) at a given energy, use program SAMRPT. Input to SAMRPT consists of two lines of information: The first is the name of a file containing the RPI portion of the PARameter file; the header line ("RPI Resolution function") may or may not be present. The second line contains the energy in $\mathrm{eV}$, mass in atomic mass units (amu), and flight-path-length in $\mathrm{m}$, in $3 \mathrm{~F}$ format (separated by commas or spaces); alternatively the same information may be given as the first line in the RPI file. [Default values for these three quantities are 150.0, 183.85, and 25.6040.]

Output from a run of SAMRPT consists of of one ASCII file, SAMMY.RPI, which gives derived quantities such as the time-width associated with each component of the resolution function, and as many as four plot (ODF) files:

SAM_RPI.ODF $\quad-\mathrm{S} 1=$ energy, $\mathrm{S} 2=($ total $)$ resolution function, $\mathrm{S} 3=$ time

SAM_RPI_BURST.ODF $-\mathrm{S} 1=$ time, $\mathrm{S} 2=$ burst-width component

SAM_RPI_TDXXX.ODF $-\mathrm{S} 1=$ time, $\mathrm{S} 2=$ target-plus-detector component

SAM_RPI_CHANN.ODF $-\mathrm{S} 1=$ time, $\mathrm{S} 2=$ channel-width component

Test case TR53 gives numerous examples (not all of which make physical sense) for the use of this program. 


\section{X.D TUTORIAL}

A series of computer exercises has been developed as an aide to persons wishing to learn how to run SAMMY. Novice users are urged to work their way through the entire series of exercises in numerical order; experienced SAMMY users may find particular exercises helpful when beginning to use an unfamiliar feature.

Files for each exercise are located in a separate subdirectory; instructions for the exercise are given in the file README.FIRST, located in that subdirectory. Results of running the exercise are in subdirectory ANS (for "answers").

Table XD.1 explains which SAMMY features are addressed in the examples. Note that each example assumes that the user has knowledge of features described in earlier examples. Also note that the first example (ex000) teaches the use of the ORNL plotting package FORODF [JG78]; for users at facilities not using this plotting packing, this example should be modified. 
Table XD.1. Computer exercises for the student

\begin{tabular}{|c|c|}
\hline No. & Description of feature emphasized in this example \\
\hline 000 & Use of plotting package FORODF \\
\hline 001 & Simple one-resonance nonfissile nucleus; capture experiment \\
\hline 002 & Fissile nucleus, several resonances; capture experiment \\
\hline 003 & Different kinds of cross sections \\
\hline 004 & $\ell>0(\mathrm{~s}, \mathrm{p}, \mathrm{d}$ waves $) ; I>0$ \\
\hline 005 & Doppler broadening \\
\hline 006 & Resolution broadening (Gaussian) \\
\hline 007 & Resolution broadening (ORR) \\
\hline 008 & Resolution broadening (RPI) \\
\hline 009 & Normalization \\
\hline 010 & Backgrounds \\
\hline 011 & More than one channel radius \\
\hline 012 & Multiple nuclides within a single sample \\
\hline 013 & Uncertainties on parameters \\
\hline 014 & Angular distributions \\
\hline 015 & Sequential vs simultaneous fitting of data \\
\hline 016 & $\begin{array}{l}\text { Sequential fitting of three data sets; parameter covariance matrix } \\
\text { as input }\end{array}$ \\
\hline 017 & Several data sets; varying data-reduction parameters \\
\hline 018 & Data covariances (implicit and explicit) \\
\hline 019 & Self-shielding and multiple-scattering corrections to capture yields \\
\hline 020 & Integral quantities \\
\hline 021 & Almost real data: $W$ transmission with many complications \\
\hline 022 & Almost real data: U235. How to do an evaluation \\
\hline 023 & Finding input errors \\
\hline
\end{tabular}




\section{XI.B USE OF TEMPORARY DATA FILES TO STORE INTERMEDIATE RESULTS}

Output to and input from temporary files is a time-honored method of saving core space at the expense of runtime. In a modular program such as SAMMY, the use of temporary files provides the necessary linkage from one module to another. Upon. successful completion of a run, the temporary files may be deleted. An aborted run can (sometimes) be restarted if the user takes care not to destroy these files. Debugging can also be greatly simplified by saving temporary files in order to debug one module at a time.

Temporary files generated by SAMMY are listed in Table XIB.1, along with input and output files required by or produced by the code. "Standard" names referenced in the third column of the table are "SAMxx.DAT," where $\mathrm{xx}$ is replaced by the unit number. 
Table XIB.1. Files used by SAMMY. Note that the letter A, B, or $O$ in the second column indicates whether the file is written as ASCII, binary, or ODF file

\begin{tabular}{|c|c|c|c|c|c|}
\hline $\begin{array}{l}\text { Unit } \\
\text { No. }\end{array}$ & $\begin{array}{l}\text { A, } \\
\text { B, } \\
\text { O }\end{array}$ & $\begin{array}{l}\text { File name } \\
\text { if not } \\
\text { standard }\end{array}$ & $\begin{array}{l}\text { Segment: } \\
\text { subroutines in which } \\
\text { this file is written }\end{array}$ & $\begin{array}{c}\text { Segment: subroutines } \\
\text { in which this file } \\
\text { is read }\end{array}$ & Content \\
\hline 5 & A & $\begin{array}{l}\text { (From } \\
\text { terminal, } \\
\text { or batch } \\
\text { file) }\end{array}$ & & $\begin{array}{ll}\text { mas: } & \text { inppar, fpar, } \\
& \text { sumstr, fixnam, } \\
& \text { datcov, writ16, } \\
& \text { file } 2 x \\
\text { ort: } & \text { samort } \\
\text { rpt: } & \text { samrpt } \\
\text { rsl: } & \text { samrsl } \\
\text { sta: } & \text { samsta } \\
\text { thn: } & \text { samthn }\end{array}$ & See Table VID. 1 \\
\hline 6 & A & Log file & [Many places] & & \\
\hline 10 & A & $\begin{array}{l}\text { ENDF/B- } \\
\text { VI file } 2\end{array}$ & & $\begin{array}{l}\text { mas: endfb6, rcontx, } \\
\text { rcont, rtabl, rlist }\end{array}$ & See Table VIF.1 \\
\hline 10 & A & $\begin{array}{l}\text { ENDF/B } \\
\text { file } 3\end{array}$ & & $\begin{array}{l}\text { rec: } \operatorname{read} 3, \text { rdndf3 } \\
\text { cro: } \operatorname{read3}, \text { rdndf3 } \\
\text { xct: } \operatorname{read} 3, \text { rdndf3 }\end{array}$ & $\begin{array}{l}\text { File } 3 \text { contribution } \\
\text { to cross section }\end{array}$ \\
\hline 10 & A & MXW file & & mxw: rktxxx, readkt & See Section VI.H \\
\hline 10 & A & NDF file & & $\begin{array}{l}\text { ndf: endfb6, rdndf, } \\
\text { rdntgq }\end{array}$ & See Section VI.F \\
\hline 10 & $A$ & $\begin{array}{l}\text { No } \\
\text { standard } \\
\text { name) }\end{array}$ & & thn: samthn & $\begin{array}{l}\text { File with thinning } \\
\text { instructions; see } \\
\text { Section VIII.G }\end{array}$ \\
\hline 11 & A & INPut file & & mas: finp, new, newinp & $\begin{array}{l}\text { See Tables VIA.1 } \\
\text { and VIA.2 }\end{array}$ \\
\hline 12 & A & $\begin{array}{l}\text { No } \\
\text { standard } \\
\text { name) }\end{array}$ & thn: out & & $\begin{array}{l}\text { File containing } \\
\text { thinned data in } \\
\text { "twenty" format; } \\
\text { see Section Vili.G. }\end{array}$ \\
\hline $\begin{array}{l}12 \\
32\end{array}$ & A & $\begin{array}{l}\text { Initial } \\
\text { PARa- } \\
\text { meter } \\
\text { file }\end{array}$ & & $\begin{array}{l}\text { mas: fpar } \\
\text { inp: qresp, qfudge, } \\
\text { qextr, qrext, qradi, } \\
\text { qisot, qbroa, qmisc, } \\
\text { qpmcs, qorre, } \\
\text { qrpire, qnorm, } \\
\text { qbackg, qdatp, } \\
\text { qunus, qbaga, } \\
\text { qcova, qrelu, qexpl, } \\
\text { pread }\end{array}$ & See Table VIB.1 \\
\hline
\end{tabular}




\section{Table XIB.1 (continued)}

\begin{tabular}{|c|c|c|c|c|c|}
\hline $\begin{array}{l}\text { Unit } \\
\text { No. }\end{array}$ & $\begin{array}{l}\mathrm{A} \\
\mathrm{B} \\
\mathrm{O}\end{array}$ & $\begin{array}{l}\text { File name } \\
\text { if not } \\
\text { standard }\end{array}$ & $\begin{array}{c}\text { Segment: subroutines } \\
\text { in which this file is } \\
\text { written }\end{array}$ & $\begin{array}{c}\text { Segment: subroutines } \\
\text { in which this file } \\
\text { is read }\end{array}$ & Content \\
\hline $\begin{array}{l}12, \\
32 \\
\text { cont. }\end{array}$ & & & . & $\begin{array}{l}\text { par: } \\
\text { parfil, readrs, } \\
\text { pread, readrx, } \\
\text { readex, readrd, } \\
\text { readis, brdfix, } \\
\text { readms, readpm, } \\
\text { readrp, readox, } \\
\text { readxp, readnb, } \\
\text { readbg, readba, } \\
\text { reador, readda, } \\
\text { readun, readre, } \\
\text { readab } \\
\text { amr: } \\
\text { parfix, rdwrt, } \\
\text { brdfix, mscfix, } \\
\text { pmcfix, orrfix, } \\
\text { rpifix, nbkfix, } \\
\text { bgffix, rd } \\
\text { fdc: } \\
\text { paramf } \\
\text { sta: } \\
\text { samsta }\end{array}$ & \\
\hline 12 & A & $\begin{array}{l}\text { SAMNDF. } \\
\text { PAR }\end{array}$ & $\begin{array}{l}\text { mas: write 1, write2, } \\
\text { write3 }\end{array}$ & & $\begin{array}{l}\text { SAMMY-style PAR } \\
\text { file generated from } \\
\text { ENDF/B-style file }\end{array}$ \\
\hline 13 & A & $\begin{array}{l}\text { SAMNDF. } \\
\text { INP }\end{array}$ & $\begin{array}{l}\text { mas: endf1, newinp, } \\
\text { newin2 }\end{array}$ & & $\begin{array}{l}\text { SAMMY-style } \\
\text { INPut file generated } \\
\text { from ENDF/B-style } \\
\text { file }\end{array}$ \\
\hline 13 & $\begin{array}{l}\mathrm{A} \\
\text { or } \\
\mathrm{O}\end{array}$ & DATa file & & 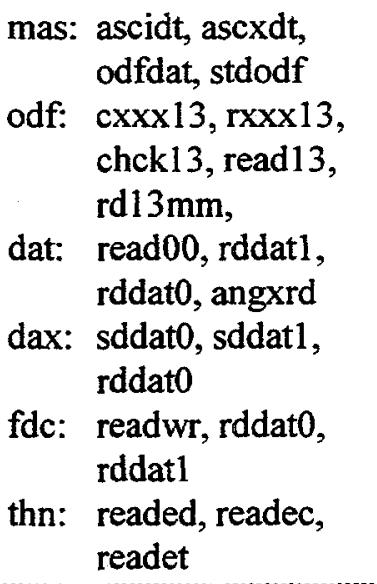 & See Table VIC.1 \\
\hline 14 & A & & mas: odfdat & $\begin{array}{l}\text { odf: } \text { chck } 13 \text {, read } 13 \\
\text { dat: } \begin{array}{l}\text { read } 00, \text { stndrd, } \\
\text { anglrd }\end{array}\end{array}$ & \\
\hline
\end{tabular}




\section{Table XIB.1 (continued)}

\begin{tabular}{|c|c|c|c|c|c|}
\hline $\begin{array}{l}\text { Unit } \\
\text { No. }\end{array}$ & $\begin{array}{l}\mathrm{A}, \\
\mathrm{B}, \\
\mathrm{O}\end{array}$ & $\begin{array}{l}\text { File name } \\
\text { if not } \\
\text { standard }\end{array}$ & $\begin{array}{c}\text { Segment: subroutines } \\
\text { in which this file is } \\
\text { written }\end{array}$ & $\begin{array}{c}\text { Segment: subroutines } \\
\text { in which this file } \\
\text { is read }\end{array}$ & Content \\
\hline 15 & A & $\begin{array}{l}\text { SAMMY. } \\
\text { DA2 }\end{array}$ & fdc: $\begin{array}{l}\text { readwr, rddato, } \\
\text { rddatl }\end{array}$ & & New DATa file \\
\hline 15 & B & & ssm: samssw & ssm: ssssds & \\
\hline 15 & A & $\begin{array}{l}\text { SAMMY. } \\
\text { FFF }\end{array}$ & & fff: many & $\begin{array}{l}\text { FITACS input file, } \\
\text { see Section V.J }\end{array}$ \\
\hline 16 & A & & $\begin{aligned} \text { mas: } & \text { sammy, sumstr, } \\
& \text { wrt } 16 \mathrm{x} \text {, writ } 16 \text {, } \\
& \text { file } 2 \mathrm{x}\end{aligned}$ & $\begin{array}{l}\text { inp: saminp, files, } \\
\text { qcova, filesx } \\
\text { new: addup } \\
\text { old: addup }\end{array}$ & $\begin{array}{l}\text { Controls for passes } \\
1 \text { and } 2 \text { through } \\
\text { SAMMY }\end{array}$ \\
\hline 17 & $\mathrm{~A}$ & & $\begin{array}{l}\text { mas: finish } \\
\text { end: samend }\end{array}$ & $\begin{array}{l}\text { end: samend } \\
\text { inp: files }\end{array}$ & $\begin{array}{l}\text { Unit numbers for } \\
\text { IBM version }\end{array}$ \\
\hline 18 & $A$ & & $\begin{array}{l}\text { mas: finp, writ19, } \\
\text { file } 2 x \\
\text { odf: chck1 } 8\end{array}$ & odf: $\operatorname{chck} 18, \operatorname{read} 18$ & $\begin{array}{l}\text { Controls for running } \\
\text { ODF segment }\end{array}$ \\
\hline 19 & A & & mas: writ 19 , file $2 x$ & $\begin{array}{l}\text { inp: saminp, files, } \\
\text { qcova, filesx }\end{array}$ & $\begin{array}{l}\text { Controls for pass } 3 \\
\text { through SAMMY }\end{array}$ \\
\hline 20 & A & & amr: intkbn & . & $\begin{array}{l}\text { Normalization and } \\
\text { background } \\
\text { parameters to be } \\
\text { introduced (see } \\
\text { Section VIII.A) }\end{array}$ \\
\hline 20 & $\mathrm{~B}$ & & (all): finish & (all): initil & $\begin{array}{l}\text { Information stored } \\
\text { in COMMONs }\end{array}$ \\
\hline 21 & $\mathrm{~A}$ & $\begin{array}{l}\text { SAMMY. } \\
\text { LPT }\end{array}$ & [many places] & & Line-printer output \\
\hline 22 & $\mathrm{~A}$ & $\begin{array}{l}\text { NPUT. } \\
\text { NEW }\end{array}$ & inp: rdspnx & & $\begin{array}{l}\text { Error message with } \\
\text { possible new } \\
\text { portion of INPut file }\end{array}$ \\
\hline 22 & A & & mas: new, sett, set & $\begin{array}{l}\text { inp: inp2, gg1234, } \\
\text { gg4xxx, gggg56, } \\
\text { gggg78, ggg10o, } \\
\text { gggg10, gggg11, } \\
\text { inpfil, rdone, huh, } \\
\text { rdbrd, only, combi, } \\
\text { rdspin, rdspn0, } \\
\text { rdspnd }\end{array}$ & $\begin{array}{l}\text { Copy of INPut file, } \\
\text { with appropriate } \\
\text { modifications for } \\
\text { first pass through } \\
\text { SAMMY }\end{array}$ \\
\hline
\end{tabular}


Table XIB.1 (continued)

\begin{tabular}{|c|c|c|c|c|c|}
\hline $\begin{array}{l}\text { Unit } \\
\text { No. }\end{array}$ & $\begin{array}{l}\mathrm{A} \\
\mathrm{B}, \\
\mathrm{O}\end{array}$ & $\begin{array}{l}\text { File name } \\
\text { if not } \\
\text { standard }\end{array}$ & $\begin{array}{c}\text { Segment: subroutines } \\
\text { in which this file is } \\
\text { written }\end{array}$ & $\begin{array}{c}\text { Segment: subroutines } \\
\text { in which this file } \\
\text { is read }\end{array}$ & Content \\
\hline $\begin{array}{l}23 \\
24\end{array}$ & A & & & & $\begin{array}{l}\text { Like } 22 \text {, for passes } 2 \\
\text { and } 3\end{array}$ \\
\hline 25 & B & $\begin{array}{l}\text { SAMMY. } \\
\text { SSM }\end{array}$ & inp: qqqwrt & ssm: qqqxxx, qqqget & $\begin{array}{l}\text { Edge effects for } \\
\text { single-scattering } \\
\text { corrections to } \\
\text { capture or fission } \\
\text { yields }\end{array}$ \\
\hline $\begin{array}{l}26 \\
27\end{array}$ & $\mathrm{~A}$ & & $\begin{array}{l}\text { inp: saminp } \\
\text { fin: file } 2 x \\
\text { avg: again }\end{array}$ & $\begin{array}{l}\text { fin: file } 2 x \\
\text { avg: tryrng, file } 2 x \text {, again } \\
\text { mxw: rktxxx } \\
\text { ndf: endfb6 }\end{array}$ & $\begin{array}{l}\text { Similar to } \\
\text { SAM16.DAT }\end{array}$ \\
\hline 28 & A & AVG file & & avg: tryrng, range & See Section VI.E \\
\hline 29 & B & & (all): timer & (all): timer & $\begin{array}{l}\text { Information for } \\
\text { timing routines, for } \\
\text { systems using this } \\
\text { feature }\end{array}$ \\
\hline 30 & $\mathrm{~B}$ & & acs: wrt30 & mpw: readwx & $\begin{array}{l}\text { Arrays } W \text { and } X \text { for } \\
\text { MPW inversion } \\
\text { scheme (see Section } \\
\text { II.A.1) }\end{array}$ \\
\hline 30 & A & & idc: wrt30 & $\begin{array}{l}\text { ipq: } \text { estipq, findxx } \\
\text { npv: samnpv, findxx }\end{array}$ & $\begin{array}{l}\text { Implicit data } \\
\text { covariance } \\
\text { information }\end{array}$ \\
\hline 30 & B & & ntg: wrntgq & npv: rdntg0, rdntg1 & $\begin{array}{l}\text { Integral data } \\
\text { information }\end{array}$ \\
\hline 31 & B & & mas:setcon & (many) & Constants \\
\hline 32 & A & $\begin{array}{l}\text { SAMMY. } \\
\text { PAR }\end{array}$ & $\begin{array}{l}\text { fin: } \\
\text { amr: } \text { parfix, rdwrt, } \\
\text { brdfix, mscfix, } \\
\text { pmcfix, orrfix, } \\
\text { rpifix, nbkfix, } \\
\text { bgffix, wrtusd, } \\
\text { wrtbag }\end{array}$ & fdc: paramf & $\begin{array}{l}\text { The output } \\
\text { PARameter file }\end{array}$ \\
\hline 32 & A & $\begin{array}{l}\text { SAMMY. } \\
\text { PAR }\end{array}$ & fit: writep & & $\begin{array}{l}\text { Modified PAR file } \\
\text { for FITACS; see } \\
\text { Section V.J }\end{array}$ \\
\hline 33 & A & $\begin{array}{l}\text { SAMMY. } \\
\text { PA2 }\end{array}$ & fdc: paramf & & $\begin{array}{l}\text { Modified PAR file; } \\
\text { see Section VI.C. } 2\end{array}$ \\
\hline
\end{tabular}


Table XIB.1 (continued)

\begin{tabular}{|c|c|c|c|c|c|}
\hline $\begin{array}{l}\text { Unit } \\
\text { No. }\end{array}$ & $\begin{array}{l}\mathrm{A}, \\
\mathrm{B}, \\
\mathrm{O}\end{array}$ & $\begin{array}{l}\text { File name } \\
\text { if not } \\
\text { standard }\end{array}$ & $\begin{array}{c}\text { Segment: subroutines } \\
\text { in which this file is } \\
\text { written }\end{array}$ & $\begin{array}{c}\text { Segment: subroutines } \\
\text { in which this file } \\
\text { is read }\end{array}$ & Content \\
\hline 34 & A & $\begin{array}{l}\text { SAMMY. } \\
\text { IDC }\end{array}$ & fdc: paramf & $\begin{array}{l}\text { idc: skmidc, pread, } \\
\text { qnorm, qbackg, } \\
\text { qexpl, idcfil, } \\
\text { read11, read22, } \\
\text { read12 }\end{array}$ & See Section VI.C.2 \\
\hline $\begin{array}{l}33- \\
35\end{array}$ & A & & npv: outnpv & & Debug printout \\
\hline 36 & B & & inp: hhhset & inp: qqqwrt & $\begin{array}{l}\text { Intermediate results } \\
\text { for edge-effects } \\
\text { correction for single } \\
\text { scattering }\end{array}$ \\
\hline \multicolumn{6}{|l|}{$\begin{array}{l}37- \\
40\end{array}$} \\
\hline 41 & B & & $\begin{array}{l}\text { old: } \text { set } 41 \\
\text { new: set } 41\end{array}$ & fin: compar & \\
\hline 42 & B & & $\begin{aligned} & \text { new: offres, offext, } \\
& \text { offrad, offiso, } \\
& \text { offbrd, offmsc, } \\
& \text { offpmc, offorr, } \\
& \text { offrpi, offnbk, } \\
& \text { offbgf, offdtp } \\
& \text { old: } \\
& \text { rdcov } \\
& \text { fin: } \text { gnalvr, gncrfn, } \\
& \text { gnradi }\end{aligned}$ & $\begin{array}{l}\text { new: set } 41 \text {, addup } \\
\text { old: set } 41 \text {, addup } \\
\text { fin: wrcov, compar } \\
\text { amr: covfix }\end{array}$ & $\begin{array}{l}\text { Temporary storage } \\
\text { for covariance } \\
\text { matrices etc. }\end{array}$ \\
\hline 43 & B & & dat: rddatx, stndrd & $\begin{array}{l}\text { dat: wr44 } \\
\text { dax: wr44 } \\
\text { the: uset }\end{array}$ & $\begin{array}{l}\text { Data, uncertainties, } \\
\text { and partial } \\
\text { derivatives with } \\
\text { respect to data- } \\
\text { reduction } \\
\text { parameters }\end{array}$ \\
\hline 44 & B & & $\begin{array}{l}\text { dat: wr44 } \\
\text { dax: wr } 44 \\
\text { the: uset }\end{array}$ & $\begin{array}{ll}\text { int: } & \text { pdwrit } \\
\text { ipq: } & \text { rdatf2 } \\
\text { npv: } & \text { rdatfl } \\
\text { avg: } & \text { datfix }\end{array}$ & $\begin{array}{l}\text { Data, uncertainties, } \\
\text { and partial } \\
\text { derivatives with } \\
\text { respect to data- } \\
\text { reduction } \\
\text { parameters }\end{array}$ \\
\hline 45 & B & & npv: setvdt & fin: vodf & \\
\hline
\end{tabular}


Table XIB.1 (continued)

\begin{tabular}{|c|c|c|c|c|c|}
\hline $\begin{array}{l}\text { Unit } \\
\text { No. }\end{array}$ & $\begin{array}{l}\text { A, } \\
\text { B, } \\
\text { O }\end{array}$ & $\begin{array}{l}\text { File name } \\
\text { if not } \\
\text { standard }\end{array}$ & $\begin{array}{c}\text { Segment: subroutines } \\
\text { in which this file is } \\
\text { written }\end{array}$ & $\begin{array}{c}\text { Segment: subroutines } \\
\text { in which this file } \\
\text { is read }\end{array}$ & Content \\
\hline 46 & B & & $\begin{array}{l}\text { new: offres, offext, } \\
\text { offrad, offiso, } \\
\text { offbrd, offmsc, } \\
\text { offpmc, offorr, } \\
\text { offrpi, offnbk, } \\
\text { offbgf, offdtp, } \\
\text { addup } \\
\text { old: rdcov, addup } \\
\text { ipq: chngc } 2 \\
\text { npv: chngcv } \\
\text { mpw: newpar }\end{array}$ & $\begin{array}{l}\text { new: set } 41 \\
\text { old: set } 41 \\
\text { squ: samsqu } \\
\text { fin: gnalvr, wrcov, } \\
\\
\text { fit: compar } \\
\text { amr: covfix }\end{array}$ & $\begin{array}{l}\text { Covariance matrix } \\
\text { for } u \text {-parameters in } \\
\text { triangular form }\end{array}$ \\
\hline 47 & B & & $\begin{array}{l}\text { squ: samsqu } \\
\text { mpw: newpar }\end{array}$ & $\begin{array}{l}\text { ipq: newpa2 } \\
\text { npv: setemg } \\
\text { mpw: newpar } \\
\text { avg: fixcov } \\
\text { mxw: fixcov } \\
\text { ntg: fixcov }\end{array}$ & $\begin{array}{l}\text { Covariance matrix } \\
\text { for } u \text {-parameters in } \\
\text { full square form }\end{array}$ \\
\hline 48 & B & & $\begin{array}{l}\text { cro: work } \\
\text { mlb: work } \\
\text { xct: work } \\
\text { int: inter, interp, } \\
\text { interx } \\
\text { dbd: dopplr } \\
\text { dop: dopplr } \\
\text { fgm: dopfgm } \\
\text { rsl: resolu } \\
\text { orr: orresl } \\
\text { rpi: rpirsl } \\
\text { ang: diffee }\end{array}$ & $\begin{array}{l}\text { int: outg, pdwrit } \\
\text { ipq: rdatf } 2 \\
\text { npv: setg }\end{array}$ & Partial derivatives \\
\hline 49 & B & & $\begin{array}{l}\text { new: betset } \\
\text { old: rdcov } \\
\text { ipq: samipq, writeu } \\
\text { npv: samnpv, writeu } \\
\text { mpw: sammpw, writeu }\end{array}$ & $\begin{array}{l}\text { int: samint, readu } \\
\text { squ: samsqu } \\
\text { ipq: samipq, readu } \\
\text { npv: samnpv, readu } \\
\text { mpv: sammpw, readu } \\
\text { fin: samfin, convrt, } \\
\\
\quad \text { wrcov } \\
\text { fit: parnew } \\
\text { avg: samavg }\end{array}$ & $\begin{array}{l}\text { Dimensions, etc., as } \\
\text { needed by matrix } \\
\text { manipulator routines }\end{array}$ \\
\hline
\end{tabular}


Table XIB.1 (continued)

\begin{tabular}{|c|c|c|c|c|c|}
\hline $\begin{array}{l}\text { Unit } \\
\text { No. }\end{array}$ & $\begin{array}{l}\mathrm{A}, \\
\mathrm{B}, \\
\mathrm{O}\end{array}$ & $\begin{array}{l}\text { File name } \\
\text { if not } \\
\text { standard }\end{array}$ & $\begin{array}{c}\text { Segment: subroutines } \\
\text { in which this file is } \\
\text { written }\end{array}$ & $\begin{array}{c}\text { Segment: subroutines } \\
\text { in which this file } \\
\text { is read }\end{array}$ & Content \\
\hline 50 & B & v & $\begin{array}{l}\text { dat: } \\
\text { dax } 44 \\
\text { dar44 }\end{array}$ & $\begin{array}{l}\text { int: interp } \\
\text { avg: gete } \\
\text { ipq: findxx, compar } \\
\text { npv: compar }\end{array}$ & $\begin{array}{l}\text { Experimental } \\
\text { energies }\end{array}$ \\
\hline 51 & B & & $\begin{array}{l}\text { dbd: dopplr } \\
\text { dop: doppir } \\
\text { fgm: dopfgm } \\
\text { ssm: ssssds }\end{array}$ & $\begin{array}{l}\text { int: inter, interp, interx } \\
\text { rsl: readgb } \\
\text { orr: readgb } \\
\text { rpi: readgb } \\
\text { ang: diffee } \\
\text { mxw: } \text { mxwell } \\
\text { ssm: orgniz }\end{array}$ & $\begin{array}{l}\text { Doppler-broadened } \\
\text { partial derivatives }\end{array}$ \\
\hline \multicolumn{6}{|l|}{52} \\
\hline 53 & B & & $\begin{array}{l}\text { npv: compar, rdatfl } \\
\text { ipq: compar, rdatf2 }\end{array}$ & cmp: samcmp, cmpodf & Energy, data, theory \\
\hline 53 & A & & cmp: ascii & & $\begin{array}{l}\text { Comparison } \\
\text { information; see } \\
\text { Section VIII:H }\end{array}$ \\
\hline 54 & B & & $\begin{array}{l}\text { cro: work } \\
\text { mlb: work } \\
\text { xct: work } \\
\text { rec: } \\
\text { ssm: }\end{array}$ & $\begin{array}{l}\text { dbd: readgb } \\
\text { dop: dopplr } \\
\text { fgm: readgb } \\
\text { int: inter, interp } \\
\text { ang: diffee } \\
\text { mxw: mxwell } \\
\text { orr: readgb } \\
\text { rpi: readgb } \\
\text { rsl: readgb } \\
\text { ssm: orgniz }\end{array}$ & $\begin{array}{l}\text { Unbroadened partial } \\
\text { derivatives }\end{array}$ \\
\hline 55 & $\mathrm{~A}$ & & $\begin{array}{l}\text { ndf: endfb6, wrres6, } \\
\text { cont, tab1, list }\end{array}$ & & Output ENDF file \\
\hline 55 & $A$ & $\begin{array}{l}\text { non- } \\
\text { standard } \\
\text { name }\end{array}$ & & $\begin{array}{l}\text { ort: } \text { setpar, reador, scan } \\
\text { rpt: } \\
\text { setpar, readrp, scan }\end{array}$ & $\begin{array}{l}\text { Resolution portion } \\
\text { of PAR file }\end{array}$ \\
\hline 56 & B & & npv: setemg & npv: setvdt & Array EMG \\
\hline \multicolumn{6}{|l|}{57} \\
\hline 58 & $\mathrm{~B}$ & & $\begin{array}{ll}\text { ipq: } & \text { rdatf } 2 \\
\text { npv: } & \text { setg, rdatfl }\end{array}$ & $\begin{array}{ll}\text { ipq: } & \text { stqp1 } \\
\text { npv: } & \text { setvdt }\end{array}$ & Partial derivatives \\
\hline
\end{tabular}


Table XIB.1 (continued)

\begin{tabular}{|c|c|c|c|c|c|}
\hline $\begin{array}{l}\text { Unit } \\
\text { No. }\end{array}$ & $\begin{array}{l}\mathrm{A}, \\
\mathrm{B}, \\
\mathrm{O}\end{array}$ & $\begin{array}{l}\text { File name } \\
\text { if not } \\
\text { standard }\end{array}$ & $\begin{array}{c}\text { Segment: subroutines } \\
\text { in which this file is } \\
\text { written }\end{array}$ & $\begin{array}{c}\text { Segment: subroutines } \\
\text { in which this file } \\
\text { is read }\end{array}$ & Content \\
\hline 59 & B & . & $\begin{array}{ll}\text { cro: } & \text { wr59 } \\
\text { xct: } & \text { wr59 } \\
\text { mlb: } & \text { wr59 }\end{array}$ & $\begin{array}{ll}\text { int: } & \text { wr } 59 \\
\text { squ: } & \text { samsqu } \\
\text { ipq: } & \text { samipq, readu, } \\
& \text { readiu } \\
\text { npv: } & \text { sqmnpv, readu, } \\
& \text { readiu } \\
\text { avg: } & \text { samavg, readu, } \\
& \text { readiu } \\
\text { mxw: } & \text { sammxw, readiu } \\
\text { ntg: } & \text { samntg, readiu }\end{array}$ & $\begin{array}{l}\text { Miscellaneous } \\
\text { information } \\
\text { including } u- \\
\text { parameters }\end{array}$ \\
\hline 60 & B & $\begin{array}{l}\text { SAMMY. } \\
001\end{array}$ & & odf: odfio & \\
\hline 60 & A & & mas: writl 6 & $\begin{array}{ll}\text { rec: } & \text { read3 } \\
\text { ntg: } & \text { rdntgq }\end{array}$ & $\begin{array}{l}\text { name of ENDF file } \\
3 ; \text { name of NTG file }\end{array}$ \\
\hline 61 & A & & mxw: mxwell & & $\begin{array}{l}\text { Maxwellian- } \\
\text { averaged capture } \\
\text { cross sections in } \\
\text { legible format }\end{array}$ \\
\hline 62 & B & & & 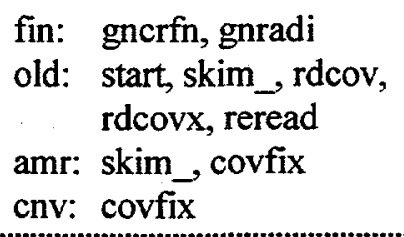 & $\begin{array}{l}\text { Input binary } \\
\text { covariance matrix } \\
\text { for P-parameters }\end{array}$ \\
\hline 63 & A & DCV file & & dat: qdatcv & $\begin{array}{l}\text { Input covariance } \\
\text { matrix for data }\end{array}$ \\
\hline 64 & B & $\begin{array}{l}\text { SAMMY. } \\
\text { COV }\end{array}$ & $\begin{array}{l}\text { fin: wrcov } \\
\text { amr: covfix }\end{array}$ & & $\begin{array}{l}\text { Output binary } \\
\text { covariance matrix } \\
\text { for P-parameters }\end{array}$ \\
\hline \multicolumn{6}{|l|}{65} \\
\hline 66 & A & fort. 66 & ssm: ssssds & & $\begin{array}{l}\text { Debug printout of } \\
\text { corrections to } \\
\text { capture yield }\end{array}$ \\
\hline \multicolumn{6}{|l|}{$\begin{array}{l}67- \\
69\end{array}$} \\
\hline 70 & $A$ & $\begin{array}{l}\text { SAMMY. } \\
\text { IO }\end{array}$ & $\begin{array}{l}\text { new: outpa2 } \\
\text { old: outpa2 } \\
\text { fin: outpa2 }\end{array}$ & & $\begin{array}{l}\text { Like SAMMY.LPT } \\
\text { (unit } 21 \text { ), except } \\
\text { contains only input } \\
\text { and output }\end{array}$ \\
\hline
\end{tabular}


Table XIB.1 (continued)

\begin{tabular}{|c|c|c|c|c|c|}
\hline $\begin{array}{l}\text { Unit } \\
\text { No. }\end{array}$ & $\begin{array}{l}\mathrm{A}, \\
\mathrm{B}, \\
\mathrm{O}\end{array}$ & $\begin{array}{l}\text { File name } \\
\text { if not } \\
\text { standard }\end{array}$ & $\begin{array}{c}\text { Segment: subroutines } \\
\text { in which this file is } \\
\text { written }\end{array}$ & $\begin{array}{l}\text { Segment: subroutines } \\
\text { in which this file } \\
\text { is read }\end{array}$ & Content \\
\hline 71 & A & $\begin{array}{l}\text { SAMMY. } \\
\text { PDS }\end{array}$ & $\begin{array}{l}\text { new: opnpds } \\
\text { int: pdwrit }\end{array}$ & & $\begin{array}{l}\text { Partial derivatives, } \\
\text { for use in generating } \\
\text { parameter } \\
\text { covariance matrix }\end{array}$ \\
\hline 72 & $\begin{array}{l}\mathrm{O} \\
\text { or } \\
\mathrm{B}\end{array}$ & $\begin{array}{l}\text { SAMMY. } \\
\text { ODF }\end{array}$ & $\begin{array}{l}\text { odf: fixodf } \\
\text { int: thodf } \\
\text { fin: vodf }\end{array}$ & $\begin{array}{l}\text { int: thodf } \\
\text { fin: vodf }\end{array}$ & $\begin{array}{l}\text { ODF file containing } \\
\text { broadened cross } \\
\text { sections, from } \\
\text { which plots can be } \\
\text { made }\end{array}$ \\
\hline 73 & $\begin{array}{l}\mathrm{O} \\
\text { or } \\
\mathrm{B}\end{array}$ & $\begin{array}{l}\text { SAMXAC. } \\
\text { ODF }\end{array}$ & mxw: xacodf & & $\begin{array}{l}\text { ODF file containing } \\
\text { unbroadened cross } \\
\text { section }\end{array}$ \\
\hline 73 & $\begin{array}{l}\mathrm{O} \\
\text { or } \\
\mathrm{B}\end{array}$ & $\begin{array}{l}\text { SAMMXW. } \\
\text { ODF }\end{array}$ & mxw: mxwodf & & $\begin{array}{l}\text { ODF file containing } \\
\text { stellar-averaged } \\
\text { cross sections }\end{array}$ \\
\hline 77 & $A$ & $\begin{array}{l}\text { SAMMY. } \\
\text { CCV }\end{array}$ & old:covndf & & $\begin{array}{l}\text { Covariance matrix } \\
\text { in proposed ENDF } \\
\text { format }\end{array}$ \\
\hline
\end{tabular}




\section{XI.C DIVISION OF THE PROGRAM INTO STAND-ALONE SEGMENTS}

The structure of program SAMMY makes it ideally suited for overlay, because each major operation is independent of the others. However, because overlay was cumbersome on the PDP10 computer for which SAMMY was originally developed, the author chose instead to make use of the "CALL RUN" option, which allows a FORTRAN program to initiate the execution of another program. With migration to other computers, this structure was maintained, since it has proven to be particularly effective when debugging or adding new options to the code. Casual users, on the other hand, do not even notice that this code operates somewhat differently from most codes.

SAMMY now consists of nearly fifty segments (or modules), not all of which are used for every SAMMY run. Table XIC.1 describes the functions of each segment and indicates the calling sequence. The order of the segments in the table is alphabetical; a flow chart (at the end of the table) shows the order in which the modules are used.

In addition to the segments that operate within a SAMMY run, a number of auxiliary programs are available to be used in conjunction with SAMMY. These programs are described in Section VIII.8; however, many are also included in Table XIC.1. 
Table XIC.1. Segments of the code SAMMY

\begin{tabular}{|c|c|c|c|c|}
\hline $\begin{array}{l}\text { Seg- } \\
\text { ment }\end{array}$ & $\begin{array}{l}\text { Alter- } \\
\text { native } \\
\text { seg- } \\
\text { ments }\end{array}$ & Primary functions & $\begin{array}{l}\text { Control passes to } \\
\text { which segment? }\end{array}$ & $\begin{array}{l}\text { Control comes } \\
\text { from which } \\
\text { segment? }\end{array}$ \\
\hline $\mathrm{ACS}$ & & $\begin{array}{l}\text { Calculate FITACS cross } \\
\text { sections etc. }\end{array}$ & MPW & FFF, FIT \\
\hline AMR & & $\begin{array}{l}\text { Reorganize covariance file } \\
\text { when changing data- } \\
\text { reduction parameters } \\
\text { (Section VIII.A) }\end{array}$ & (Stand-alone program & \\
\hline ANG & & $\begin{array}{l}\text { Generate angular distribution } \\
\text { (Section III.E) }\end{array}$ & $\begin{array}{l}\text { INT, ORR, RPI, or } \\
\text { RSL }\end{array}$ & $\begin{array}{l}\text { INT, DBD, DOP, } \\
\text { FGM, or XCT }\end{array}$ \\
\hline $\mathrm{AVG}$ & & $\begin{array}{l}\text { Generate averages of } \\
\text { theoretical and experimental } \\
\text { cross sections (Section V.C) }\end{array}$ & DAT or END & SQU \\
\hline $\mathrm{BIN}$ & & $\begin{array}{l}\text { Convert from binary plot file } \\
\text { to another option }\end{array}$ & (Stand-alone program & \\
\hline BLK & & (Subdirectory stores common & locks) & \\
\hline CMP & & $\begin{array}{l}\text { Read binary file } \\
\text { SAM53.DAT (which was } \\
\text { generated by samnpv or } \\
\text { samipq) and create ODF file }\end{array}$ & (Stand-alone program & \\
\hline $\mathrm{CNV}$ & & $\begin{array}{l}\text { CoNVert the binary } \\
\text { COVariance file to an ASCII } \\
\text { file which contains the } \\
\text { complete covariance matrix } \\
\text { for all resonance parameters }\end{array}$ & (stand-alone program) & \\
\hline $\mathrm{CRO}$ & $\begin{array}{l}\text { MLB, } \\
\mathrm{XCT}\end{array}$ & $\begin{array}{l}\text { Generate theoretical cross } \\
\text { sections using the Reich- } \\
\text { Moore approximation to } \\
\text { multilevel R-matrix theory } \\
\text { (Section III.A) }\end{array}$ & $\begin{array}{l}\text { DBD, DOP, FGM, } \\
\text { INT, MXW, NTG, } \\
\text { ORR, RPI, RSL, } \\
\text { or SQU }\end{array}$ & THE \\
\hline DAT & DAX & $\begin{array}{l}\text { Read the DATa file; } \\
\text { generate the auxiliary energy } \\
\text { grid used for broadening }\end{array}$ & IDC, REF, or THE & $\begin{array}{l}\text { AVG, FIN, NEW, } \\
\text { or OLD }\end{array}$ \\
\hline $\mathrm{DAX}$ & DAT & $\begin{array}{l}\text { Original version of DAT; } \\
\text { now seldom used }\end{array}$ & REF, THE & $\begin{array}{l}\text { FIN, NEW, or } \\
\text { OLD }\end{array}$ \\
\hline
\end{tabular}




\begin{tabular}{|c|c|c|c|c|}
\hline $\begin{array}{l}\text { Seg- } \\
\text { ment }\end{array}$ & $\begin{array}{l}\text { Alter- } \\
\text { native } \\
\text { seg- } \\
\text { ments } \\
\end{array}$ & Primary functions & $\begin{array}{l}\text { Control passes to } \\
\text { which segment? }\end{array}$ & $\begin{array}{l}\text { Control comes } \\
\text { from which } \\
\text { segment? } \\
\end{array}$ \\
\hline $\mathrm{DBD}$ & $\begin{array}{l}\text { DOP } \\
\text { FGM }\end{array}$ & $\begin{array}{l}\text { Doppler-broaden the } \\
\text { theoretical cross section } \\
\text { using the original method. } \\
\text { (Section IV.A.1) }\end{array}$ & $\begin{array}{l}\text { ANG, INT, ORR, } \\
\text { RPI, RSL, or SSM }\end{array}$ & $\begin{array}{l}\text { CRO, INT, MLB, } \\
\text { or XCT }\end{array}$ \\
\hline DIS & & $\begin{array}{l}\text { Calculate statistical } \\
\text { properties }\end{array}$ & (Stand-alone progre & \\
\hline DOP & $\begin{array}{l}\text { DBD, } \\
\text { FGM }\end{array}$ & $\begin{array}{l}\text { Doppler-broaden the } \\
\text { theoretical cross section } \\
\text { using the Leal-Hwang } \\
\text { method (Section IV.D) }\end{array}$ & $\begin{array}{l}\text { ANG, INT, ORR, } \\
\text { RPI, RSL, or SSM }\end{array}$ & $\begin{array}{l}\text { CRO, INT, MLB, } \\
\text { or XCT }\end{array}$ \\
\hline END & & $\begin{array}{l}\text { Reorganize files for another } \\
\text { pass, or delete temporary } \\
\text { files at end of run }\end{array}$ & NNP or quit & $\begin{array}{l}\text { AVG, FIN, MAS, } \\
\text { MXW, NDF, } \\
\text { ODF, or REC }\end{array}$ \\
\hline FDC & & $\begin{array}{l}\text { Update data file with } \\
\text { implicit data covariance } \\
\text { information }\end{array}$ & (Stand-alone progr & \\
\hline FFF & & $\begin{array}{l}\text { Read input for FITACS } \\
\text { program }\end{array}$ & $\mathrm{ACS}$ & MAS \\
\hline FGM & $\begin{array}{l}\text { DBD, } \\
\text { DOP }\end{array}$ & $\begin{array}{l}\text { Doppler-broaden via the free } \\
\text { gas model (Section IV.F) }\end{array}$ & $\begin{array}{l}\text { ANG, INT, ORR, } \\
\text { RPI, RSL, or SSM }\end{array}$ & CRO, MLB \\
\hline FIN & & $\begin{array}{l}\text { Convert results from } u \text { - } \\
\text { parameters to physical } \\
\text { parameters; output results }\end{array}$ & $\begin{array}{l}\text { DAT, DAX, END, } \\
\text { or THE }\end{array}$ & IPQ or NPV \\
\hline FIT & & $\begin{array}{l}\text { Output results for FITACS } \\
\text { program }\end{array}$ & $\mathrm{ACS}$ & MPW \\
\hline FNC & & \multicolumn{3}{|c|}{ (Subdirectory contains coding for frequently used functions) } \\
\hline IDC & & $\begin{array}{l}\text { Read and sort implicit data } \\
\text { covariance information }\end{array}$ & RST, THE & DAT \\
\hline NP & & $\begin{array}{l}\text { Read INPut file for control } \\
\text { commands and for } \\
\text { information about the data } \\
\text { set; read through PARameter } \\
\text { file to set array sizes }\end{array}$ & PAR & END or MAS \\
\hline
\end{tabular}


Table XIC.1 (continued)

\begin{tabular}{|c|c|c|c|c|}
\hline $\begin{array}{l}\text { Seg- } \\
\text { ment }\end{array}$ & $\begin{array}{l}\text { Alter- } \\
\text { native } \\
\text { seg- } \\
\text { ments } \\
\end{array}$ & Primary functions & $\begin{array}{l}\text { Control passes to } \\
\text { which segment? }\end{array}$ & $\begin{array}{l}\text { Control comes } \\
\text { from which } \\
\text { segment? }\end{array}$ \\
\hline INT & & $\begin{array}{l}\text { Print theoretical cross } \\
\text { sections and/or partial } \\
\text { derivatives; write parts of } \\
\text { ODF file }\end{array}$ & $\begin{array}{l}\text { ANG, DBD, DOP, } \\
\text { NPV, ORR, RPI, } \\
\text { RSL, SQU, or } \\
\text { SSM }\end{array}$ & $\begin{array}{l}\text { ANG, CRO, DBD, } \\
\text { DOP, FGM, MLB, } \\
\text { ORR, RPI, RSL, } \\
\text { SSM, or XCT }\end{array}$ \\
\hline IPQ & $\begin{array}{l}\text { MPW, } \\
\text { NPV }\end{array}$ & $\begin{array}{l}\text { Solve }(I+Q \text { ) form of } \\
\text { Bayes' Equations (See } \\
\text { Section II.B.1.b) }\end{array}$ & FIN & SQU \\
\hline MAS & & $\begin{array}{l}\text { Read input commands from } \\
\text { teletype (or batch file) and } \\
\text { from INPut file: organize the } \\
\text { manner in which SAMMY } \\
\text { will run }\end{array}$ & $\begin{array}{l}\text { END, FFF, INP, } \\
\text { or ODF }\end{array}$ & SAMMY \\
\hline MLB & $\begin{array}{l}\mathrm{CRO} \\
\mathrm{XCT}\end{array}$ & $\begin{array}{l}\text { Generate theoretical cross } \\
\text { sections using the single or } \\
\text { multilevel Breit-Wigner } \\
\text { theory (Section III.C) }\end{array}$ & $\begin{array}{l}\text { DBD, DOP, FGM, } \\
\text { INT, MXW, NTG, } \\
\text { ORR, RPI, RSL, } \\
\text { or SQU }\end{array}$ & THE \\
\hline MPW & $\begin{array}{l}\text { IPQ, } \\
\text { NPV }\end{array}$ & $\begin{array}{l}\text { Solve Bayes' Equations via } \\
\text { the } M+W \text { method }\end{array}$ & FIT & ACS, SQU \\
\hline MXW & & $\begin{array}{l}\text { Generate stellar } \\
\text { (Maxwellian) average } \\
\text { capture cross section } \\
\text { (Section V.P) }\end{array}$ & END & $\begin{array}{l}\text { CRO, MLB, REC, } \\
\text { or SQU, or XCT }\end{array}$ \\
\hline NDF & & $\begin{array}{l}\text { Output resonance parameters } \\
\text { in format required by } \\
\text { ENDF/B-VI file } 2\end{array}$ & END & NEW or OLD \\
\hline NEW & OLD & $\begin{array}{l}\text { Generate the covariance } \\
\text { matrix for the parameters }\end{array}$ & $\begin{array}{l}\text { DAT, DAX, NDF, } \\
\text { or REC }\end{array}$ & PAR \\
\hline NPV & $\begin{array}{l}\text { IPQ, } \\
\text { MPW }\end{array}$ & $\begin{array}{l}\text { Solve }(\mathrm{N}+\mathrm{V}) \text { form of } \\
\text { Bayes' Equations (See } \\
\text { Section II.B.1.a) }\end{array}$ & FIN & $\begin{array}{l}\text { INT, NTG, or } \\
\text { SQU }\end{array}$ \\
\hline NTG & & Calculate integral quantities & NPV & $\begin{array}{l}\text { CRO, MLB, REC, } \\
\text { SQU, or XCT }\end{array}$ \\
\hline
\end{tabular}




\begin{tabular}{|c|c|c|c|c|}
\hline $\begin{array}{l}\text { Seg- } \\
\text { ment }\end{array}$ & $\begin{array}{l}\text { Alter- } \\
\text { native } \\
\text { seg- } \\
\text { ments }\end{array}$ & Primary functions & $\begin{array}{l}\text { Control passes to } \\
\text { which segment? }\end{array}$ & $\begin{array}{l}\text { Control comes } \\
\text { from which } \\
\text { segment? }\end{array}$ \\
\hline ODF & & $\begin{array}{l}\text { Initialize the ODF output file } \\
\text { by writing energies into } S 1 \text {, } \\
\text { data into } S 2 \text { and } S 6 \text {, and } \\
\text { uncertainties into } S 3 \text { and } S 7\end{array}$ & END & MAS \\
\hline OLD & NEW & $\begin{array}{l}\text { Read the covariance matrix } \\
\text { for the parameters from } \\
\text { binary file generated by } \\
\text { earlier SAMMY run }\end{array}$ & $\begin{array}{l}\text { DAT, DAX, NDF, } \\
\text { or REC }\end{array}$ & PAR \\
\hline ORR & $\begin{array}{l}\text { RPI, } \\
\text { RSL }\end{array}$ & $\begin{array}{l}\text { Resolution-broaden the } \\
\text { theoretical cross section } \\
\text { using the realistic resolution } \\
\text { broadening (Section IV.E) }\end{array}$ & $\mathrm{NNT}$ & $\begin{array}{l}\text { ANG, CRO, DBD, } \\
\text { DOP, FGM, INT, } \\
\text { MLB, SSM, or } \\
\text { XCT }\end{array}$ \\
\hline ORT & & \multicolumn{3}{|c|}{ (Stand-alone program to study ORR resolution function) } \\
\hline PAR & & $\begin{array}{l}\text { Read parameters from } \\
\text { PARameter file. }\end{array}$ & NEW or OLD & INP \\
\hline QUA & & \multicolumn{3}{|c|}{ (Stand-alone program to generate quantum numbers) } \\
\hline $\mathrm{REC}$ & & $\begin{array}{l}\text { Reconstruct point-wise cross } \\
\text { section from resonance } \\
\text { parameters }\end{array}$ & $\begin{array}{l}\text { END, MXW, or } \\
\text { NTG }\end{array}$ & NEW or OLD \\
\hline REF & & $\begin{array}{l}\text { Convert from REFIT to } \\
\text { SAMMY or vice versa }\end{array}$ & & DAT, DAX, IDC \\
\hline RPI & $\begin{array}{l}\text { ORR, } \\
\text { RSL }\end{array}$ & $\begin{array}{l}\text { Resolution-broaden the } \\
\text { theoretical cross section } \\
\text { using the RPI resolution } \\
\text { function }\end{array}$ & INT & $\begin{array}{l}\text { ANG, CRO, DBD, } \\
\text { DOP, FGM, INT, } \\
\text { MLB, SSM, or } \\
\text { XCT }\end{array}$ \\
\hline RPT & & \multicolumn{3}{|c|}{ (Stand-alone program to study RPI resolution function) } \\
\hline RSL & $\begin{array}{l}\text { ORR, } \\
\text { RPI }\end{array}$ & $\begin{array}{l}\text { Resolution-broaden the } \\
\text { theoretical cross section } \\
\text { using the original method } \\
\text { (Section IV.A.2) }\end{array}$ & INT & $\begin{array}{l}\text { ANG, CRO, DBD, } \\
\text { DOP, FGM, INT, } \\
\text { MLB, SSM, or } \\
\text { XCT }\end{array}$ \\
\hline RST & & \multicolumn{3}{|c|}{ (Stand-alone program to study RSL resolution function) } \\
\hline SAMMY & & Write logo, call MAS & MAS & start \\
\hline
\end{tabular}




\begin{tabular}{|c|c|c|c|c|}
\hline $\begin{array}{l}\text { Seg- } \\
\text { ment }\end{array}$ & $\begin{array}{l}\text { Alter- } \\
\text { native } \\
\text { seg- } \\
\text { ments }\end{array}$ & Primary functions & $\begin{array}{l}\text { Control passes to } \\
\text { which segment? }\end{array}$ & $\begin{array}{c}\text { Control comes } \\
\text { from which } \\
\text { segment? }\end{array}$ \\
\hline SQU & & $\begin{array}{l}\text { Expand the triangular } \\
\text { storage of the covariance } \\
\text { matrix to full square form }\end{array}$ & $\begin{array}{l}\text { AVG, IPQ, MPW, } \\
\text { MXW, NTG, or } \\
\text { NPV }\end{array}$ & $\begin{array}{l}\text { CRO, INT, MLB, } \\
\text { or XCT }\end{array}$ \\
\hline SSM & & $\begin{array}{l}\text { Perform self-shielding and } \\
\text { multiple-scattering } \\
\text { calculation for capture yields }\end{array}$ & $\begin{array}{l}\text { INT, ORR, RPI, or } \\
\text { RSL }\end{array}$ & $\begin{array}{l}\text { DBD, DOP, FGM, } \\
\mathbb{N N T} \text {, or XCT }\end{array}$ \\
\hline STA & & \multicolumn{3}{|c|}{ (Sand-alone program to generate stair-case plots) } \\
\hline THE & & $\begin{array}{l}\text { Perform some bookkeeping } \\
\text { related to cross-section } \\
\text { calculations }\end{array}$ & $\begin{array}{l}\text { CRO, MLB, or } \\
\text { XCT }\end{array}$ & $\begin{array}{l}\text { DAT, DAX, FIN, } \\
\text { IDC }\end{array}$ \\
\hline THN & & \multicolumn{3}{|c|}{ (Sand-alone program to thin dense data) } \\
\hline $\mathrm{XCT}$ & $\begin{array}{l}\text { CRO, } \\
\text { MLB }\end{array}$ & $\begin{array}{l}\text { Generate theoretical cross } \\
\text { sections using alternative } \\
\text { formulation of Reich-Moore } \\
\text { (Section III.D) }\end{array}$ & $\begin{array}{l}\text { ANG, DBD, DOP, } \\
\text { FGM, INT, MXW, } \\
\text { NTG, ORR, RPI, } \\
\text { RSL, SQU, or } \\
\text { SSM }\end{array}$ & THE \\
\hline $\mathrm{XXX}$ & & \multicolumn{3}{|c|}{ (Subdirectory stores often-used routines) } \\
\hline
\end{tabular}




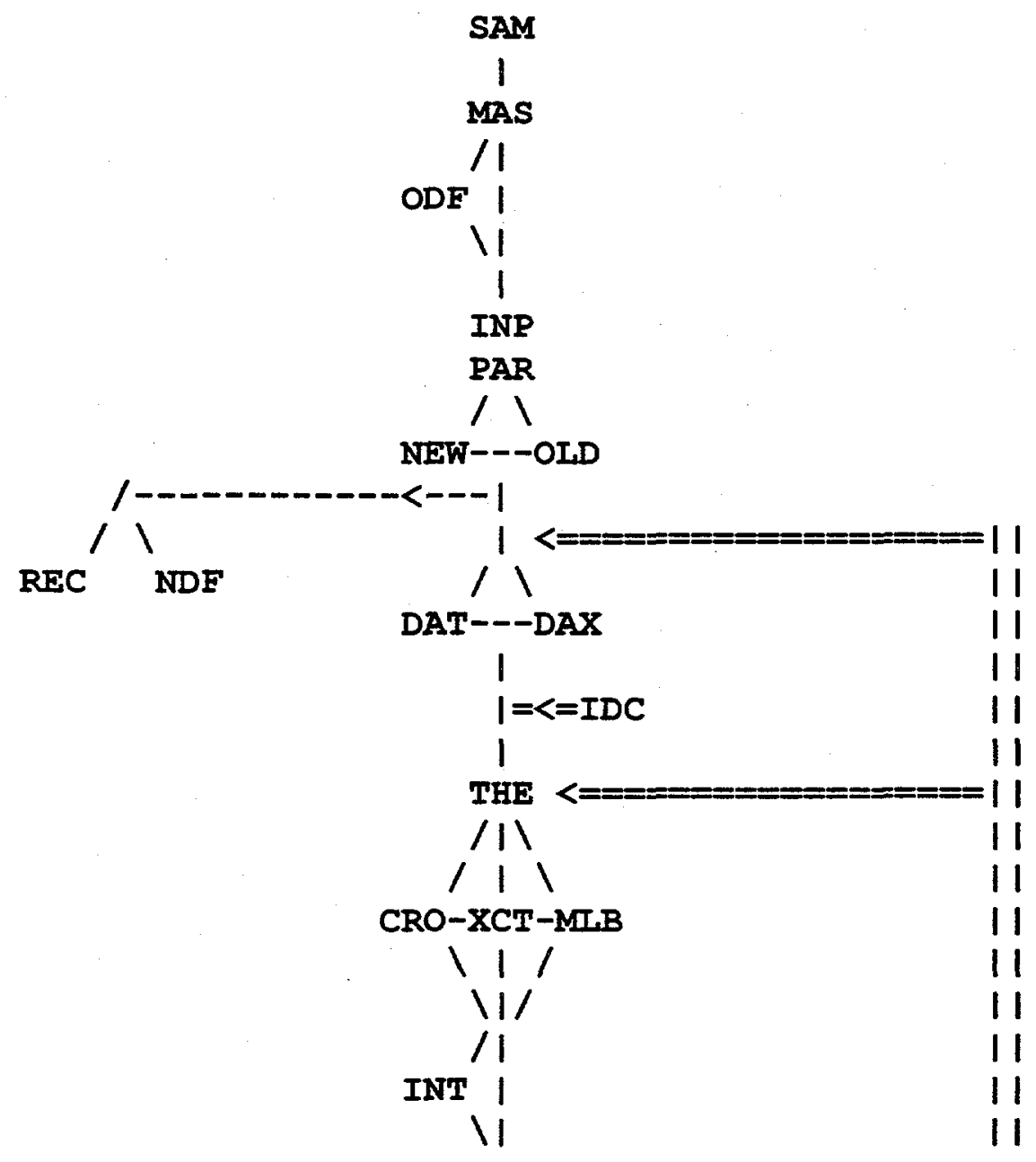

Fig. XIC.1. Flow chart for SAMMY. 


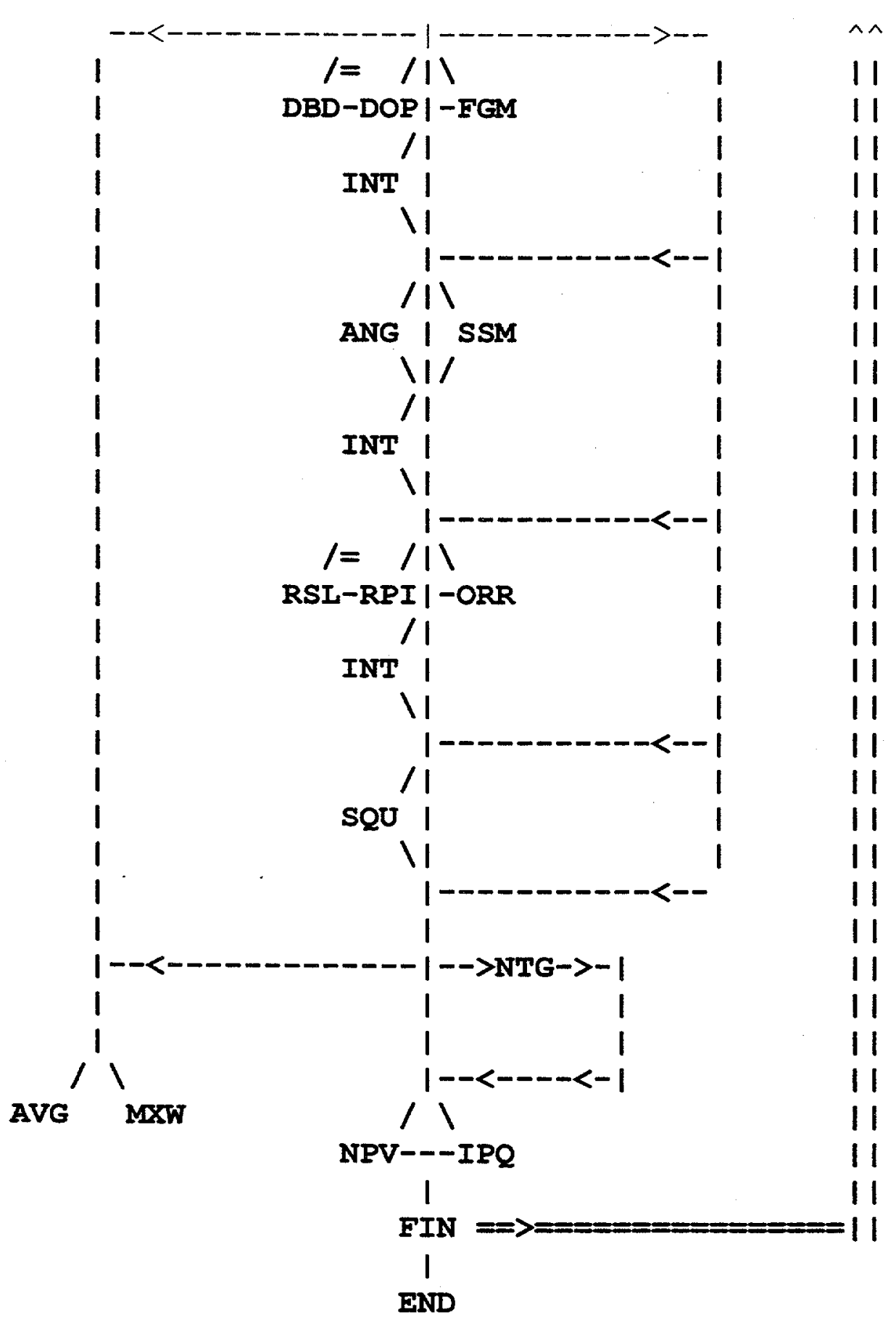

Fig. XIC.1 (continued) 


\section{XI.D QUALITY ASSURANCE}

The SAMMY quality assurance program involves a series of "test cases," each of which is designed to test a particular feature of the code. Whenever a new feature is added to SAMMY or a major bug exterminated, a new test case is developed. Prior to the release of a new version of the code, all test cases are run on several computer platforms, to ensure that recent changes have not adversely affected the behavior of older features. These test cases, both input and output, are released, along with the source codes (e.g., from RSICC); anyone wishing to port SAMMY to his or her own computer is advised to run all test cases, compare output, and resolve major differences before beginning new analyses.

Table XID.1 gives a brief description of the test cases, which are numbered chronologically in order of their development. Cases 1 through 9 are labeled "tr1" through "tr9" (where "tr" denotes "trial" number), and cases 10 through 99 are "t10" through " $t 99$." These labels are the first three characters of most files relating to these test cases; in addition each test case is in a separate subdirectory.

Note that some numbers (e.g., tr5) are omitted from the listing in Table XID.1 and are not included in the release. Note also that all experimental data used in the test cases are to be treated as "dummy" data, not to be used for any purpose other than to verify the accuracy of the SAMMY calculations. The same is true of resonance parameters used in the test cases. 
Table XID.1. SAMMY test cases

\begin{tabular}{|c|c|c|c|c|}
\hline No. & $\begin{array}{c}\text { Module } \\
\text { tested }\end{array}$ & Main feature being tested & $\begin{array}{r}\text { Data } \\
\text { type }\end{array}$ & Nuclide \\
\hline 1 & samdat & Correlated data (DCV file) & Elastic & $\mathrm{Ni60}$ \\
\hline 2 & $\begin{array}{l}\text { samipq, } \\
\text { samnpv }\end{array}$ & $\begin{array}{l}\text { Comparison of different solution methods for } \\
\text { Bayes' equations }\end{array}$ & $\begin{array}{l}\text { Trans- } \\
\text { mission }\end{array}$ & P204 \\
\hline 3 & sampar & R-external & Trans & $\mathrm{Ni60}$ \\
\hline 4 & $\begin{array}{l}\text { samfin, } \\
\text { samold }\end{array}$ & $\begin{array}{l}\text { Simultaneous vs sequential solution of Bayes' } \\
\text { equations }\end{array}$ & Trans & Ni60 \\
\hline 6 & & Resonance parameters only & Trans & $\mathrm{Ni60}$ \\
\hline 7 & samamr & Rearranging "active" data-reduction parameters & Trans & $\mathrm{Fe} 56$ \\
\hline 8 & samdat & Comparing alternative auxiliary grids & Trans & $\mathrm{Ni58}$ \\
\hline 9 & & $\begin{array}{l}\text { Simultaneous vs sequential solution of Bayes' } \\
\text { Equations; explicit input of prior uncertainties }\end{array}$ & Fission & Pu239 \\
\hline 10 & saminp & New spin group format & Trans & $\mathrm{Zr93}$ \\
\hline 11 & & R-external & Trans & $\mathrm{Fe} 54$ \\
\hline 12 & & $\begin{array}{l}\text { Varying channel radius, normalization, and/or } \\
\text { background }\end{array}$ & Trans & Ni58 \\
\hline 13 & & Channel radius & Trans & Ni58 \\
\hline 14 & samavg & Averaging experimental and theoretical data & Fissi & $\mathrm{Pu} 239$ \\
\hline 15 & samnew & $\begin{array}{l}\text { "Relative uncertainties" vs "explicit } \\
\text { uncertainties" in PARameter file }\end{array}$ & Trans & Ni58 \\
\hline 16 & & Radius & Trans & Ni58 \\
\hline 17 & & Very long run & Fission & $\mathrm{Pu} 239$ \\
\hline 18 & & Different cross sections & (All) & $\mathrm{U} 235$ \\
\hline 20 & $\begin{array}{l}\text { samfgm, } \\
\text { samdbd, } \\
\text { samdop }\end{array}$ & Different versions of Doppler broadening & Fission & $\mathrm{U} 235$ \\
\hline 21 & samorr & Oak Ridge Resolution function; vary radius & Trans & $\mathrm{Ni58}$ \\
\hline 22 & samrsl & Shift exponential tail on resolution function & Trans & $\mathrm{Fe} 56$ \\
\hline 23 & samndf & Make ENDF/B-VI file 2 & Trans & $\mathrm{P} 204, \mathrm{Ni58}$ \\
\hline 24 & & Vary radii & Trans & Natural Fe \\
\hline
\end{tabular}


Table XID.1 (continued)

\begin{tabular}{|c|c|c|c|c|}
\hline No. & $\begin{array}{l}\text { Module } \\
\text { tested }\end{array}$ & Main feature being tested & $\begin{array}{c}\text { Data } \\
\text { type }\end{array}$ & Nuclide \\
\hline 25 & sammlb & MLBW vs RM & Trans & $\mathrm{Fe} 56$ \\
\hline 26 & samfgm & Compare different Doppler broadening methods & Fission & $\operatorname{Am} 241$ \\
\hline 27 & & Generate partial derivatives & Fission & $\mathrm{U} 235$ \\
\hline 28 & samdbd & No low-energy Doppler broadening & Total & $\mathrm{Pu} 241$ \\
\hline 29 & & Abundance as a variable & Trans & $\mathrm{Ni58}$ \\
\hline 30 & & $\begin{array}{l}\text { Remove resonances using negative group } \\
\text { number in PARameter file }\end{array}$ & Trans & Ni58 \\
\hline 31 & samdop & LH vs no broadening vs FGM at thermal & Fission & $\mathrm{U} 235$ \\
\hline 32 & samamr & Vary radii, convert "active" data-reduction parameters & Trans & $\mathrm{Fe} 56$ \\
\hline 34 & samorr & ORR resolution function at thermal energies & Trans & Cu65 \\
\hline 35 & & $\Gamma_{y}$ as miscellaneous parmameter & Capture & $\mathrm{U} 235$ \\
\hline 37 & samrec & $\begin{array}{l}\text { Reconstruct point-wise cross sections from } \\
\text { resonance parameters }\end{array}$ & All & lots \\
\hline 39 & samssm & $\begin{array}{l}\text { Self-shielding and multiple-scattering } \\
\text { corrections to capture yields }\end{array}$ & Capture & Ni58 \\
\hline 42 & sammxw & Maxwellian (stellar) averages & Capture & Ni58 \\
\hline 43 & samang & Differential elastic angular distributions & $d \sigma / d \Omega$ & $\mathrm{Ni58, \textrm {Cr } 5 2 , . .}$ \\
\hline 45 & samssm & $\begin{array}{l}\text { Multiple-scattering with more than one nuclide } \\
\text { in sample }\end{array}$ & Capture & Natural Fe \\
\hline 46 & samssm & Ditto, making plots with and without corrections & Capture & Natural Fe \\
\hline 47 & & Vary tzero and eLzero & Trans & $\mathrm{Fe} 56$ \\
\hline 48 & samrsl & Channel resolution varies with energy & Fission & $\mathrm{Pu} 239$ \\
\hline 49 & $\begin{array}{l}\text { samrec, } \\
\text { sammxw }\end{array}$ & $\begin{array}{l}\text { Reconstruct point-wise cross sections, use } \\
\text { results to calculate stellar averages }\end{array}$ & Capture & Fe54 \\
\hline 50 & sammas & Use ENDF/B-VI File2 for input to SAMMY & Trans & Co59 \\
\hline 51 & sammxw & Various ways to generate stellar averages & Capture & Ba136 \\
\hline 52 & samssm & Self-shielding and multiple-scattering corrections & Capture & Bal34 \\
\hline 53 & samrpt & Generate RPI resolution function & & \\
\hline
\end{tabular}


Table XID.1 (continued)

\begin{tabular}{|c|c|c|c|c|}
\hline No. & $\begin{array}{c}\text { Module } \\
\text { tested }\end{array}$ & Main feature being tested & $\begin{array}{l}\text { Data } \\
\text { type }\end{array}$ & Nuclide \\
\hline 54 & samrpi & Use RPI resolution function & Trans & $\mathbf{W}$ \\
\hline 55 & & Paramagnetic cross section & Total & Dummy. \\
\hline 56 & & Background function & & Dummy \\
\hline 57 & samssm & Self-indication data & Self-ind & Dummy \\
\hline 58 & $\begin{array}{l}\text { samdop, } \\
\text { samfgm }\end{array}$ & Very low energy Doppler & Capture & Dummy \\
\hline 60 & samssm & Self-shielding and multiple-scatter & Capture & Bal36 \\
\hline 61 & samref & Convert REFIT input to SAMMY and $\mathrm{vv}$ & & \\
\hline 62 & samssm & Double (etc.) scattering & Capture & $W$ \\
\hline 63 & & Constant cross section & & Dummy \\
\hline 67 & samdat & Twenty significant digits for data & & Dummy \\
\hline 68 & samfgm & $\begin{array}{l}\text { Comparing REFIT, NJOY, MULTIPOLE, } \\
\text { PREPRO, and SAMMY calculations }\end{array}$ & All & "Resium" \\
\hline 69 & samntg & Integral quantities & All & $\mathrm{U} 235$ \\
\hline 70 & $\begin{array}{l}\text { samidc, } \\
\text { samfdc }\end{array}$ & Implicit data covariances & & $\mathrm{U} 235$ \\
\hline 71 & & Write covariance matrix in compact ASCII format & & \\
\hline 72 & samthn & Thinning data & & \\
\hline 73 & samfff & Fritz Froehner's FITACS code & & \\
\hline 74 & samidc & Various ways to use data covariance information & & \\
\hline 75 & samavg & $\begin{array}{l}\text { Generate group average cross sections with and } \\
\text { without covariances }\end{array}$ & & \\
\hline 76 & & Like tr39 but uncorrected & Capture & $\mathrm{Ni58}$ \\
\hline 77 & $\begin{array}{l}\text { samxct, } \\
\text { samntg }\end{array}$ & Comparison with other codes & (All) & $\mathrm{U} 235$ \\
\hline 78 & samxct & Spin-group-dependent detector efficiencies & Capture & Ba136 \\
\hline
\end{tabular}




\section{COMPUTER-SPECIFIC ROUTINES}

For the benefit of persons wishing to port SAMMY to a new computer system, a brief discussion is included here regarding routines and statements specific to a given computer. The discussion is not expected to cover all conversion problems, but merely to point out a few problems of which the author is aware.

The current version of SAMMY is expected to be compatible with most UNIX operating systems, with LINUX, and with VMS. Details are available from the Radiation Safety Information Computational Center [RSICC]. Before embarking on a conversion program, would-be SAMMY users are encouraged to contact RSICC to learn whether a version compatible with the user's computer has already been developed. 


\section{XII.A ORELA DATA FORMAT}

Plotting of results in SAMMY is accomplished by first generating a "plot file," usually named SAMMY.ODF, and using program FORODF [JC78] to produce plots. The code FORODF has both advantages and disadvantages for the user; advantages include datamanipulation capabilities not readily available in other plotting packages. The major disadvantages are the age and the lack of routine maintenance on this program.

Although FORODF is distributed by RSICC along with the SAMMY code, SAMMY "managers" on non-ORNL systems may chose to use other, more modern plotting packages. The program SAMBIN, documented in Section VIII.F, page $150 \mathrm{i}$, of this report, can be helpful toward that end.

Calls to three different ODF routines occur in the coding for SAMMY. Names and arguments for these routines are

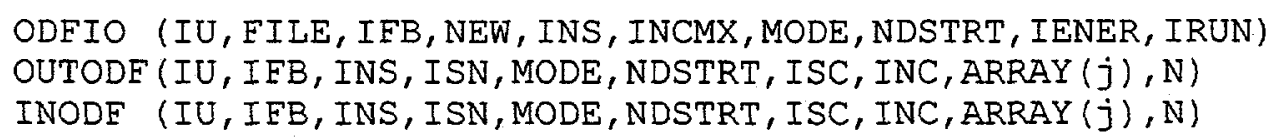

Meanings for the arguments of these subroutines are given in Table XIIA.1. The first subroutine (ODFIO) is used to open or create the plot file; the second (OUTODF), to write INC elements of ARRAY into section number ISN of the file; and the last (INODF), to read from the file. Note that access to the plot file is random rather than sequential. 
Table XIIA.1. Arguments for ODF subroutines

\begin{tabular}{|c|c|c|}
\hline Argument name & Included in which routine & Meaning of argument \\
\hline $\mathrm{IU}$ & $\begin{array}{l}\text { All three: ODFIO, } \\
\text { OUTODF, and INODF }\end{array}$ & FORTRAN unit number \\
\hline FILE & ODFIO & File name for plot file \\
\hline IFB & All three & Irrelevant to SAMMY \\
\hline NEW & ODFIO & Irrelevant \\
\hline $\mathbb{N S}$ & All & $\begin{array}{l}\text { Number of sections in the file (see } \\
\text { Table VIIC.1) }\end{array}$ \\
\hline ISN & OUTODF, INODF & $\begin{array}{l}\text { Which section is being written or read } \\
\text { now }\end{array}$ \\
\hline INCMAX & ODFIO & $\begin{array}{l}\text { Total number of data points for this } \\
\text { plot file }\end{array}$ \\
\hline MODE & All & Irrelevant \\
\hline NDSTRT & All & Irrelevant (equal to zero) \\
\hline IENER & ODFIO & Irrelevant \\
\hline IRUN & ODFIO & Irrelevant \\
\hline ISC & OUTODF, NODF & $\begin{array}{l}\text { This "write" or "read" begins with the } \\
\text { ISC" data point }\end{array}$ \\
\hline $\mathbb{N C}$ & OUTODF, INODF & $\begin{array}{l}\text { This "write" ore "read" includes a total } \\
\text { of INC data points }\end{array}$ \\
\hline $\operatorname{ARRAY}(\mathbf{j})$ & OUTODF, INODF & $\begin{array}{l}\text { This subroutine will write from or read } \\
\text { into the array elements ARRAY(j) } \\
\text { through ARRAY(j+INC-1) }\end{array}$ \\
\hline $\mathrm{N}$ & OUTODF, INODF & Irrelevant \\
\hline
\end{tabular}




\section{REFERENCES}

AF71 Anthony Foderaro, The Elements of Neutron Interaction Theory, MIT Press, 1971.

AG73 A. Gandini, Nuclear Data and Integral Measurements Correlations for Fast Reactors, Part I and II, Comitato Nazionale Energia Nucleare, Casaccia, Italy, 1973, RT/FI(73)5 and 22 (1973).

AL58 A. M. Lane and R. G. Thomas, Rev. Mod. Phys. 30, 257 (1958).

BM96 Brian E Moretti, Molybdenum Neutron Transmission Measurements and the Development of an Enhanced Resolution Neutron Target, Ph.D. Thesis in Nucl. Engineering \& Science, Rensselaer Polytechnic Institute, Troy NY, August 1996.

CC83 C. Coceva, R. Simonini, and D. K. Olsen, "Calculaton of the ORELA Neutron Moderator Spectrum and Resolution Function," Nucl. Inst. Meth. 211, 459 (1983).

CP84 C. M. Perey, Oak Ridge National Laboratory, personal communication

CP88 C. M. Perey, F. G. Perey, J. A. Harvey, N. W. Hill, N. M. Larson, and R. L. Macklin, ${ }^{58} \mathrm{Ni}+n$ Transmission, Differential Elastic Scattering and Capture Measurements and Analysis from 5 to $813 \mathrm{keV}$, ORNL/TM-10841, ENDF-347, Oak Ridge National Laboratory, 1988.

CR58 C. W. Reich and M. S. Moore, Phys. Rev. 111, 929 (1958).

DL83 D. C. Larson, N. M. Larson, J. A. Harvey, N. W. Hill, and C. H. Johnson, Application of New Techniques to ORELA Neutron Transmission Measurements and their Uncertainty Analysis: the Case of Natural Nickel from $2 \mathrm{keV}$ to $20 \mathrm{MeV}$, ORNL/TM-8203, ENDF-333, Oak Ridge National Laboratory, October 1983.

DL84 D. C. Larson, N. M. Larson, and J. A. Harvey, ORELA Flight Path 1: Determinations of Its Effective Length vs Energy, Experimental Energies, and Energy Resolution Function and Their Uncertainties, ORNL/TM-8880, Oak Ridge National Laboratory, June 1984.

ENDF-102 ENDF-102, Data Formats and Procedures for the Evaluated Nuclear Data File, ENDF-6, written by the Members of the Cross Section Evaluation Working Group, ed. V. McLane, C. L. Dunford, P. F. Rose, BNL-NCS-4495, Brookhaven National Laboratory, November 1995.

EV58 E. Vogt, Phys. Rev. 112 (1958) 203.

EW47 E. P. Wigner and L. Eisenbug, Phys. Rev. 72 (1947) 29. 
FF80 F. H. Froehner, Applied Neutron Resonance Theory, reprinted from Nuclear Theory for Applications, p. 59 ff., International Centre for Theoretical Physics, Trieste (1980). Available as KFK 2669 (1978). See also "Applied Theory of Resolved and Unresolved Resonances," Applied Nuclear Theory and Nuclear Model Calculations for Nuclear Technology Applications, M. K. Mehta and J. J. Schmidt, eds., World Scientific, Singapore, 1989, p. 170.

FF89 F. H. Froehner, "Evaluation of the Unresolved Resonance Range of ${ }^{238}$ U," Nucl. Sci. Eng. 103, 119-128 (1989).

FP84 F. G. Perey, ORNL, personal communication

FP89 F. G. Perey, ORNL, personal communication

FP89a F. G. Perey, RFUNC -- A code to Analyze Differential Elastic-Scattering Data, ORNL/TM-11112, Oak Ridge National Laboratory, March 1989.

FP92 F. G. Perey, ORNL, personal communication

GA74 George F. Auchampaugh, MULTI, A FORTRAN Code for Least-Squares Shape Fitting of Neutron Cross-Section Data Using the Reich-Moore Multilevel Formalism, LA-5473-MS, Los Alamos Scientific Laboratory, 1974.

GD78 G. deSaussure, D. K. Olsen, R. B. Perez, SIOB: A FORTRAN Code for Least-Squares Shape Fitting Several Neutron Transmission Measurements Using the Breit-Wigner Multilevel Formula, ORNL/TM-6286, ENDF-261, Oak Ridge National Laboratory, 1978.

GD84 G. deSaussure, ORNL, personal communication.

HD97 H. Derrien, N. M. Larson, and L. C. Leal, Covariance Matrices for Use in Criticality Safety Predictability Studies, ORNL/TM-13492, Oak Ridge National Laboratory, September 1997.

JB52 J. M. Blatt and L. C. Biedenharn, "The Angular Distribution of Scattering and Reaction Cross Sections," Rev. Mod. Phy. 24, 258 (1952).

JC78 J. G. Craven, OPRODF, A DECsystem-10 Data Manipulation Program for ORELA Data Formatted Files, ORNL/CSD/TM-45, Oak Ridge National Laboratory, May 1978.

JD79 J. J. Dongarra, C. B. Moler, J. R. Bunch, G. W. Stewart, LINPACK User's Guide, SIAM (1979).

JM80 J. H. Marable, C. R. Weisbin, and G. deSaussure, "Combination of Differential and Integral Data" in Sensitivity and Uncertainty Analysis of Reactor Performance Parameters, Adv. Nucl. Sci. and Technology, Plenum Press, New York, Martin Becker, ed., 1980. 
KC53 K. M. Case, F. de Hoffman, and G. Placzek, Introduction to the Theory of Neutron Diffusion, Los Alamos Scientific Laboratory, 1953.

KW84 K. Wisshak, F. Kappeler, G. Reffo, and F. Fabbri, "Neutron Capture in $s$-Wave Resonances of Iron-56, Nickel-58, and Nickel-60," Nucl. Sci. Eng. 86, 168 (1984).

LL85 L.C. Leal, ORNL, personal communication, 1985

LL95 L. C. Leal and N. M. Larson, SAMDIST, A Computer Code for Calculating Statistical Distributions for R-Matrix Resonance Parameters, ORNL/TM-13092, Oak Ridge National Laboratory, September 1995.

LL96 L. C. Leal and N. M. Larson, in preparation.

MM64 M. D. Mintz and D. P. Jordan, A 'Progressive' Interpolation Scheme for Hand and Digital Computer Analysis of Tabulated Data, Report UCRL-7681, Lawrence Livermore Laboratory, 1964.

MM89 M. C. Moxon, "REFIT2: A Least Squares Fitting Program for Resonance Analysis of Neutron Transmission and Capture Data," NEA-0914/02, July 1989.

NAG Numerical Algorithms Group (USA) Inc., 1250 Grace Court, Downers Grove, Illinois 60516, USA.

NL80 N. M. Larson and F. G. Perey, User's Guide for SAMMY: A Computer Model for Multilevel R-matrix Fits to Neutron Data Using Bayes' Equations, ORNL/TM-7485, ENDF-297, Oak Ridge National Laboratory, November 1980.

NL82 N. M. Larson, User's Guide for BAYES: A General-Purpose Computer Code for Fitting a Functional Form to Experimental Data, ORNL/TM-8185, ENDF-323, Oak Ridge National Laboratory, August 1982.

NL84 N. M. Larson, User's Guide for ALEX: Uncertainty Propagation from Raw Data to Final Results for ORELA Transmission Measurements, ORNL/TM-8676, ENDF-332, Oak Ridge National Laboratory, February 1984.

NL89 N. M. Larson, D. C. Larson, C. M. Perey, and F. G. Perey, LEVDEN: A Level Density Code Using the Fermi-Gas Model, ORNL/TM-10843, in preparation.

NL97 N. M. Larson, L. C. Leal, H. Derrien, Integral Data Analysis for Resonance Parameters Determination, ORNL/TM-13495, Oak Ridge National Laboratory, September 1997. Submitted to Nuc. Sci. Eng.

NL98 N. M. Larson, M. C. Moxon, L. C. Leal, and H. Derrien, Doppler Broadening Revisited, ORNL/TM-13525, Oak Ridge National Laboratory, 1998. 
NL98a N. M. Larson, "Introduction to the Theory and Analysis of Resolved (and Unresolved) Neutron Resonances via SAMMY," Proceedings the IAEA Workshop on "Nuclear Reaction Data and Nuclear Reactors: Physics, Design and Safety" held at the International Centre for Theoretical Physics, Trieste, Italy, 23 February -27 March 1998, to be published 1999. Also published as ORNL/M-6576, July 1998.

NL98b N. M. Larson, L. C. Leal, and H. Derrien, "Efficient Use of Bayes' Equations for Fitting Neutron-Induced Cross Section and Integral Data," International Conference on the Physics of Nuclear Science and Technology, October 5-8, 1998, Islandia Radisson Hotel, Long Island, New York.

NL99a N. M. Larson, Multiple-Scattering Corrections to Capture and Fission Yields, in preparation.

NL99b N. M. Larson, ORELA Realistic Resolution Function for SAMMY, in preparation.

NL99c N. M. Larson, RPI Resolution Function for SAMMY, in preparation.

RH87 R. Hwang, Nucl. Sci. Eng. 96, 192 (1987).

RM82 R. E. MacFarlane, D. W. Muir, and R. M. Boicourt, The NJOY Nuclear Data Processing System, Volume II: The NJOY, RECONR, BROADR, HEATR, and THERMR Modules, LA-9303-M, Vol. II (ENDF-324) (May 1982). Also R. E. MacFarlane, Introducing NJOY 89, LA-UR 89-2057, June 1989.

RM98 R. E. MacFarlane, Los Alamos National Laboratory, personal communication, 1998.

RP80 R. W. Peelle, "Uncertainty in the Nuclear Data Used for Reactor Calculations, in Sensitivity and Uncertainty Analysis of Reactor Performance Parameters," in $A d v$. Nucl. Sci. Tech., Plenum Press, Martin Becker, ed., 1980.

RP86 R. B. Perez, G. deSaussure, N. M. Larson, R. L. (Roger) Macklin, "Multilevel Analysis of the Low-Energy ${ }^{239}$ Pu Cross Sections," Nucl. Sci. Eng. 93, $31-42$ (1986).

RSICC Radiation Safety Information Computational Center (formerly the Radiation Shielding Information Center), Oak Ridge National Laboratory, Bldg 6025, MS 6362, P.O. Box 2008, Oak Ridge, TN 37831-6362.

SC92 S. N. Cramer and F. G. Perey, "Time-Dependent Monte Carlo Calculations of the Oak Ridge Electron Linear Accelerator Target Neutron Spectrum," Nucl. Sci. Eng. 111, $102-111$ (1992).

WV12 W. Voigt, Sitz-Ber. Bayer. Akad. Wiss. (1912) 603.

YD98 Y. Danon et al., "Neutron Total Cross Section Measurements and Resonance Parameter Analysis of Ho, Tm, and Er from $0.001 \mathrm{eV}$ to $20 \mathrm{eV}$," Nucl. Sci. Eng. 128, 61-69 (1998). 


\section{APPENDIX D: ANALYSES USING SAMMY}

1. C. M. Perey, J. A. Harvey, Richard L. Macklin, R. R. Winters, and F. G. Perey, Neutron Transmission and Capture Measurements and Analysis of ${ }^{60}$ Ni from 1 to $450 \mathrm{keV}$, ORNL5893, ENDF-330, 1982.

2. C. M. Perey, J. A. Harvey, Richard L. Macklin, F. G. Perey, and R. R. Winters, "Resonance Parameters of ${ }^{60} \mathrm{Ni}+\mathbf{n}$ from Measurements of Transmission and Capture Yields from 1 to $450 \mathrm{keV}$," Phys. Rev. C 27, 2556 (1983).

3. J. A. Harvey, W. M. Good, R. F. Carlton, B. Castel, J. B. McGrory, and S. F. Mughabghab, "Neutron Spectroscopy as a High-Resolution Probe: Identification of the Missing 1/2+ States in ${ }^{31} \mathrm{Si}$," Phys. Rev. C 28, 24 (1983).

4. S. Raman, B. Fogelberg, J. A. Harvey, Richard L. Macklin, P. H. Stelson, A. Shroeder, and K. L. Kratz, "Overlapping Beta Decay and Resonance Neutron Spectroscopy of Levels in ${ }^{87} \mathrm{Kr}$," Phys. Rev. C 28, 602 (1983).

5. R. F. Carlton, W. M. Good, J. A. Harvey, Richard L. Macklin, and B. Castel, "Determination of Unbound States in ${ }^{34}$ S," Phys. Rev. C 29, 1980 (1984).

6. R. F. Carlton, J. A. Harvey, and C. H. Johnson, "s- and $p$-wave Neutrons on ${ }^{30} \mathrm{Si}$ and ${ }^{34} \mathrm{~S}$ : Spherical Optical Model Analysis," Phys. Rev. C 29, 1988 (1983).

7. G. de Saussure, R. B. Perez, and Roger L. Macklin, "Multilevel Analysis of the LowEnergy ${ }^{239}$ Pu Cross Sections," ANS/ENS International Meeting, Washington, D.C. (1984).

8. G. P. Coddens, M. Salah, J. A. Harvey, and N. W. Hill, "Neutron, Alpha and Total Widths and Spin Assignments for Resonances in ${ }^{33} \mathrm{~S}+\mathrm{n}$ from 10-400 keV," Neutron-Nucleus Collisions, a Probe of Nuclear Structure, AIP Conference Proceedings, eds. J. Rapaport, R. W. Finlay, S. M. Grimes, and F. S. Dietrich, 124, 302 (1985).

9. J. A. Harvey, C. H. Johnson, R. F. Carlton, and B. Castel, " $\mathrm{d}_{5 / 2}$-single Particle Strength in ${ }^{48} \mathrm{Ca}+\mathrm{n}$," Ibid., 304 (1985).

10. R. F. Carlton, J. A. Harvey, and C. H. Johnson, "Optical Model Scattering Functions for Low Energy Neutrons on ${ }^{86} \mathrm{Kr}$," Ibid., 308 (1985).

11. R. F. Carlton, J. A. Harvey, N. W. Hill, and Richard L. Macklin, "Neutron Capture and Total Cross Sections for ${ }^{48} \mathrm{Ca}$ : Astrophysical Implications," Capture Gamma-Ray Spectroscopy and Related Topics -- 1984, AIP Conference Proceedings, ed. S. Raman, 125, 774 (1985).

12. B. Fogelberg, J. Harvey, M. Mizumoto, and S. Raman, "Observation of Extremely Low $s$-wave Strength in the Reaction ${ }^{136} \mathrm{Xe}+\mathrm{n}$," Ibid., 493 (1985).

13. D. J. Horen, C. H. Johnson, and A. D. MacKellar, " $\ell J$-dependence of the Real Optical Potential Near Neutron Threshold," Physics Letters 161B, 217-222 (1985). 
14. Richard L. Macklin, J. A. Harvey, and N. W. Hill, 'Neutron Transmission Measurement and Resonance Analysis of ${ }^{93} \mathrm{Zr}$ from 60 to $6000 \mathrm{eV}$," Nucl. Sc. Eng. 92, 525-530 (1986).

15. R. B. Perez, G. de Saussure, N. M. Larson, and Roger L. Macklin, "Multilevel Analysis of the Low energy ${ }^{239} \mathrm{Pu}$ Cross Sections," Nucl. Sci. Eng. 93, 31-42 (1986).

16. C. M. Perey, F. G. Perey, J. A. Harvey, N. W. Hill, and R. L. Macklin, ${ }^{\circ 58} \mathrm{Ni}+\mathrm{n}$ Transmission, Capture and differential Elastic Scattering Data Analysis in the Resonance Region," p. 1639 in Proceedings of the International Conference on Nuclear Data for Basic and Applied Science, Santa Fe, N. M., May 13-17, 1985.

17. G. de Saussure, R. B. Perez, and Roger L. Macklin, "R-matrix Analysis of the ${ }^{239} \mathrm{Pu}$ Neutron Cross Sections," Ibid., p. 1635, 1985.

18. F. G. Perey, "Status of the Parameters of the 1.15-keV Resonance of ${ }^{56}$ Fe," Ibid., p. 1523, 1985.

19. M. Sowerby, "Summary of the Work of the NEANDC Task Force on ${ }^{238} \mathrm{U}$," Ibid., 1511, 1985.

20. R. R. Winters, R. F. Carlton, J. A. Harvey, and N. W. Hill, "Spherical Optical Model Potential for the Re/Os Stellar Nucleosynthesis Chronometer from $s$-wave Neutrons on 186,187,188 Os," Phys. Rev. C 34, 840 (1986).

21. H. Derrien, G. de Saussure, R. B. Perez, N. M. Larson, Roger L. Macklin, R-Matrix Analysis of the ${ }^{239} \mathrm{Pu}$ Cross Sections up to $1 \mathrm{keV}$, ORNL/TM-10098, June 1986.

22. D. J. Horen, C. H. Johnson, J. L. Fowler, A. D. MacKellar, B. Castel, " ${ }^{208} \mathrm{~Pb}+\mathrm{n}$ Reaction and the Mean Nuclear Field near Threshold," Phys. Rev. C 34, 429-42 (1986).

23. R. F. Carlton, J. A. Harvey, R. L. Macklin, C. H. Johnson, and B. Castel, "Nuclear Structure of ${ }^{49} \mathrm{Ca}$ Above $5 \mathrm{MeV}$ Excitation from $n+{ }^{48} \mathrm{Ca}$ and Astrophysics for $30 \mathrm{keV}$ Neutrons," Nucl. Phys. A465, 274-290 (1987).

24. R. R. Spencer, J. A. Harvey, N. W. Hill, and L. W. Weston, "Parameters of the 1.056-eV Resonance in ${ }^{240} \mathrm{Pu}$ and the $2200 \mathrm{~m} / \mathrm{s}$ Neutron Total Cross Sections of ${ }^{235} \mathrm{U},{ }^{239} \mathrm{Pu}$, and ${ }^{240} \mathrm{Pu}, "$ Nucl. Sci. Eng. 96, 318-329 (1987).

25. H. Derrien, N. M. Larson, G. de Saussure, and R. B. Perez, "R-Matrix Analysis of the ${ }^{241} \mathrm{Pu}$ Cross Sections up to $100 \mathrm{eV}, "$ Nucl. Sci. Eng. 96, 58-65 (1987).

26. G. P. Coddens, M. Salah, J. A. Harvey, N. W. Hill, and N. M. Larson, "Resonance Structure of ${ }^{33} \mathrm{~S}+\mathrm{n}$ from Transmission Measurements," Nucl. Phys. A469, 480-96 (1987).

27. C. M. Perey, F. G. Perey, J. A. Harvey, N. W. Hill, N. M. Larson, and Richard L. Macklin, ${ }^{58} \mathrm{Ni}+n$ Transmission, Capture and Differential Elastic Scattering and Capture Measurements and Analysis from 5 to $813 \mathrm{keV}$, ORNL/TM-10841; ENDF-347, 1988. 
28. H. Derrien, G. de Saussure, N. M. Larson, L. C. Leal, R. B. Perez, "R-Matrix Analyses of the 235U and 239Pu Neutron Cross Sections," Proceedings of the International Conference on Nuclear Data for Science and Technology, Mito, Japan, May 30-June 3, 1988, ed. S. Igarasi, Saikon Publishing Company Limited, 83 (1988).

29. ${ }^{58} \mathrm{Ni}+n$ Transmission, Differential Elastic Scattering and Capture Measurements and Analysis from 5 to $813 \mathrm{keV}$, C. M. Perey, F. G. Perey, J. A. Harvey, N. W. Hill, N. M. Larson, and R. L. Macklin, ORNL/TM-10841 and ENDF-347, September 1988.

30. G. de Saussure, L. C. Leal, R. B. Perez, N. M. Larson, and M. S. Moore, "A New Resonance-Region Evaluation of Neutron Cross Sections for ${ }^{235} \mathrm{U}, " 193$ in Proceedings of the International Conference on Reactor Physics, Jackson Hole, Wyo, September 18-21, Vol. I, 293 (1988); also Nucl. Sci. Eng. 103, 109-118 (1989).

31. M. S. Moore, G. de Saussure, L. C. Leal, R. B. Perez, and N. M. Larson, "Resonance Structure in the Fission of $\left.{ }^{235} \mathrm{U}+\mathrm{n}\right)$," International Conference Fifty Years Research in Nuclear Fission, Berlin, Germany, April 3-7, 1989.

32. H. Derrien and G. de Saussure, "R Matrix Analysis of the ${ }^{241} \mathrm{Pu}$ Neutron Cross Sections in the Thermal to 300-eV Energy Range," Nucl. Sci. Eng. 106, 415-433 (1990).

33. H. Derrien, G. de Saussure, and R. B. Perez, "R Matrix Analysis of the ${ }^{239} \mathrm{Pu}$ Neutron Cross Sections in the Energy Range Up to $1000 \mathrm{eV}$," Nucl. Sci. Eng. 106, 434-51 (1990).

34. C. M. Perey, F. G. Perey, J. A. Harvey, N. W. Hill, N. M. Larson, ${ }^{56} \mathrm{Fe}$ Resonance Parameters for Neutron Energies up to $850 \mathrm{keV}$, ORNL/TM-11742, December 1990.

35. C. M. Frankle et al., "Sign Correlations and Parity Nonconservation for Neutron Resonances in ${ }^{232}$ Th," Phys. Rev. Letters 67, 564-67, 1991.

36. D. M. Hetrick, D. C. Larson, N. M. Larson, and C. Y. Fu, Description of Evaluations for ${ }^{50,52,53,54} \mathrm{Cr}$ Performed for ENDF/B-VI, BNL Report ENDF-201,131 (1991).

37. C. Y. Fu, D. M. Hetrick, C. M. Perey, F. G. Perey, N. M. Larson, and D. C. Larson, Description of Evaluations for ${ }^{54,56,57,58} \mathrm{Fe}$ Performed for ENDF/B-VI, BNL Report ENDF201, 149, 1991.

38. C. Y. Fu, D. C. Larson, and N. M. Larson, Description of Evaluations for ${ }^{206,207,208} \mathrm{~Pb}$ Performed for ENDF/B-VI, BNL Report ENDF-201, 336, 1991.

39. G. de Saussure, N. M. Larson, J. A. Harvey, and N. W. Hill, Multilevel Resonance Analysis of ${ }^{59}$ Co Neutron Transmission Measurements, ORNL/TM-11762, May 1991.

40. G. de Saussure, N. M. Larson, and J. A. Harvey, "Evaluation of the ${ }^{59} \mathrm{Co}$ Resolved Resonance Region," Transactions of the 1991 Annual Meeting of the American Nuclear Society 63, 425, 1991.

41. G. de Saussure and N. M. Larson, "Analysis of ${ }^{249} \mathrm{Cf}$ Neutron Cross Sections in the Resolved Resonance Region," Transactions of the 1991 Winter Meeting of the American Nuclear Society 64, 540, November 1991. 
42. J. A. Harvey, N. W. Hill, N. M. Larson, and D. C. Larson, "Measurement of the Nitrogen Total Cross Section from $0.5 \mathrm{eV}$ to $50 \mathrm{MeV}$, and Analysis of the 433-keV Resonance," p. 729 in Proceedings of the International Conference on Nuclear Data for Science and Technology, 13-17 May 1991, Juelich, Germany, ed. S. M. Qaim, Springer-Verlag Berlin Heidelberg, (1992).

43. C. M. Perey, F. G. Perey, J. A. Harvey, N. W. Hill, and N. M. Larson, ${ }^{656} \mathrm{Fe}$ and ${ }^{60 \mathrm{Ni}}$ Resonance Parameters," Ibid, 41 (1992).

44. G. de Saussure and N. M. Larson, "Multilevel Resonance Analysis of ${ }^{59}$ Co Transmission Measurements," Ibid, 109 (1992).

45. D. M. Hetrick, D. C. Larson, N. M. Larson, C. Y. Fu, and S. J. Epperson, "Evaluation of the Silicon Isotopes for ENDF/B-VI," Ibid, 909 (1992).

46. G. de Saussure, N. M. Larson, J. A. Harvey, and N. W. Hill, "Multilevel Resonance Analysis of ${ }^{59}$ Co Neutron Transmission Measuurements," Ann. Nucl. Energy 19, 393-402 (1992).

47. C. M. Frankle et al., "Parity Nonconservation for Neutron Resonances in ${ }^{232} \mathrm{Th}$," Phys. Rev. C 46, 778-787 (1992).

48. C. M. Perey, F. G. Perey, J. A. Harvey, N. W. Hill, N. M. Larson, R. L. Macklin, and D. C. Larson, " ${ }^{58} \mathrm{Ni}+\mathrm{n}$ Transmission, Differential Elastic Scattering and Capture Measurements and Analysis Up to $813 \mathrm{keV}, "$ Phys. Rev. C 47, 1143-1169 (1993).

49. C. O. Beasley, Jr., N. M. Larson, J. A. Harvey, D. C. Larson, and G. M. Hale, "Measurement and Analysis of the Nitrogen Total and Differential Scattering Cross Sections in the Resonance Region," poster paper at the Eighth ASTM-EURATOM Symposium on Reactor Dosimetry, Aug. 29- Sept. 3, 1993, Vail, Colorado. To be published in Reactor Dosimetry ASTM STP 1228, Harry Farrar IV, E. P. Lippincott, J. G. Williams, and D. W. Vehar, eds., American Society for Testing and Materials, Philadelphia (1994).

50. C. M. Frankle et al., "Neutron resonance spectroscopy on ${ }^{113} \mathrm{Cd}$ to $\mathrm{E}_{\mathrm{n}}=15 \mathrm{keV}$," Phys. Rev. C 50, 2774-2785 (1994).

51. H. Derrien, "R-Matrix Analysis of Neutron Effective Total Cross Section, Fission Cross Section and Capture Cross Section of ${ }^{233} \mathrm{U}$ in the Energy Range from Thermal to $150 \mathrm{eV}$," J. Nucl. Sci. Technol., 31(5), 379 (1994).

52. O. Bouland, H. Derrien, N. M. Larson, and L. C. Leal, "Reich-Moore Evaluation of the ${ }^{240} \mathrm{Pu}$ Resonance Parameters,"American Nuclear Society Winter Meeting, San Francisco, Calif., November 1995.

53. L. C. Leal, N. M. Larson, and H. Derrien, "Re-evaluation of the ${ }^{235} \mathrm{U}$ Cross Section for ENDF/B-VI", American Nuclear Society Winter Meeting, San Francisco, Calif., November 1995. 
54. P. E. Koehler et al., "Resonance Neutron Capture and Transmission Measurements and the Stellar Neutron Capture Cross Sections of ${ }^{134} \mathrm{Ba}$ and ${ }^{136} \mathrm{Ba}$," Phys. Rev. C 54, 1463-1477 (1996).

55. O. Bouland, H. Derrien, N. M. Larson, and L. C. Leal, "R-Matrix Analysis of the ${ }^{240} \mathrm{Pu}$ neutron Cross Sections in the Thermal to 5700-eV Energy Range," Nucl. Sci. Eng. 127 105-129 (1997). Also published as ORNL/TM-13450, August 1997.

56. L. C. Leal, N. M. Larson, D. C. Larson, and D. M. Hetrick, "R-Matrix Evaluation of ${ }^{28} \mathrm{Si}$, ${ }^{29} \mathrm{Si},{ }^{30} \mathrm{Si}$ up to $1.8 \mathrm{MeV}$," International Conference on Nuclear Data for Science and Technology, May 19-24, 1997, Trieste, Italy.

57. L. C. Leal, H. Derrien, and N. M. Larson, "Statistical Properties of the $s$-Wave Resonances of ${ }^{235} \mathrm{U}$," International Conference on Nuclear Data for Science and Technology, May 19-24, 1997, Trieste, Italy.

58. D. M. Hetrick, D. C. Larson, N. M. Larson, L. C. Leal, and S. J. Epperson, Evaluation of 28, 29, 30 Si Neutron Induced Cross Sections for ENDF/B-VI, ORNL/TM-11825, April 1997.

59. L. C. Leal, H. Derrien, N. M. Larson, R. Q. Wright, R-Matrix Analysis of ${ }^{235} U$ Neutron Transmission and Cross Sections in the Energy Range 0 to $2.25 \mathrm{keV}$, ORNL/TM-13516 (November 1997). Accepted by Nucl. Sci. Eng., July, 1998.

60. P. E. Koehler et al., "New Neutron Capture and Transmission Measurements for ${ }^{134,136}$ ba at Orela and Their Impact on $S$-process Nucleosynthesis Calculations," Nucl. Phys. A.621, 258c-261c (1997).

61. K. H. Guber, R. R. Spencer, P. E. Koehler, and R. R. Winters, " $\mathrm{A} \mathrm{BaF}_{2}$ detector system for $(\mathrm{n}, \gamma)$ cross section measurements at ORELA," Nucl. Phys. A 621, 254c-257c (1997).

62. K. H. Guber, R. R. Spencer, P. E. Koehler, and R. R. Winters, "Measurements of ${ }^{142,144} \mathrm{Nd}$ $(\mathrm{n}, \gamma)$ cross sections at ORELA for astrophysical s-process studies," Nucl. Phys. A 621, 266c (1997).

63. K. H. Guber, R. R. Spencer, P. E. Koehler, and R. R. Winters, "New ${ }^{142,144} \mathrm{Nd}(\mathrm{n}, \gamma)$ Cross Sections and the $s$-process Origin of the Nd Anomalies in Presolar Meteoric Silicon Carbide Grains," Phys. Rev. Letters 78, 2704-2707 (1997).

64. Y. Danon, C. J. Werner, G. Youk, R. C. Block, R. E. Slovacek, and N. C. Francis, "Neutron Total Cross-Section Measurements and Resonance Parameter Analysis of Holmium, Thulium, and Erbium from 0.001 to $20 \mathrm{eV}$," Nucl. Sci. Eng. 128, 61-69 (1998).

65. L. C. Leal, R. O. Sayer, and N. M. Larson, "R-Matrix Evaluation of ${ }^{16} \mathrm{O}$ Neutron Cross Sections up to $6.3 \mathrm{MeV}$," November 1998 ANS Conference in Washington, D. C. 


\section{APPENDIX E: CONSTANTS}

\section{Recommendation of the Csewg Constants Task Force \\ October 20, 1998}

CSEWG participants: Mark Chadwick, Maurice Greene, Richard Hwang, Nancy Larson (chair), Robert MacFarlane, Vicki McLane, John White

Other participants: Dermott Cullen, Mick Moxon

In order to eliminate the use of different values for physical and mathematical constants as a source of discrepancy between calculations using different computer codes, CSEWG should take the following actions:

(1) Formally designate as official CSEWG constants the values reported in "1986 CODATA Internationally recommended values of the Fundamental Physical Constants" on the Web site http://physics.nist.gov/cuu/Constants/. This is the "NIST Reference on Constants, Units, and Uncertainty, one of the technical activities of the Fundamental Constants Data Center of the NIST Physics Laboratory. The contents of this site have been prepared by Barry N. Taylor of the Data Center in close collaboration with Peter J. Mohr of the Physics Laboratory's Atomic Physics Division."

a. Relevant numbers from the CODATA list will be published in ENDF-102.

b. Evaluators and code developers should use the values published in ENDF-102, updating only when that document is updated.

(2) Within the text of the next update of ENDF-102, remove numerical values for physical constants and replace by variable names; provide numerical values (and units) in a list in an appendix. This list should include (but is not limited to) the following:

a. $\quad m_{n}=$ mass of neutron in atomic mass units (u)

[Remove values from pages 0.18 and D.4 of the Nov. 1995 version of ENDF-102].

Recommended value from CODATA: $m_{n}=1.008664904 \mathrm{u}$

b. Boltzmann's constant $k$.

Recommended value from CODATA: $k=8.617385 \times 10^{-5} \mathrm{eV} \mathrm{K}^{-1}$

c. $\sqrt{2 m_{n}} / \hbar=\{$ sqrt (2 mass of neutron) / Plank's constant $\}$. [Remove value from p. D.3.]

Recommended value based on information in CODATA:

$$
\sqrt{2 m_{n}} / \hbar=0.002196807122623 /\left(10^{-12} \mathrm{~cm} \sqrt{\mathrm{eV}}\right)
$$

d. $2(\mathrm{amu}) / \hbar^{2}$. [Remove value from Eq. (6.9).]

Recommended value based on information in CODATA:

$$
2(\mathrm{amu}) / \hbar^{2}=4.784504258066 \times 10^{-6} /\left(\left[10^{-12} \mathrm{~cm}\right]^{2} \mathrm{eV}\right) \text {. }
$$


e. $\left(\mathrm{e}^{2} / \hbar\right)^{2}$ amu. [Remove value from Eq. (6.10).]

Recommended value based on CODATA:

$$
\left(\mathrm{e}^{2} / \hbar\right)^{2} \mathrm{amu}=2.480167060319 \times 10^{4} \mathrm{eV} .
$$

(3) Encourage code developers to locate any values for physical constants that may be currently buried deep within the coding, and replace by variables whose values are specified in one site only (e.g., in a block data statement). This ensures internal consistency, and expedites any necessary updates.

(4) Encourage code developers to double-check that numerical constants (e.g., $\pi$ or $e$ ) are represented to a degree of accuracy consistent with the precision of the computers on which the codes are to be run.

(5) Encourage evaluators to use mass numbers, Q-values, etc., as specified on CODATA, for evaluations submitted for acceptance by ENDF. Values not found in CODATA should be obtained from G. Audi and A. H. Wapstra, Nucl. Phys. A, 595, 409 (1995). The Web site for these values is maintained by the Atomic Mass Data Center, and located at http://csnwww.in2p3.fr/massatom/masseval.html.

(6) Encourage evaluators to specify values for "hidden" physical constants within the header text of the ENDF file, to prevent future confusion in the event of changes in the accepted values.

Submitted by the CSEWG Constants Task Force, N. M. Larson, Chair 


\section{APPENDIX F: QUESTIONNAIRE RE SAMMY RESTRUCTURING}

October, 1998

At some as-yet-undetermined future date, the multilevel R-matrix code SAMMY will be restructured to take full advantage of the strengths inherent in Bayes' equations, to provide the ability to perform truly simultaneous fits to multiple experimental data sets (both differential and integral). Details of this proposed restructuring are discussed elsewhere [NL98b]. The restructured code will be denoted SAMSON (SON of SAMMY).

Since major changes to input are required to accomplish this restructuring, this would seem to be a good time to make other (helpful but not necessary) changes as well. A short description of both necessary and optional changes is given here:

\section{INPUT FILES:}

Information from the SAMMY INPut file will be located more logically: A title line, and commands relevant to the complete run, will be in a new COMmand file. Spin group definitions (quantum numbers etc) will be placed in the PARameter files, along with values for any R-matrix parameters such as channel radii. Experiment-specific information (type of data, nuclear abundances, Doppler temperature, resolution parameters, etc.) will appear in a new EXPeriment file.

The SAMSON PARameter file will contain all R-matrix information, including spin group definitions (quantum numbers etc.) that had been in the SAMMY INPut file. Resonance parameters will remain in the PARameter file. No experiment-specific information (e.g. nuclear abundances) will be in the new PAR file. Although the SAMMY PARameter file often contains resonance parameters for more than one nuclide, the SAMSON PAR file will relate to one nuclide only; hence several PAR files may be needed for any given run.

The SAMSON EXPeriment file will contain all information relevant to one particular experimental data set; some of this information had been in the SAMMY INPut file, and some in the SAMMY PARameter file.

The SAMSON DATa file is identical to the SAMMY DATa file.

\section{OUTPUT FILES:}

SAMMY.LPT will be similar to the SAMMY file.

An updated version of the SAMSON PARameter file will be created for each PAR file that contains flagged (varied) parameters.

An updated version of the EXPeriment file will be created for each EXP file that contains flagged (varied) parameters.

A binary COVariance file will be produced, containing essentially the same information as is now included in the SAMMY COVariance file. 


\section{SAMMY USER PREFERENCES}

Name, address, e-mail

1. a. Output PARameter files should be given the same name as the corresponding input PAR file, with extension (please specify) to distinguish the two.

YES

YES

YES

b. Output PAR files should be named SAM01.PAR, SAM02.PAR, ...

c. Output PAR file names should be specified by the user. If yes, how/where?

2. a. Output PAR files should contain the initial uncertainties for flagged parameters.

b. Output PAR files should contain the updated uncertainties for flagged parameters.

3. a. Output EXPeriment files should be given the same name as the corresponding input EXP file, with extension (please specify) to distinguish the two.

b. Output EXP files should be named SAM01.EXP, SAM02.EXP, ...

c. Output EXP file names should be specified by the user. If yes, how/where?

4. a. Output EXP files should contain the initial uncertainties for flagged parameters.

b. Output EXP files should contain the updated uncertainties for flagged parameters.

5. a. Output plot files should be given the same name as the corresponding input EXPeriment file, with extension (please specify) to distinguish the two.

b. Output plot files should be named SAM01.ODF, SAM02.ODF, ...

c. Output plot file names should be specified by the user. If yes, how/where?

6. a. Default uncertainties for all parameters should be specified by the same value of FUDGE, which is given in the COM file.

b. A value for FUDGE should be given in each PAR and EXP file.

7. An option should be added to provide resonance parameter uncertainties on the line following the parameter values in the SAMSON PARameter file.

YES

YES

YES

NO

YES

YES

NO

NO

YES

NO

YES

YES

NO

NO

$\mathrm{NO}$

NO

YES N NO

$\mathrm{NO}$

ES

NO

ES NO

ES - NO

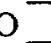

8. Please send suggestions re formatting for the input data covariance matrix.

9. Use this space for any other suggestions regarding SAMMY and/or SAMSON.

Please return completed questionnaire to N. M. Larson, Oak Ridge National Laboratory, Building 6011, MS 6370, Post Office Box 2008, Oak Ridge, TN 37831-6370. Or e-mail responses to nml@ornl.gov. 
ORNL/TM-9179/R4

\section{INTERNAL DISTRIBUTION}

$\begin{aligned} \text { 1. } & \text { B. L. Broadhead } \\ \text { 2. } & \text { H. Derrien } \\ \text { 3. } & \text { F. C. Difilippo } \\ \text { 4. } & \text { M. E. Dunn } \\ \text { 5. } & \text { C. Y. Fu } \\ 6 . & \text { N. M. Greene } \\ 7 . & \text { K. Guber } \\ 8 . & \text { F. B. Guimaraes } \\ 9 . & \text { J. A. Harvey } \\ \text { 10. } & \text { C. M. Hopper } \\ \text { 11. } & \text { D. T. Ingersoll } \\ \text { 12. } & \text { P. E. Koehler } \\ \text { 13. } & \text { M. A. Kuliasha } \\ \text { 14. } & \text { D. C. Larson } \\ \text { 15-19. } & \text { N. M. Larson }\end{aligned}$

1. B. L. Broadhead

Derrien

F. C. Difilippo

unn

. C. Y.Fu

6. N. M. Greene

K Guber

8. F. B. Guimaraes

10. C. M. Hopper

11. D. T. Ingersoll

12. P. E. Koehler

13. M. A. Kuliasha

15-19. N. M. Larson
20. L. C. Leal

21. C. V. Parks

22. R. W. Roussin

23. R. O. Sayer

24. C. H. Shappert

25. M. S. Smith

26. R. R. Spencer

27. R. M. Westfall

28. J. E. White

29. R. Q. Wright

30. RSICC

30-31. Laboratory Records for submission to OSTI

33. Laboratory Records, ORNL-RC

34. Central Research Library

\section{EXTERNAL DISTRIBUTION}

35. C. Bastien, Central Bureau for Nuclear Measurements, Steenweg op Retie, 2240 Geel, Belgium

36. P. Blaise, DER/SPRC/LEPH, Batiment 230, Centre d'Etudes de CADARACHE, 13108 Saint Paullez-Durance, France

37. R. Block, Gaerttner LINAC Laboratory, Department of Environmental and Energy Engineering, Rensselaer Polytechnic Institute, Troy, NY 12180-3590

38. O. Bouland, DER/SPRC/LEPH, Batiment 230, Centre d'Etudes de CADARACHE, 13108 Saint Paul-lez-Durance, France

39. A. Brusegan, Central Bureau for Nuclear Measurements, Steenweg op Retie, 2240 Geel, Belgium

40. David Buchan P41 E1, Pickering Nuclear Generating Station, Ontario Hydro, 1675 Montgomery Park Rd., Pickering, Ontario CANADA LIV 2R5

41. J. Burke, Gaerttner LINAC Laboratory, Department of Environmental and Energy Engineering, Rensselaer Polytechnic Institute, Troy, NY 12180-3590

42. D. Cabrilla, U.S. Department of Energy, EM-66, Clover Leaf, Room 1199, 19901 Germantown Road, Germantown, MD 20874-1290

43. D. E. Carlson, Reactor and Plant System Branch, Division of System Research, Office of Nuclear Regulatory 'Research, U.S. Nuclear Regulatory Commission, MS T-10 G6, RM T-10, 17, Washington, DC 20555-0001

44. M. Chadwick, T-2, MS B243, Los Alamos National Laboratory, P. O. Box 1663, Los Alamos, NM 87545

45. F. Corvi, Central Bureau for Nuclear Measurements, Steenweg op Retie, 2240 Geel, Belgium

46. D. E. Cullen, MS L-298, Lawrence Livermore National Laboratory, P. O. Box 808, Livermore, CA 94550

47. Y. Danon, Physics Department, NRCN, P. O Box 9001, Beer-Sheva 84190, Israel

48. R. L. Dintaman, U.S. Department of Energy, DP-13, Washington, DC 20585 
49. C. Dunford, Bldg 197D, National Nuclear Data Center, Brookhaven National Laboratory, Upton, NY 11973

50. J. R. Felty, U.S. Department of Energy, DP-311, Washington DC 20585

51. P. Finck, Argonne National Laboratory, Reactor Analysis Division, Bldg 208, Argonne, IL 60439

52. E. Fort, DER/SPRC/LEPH, Batiment 230, Centre d'Etudes de CADARACHE, 13108 Saint Paullez-Durance, France

53. N. Francis, Gaerttner LINAC Laboratory, Department of Environmental and Energy Engineering, Rensselaer Polytechnic Institute, Troy, NY 12180-3590

54. C. M. Frankle, NIS-6, MS J562, Los Alamos National Laboratory, Los Alamos, NM 87545

55. S. C. Frankle, X-CI, MS F663, Los Alamos National Laboratory, Los Alamos, NM 87545

56. F. Froehner, Kernforschungszentrum Karlsruhe, Institut fur Neutronenphysik und Reacktortechnik, Postfach 336 40, D-76021 Karlsruhe, Germany

57. W. Furman, Frank Laboratory of Neutron Physics, JINR, Dubna, Russia

58. S. Ganesan, Head, Nuclear Data Section, Indira Gandhi Centra for Atomic Research, Kalpakkam 603 102, Tamilnadu, India

59. Chris Gould, Physics Dept., North Carolina State University, Box 8202, Raleigh, NC 27695-8202

60. H. Gruppelaar, Netherlands Energy Research Foundation ECN, Westerduinweg 3, P. O. Box 1, NL 1755 ZG Petten, Netherlands

61. F. Gunsing, Centre D'Etudes De Saclay, F-Saclay - 91191 GIF-SUR-YVETTE Cedex, France

62. G. M. Hale, T-2, MS B243, Los Alamos National Laboratory, P. O. Box 1663, Los Alamos, NM 87545

63. A. Hasagawa, Nuclear Data Center, Japan Atomic Energy Research Institute, Tokai-mura, Nakagun, Ibaraki-ken 319-11, Japan

64. R. N. Hwang, Argonne National Laboratory, Reactor Analysis Division, Bldg 208, Argonne, IL 60439

65. R. P. Jacqmin, DER/SPRC/LEPH, Batiment 230, Centre d'Etudes de CADARACHE, 13108 Saint Paul-lez-Durance, France

66. N. Janeva, Bulgarian Academy of Sciences, 72, Boul, Tzarigradsko shosse, Sofia 1784, Bulgaria

67. L. Lois, 08 E23, U.S. Nuclear Regulatory Commission, 11555 Rockville Pike, Rockville, MD 20852-2746

68. G. Leinweber, Gaerttner LINAC Laboratory, Department of Environmental and Energy Engineering, Rensselaer Polytechnic Institute, Troy, NY 12180-3590

69. R. Little, X-CI, MS F663, Los Alamos National Laboratory, Los Alamos, NM 87545

70. C. Lubitz, Knolls Atomic Power Laboratory, P. O. Box 1072, Schenectady, NY 12301

71. R. E. MacFarlane,T-2, MS B243, Los Alamos National Laboratory, P. O. Box 1663, Los Alamos, NM 87545-1663

72. C. Mounier, CEN Saclay, DMT/SERMA/LENR, 91191 Gif Sur Yvette Cedex, France

73. M. C. Moxon, 3 Hyde Copse, Marcham, Abingdon, Oxfordshire, England

74. D. Muir, IAEA Nuclear Data Section, Wagramerstr. 5, P. O. Box 100, A-1400 Wien, Austria

75. C. W. Nilson, Office of Nuclear Regulatory Research, U.S. Nuclear Regulatory Commission, Mail Stop TWFN 9-F-33, Washington, DC 20555

76. C. Nordborg, OECD/NEA, Le Seine St-Germain 12, Boulevard Iles, 92130 Issy-les-Moulineaux, France

77. Soo Youl OH, Nuclear Data Evaluation Lab., Korea Atomic Energy Research Institute, P. O. Box 105, Yusung, Taejon, 305-600 Korea

78. Albert Popov, Frank Laboratory of Neutron Physics, Joint Institute for Nuclear Research, RU-141980 Dubna, Moscow Region, Russia

79. C. Raepsaet, CEN Saclay, DMT/SERMA/LEPP, 91191 Gif Sur Yvette Cedex, France

80. M. Salvatores, DRN/P, Batiment 707, C. E. CADARACHE, 13108 Saint Paul-lez-Durance, France

Distribution List

$246(\mathrm{R} 4)$

Page 2 
81. E. Sartori, OECD/NEA, Le Seine St-Germain 12, Boulevard Iles, 92130 Issy-les-Moulineaux, France

82. O. A. Shcherbakov, Petersburg Nuclear Physics Institute, 188350 Gatchina, Leningrad District, Russia

83. R. Shelley, Central Bureau for Nuclear Measurements, Steenweg op Retie, 2240 Geel, Belgium

84. K. Shibata, Nuclear Data Center, Japan Atomic Energy Research Institute, Tokai-mura, Naka-gun, Ibaraki-ken 319-11, Japan

85. R. Slovacek, Gaerttner LINAC Laboratory, Department of Environmental and Energy Engineering, Rensselaer Polytechnic Institute, Troy, NY 12180-3590

86. A. B. Smith, Technology Development Division, D-207, AA115, Argonne National Laboratory 9700 South Cass Avenue Argonne, IL 60439

87. D. L. Smith, TD-207-DB116, Argonne National Laboratory, Argonne, IL 60544

88. H. Takano, Nuclear Data Center, Japan Atomic Energy Research Institute, Tokai-mura, Ibaraki-ken 319-11, Japan

89. J.J. Wagschal, Racah Institute of Physics, The Hebrew University of Jerusalem, 91904, Jerusalem, ISRAEL

90. H. Weigmann, Central Bureau for Nuclear Measurements, Steenweg op Retie, 2240 Geel, Belgium

91. C. Werner, Los Alamos National Laboratory, Los Alamos, NM 87545

92. Roger M. White, Lawrence Livermore National Laboratory, P. O. Box 808, Livermore, CA 94550

93. M. Williams, Nuclear Science Center, Louisiana State University, Baton Rouge, LA 70803 